\title{
Institutional Designs of Public Goods in the Context of Cultural Property
}

\author{
Dissertation \\ zur Erlangung des wirtschaftswissenschaftlichen Doktorgrades \\ der Wirtschaftswissenschaftlichen Fakultät \\ der Universität Göttingen
}

Vorgelegt von

Matthias Lankau, M.A. Int. Econ., Dipl.-BW. (FH)

aus Rathenow

Göttingen, Februar 2014 
Erstgutachter: Prof. Dr. Kilian Bizer

Zweitgutachterin: Prof. Marcela Ibañez Diaz, Ph.D.

Tag der mündlichen Prüfung: 20. November 2013 


\section{Danksagung}

Verschiedene Personen haben zu dem gelingen dieser Doktorarbeit beigetragen, denen ich hiermit ganz herzlich danken möchte. In allererster Linie ist hierbei mein Doktorvater Prof. Dr. Kilian Bizer zu nennen, der meine Promotion fortwährend begleitet und mich in vielerlei Hinsicht unterstützt hat. Für die engagierte Zweitbetreuung bedanke ich mich ebenfalls bei Prof. Marcela Ibañez Diaz, Ph.D. Darüber hinaus bin ich Prof. Dr. Regina Bendix sowohl für ihre Mitgliedschaft in meiner Prüfungskommission als auch für den Impuls, mich in das kalte Wasser der Lehre zu werfen, dankbar.

Ganz besonderer Dank gilt meiner Kollegin, Koautorin und guten Freundin Marianna Bicskei, die mir während der gesamten Promotionszeit mit Rat und Tat zur Seite stand und deren wissenschaftliche Expertise ich sehr schätze.

Meinen Kollegen am Lehrstuhl möchte ich hiermit recht herzlich für ihren Input während der Doktorandenkolloquien unseres Lehrstuhls danken. Darüber bedanke ich mich bei den Teilnehmern der GLOBE-Diskussionsrunden für deren Hilfe in Bezug auf mein experimentelles Design sowie den Kollegen des volkswirtschaftlichen Institut für Mittelstand und Handwerk an der Universität Göttingen (ifh) für die Unterstützung und das angenehme Arbeitsumfeld, in das ich aufgenommen wurde.

Für die Hilfe bei der Programmierung meiner Experimente möchte ich Markus Nabernegg und Dennis Kotte, der mich ebenfalls bei deren Durchführung im Labor unterstützte, danken.

Auf zahlreiche Freunde konnte ich mich während dieser Promotion stets verlassen. Mein ganz besonderer Dank gilt Elke Schaffland für ihr experimentelles Know-how, Maximilian Riedl für seine ökonometrische Expertise, Torben Behmer und Martin Bresslein für eine Qualität und Geschwindigkeit an Kontrolle meiner Texte, für die ich andernorts hätte teuer zahlen müssen, sowie Nora Vogt, Nelia Römling, Maya Schmaljohann und Malte Reimers.

Zu guter Letzt danke ich von ganzem Herzen meinen Eltern Dagmar und Helmut, die mich stets förderten und mir während meiner gesamten Ausbildungszeit auch in schwierigsten Phasen ihre Unterstützung zukommen ließen. Insbesondere möchte ich meiner Schwester Maria danken, die mir trotz größter persönlicher Belastung stets den Rücken frei hielt und mir die Zeit gab, die nötig war, diese Arbeit zu vollenden. Meiner Familie ist diese Arbeit gewidmet.

Göttingen, Februar 2014. 



\section{TABLE OF CONTENTS}

\section{Chapter I}

Introduction and Summary

\section{Chapter II}

A Comparative Economic Analysis of sui generis Rights for the Protection of Traditional Cultural Expressions

Published in: Bizer, K., Lankau, M., Spindler, G. (Eds.). Sui Generis Rechte zum Schutz traditioneller kultureller Ausdrucksweisen: Interdisziplinäre Perspektiven. Göttinger Studien zu Cultural Property, Volume 5, Göttingen: Universitätsverlag,2013, pp. 107-138.

\section{Chapter III}

Sui generis Rights for the Protection of Traditional Cultural Expressions Policy Implications

Coauthors: Kilian Bizer, Gerald Spindler and Philipp Zimbehl

Published in: Journal of Intellectual Property, Information Technology and

E-Commerce Law (JIPITEC), Volume 2, Issue 2, 2011, pp. 114-119.

Also published in: Bizer, K., Lankau, M., Spindler, G. (Eds.). Sui Generis Rechte zum

Schutz traditioneller kultureller Ausdrucksweisen: Interdisziplinäre Perspektiven. Göttinger

Studien zu Cultural Property Volume 5, Göttingen: Universitätsverlag, 2013, pp. 107-138

\section{Chapter IV}

Cooperation Preferences in the Provision of Public Goods - An Experimental

Study on the Effects of Social Identity

Coauthors: Marianna Bicskei and Kilian Bizer

Submitted to Games and Economic Behavior

\section{Chapter V}

The Role of Expectations in the Provision of Public Goods under the

Influence of Social Identity

Coauthors: Marianna Bicskei and Kilian Bizer

Working Paper

\section{Chapter VI}

How Peer-Punishment Affects Cooperativeness in Homogeneous and Heterogeneous Groups - A Public Good Experiment with Social Identity.

Coauthors: Marianna Bicskei and Kilian Bizer

Working Paper

\section{Chapter VII}

Negative Reciprocity and its Relation to Anger-Like Emotions in Homogeneous and Heterogeneous Groups - An Experimental Study with Peer-Punishment and Social Identity

Coauthors: Marianna Bicskei and Kilian Bizer

Submitted to Journal of Economic Psychology, currently under review 


\section{Publication that is not part of this dissertation}

Die verborgene Effektivität minimaler Resultate in internationalen Verhandlungen: der Fall der WIPO

Coauthors: Kilian Bizer and Zulia Gubaydullina

Published in: Bendix, R., Bizer, K., Groth, S. (Eds.): Die Konstituierung von Cultural Property: Forschungsperspektiven. Göttingen: Universitätsverlag, 2010, pp. 197-216. 


\section{ChAPTER I}

INTRODUCTION AND SUMMARY 


\section{Public Goods in the Context of Cultural Property}

This dissertation is inspired by research within the Interdisciplinary Research Group on Cultural Property at the University of Göttingen. Combining the disciplines of civil law and economics the subproject "The Law and Economics of Cultural Property: an Economic Analysis of the Institutions of Rule-Making" analyzed multiple questions regarding regulatory institutions for different types of cultural property. In this context, institutions are understood both as formal and informal rules that guide individuals' behavior (cf. Bizer, 2002). On this basis, one of its main aims was to derive specific policy recommendations for the protection of cultural property. Particular attention was paid to a subset of cultural property, namely to traditional cultural expressions (TCEs). Typically, TCEs are intangible expressions of cultural heritage, such as holy rituals, ceremonies or dances, that have been created in the past and are maintained and developed by traditional communities over generations (cf. WIPO, 2006). From an economic perspective, cooperation in the provision of TCEs offers many similarities to cooperation in the provision of public goods in general. Firstly, TCEs are also jointly provided by community members often devoting a considerable amount of personal resources such as time and effort. Secondly, TCEs benefit all community members and use of TCEs by one group member does not diminish their availability to others. Consequently, due to these similarities, this dissertation aims to shed light on different institutional designs that can be applied to public goods in the context of cultural property and to evaluate their economic impacts. To this purpose, the dissertation is divided in two parts. The first part examines the case of how TCEs can be protected by formal institutions of collective property rights against unauthorized use by non-community members. Specifically, two chapters evaluate and compare economic impacts of so called sui generis rights for the protection of TCEs and derive policy recommendations. The second part is devoted to the more general question of how public goods in the context of cultural property are provided by group members. In particular, a strong cultural and thus social identity in case of TCEs holds community members together and guides their behavior similar to formal institutions. As a result, four chapters investigate to what extent social identity impacts on the provision of public goods.

\section{Sui generis Rights for the Protection of Traditional Cultural Expressions}

Due to their immaterial nature TCEs are to be classified as intellectual property. Nevertheless, classic intellectual property rights (IPRs) are not adequate to protect TCEs (cf. Lewinski, 2007). A copyright, for instance, is granted solely to individual authors. Moreover, it requires novelty of a created work and is restricted in duration. However, TCEs are typically owned by entire communities and usually have been created generations ago requiring an unlimited term of protection. In order to account for 
these shortcomings the international community has developed five major model laws ${ }^{1}$ for the protection of TCEs. These are also referred to as sui generis (Latin: of its own kind) rights, because they systematically depart from classic copyright law - for instance by granting rights to entire groups - and exclusively target TCEs. These model laws are the UNESCO/WIPO Tunis Model Law on Copyright for Developing Countries of 1976, the Model Provisions of the UNESCO/WIPO of 1982, the South Pacific Model Law for National Laws of 2002 drafted by the Secretariat of the Pacific Community, the WIPO Draft Provisions of 2004, and the ARIPO Provisions of 2010. Despite their innovative character these formal institutions have not been analyzed from a law and economics perspective, so far. Consequently, Chapter 2 comparatively evaluates the expected economic impacts resulting from these model laws. Firstly, the article compares and ranks the sui generis rights with regard to inherent transaction costs occurring when non-traditional actors seek access to TCEs. This is of economic relevance since high transaction costs can lead to underuses lowering social welfare (cf. Heller, 1998). This analysis is predominantly based the model laws' systems of right allocation to TCEs. In particular, the article distinguishes between legal owners of TCEs, actors responsible to negotiate access to TCEs with non-traditional actors as well as beneficiaries of protection, who are compensated for non-traditional access. In addition, the article analyzes the impact of the model laws' scope of protection on transaction costs. Secondly, it compares the extent to which the sui generis rights serve traditional communities' preferences for protection. Finally, the article sheds light on the sui generis rights' possible effects on the creation, preservation and development of TCEs within their traditional environments. The chapter applies a research methodology that is based on specific behavioral hypotheses for actors that are affected by these formal institutions. In this context, it considers communities from which TCEs originate, state agencies that assist communities of origin in the management of rights, and finally non-traditional parties seeking access to TCEs as relevant actors. Behavioral hypotheses include the socially oriented motivation to establish political justice (cf. Faber et al., 2002), rationality in seeking to maximize personal payoffs as well as the motivation to engage in corrupt behavior. This article's main results are firstly that a model law, which allocates all relevant rights to TCEs to the respective community of origin will result in the highest transaction costs. This is due to comparably high costs in finding traditional owners as well as high negotiation costs, potentially involving multiple parties. Conversely, a completely centralized allocation of rights involving a state agency is likely to cause the lowest transaction costs, because negotiation and search costs are reduced to a minimum. Any law that uses that allocates rights to a state agency as well as to the local communities is likely to be ranked in between. Secondly, it shows that a principal-agent problem occurs if state agencies are provided with a lot of bargaining power over the protection of TCEs. In this case bureaucrats will serve their own purposes more than those

\footnotetext{
${ }^{1}$ A model law is a legal blue-print developed for a possible enactment into national law by interested countries.
} 
of the actual holders of sui generis rights. This will lead to an imperfect representation of communities' preferences for protection. Lastly, there is a clear tradeoff between both effects of sui generis protection: The more a law respects the local communities' protection preferences, the higher its transaction and thus social costs.

On the basis of this in-depth analysis of the sui generis rights' economic effects, Chapter 3 extracts the main arguments and focuses on policy implications for political actors who wish to implement sui generis protection. ${ }^{2}$ Specifically, it stresses how the model laws' different right allocation systems affect transaction costs and the degree to which each model law respects local communities' preferences for protection. The resulting trade-off then calls upon policy-makers to carefully weigh their priorities and choose a model law that allocates rights accordingly. In addition, in case rights to TCEs are allocated to the communities of origin, the article suggests an administration of these rights through a system private ordering. Essentially, this involves the use of specific bilateral licensing agreements, which guarantee that all non-traditional uses of TCEs respect local communities' preferences for protection.

\section{The Role of Social Identity in the Provision of Public Goods}

The second part of the dissertation addresses the question of how public goods in the context of cultural property, such as TCEs, are provided by group members. This is of economic importance since the private provision of public goods represents a social dilemma. In particular, from an individual perspective there are strong incentives not to contribute to the provision of a public good since nobody can be excluded from the benefits it provides. Thus, rationally acting individuals can be expected to always free-ride on their group members' contributions. If individuals act in pure selfinterest, societies' welfare is diminished by an under-provision of public goods. Yet, many laboratory experiments revealed that individuals are actually willing to contribute in spite of the rational strategy of free-riding (see amongst many Andreoni, 1988; 1995). As an explanation Fischbacher et al. (2001) find that subjects are strongly motivated by the social preference of positive reciprocity. In general, positive reciprocity describes subjects' inclination to reward cooperative behavior with own cooperation (cf. Fehr and Fischbacher, 2002; Falk and Fischbacher, 2006). Specifically, they show that a majority of subjects would actually like to contribute more to the public good as their group members' cooperation increases. These are termed conditional cooperators. Only around 30 percent of their subjects are to be classified as full free-riders, i.e. subjects who always contribute nothing no matter what their group members contribute. Additionally, experimental evidence has shown that negative reciprocity seems to be a decisive behavioral pattern in the public good context, as well. In contrast to positive reciprocity, this social preference captures individuals' proclivity to punish unkind

\footnotetext{
${ }^{2}$ The authors' contribution to this article constitutes approximately 70 percent.
} 
behavior (Falk, 2003). Accordingly, subjects are willing to punish group members who contributed less to the public good than they did, even if this is costly and thus reduces their personal payoffs (cf. Fehr and Gächter, 2002; Fehr and Gächter, 2000). However, in spite of the disciplinary effect of punishment on individuals' contributions, the cost of punishment in turn may reduce social welfare. In sum, subjects' social preferences for both positive and negative reciprocity strongly influence cooperation and thereby social welfare with regard to the provision of public goods. On this basis, the second part of this dissertation specifically asks to what extent social identity affects subjects' degree of positive and negative reciprocity when they jointly contribute to a public good.

Generally, social identity is defined as "the individual's self-concept derived from perceived membership in social groups" (Charness et al., 2007, p. 1342). Research on its effects on individuals' behavior was pioneered by Tajfel and Turner (1979). Their social identity theory describes three interlinked processes that are mainly responsible for identity-based discriminatory behavior. ${ }^{3}$ Firstly, individuals relatively quickly sort themselves by certain social categories such as gender or race (categorization). Secondly, they derive self-esteem from their (in-) group (identification) and, lastly, compare their in-group with out-groups with whom they do not identify (comparison). Jointly, these processes lead individuals to favor their in-group and discriminate against out-group members, commonly referred to as in-group bias (cf. Tajfel and Turner, 1986; Hoff and Pandey, 2006). This phenomenon seems to be deeply rooted in human nature and is pervasive in many different forms of social interactions (Eaton et al., 2011). For instance, in the context of two-person response games, Chen and Li (2009) discovered that when subjects are matched with in-group members they show significantly more positive reciprocity than when matched with out-group members. Concerning negative reciprocity, recent literature is controversial about the effect of social identity. On the one hand, within two-person dictator and response games Chen and Li (2009) find that in-group matches are less likely to engage in negative reciprocity than out-group matches. McLeish and Oxoby (2007), on the other hand, find that in two-person bargaining games in-group matches impose more punishment and in higher frequency than out-group matches. These results non-withstanding, there is still a research gap concerning social identity's influence on subjects' positive and negative reciprocity when they cooperate in the provision of a public good.

In order to close this research gap, each chapter of the second part of this dissertation uses a unique research design. However, there are three main methodological commonalities. Firstly, all of them make use of controlled laboratory experiments containing differing variants of a public good game. Generally, a public good game entails each subject's decision of whether an initial endowment of 20

\footnotetext{
${ }^{3}$ For a detailed account on theoretical and empirical findings concerning social identity theory, please see Chen and Li (2009).
} 
experimental points ${ }^{4}$ is to be invested for a purpose that benefits the whole group, i.e. the public good, or to be kept for private matters. In particular, monetary incentives are set so that it is more beneficial to keep resources for private purposes. One specific type of public good game that all four chapters employ involves the use of the strategy method (cf. Fischbacher et al., 2001). Here, subjects are asked to state their unconditional and their conditional contribution to the public good. Regarding the former, subjects simply have to indicate how much of their endowment they would like to invest in the public good. For their conditional contributions subjects are required to specifically decide how much they would invest in the public good given all 21 possible average contribution levels of their group members (0-20). After both decisions are made, one group member is randomly chosen to contribute according to the specific conditional contribution decision. The remaining group members contribute according to their unconditional contributions. Since the strategy method allows eliciting in detail how individuals would react to differing degrees of their group members' cooperativeness, it is particularly suited to elicit subjects' degree of conditional cooperation and thus positive reciprocity. Moreover, it allows the researcher to classify individuals into certain cooperation types, which improves the understanding of identity treatment effects (cf. Fischbacher et al., 2001). Secondly, in spite of the possibility of priming real, pre-existing identities, in each case social identity is induced artificially in the laboratory. To this purpose, the articles draw on insights of Chen and Li (2009) and Eckel and Grossman (2005) using a design first introduced by Ibañez and Schaffland (2012). In particular, subjects are assigned to small groups, where each group is identified by a different color. Subsequently, these groups solve a simple group task designed to create a positive feeling of belonging together. Specifically, they have to jointly find hidden objects in a picture and report their location to the experimenter. Communication is possible via an anonymous chat tool and answers are only counted as correct if each group member gives the correct entry. Moreover, groups play against each other so that the group that finds the most objects wins this task. However, there are no financial incentives and the winning group merely receives a message of congratulation at the end of the experiment. This is done in order to prevent any negative effects of not winning during the course of the experiment. Thirdly, after having induced social identity two basic identity treatments are in effect. Subjects either interact only with members of their own color and thus identity (in-group matching), or with members of different identities (out-group matching). A final matching condition that does not involve any identity induction serves as a control treatment (random or partner matching).

The following sections provide brief summaries of each chapter's research questions, hypotheses, experimental designs and main results. Generally, while Chapter 4, 5 and 6 analyze subjects'

\footnotetext{
${ }^{4}$ At the end of the experiment, experimental points are converted into Euro at a pre-specified conversion rate.
} 
tendency to reveal different degrees of positive reciprocity, Chapter 7 compares their negative reciprocity under the influence of social identity.

To start with, Chapter 4 analyzes whether cooperation preferences in public good provision vary under the influence of social identity. ${ }^{5}$ Specifically, based on Chen and Li's (2009) finding that ingroup matches show stronger positive reciprocity among each other than out-group matches, the article hypothesizes that in-group members reveal the highest levels of conditional cooperation. Additionally, it assumes that there is a greater likelihood for subjects to be conditional cooperators, and accordingly, a reduced likelihood to be free-riders when matched with in-group than with outgroup members. In order to test these hypotheses the experiment features a within-subject design based on one-shot public good games using the strategy method over four stages. Stage 1 comprises a public good game in random matching in order to elicit subjects' cooperation preferences without the influence of social identity. In the following stage, subjects take part in the identity induction game. Then, in Stage 3 and 4 they play the one-shot game either in in-group matching followed by out-group matching or vice versa to control for treatment-order effects. Results indicate that cooperation preferences indeed vary depending on the social environment. Specifically, when subjects interact with members of their own identity they show the preference for higher levels of conditional cooperation and thus less self-serving bias than in out-group matching. In particular, ingroup matches are willing to reciprocate every possible level of their group members' average contribution by higher own contributions than subjects matched with out-group members. Additionally, while the probability to be a conditional cooperator remains stable in both treatments, subjects are more likely to be a free-rider when matched with individuals of a different identity. These results indicate that it can be reasonable to devise policy institutions that strengthen the feeling of belonging to a particular group in order to enhance subjects' degree of positive reciprocity and thus social welfare in the provision of public goods.

While Chapter 4 documents that subjects' hold differing cooperation preferences depending on group composition, which is elicited by using the strategy method, Chapter 5 seeks to analyze subjects' actual conditional cooperation. ${ }^{6}$ Specifically, the article compares the degree to which subjects in different social environments reciprocate their expectations on their group members' contributions by own contributions in the course of a multiple-period public good game. This follows the purpose of contributing to the literature of why subjects lastingly show higher contributions to public goods when interacting with members of their own identity than with mere partners or group members with different identities (cf. Eckel and Grossman, 2005). On the basis of both psychological and economic experimental research the article derives two main research hypotheses. Firstly, the

\footnotetext{
${ }^{5}$ The authors' contribution to this article constitutes approximately 65 percent.

${ }^{6}$ The authors' contribution to this article constitutes approximately 65 percent.
} 
level of expectations in identity homogeneous groups is expected to be higher than in identity heterogeneous groups, thus triggering increased contributions in in-groups (cf. Yamagishi and Jin, 1999). Moreover, following Chen and Li (2009) as well as Chapter 4's insights, in-group matches should reveal the highest degree of reciprocating these expectations by own contributions (i.e. the highest degree of actual conditional cooperation). The article tests these hypotheses by implementing a between-subject design involving three stages. Similar to Chapter 4 , subjects first play a one-shot public good game using the strategy method and subsequently take part in the identity induction game. The third and final stage then involves a public good game that is repeated ten times with stable group composition. Again, subjects either interact with in-group or out-group members. While the first period is played in strategy method, the remaining nine periods merely require subjects to state their unconditional contributions to the public good. Additionally, in each period subjects have to indicate how much they expect their group members to contribute on average. Concerning the results, the article yields that comparatively higher expectations on in-group than on out-group members' cooperativeness are the main driver for welfare enhancements when subjects interact with members of a common identity. The degree of conditional cooperation, i.e. to what extent subjects reciprocate these expectations by own contributions is, however, similar in all matching protocols. Merely individuals initially identified as free-riders seem to reciprocate a limited range of expectations by higher own contributions when matched with in-group than with out-group members. Nevertheless, the results of this article clearly underline the paramount importance of expectations in determining cooperation under social identity.

Chapter 6 introduces the possibility of punishing group members for uncooperative behavior (peerpunishment) and analyzes how this affects subjects' degree of positive reciprocity in different social identity settings. ${ }^{7}$ Based on prior literature on the effects of peer-punishment on cooperation the article assumes, first of all, that the threat of peer-punishment equally impacts subjects' cooperativeness under social identity independent of group composition. Secondly, even under peerpunishment threat individuals should reveal the typical in-group bias in cooperativeness. Testing these hypotheses, the article relies on an experimental design based on one-shot public good games in strategy method containing three stages and two types of treatments - a Punishment $(P)$ and NoPunishment (NP) treatment. Specifically, after all subjects play the public good game without punishment in randomly matched groups in Stage A, Stage B induces social identity. Lastly, Stage C implements the in-group and out-group matching conditions. In the NP-treatments, on the one hand, subjects play a one-shot public good game similar to stage A. In the P-treatments, on the other hand, subjects are additionally given the possibility to distribute punishment points to their group members after having learned how much each of them contributed to the public good. Punishment points are

\footnotetext{
${ }^{7}$ The authors' contribution to this article constitutes approximately 45 percent.
} 
costly both for the punisher and the punished. Firstly, the article finds that regardless of group composition determined by subjects' identity affiliation peer-punishment seems to increase cooperativeness. Yet, the strongest increase is clearly evident when subjects interact with members of different identities, which is especially the case for those individuals that were initially categorized as free-riders. This is most likely due a comparably stronger fear of being punished by outsiders than by insiders. Secondly, the presence of peer-punishment clearly eliminates the existence of an ingroup bias, which is present in the No-Punishment treatments. Lastly, the results indicate that the institutions of peer-punishment and social identity may be complemented in order to raise subjects' cooperativeness. Both in in-group and out-group matching subjects' cooperativeness under punishment is significantly elevated as compared to the random matching condition under punishment, which does not involve salient group identities and served as a control treatment.

Focusing on negative reciprocity, Chapter 7 asks how social identity affects individuals' proclivity to apply costly sanctions to their group members for deviant behavior in identity homogenous and heterogeneous groups. ${ }^{8}$ In this regard, the article relies on the hypothesis that social identity does have an impact on negative reciprocity in the public good context. Additionally, it devotes particular attention to the role of anger-like emotions as determinants of negative reciprocity in the different social environments. Here, the hypothesis is formulated that subjects reveal different emotional reactions in terms of anger-like emotions to acts of their group members that they deem unkind (i.e. uncooperative behavior). In terms of methodology, the experiment is based on one-shot public good games in strategy method. It features a between-subject design comprising an in-group, an outgroup and a control treatment and a total of three stages. In Stage A subjects play a one-shot public good game in random matching without punishment. Then, Stage B induces social identity for the inand out-group treatment. Lastly, Stage C comprises a one-shot public good game with costly punishment. The article demonstrates that in-group members punish much less often and in smaller amounts than out-group members in the event they face contributions smaller than their own. Moreover, it shows that anger-like emotions influence punishment behavior much stronger when individuals are matched with members of different identities than in identity homogenous groups. Consequently, a common group identity leads subjects to control their negative emotions to the benefit of their group. All in all, the results of Chapter 7 show that preferences for negative reciprocity are differently affected depending on group composition. Groups that consist of members of different identities clearly react more negatively to uncooperative behavior of their group members. While this may discipline their group members to be more cooperative, the cost of punishment may decrease social welfare, as well.

\footnotetext{
${ }^{8}$ The authors' contribution to this article constitutes approximately 25 percent.
} 
All in all, the second part of this dissertation demonstrates that in the provision of public goods social identity influences subjects' degree of positive as well as negative reciprocity to a certain extent. It should thus be considered as a determining factor in the provision of specific types of cultural property, such as TCEs, as well. 


\section{References}

Andreoni, J., 1988. Why free ride? : Strategies and learning in public goods experiments. Journal of public economics 37 (3), 291-304.

Andreoni, J., 1995. Cooperation in Public-Goods Experiments: Kindness or Confusion? The American Economic Review 85 (4), 891-904.

Bizer, K., 2002. Ökonomisch-juristische Institutionenanalyse - Ziele und praktische Anwendung. In: Bizer, K., Führ, M., Hüttig, C. (Eds.). Responsive Regulierung, Tübingen: Mohr Siebeck, 143-165.

Charness, G., Rigotti, L., Rustichini, A., 2007. Individual behavior and group membership. The American Economic Review 97 (4), 1340-1352.

Chen, Y., Li, S.X., 2009. Group Identity and Social Preferences. The American Economic Review 99 (1), $431-457$.

Eaton, B.C., Eswaran, O.M., Robert J. Netzer, 2011. Us and Them: the origin of identity, and its economic implications. Canadian Journal of Economics 44 (3), 719-748.

Eckel, C.C., Grossman, P.J., 2005. Managing diversity by creating team identity. Journal of Economic Behavior \& Organization 58 (3), 371-392.

Faber, M., Petersen, T., Schiller, J., 2002. Homo oeconomicus and homo politicus in Ecological Economics. Ecological Economics 40 (3), 323-333.

Falk, A., 2003. Homo Oeconomicus versus Homo Reciprocans: Ansätze für ein neues Wirtschaftspolitisches Leitbild? Perspektiven der Wirtschaftspolitik 4 (1), 141-172.

Falk, A., Fischbacher, U., 2006. A theory of reciprocity. Games and Economic Behavior 54 (2), 293-315.

Fehr, E., Fischbacher, U., 2002. Why social preferences matter- the impact of non-selfish motives on competition, cooperation and incentives. The Economic Journal 112 (478), C1-C33.

Fehr, E., Gächter, S., 2000. Cooperation and Punishment in Public Goods Experiments. The American Economic Review 90 (4), 980-994.

Fehr, E., Gächter, S., 2002. Altruistic punishment in humans. Nature 415 (6868), 137-140.

Fischbacher, U., Gächter, S., Fehr, E., 2001. Are people conditionally cooperative? Evidence from a public goods experiment. Economics Letters 71 (3), 397-404.

Heller, M.A., 1998. The tragedy of the anticommons: Property in the transition from Marx to markets. Harvard Law Review 111 (3), 621-688.

Hoff, K., Pandey, P., 2006. Discrimination, Social Identity, and Durable Inequalities. The American Economic Review 96 (2), 206-211.

Ibañez Diaz, M., Schaffland, E., 2012. Leadership Working Behavior and Group Cooperation: An Experiment of Group Identity: Unpublished Manuscript. Georg-August-Universität Göttingen.

Lewinski, S. von, 2007. Adequate protection of folklore - a work in progress. In: Torremans, P. (Ed.). Copyright Law - A Handbook of Contemporary Research, Cheltenham, UK: Edward Elgar Publishing Limited, $207-231$.

McLeish, K.N., Oxoby, R.J., 2007. Identity, cooperation, and punishment, IZA Discussion Paper 2572. Institute for the Study of Labor (IZA). http://papers.ssrn.com/sol3/papers.cfm?abstract_id=961379 (accessed 16 August 2013).

Tajfel, H., Turner, J., 1979. An Integrative Theory of Intergroup Conflict. In: Worchel, S., Austin, W. (Eds.). The Psychology of Intergroup Relations, Monterey: CA: Brooks/Cole, 33-47.

Tajfel, H., Turner, J., 1986. The Social Identity Theory of Intergroup Behaviour. In: Worchel, S., Austin, W. (Eds.). The Psychology of Intergroup Relations, Chicago: Nelson-Hall, 7-24.

WIPO, 2006. The Protection of Traditional Cultural Expressions/Expressions of Folklore: Revised Objectives and Principles WIPO/GRTKF/IC/9/4. http://www.wipo.int/meetings/en/doc_details.jsp?doc_id=55137 (accessed 29 September 2011).

Yamagishi, T., Jin, N.a.K.T., 1999. Bounded Generalized Reciprocity: Ingroup Boasting and Ingroup Favoritism. Advances in Group Processes 16, 161-197. 
CHAPTER II

A COMPARATIVE ECONOMIC ANALYSIS OF SUI GENERIS RIGHTS FOR THE Protection of Traditional Cultural Expressions

Matthias Lankau 


\section{Introduction}

Traditional cultural expressions (TCEs) are a special form of intellectual property. They are typically generated by traditional communities, who - oftentimes over the course of multiple generations preserve and develop them. Yet, the current system of intellectual property rights does not provide adequate protection of TCEs. Consequently, during the last 40 years the international community has held ongoing debates on a possible legal instrument suiting the needs of local communities. However, this process has not yielded any tangible results, so far (Lankau et al., 2010; von Lewinski, 2013). Despite this lack of an international legally binding accord, multiple proposals have been advanced. These so-called model laws ${ }^{1}$ are the UNESCO/WIPO Tunis Model Law on Copyright for Developing Countries of 1976, the Model Provisions of the UNESCO/WIPO of 1982, the South Pacific Model Law for National Laws of 2002 drafted by the Secretariat of the Pacific Community, the WIPO Draft Provisions $^{2}$ of 2004 and the ARIPO Provisions of 2010 (see Table 1). They are also referred to as being sui generis, which means rules "of their own kind", since they exclusively target TCEs and depart from the classic realm of intellectual property rights. Yet, while there is extensive research in the field of law and economics on patents, copyrights and trademark law both from a normative and a positive perspective, the sui generis rights have not receive much attention, so far. Nevertheless, it is essential to understand their effects, as they for instance provide the basis for current discussion on the protection of TCEs within the Intergovernmental Committee (IGC) of the World Intellectual Property Organization (WIPO) and are already implemented by certain countries.

This article aims to address this academic void. Specifically, it asks how the regulatory effects of the sui generis model laws can be economically interpreted and compared, ${ }^{3}$ assuming that protection of TCEs is a socially beneficial goal. ${ }^{4}$ The results of this study are designed to inform policy-makers, who wish to implement sui generis protection for TCEs within their respective countries. ${ }^{5}$

\footnotetext{
${ }^{1} \mathrm{~A}$ model law is a legal text that is developed for a possible enactment by interested countries.

${ }^{2}$ The version that is used here is WIPO/GRTKF/IC/9/4 (WIPO, 2006). By now there have been many discussions on how to improve these provisions. Yet, the ideas included in this document shall nevertheless serve as a first baseline of comparison.

${ }^{3}$ A shorter version of this paper with a special focus on policy implications was first published in the Journal of Intellectual Property, Information Technology and E-Commerce Law, 2011, 2(2): 114-119.

${ }^{4}$ Normative justification for the protection of cultural goods is for instance given by Bicskei et al. (2012), Hilty (2009) or Hughes (2013)

${ }^{5}$ Please note that the model laws are left to implementing states to adapt and fine-tune. It is thus rather difficult to predict regulatory effects without knowing how the final law will be formulated and implemented exactly. Consequently, they are analyzed according to how they are phrased at the moment.
} 


\begin{tabular}{|l|l|c|}
\hline Model Law & Year & Abbreviation \\
\hline Tunis Model Law on Copyright for Developing Countries & 1976 & TML \\
\hline Model Provisions of the UNESCO/WIPO & 1982 & MPUW \\
\hline South Pacific Model Law for National Laws & 2002 & SPML \\
\hline WIPO Draft Provisions & 2004 & WDP \\
\hline ARIPO Provisions & 2010 & ARIPO \\
\hline
\end{tabular}

Table 1: Sui Generis Model Laws

So far, there is only limited empirical evidence on the effects of the sui generis rights, so that the analyses will be mainly of theoretical nature. Firstly, section 2 provides a general characterization as well as a comparison of the model laws' key differences. This will, however, exclude the MPUW. In contrast to the remaining model laws, the MPUW's drafters left essential regulatory details to be established by the respective countries' legislature, rendering a proper comparison beyond the scope of this paper. On this basis, section 3 develops a comparative analysis of the model laws' effects, which is split into effects regarding costs, the character of TCE protection as well as creation, preservation and development of TCEs within local communities. Specifically, costs mainly capture transaction costs, since the model laws generally create barriers to non-traditional access to TCEs. Protection predominantly implies the degree to which local communities' preferences for protecting their TCEs are honored by the model laws. Finally, section 4 summarizes and derives relevant policy implications.

\section{Characterization of the sui generis Rights}

Characteristically, the nature of sui generis rights is most closely aligned with copyright law, ${ }^{6}$ for which there is a plethora of law and economics research and a general understanding of its positive behavioral consequences. Laying the foundation for later analysis, section 2.1 first compares the model laws' commonalities with existing copyright law. Section 2.2 then presents their key differences, which will be at the heart of section $3^{\prime}$ s comparative effects assessment. ${ }^{7}$ These include the specificities of who holds which rights in the TCEs as well as their scope of protection.

\footnotetext{
${ }^{6}$ For further information please see Lewinski (2007), WIPO (2004), and Zimbehl (2013).

${ }^{7}$ For a detailed account on commonalities and differences of the model laws from a civil law perspective, please see Zimbehl (2013).
} 


\subsection{Commonalities of the sui generis rights}

Table 2 depicts the commonalities and differences between sui generis rights and existing copyright law. As a starting point, while copyright protects all works derived from human creativity, sui generis rights solely target TCEs. These are consistently defined as tangible or intangible expressions of traditional heritage that are maintained by a community or by an individual on behalf of the community. The aspect of tradition complements the qualitative requirements for protection, necessitating that TCEs have been passed on from generation to generation. Examples of this common definition are performances such as ceremonies, rituals or dances; musical expressions such as songs or verbal expression such as stories or legends (WIPO, 2006, p. 17).

What is more, the sui generis rights must be classified as group rights. By departing from copyright's concept of individual creation, they grant ownership of TCEs to the traditional community as a whole from which the TCEs originate. Likewise, the model laws abandon the aspect of protecting newly created ideas, as it is anchored in copyright law, by protecting only traditional TCEs. Additionally, contrary to copyright's limited protection duration of lifespan plus 70 years for natural persons, ${ }^{8}$ sui generis rights explicitly seek unlimited protection. Lastly, while copyright requires the work to be fixated, (i.e., recorded in a digital manner or on paper or canvas) sui generis rights explicitly do not require any kind of fixation of TCEs in order for protection to take effect. ${ }^{9}$

\begin{tabular}{|l|l|l|l|}
\hline & Criteria & Copyright & Sui Generis Rights \\
\hline Differences & $\begin{array}{l}\text { Object of protection } \\
\text { Protection criterion } \\
\text { Creator } \\
\text { Fixation of the work } \\
\text { Duration of the right }\end{array}$ & $\begin{array}{l}\text { Mental Creations } \\
\text { Novelty } \\
\text { Individual } \\
\text { Yes } \\
\text { Commonalities }\end{array}$ & $\begin{array}{l}\text { TCEs } \\
\text { Tradition } \\
\text { Group } \\
\text { No } \\
\text { Conlimited }\end{array}$ \\
& \multicolumn{2}{|c|}{ Economic and moral rights; } \\
\hline
\end{tabular}

Table 2: Comparison of sui generis Rights with Copyright

The regulatory aspects that copyright and sui generis rights have in common relate predominantly to the establishment of economic as well as moral rights for traditional owners of TCEs (Zimbehl, 2013).

\footnotetext{
${ }^{8}$ With regards to juristic persons copyrights' duration even extends to lifespan plus 95 years (Mackaay, 2013).

${ }^{9}$ Similarly, all model laws contain civil and criminal law provisions regulating misuses of TCEs. However, since unclearly defined they are ill-suited for economic analyses.
} 
These solely target uses occurring outside the traditional context. Any use of TCEs within the communities from which they originate is explicitly not regulated by the model laws. Economic rights include the exclusive right to reproduce, publish, translate, adapt, arrange and transform TCEs (WIPO, 2004, Annex II, p. 5). Hence, any non-traditional user essentially has to seek prior authorization by negotiating the terms of access, entailing compensation payments such as license fees or benefit sharing schemes. Yet, there are regulatory details concerning the scope of sui generis rights, which will be introduced in section 2.2.2. Lastly, as it is the case with copyright law, sui generis protection is granted automatically without any kind of formalities. ${ }^{10}$

\subsection{Variations in the sui generis rights}

\subsubsection{Allocation of Rights to TCEs - Differing Systems}

The four sui generis rights differ in how specific rights to TCEs are allocated. For the sake of this article right holders are split into (1) legal owners (title holders) of TCEs, (2) negotiation partners, i.e. actors responsible for negotiating access to TCEs with non-traditional users, and (3) beneficiaries of protection, who are entitled to receive compensation for non-traditional access to TCEs. As can be seen in Table 3, the envisaged concepts range from complete state control, to systems completely controlled by local communities and to mixed approaches.

\begin{tabular}{|c|c|c|c|c|}
\hline & \multicolumn{4}{|c|}{ Sui Generis Rights } \\
\hline Rights & TML & ARIPO & WDP & SPML \\
\hline Holder & State Agency & Community & Community & $\begin{array}{c}\text { Community } \\
\text { State Agency if } \\
\text { no owner found }\end{array}$ \\
\hline $\begin{array}{c}\text { Negotiation } \\
\text { Partner }\end{array}$ & State Agency & $\begin{array}{c}\text { State Agency, } \\
\text { Veto right by } \\
\text { community }\end{array}$ & $\begin{array}{c}\text { Community } \\
\text { State Agency if } \\
\text { mandated by } \\
\text { the community }\end{array}$ & Community \\
\hline Beneficiaries & National TCEs & Community & Community & Community \\
\hline
\end{tabular}

Table 3: Systems of Right Holders in TCEs

Within the TML TCEs are completely under state authority. Indigenous communities are not entitled to voice concerns about non-traditional uses of their TCEs. All the relevant rights rest in and are executed by a responsible state agency, which is, however, charged with representing local communities' interests (Section 6, 18). It negotiates external use of TCEs and collects associated license fees or benefit shares, as well. Proceeds are intended for the protection and dissemination of

\footnotetext{
${ }^{10}$ However, some of the sui generis rights encourage registration of certain TCEs in order to establish a particularly high protection level. For this please see the next section.
} 
national TCEs as a whole. It is thus unlikely that individual communities from which TCEs originate benefit directly.

In contrast, within WDP and the SPML local communities ultimately control their TCEs. In both approaches the community is the holder of the right to their TCEs, beneficiary of protection, as well as the entity responsible for negotiating access with non-traditional users (SPML Section 4; WDP Art. $2,4)$. However, in case of the WDP local communities have the option to mandate the state agency to negotiate on its behalf. Additionally, if it is impossible to identify the TCEs' traditional owner the state agency may be the negotiation partner within the SPML (Section 19, 1a). What is more, both model laws allocate auxiliary responsibilities to the state agency. In the context of the SMPL its main function is the regulation and supervision of the licensing process. In that capacity it mediates between traditional owners and non-traditional users of TCEs, for instance by identifying the affected right owners with whom negotiations are to be held (Section 16). Upon publishing of a "user request" for a TCE by the state agency, the affected community is expected to subsequently claim ownership. Additionally, it monitors non-traditional use of licensed TCEs (Section 37) and settles disputes of ownership in TCEs among different local communities (Section 18, 19). Within the WDP the state agency is required to monitor non-traditional uses of licensed TCEs and support communities to enforce their rights (Art. 4, 8b).

The ARIPO model establishes a mixed system of right holders. While the local community holds the title to their TCEs (Section 18), a state agency is responsible for negotiating access with nontraditional users (Section 22.2). It is, however, not completely free in its decisions, as the respective local community holds a veto right and thus has to give permission to any decisions taken. Proceeds collected are directly transferred to the community from which the TCEs originate (Section 22.3, d).

\subsubsection{Scope of the sui generis Rights}

The scope of the model laws differs first of all in terms of the protective system. ${ }^{11}$ Either all elements of TCEs enjoy uniform protection or protection is differentiated depending on the concerned TCE. Additionally, the drafts vary with respect to the regulation of particular non-traditional uses, such as uses with gainful intent, as well as concerning permission of non-traditional uses without any restrictions (i.e., fair use). ${ }^{12}$ The results of this section are summarized in Table 4.

Starting with the protective systems, on the one hand, the SPML and the TML envision protection according to which any non-traditional use of folklore, no matter whether it is with gainful intent or

\footnotetext{
${ }^{11}$ The term "scope" is borrowed from Varian (2005).

${ }^{12}$ Please note that the analysis only includes those elements of scope, which differ between the sui generis rights. Yet, the scope similarly comprises that no fixation is required for protection to come into effect. This renders all model laws comparatively wide in scope, since concepts, ideas and methods enjoy protection in addition to fixated works.
} 
without has to be permitted either by a state agency (TML, Section 6) or by the local communities (SPML, Section 7). With regard to the TML, permissions require an obligatory payment of a fixed benefit share to this agency. ${ }^{13}$ The SPML envisages that the relevant community receives all necessary information on the non-traditional use of their TCEs in order to be able to give a prior and informed consent (Section 14-25). Depending on how this prior informed consent is negotiated, it may entail payments of benefit shares as well as other forms of compensation to the communities. Moreover, non-traditional users have to pay administration fees to the state agency (Section $152 \mathrm{~d}$ ).

The WIPO and ARIPO provisions, on the other hand, distinguish between different kinds of TCEs and grant protection accordingly (WDP Art. 3; ARIPO Section 19): (1) TCEs of particular value, (2) TCEs of minor value and (3) secret TCEs, i.e. cultural expressions for which the respective community tries to prevent publication outside of their traditional context. In both provisions, it is essentially up to the relevant communities to decide which level of protection is desirable for particular elements of their TCEs. Regarding the highest level of protection, communities have to be asked for their prior and informed consent in any case, i.e. whether outside use is with gainful intent or not, and are entitled to compensation for instance in the form of benefit-sharing or licensing fees. These forms have to be registered at the state agency (WDP Art. 3a; ARIPO Section 19.2). In case of TCEs of minor value or secret TCEs no registration is needed. Non-traditional access to TCEs of minor value does not require prior and informed consent. What is more, their protection is restricted to those uses that are made with gainful intent in which case communities are entitled to a share of the benefits. The specific size of the share is determined by the state agency after consultation with the respective local community (WDP Art. 3b; ARIPO Section 19.3). Moreover, both provisions stress that each nontraditional use has to respect local communities' moral rights. Lastly, pertaining to secret TCEs, communities shall have the defensive right to prevent any unauthorized use as well as to grant intellectual property rights to a third party, which draws on their TCEs.

Likewise, the model laws differ according to their provisions on fair use. On the one hand, under each model law TCEs can inter alia be used for educational purposes without negotiating terms of access. On the other hand, the TML envisages comparatively few fair uses. It merely allows non-commercial uses by public entities and thus excludes incidental uses as well as criticism of or reports on TCEs (Section $6,1^{\text {bis }}$ ). The WDP and ARIPO provisions contain more fair uses, providing for instance for unrestricted reviews of TCEs, scientific research, or their repository for purposes of heritage safeguarding (WDP Art. 5, ARIPO Section 20). The SPML strikes a balance between the alternatives. It

\footnotetext{
${ }^{13}$ The TML seeks to establish a "Domaine Public Payant" (Section 18), which is a concept that relates to an extension of regular copyrights. Works for which copyright protection has expired and which consequently fall back into the public domain are freely accessible for any user upon payment of a fixed fee. Some forms of this concept have for instance been implemented by Argentina or Mexico.
} 
limits the possibilities of fair compared to WDP/ARIPO, but it is more lenient than the TML with regard to the regulation of non-traditional use.

\begin{tabular}{|c|c|c|c|}
\hline & \multicolumn{3}{|c|}{ Sui Generis Rights } \\
\hline & TML & WDP / ARIPO & SPML \\
\hline Protection system & Standardized & $\begin{array}{l}\text { Protection levels } \\
\text { (1) TCEs of particular value } \\
\text { (2) TCEs of minor value } \\
\text { (3) Secret TCEs }\end{array}$ & Standardized \\
\hline $\begin{array}{l}\text { Regulated kinds of } \\
\text { non-traditional } \\
\text { uses }\end{array}$ & $\begin{array}{l}\text { Any use: } \\
\text { Authorization } \\
\text { Fixed benefit share }\end{array}$ & $\begin{array}{l}\text { (1) Any use: } \\
\text { prior informed consent } \\
\text { Benefit share } \\
\text { Moral \& defensive rights } \\
\text { (2) Commercial Use: } \\
\text { Benefit share } \\
\text { Moral rights } \\
\text { (3) Any use: } \\
\text { Defensive rights }\end{array}$ & $\begin{array}{l}\text { Any use: } \\
\text { prior informed consent } \\
\text { Benefit share }\end{array}$ \\
\hline Fair Use & $\begin{array}{l}\text { Use by public } \\
\text { entities for non- } \\
\text { commercial } \\
\text { purposes }\end{array}$ & $\begin{array}{l}\text { Education } \\
\text { Research } \\
\text { Criticism } \\
\text { Review } \\
\text { Reporting } \\
\text { Archive/Inventory for } \\
\text { Heritage safeguarding } \\
\text { Incidental use }\end{array}$ & $\begin{array}{l}\text { Education } \\
\text { Criticism } \\
\text { Reporting } \\
\text { Incidental use } \\
\text { Judicial proceedings }\end{array}$ \\
\hline
\end{tabular}

Table 4: Variations in Scope of the sui generis Rights

In conclusion, there is considerable variation among the sui generis rights concerning the allocation of rights to TCEs as well as their scope. The following sections will structurally compare and analyze resulting economic effects.

\section{Economic Effects of the sui generis Rights}

There is an established law and economics research on copyright law that this article draws on to analyze the sui generis rights' economic effects. Starting with the normative perspective, granting a copyright protection can be justified by characterizing intellectual goods as public goods (MüllerLanger and Scheufen, 2011). In a world without exclusive property rights for intellectual goods, there would be few incentives to carry out cost-intensive innovations, because no one could be excluded from the profits innovations will generate in the future. Since individuals have strong incentives to free ride on others' efforts, the market for innovative creations is likely to fail. In order to prevent this market failure copyright law grants monopoly rights to individual creators under which these can demand appropriate compensation or even exclude others altogether from their creation's profits. Consequently, by creating monetary incentives for individual innovations, a copyright achieves the privatization of an otherwise public good. 
Yet, these exclusive monopoly rights come with social costs. They raise society's cost of access to new creations, especially through increased transaction costs, which potentially stifles follow-up innovations (Posner, 1992) ${ }^{14}$ Consequently, copyright law is designed to moderate between creating incentives for individuals to invest in innovations and society's demand for access to these innovations. As chronicled by Varian (2005), this goal is achieved by restricting copyright law's depth, length and width. First of all, depth refers to the degree of novelty that is required for a work to enjoy protection. In case of copyright, the necessary degree is rather small, since almost all fixated works enjoy protection automatically (Varian, 2005, p. 124). Secondly, a copyright's length is restricted to 70 years after the author's death. Afterwards, the work belongs to the public domain and can be used by anyone without restrictions, which reduces social access costs. Lastly, the width of copyright law relates to its scope. This is relatively narrow (Varian, 2005, p. 125), since only fixated works are protected, which excludes ideas, concepts or methods, for instance (see section 2.1). Moreover, certain limits to copyright protection termed "fair uses" are imposed. In some cases, these limits allow third parties full access to the created work. This concerns for instance the citation of scientific works with a clear source or the free use of the work's underlying idea for the creation of a derivative work. All in all, especially the restrictions in length and width reduce a copyright's social costs, which are supposed to be compensated by welfare gains through the creation of individual incentives for innovation (Müller-Langer and Scheufen, 2011, p. 138). ${ }^{15}$

The outlined analytical framework can be partially transferred to the sui generis rights' cost analysis. As described in section 2.1, all model laws contain exclusive economic rights, which lead to social costs by restricting society's access to TCEs and thus the pool of knowledge from which socially desirable innovations can be derived. ${ }^{16}$ These costs may well be substantial, since the sui generis rights do not contain restrictions in terms of duration, for instance. It follows that TCEs are permanently withdrawn from society's publicly accessible knowledge pool, stifling follow-up innovations. In a similar vein, the rights are comparatively large in width, since they also protect nonfixated works such as ideas or concepts. This should cover the majority of TCEs. Still, due to the imprecise definition of their width, it also creates uncertainties as to which TCEs are worthy of

\footnotetext{
${ }^{14}$ Many authors have pointed out the high social costs in stifling innovations that are generated by the system of intellectual property rights. For more details please see Boldrin and Levine (2008), Heller (2008), Jaffe and Lerner (2004).

${ }^{15}$ However, it is questionable whether copyright's current length is optimally chosen to strike the balance between creators' and society's interests. For more information on this matter, see Mackaay (2013; in press).

${ }^{16}$ Such innovations may be books, movies or theatre pieces which are based on TCEs. The relatively recent movie "Twilight Eclipse" is a case in point. Here, the founding legend of the Quileute, a tribe in the Western United States who believes that their ancestors were shape shifters between men and wolves, is employed for the plot of the movie.
} 
protection. ${ }^{17}$ However, since the sui generis rights vary strongly in width and right allocation, they are likely to result in different levels of social costs. These will be analyzed and compared in section 3.1 in order to deduce an ordinal ranking of the model laws with regard to social costs.

On the normative level, a comparison to copyright is more difficult, since there is no coherent justification why protection of TCEs is a socially beneficial goal. Clearly, since the sui generis rights aim to protect tradition, their goal - in contrast to copyright law - cannot be the creation of new forms of traditional expressions. Apparently, the model laws rather aim to protect the interests of traditional owners than to increase overall social welfare (Mackaay, 2013). This normative uncertainty thus renders the assessment of the laws' social benefits somewhat unclear. Accordingly, it can neither be judged whether the social costs incurred by the sui generis rights are justified by their social benefits nor which model law is most efficient. For this reason, section 3.2 limits itself to a comparison of the degree of the protection within the individual model laws, focusing on the question to what extent local communities' protection preferences regarding their TCEs would be considered. Lastly, section 3.3 discusses the effects of the sui generis rights on communities' propensity to create, preserve and develop their TCEs.

The incentives created by the model laws and their behavioral effects are at the center of the following analysis. Here, the unit of analysis is the rationally acting individual, who seeks to maximize personal utility. Actors that are involved in this context are: (1) representative/members of local communities, from which TCEs originate, (2) (leading) bureaucrats within a state agency and (3) individuals and enterprise representatives seeking access to TCEs for marketing purposes, for instance.

\subsection{Social Costs of the sui generis Rights}

The sui generis rights affect social costs of access to TCEs and thus costs of gaining knowledge and deriving innovations from TCEs to varying degrees. This section compares these social costs by focusing on the transaction costs generated by each of the model laws. These will be split into identification costs - incurred to identify traditional owners and negotiation partners - and negotiation costs - incurred to negotiate access to TCEs. Consequently, transaction costs are predominantly influenced by the specific allocation of rights to TCEs within the model laws (section 2.2.1). Still, they vary with the rights' width, as well. For instance, if two model laws equally allocate rights to TCEs the law with the smaller width leads to lower transaction costs. The following two sections apply this logic to the sui generis rights.

\footnotetext{
${ }^{17}$ With regards to patent law Bessen and Meurer (2008) show that an imprecise definition of patents' boundaries, i.e. which invention is protectable under patent law and which not, leads to high costs of access, which potentially stifle followup innovations.
} 


\subsubsection{Allocation of Rights to TCEs}

The analysis begins with the WDP and SMPL, which envisage a completely local allocation of rights. Especially for TCEs it can be very challenging to exactly determine to which community rights should be allocated. Certainly there are expressions that are easily attributable. However, it is conceivable that several groups simultaneously claim rights to the same TCE. For instance, even if an expression is currently practiced by Group A, it may well be rooted in traditions of Group B, too. It is thus very likely that a local rights allocation raises identification and thus transaction costs merely through the intricacies of clearly determining exactly whom the rights should actually be allocated to. ${ }^{18}$ The drafters of the SPML seek to facilitate this process by charging the state agency to identify traditional owners. If a non-traditional actor demands access to a TCE, the state agency publishes a user request (see section 2.2.1). It is expected that the community from which the demanded TCE originates truthfully claims ownership. Yet, it can be hypothesized that the prospects of monetary compensation incentivizes communities' representatives to make questionable claims of ownership. It is thus very likely that there will be conflicting claims to ownership to a single user request. ${ }^{19}$ Thus, SPML's method to lower identification costs creates incentives which potentially counteract this goal. With respect to negotiation costs, both model laws presuppose efficient internal decision-making according to customary law and adequate group representation in negotiations with outsiders seeking access to TCEs. If this was the case, it would allow external users comparatively inexpensive negotiations on access to TCEs, as they would at best only deal with few representatives who might in turn make decisions accepted by the entire community. Yet, it is highly questionable whether this concept holds true in reality. Communities may as well not be represented by single actors and representation could be contested. Moreover, there could be many actors within the community that demand exclusive rights to TCEs. In this case external users would have to negotiate access with every single right holder who might need to be compensated separately. This drastically increases negotiation costs causing interested external users to refrain from access altogether. As a result, demand for TCEs could be lower than if rights were held by a single actor.

In economic terms, this scenario can be described as a tragedy of the anti-commons (Heller, 2008). ${ }^{20}$ It is tragic, because by the very fact that several actors hold exclusive rights to a

\footnotetext{
${ }^{18}$ An example of this is the case of the identification of the owner of a melody, documented by the film "Whose song is this?". Citizens of several Balkan countries, sometimes vigorously, claim the melody for themselves and do not accept that others do the same. Should one group be given a property right on this melody, it would certainly lead to intense conflicts.

${ }^{19}$ The law specifies that such disputes are to be settled on the basis of customary law, i.e., legal systems existing alongside national systems of law that are practiced by and within local communities. The effects of this link to customary law are far beyond the scope of this paper.

${ }^{20}$ Heller (2008) describes the problem of resources for which there are too many property rights, in general. According to his theory this prevents trade and hence the most efficient use of resources, which in turn hampers innovation and progress.
} 
resource, negotiations become so expensive such that little or no trading takes place, even if all actors agree to trade individually. Not only does this scenario leave communities worse off, since they do not receive compensation, but also society, which loses potential TCE-based creations. The magnitude of this problem could even multiply, should there be more than one group claiming ownership to the TCE. Negotiations would have to be held with each group and all actors holding exclusive rights within these groups. All in all, a local rights allocation thus leads to substantial transaction costs due to negotiation and prevents access to TCEs, in spite of the potential agreement of the communities of origin.

Within the TML-approach of central rights allocation, transaction costs are of less concern. The state agency holds all relevant rights and is empowered to make decisions without the involvement of the communities of origin. Assuming that the state agency can be found with cost close to zero, identification costs are negligible in this case. Moreover, actual transaction costs are greatly reduced compared to systems of local rights allocation, because external users merely have to negotiate with a single actor. ${ }^{21}$

In the ARIPO-system of mixed right allocation, the question of ownership of the folklore arises just like in the WDP and the SPML. This should result in similar identification costs. However, negotiation costs are relatively lower. As explained in section 2.2, it is always the state agency which carries out negotiations on behalf of the communities of origin. This reduces transaction costs as external users only have to negotiate with a single actor. Although the agency has to obtain approval from the respective communities for each of its access decisions, it may still realize learning curve effects in dealing with communities under its jurisdiction. From a dynamic perspective, it is thus likely that the mixed rights allocation within the ARIPO-provisions leads to lower transaction costs than an entirely local allocation. ${ }^{22}$

All in all, the specific rights' allocation regarding TCEs considerably influences the level of transaction costs, which result from requests for non-traditional access. As shown in Table 5, a local allocation (WDP, SPML) causes the highest (rank 4) and a central allocation (TML) the lowest (rank 1) transaction costs by far. The mixed approach (ARIPO) is ranked in between. Yet, due to the learning effects of the state agency transaction costs tend to be closer to the central than to the local system of rights allocation.

\footnotetext{
${ }^{21}$ However, in the event that ethnic groups are spread across different nations the number of negotiation partners (i.e. state agency and local communities' representative) and thus transaction costs will increase.

${ }^{22}$ Under the WDP system, the communities of origin can mandate the state agency to negotiate in their stead (as within the ARIPO provisions). However, there are strong incentives within each group to exercise that right independently.
} 


\begin{tabular}{|c|c|c|c|c|}
\hline \multirow{2}{*}{} & \multicolumn{4}{|c|}{ Rights Allocation } \\
\cline { 2 - 5 } & $\begin{array}{c}\text { Central } \\
\text { TML }\end{array}$ & $\begin{array}{c}\text { Local-Central } \\
\text { ARIPO }\end{array}$ & $\begin{array}{c}\text { Local } \\
\text { WDP }\end{array}$ & $\begin{array}{c}\text { Local } \\
\text { SPML }\end{array}$ \\
\hline Identification Costs & - & high & high & High \\
\hline Negotiation Costs & lowest & medium-high & highest & Highest \\
\hline $\begin{array}{c}\text { Ranking of Transaction } \\
\text { Costs }\end{array}$ & $\begin{array}{c}\text { lowest } \\
(1)\end{array}$ & $\begin{array}{c}\text { medium-high } \\
(2-3)\end{array}$ & $\begin{array}{c}\text { highest } \\
(4)\end{array}$ & $\begin{array}{c}\text { Highest } \\
(4)\end{array}$ \\
\hline
\end{tabular}

Table 5: The Impact of Rights Allocation on Transaction Costs

In order to compare the model laws' transaction costs more completely, the next section broadens the perspective to the width of the respective rights. This includes an analysis of which TCEs are protected, how they are protected, and how non-traditional uses are regulated. Fair uses exhibit only small differences in the sui generis rights (see section 2.2.2), which is why they are excluded from subsequent analyses. ${ }^{23}$

\subsubsection{Width of the sui generis Rights}

On the one hand, the SPML as well as the TML envisage a protection system, which establishes the same level of protection for all TCEs (see section 2.2). Yet, this system also entails high access barriers for all TCEs, since non-traditional uses require - without exception ${ }^{24}$ - authorization by the state agency (TML) or prior informed consent by the communities of origin (SPML). Taking into account the arguments of the previous section, this protection system could stifle non-traditional creativity and innovation even for those TCEs, for which external access is completely conflictfree from the community of origin's perspective. ${ }^{25}$ However, the TML tends to regulate nontraditional access more transparently, since each access requires a fixed benefit share that is not subject to negotiations with the state agency. This reduces uncertainty and thus lowers transaction costs in comparison to what can be expected to result from the SMPL. Here, each non-traditional access requires negotiating the terms of a prior informed consent with the community of origin, which may lead to high transaction costs and fewer access decisions even for those TCEs that are regarded as unproblematic by the communities of origin.

The WDP and the ARIPO provisions, on the other hand, establish a differentiated protection system, taking into account how the communities of origin judge the value of their TCEs. This differentiation

\footnotetext{
${ }^{23}$ Although fair uses affect non-traditional access costs, the model laws' fair uses do not sufficiently differ to cause crucial discrepancies in transaction costs.

${ }^{24}$ This argumentation neglects, of course, fair uses, which are present in all model laws.

${ }^{25}$ Funeral rituals performed by Toraja in Indonesia may serve as a suitable example. Anthropological field research has shown that the Toraja benefit from the recording and dissemination of these rituals and do not require being asked for permission (cf. Klenke and Socha, 2013; Engelbrecht, 2010).
} 
was explicitly created to reduce the width of the rights and to prevent excessive access barriers for TCEs which are - in the eyes of the communities of origin - less worthy of protecting (WIPO, 2006). While the strongest protection calls for the prior informed consent by the community of origin for any non-traditional uses, the second protection level is much more relaxed. First, there are no restrictions for usage without any gainful intend. Second, commercial uses do not require a prior informed consent. However, the exact amount of the benefit share charged for commercial uses is not fixed a priori. Consequently, external users have to negotiate the terms of access with the state agency in the second level of protection, as well, in order to pay an acceptable amount. Still, since negotiations involving a single partner come with much lower transaction costs than negotiations with - potentially - many partners, access barriers for TCEs of level 2 will generally be significantly lower than those of the level $1 .{ }^{26}$ Accordingly, should the communities of origin truthfully register their TCEs, the width of the WDP and ARIPO provisions is smaller than that of SPML or the TML provisions. From an economic perspective, however, this is doubtful. Both model laws set strong incentives for rational community members to register their TCEs as being of particular value (level 1) even if they are actually not. This is due to the tendency that external demand for TCEs is not necessarily correlated with the perception of their value within the community. Registering TCEs as belonging to level 1 although they would truthfully belong to level 2 thus increases prospects of receiving higher compensation payments. In the end, this results in an excessive registration of level-1-TCEs. Yet, for this protection level access restrictions are very similar to those in the SPML so there is a risk that the width of the WDP and ARIPO approximates that of the SPML. ${ }^{27}$

\subsubsection{Summary}

Table 6 shows the comparative ranking of transaction costs resulting from the model laws (1-lowest costs, 4-highest costs). As already mentioned, transaction costs are mainly determined by the allocation of rights to the TCEs. In addition, they can be both increased and decreased by differences in the rights' width.

Accordingly, the highest transaction costs arise through the SPML, which is due to the complete local rights allocation and its comparatively large width. The WDP provisions are in third place. They lead to similar transaction costs from local rights allocation, yet their width is more restricted than that of the SPML. However, due to the danger of too many registrations of level-1TCEs, their width and thus their transaction costs could approximate those in the SPML. Both

\footnotetext{
${ }^{26}$ An economic interpretation of the third protection level targeting secret TCEs can be found in Mackaay (2013).

${ }^{27}$ This disincentive could be weakened by an implementation of fixed and non-negotiable compensations for the use of level-1-TCEs, payable to the state agency. However, this would affect the character of protection, as well (see section 3.2).
} 
model laws thus seriously risk increasing access costs to TCEs in such a way that it leads to a tragic underuse of TCEs crucially impeding the creation of follow-up innovations. The ARIPO provisions are identical in width with the WDP, however, they lead to lower transaction costs due to the mixed rights allocation. Because of the fully centralized allocation of rights the TML lead to the lowest transaction costs by far.

\begin{tabular}{|c|c|c|c|c|}
\hline & \multicolumn{4}{|c|}{ Sui Generis Rights } \\
\cline { 2 - 5 } & TML & ARIPO & WDP & SPML \\
\hline $\begin{array}{c}\text { Transaction costs through } \\
\text { rights allocation }\end{array}$ & $\begin{array}{c}\text { lowest } \\
(1)\end{array}$ & $\begin{array}{c}\text { medium-high } \\
(2-3)\end{array}$ & $\begin{array}{c}\text { highest } \\
(4)\end{array}$ & $\begin{array}{c}\text { highest } \\
(4)\end{array}$ \\
\hline Width of the rights & $\begin{array}{c}\text { wide } \\
(2)\end{array}$ & $\begin{array}{c}\text { Less wide } \\
\text { widest } \\
(1-3)\end{array}$ & $\begin{array}{c}\text { Less wide } \\
- \\
\text { widest } \\
(1-3)\end{array}$ & $\begin{array}{c}\text { widest } \\
(3)\end{array}$ \\
\hline $\begin{array}{c}\text { Overall ranking of } \\
\text { transaction costs }\end{array}$ & (1) & (2) & $(3-4)$ & (4) \\
\hline
\end{tabular}

Table 6: Overall Ranking of sui generis Rights' Transaction Costs

\subsection{Character of Protection within the sui generis Rights}

Communities' preferences relating to protection of their TCEs are based largely on positive or negative utility effects, stemming from non-traditional uses. According to Bicskei et al. (2012) TCEs, as an example of cultural goods, can yield both direct and indirect utility for the communities of origin. ${ }^{28}$ On the one hand, direct utility results from monetary compensations by non-traditional consumers. If they pay for their external use direct utility increases, if they do not it decreases. Indirect utility, on the other hand, derives from a sense of cultural identity, which TCEs provide for the communities of origin. Non-traditional uses of TCEs can either enhance or decrease indirect utility, which crucially depends on the particular form of expression. Bicskei et al. (2012) give several examples of cultural goods that affect indirect utility of their carriers to varying degrees. The use of a language by a third party, for instance, increases indirect utility within the native speakers' community, since the generation of identity increases along with the size of the community. However, commercial dissemination of certain sacred rituals by third parties can among other things result in indirect utility losses, as the identity generating effect fades (Bicskei et al., 2012, p. 105). Preferences for protection are thus a function of how strong external access affects communities' individual utility elements. If indirect utility losses are prohibitively high, local

\footnotetext{
${ }^{28}$ The utility function introduced by Bicskei et al. (2012) refers to cultural goods in general, yet applies to the special case of TCEs, as well.
} 
communities will not agree to an external access. ${ }^{29}$ Should they prove moderate, however, access could be compensated, e.g. by payments of access fees. If external access increases both direct and indirect utility, it would be in the interest of the community of origin to choose the lowest possible level of protection. To which degree these different preferences for protection are taken into account when outsiders seek access to TCEs depends first and foremost on the specific allocation of rights to TCEs (see section 2.2.1). ${ }^{30}$ This issue will be discussed in the following section.

The analysis begins with the system of local rights allocation, which is envisaged by the WDP and the SPML. In both cases, the local community is responsible for negotiating the conditions of nontraditional access and has the right to collect compensation. Thus, access decisions are made by the actor with whom the utility effects stemming from the use of TCEs arise, which will then be reflected in the amount of compensation. Consequently, this guarantees that an external access only occurs if the local community realizes an increase in net utility. If indirect utility losses are high, compensation has to be equally high in order for communities to accept external use. Besides setting the price, local communities have the opportunity to introduce license conditions for external uses such that they minimize negative utility effects (Bizer et al., 2011). For instance, communities might only allow a certain type of use that does not affect the identity providing effect of the underlying expression. This would effectively increase access barriers and thus implicitly also decrease its value for non-traditional actors, thus reducing demand for TCEs (Lechner et al., 2008). In contrast, utility losses for less critical TCEs can be much lower, resulting in a lower price and thus facilitated access. All in all, local rights allocation most likely leads to a manner of protection, which essentially depends on how local communities perceive the value of their TCEs. Accordingly, their preferences for protection will be considered. ${ }^{31}$

Under the TML-system all rights are assigned centrally. A state agency assumes the task of representing local communities' interests in protecting TCEs. From an economic perspective, this constellation may thus be interpreted as a principal-agent relationship, with the community being the principal for the state agency acting on its behalf. As in any principal-agent situation, there will be asymmetric information to the detriment of the principal, which the state agency could exploit in order to pursue its own interests in negotiating access to TCEs at the expense of the community. Yet, how problematic this relationship crucially depends on the behavioral incentives of the state

\footnotetext{
${ }^{29}$ This could be the case if an external use infringes the fundamental identity (dignity) of the community of origin (Bicskei et al., 2012).

${ }^{30}$ The rights' width additionally influences the consideration of communities' preferences for protection, especially the possibility to establish a higher protection level for particularly valuable TCEs (WIPO/ARIPO). This, however, merely plays a minor role.

${ }^{31}$ This argument is subject to the assumption that communities are organized well enough to clearly express their preferences. As argued in the last section, however, this may not always be the case.
} 
agency's bureaucrats and on the extent to which these incentives are related to those of the local communities. The following sections discuss implications of various behavioral assumptions, which are summarized by Table 7.

First, it can be assumed that a bureaucrat's goal is to maximize social welfare. To this end, Faber et al. introduce the behavioral model of the homo politicus (Faber et al., 2002). The homo politicus seeks political justice, which is a political order he considers to be just and for which he expects ex ante the consent of all individuals in society (Faber et al., 2002, p. 328). He even accepts that this may restrict his personal interests. The authors find evidence for such behavior, for instance, with German ministry officials in the field of environmental policy (Faber et al., 2002, p. 330). Under this assumption bureaucrats will take the interests of local communities into account to a certain degree when deciding on access to their TCEs. Thereby, the principalagent problem would be comparatively small.

Second, consider the assumptions of the economic theory of bureaucracy, which are based on the behavioral model of the homo economicus. These state that bureaucrats exclusively act according to self-interest, which is determined by personal income, influence and prestige (Mueller, 2008). In case of leading bureaucrats, the latter two effects can be best approximated by the size of their budget (Niskanen, 1971). Ruling out that negotiations on access to TCEs affect personal income, bureaucrats within the state agency will predominantly display a budgetmaximizing behavior in order to increase their personal utility. Consequently, incentives exist to inflate the number of accesses to TCEs, since this will increase the number of required employees in the agency and thus the size of the budget (Mackaay, 2013). Under this assumption, bureaucrats are thus likely to deal less restrictively with those TCEs that are of increased value to the communities of origin, which will result in a higher number of accesses compared to the situation when decisions were made exclusively by the respective community. Accordingly, despite the state agency's statutory duty to represent local communities' interests, the principal-agent problem is likely to be pronounced.

Lastly, the assumption of behavior driven by self-interest can be extended assuming that bureaucrats are corrupt and thus susceptible to bribery, increasing personal income. In this manner, external parties can gain fast and non-bureaucratic access to TCEs, for which lengthy negotiations would be necessary otherwise. Assuming that external users have a higher willingness to offer a bribe to agency officials than the community of origin, this would result in a large number of access decisions, which in no way reflect the preferences of the local community. As a result, following this behavioral assumption the principal-agent problem would be most pronounced.

Principal-agent problems of this type can be reduced by introducing - supposedly costly - measures to monitor the agent or by aligning her behavioral incentives with the ones of the principal. However, 
the TML contains no such provisions. Neither can the communities control the state agency's decisions nor does the model law contain a design that aligns behavioral incentives of the communities of origin and the state agency.

\begin{tabular}{|c|c|}
\hline Behavioral Assumption & $\begin{array}{c}\text { Manifestation of the } \\
\text { principal-agent problem }\end{array}$ \\
\hline $\begin{array}{c}\text { Pursuit of social welfare } \\
\text { (political justice) }\end{array}$ & weakest \\
\hline Pursuit of self-interest & medium \\
\hline $\begin{array}{c}\text { Pursuit of self-interest and } \\
\text { corruption }\end{array}$ & strongest \\
\hline
\end{tabular}

Table 7: The Principal-Agent Problem between Communities and Bureaucrats under certain Behavioral Assumptions

In the system of mixed rights holders (ARIPO) the state agency serves as the agent of the local communities, as well. Yet, the provisions grant local communities veto powers over all access decisions of the agency. These are primarily intended as a tool to control the agent since the local community should not tolerate decisions that mainly serve bureaucrats' self-interest. Consequently, under the ARIPO provisions the state agency is granted much less discretion than under the TML. Nevertheless, representation of the local communities by the agency will still be imperfect, because the agency could still be subject to differing behavioral incentives and it holds an informational advantage over local communities. ${ }^{32}$ Due to the incentive structure, it is likely that the bureaucrats exploit this information asymmetry to achieve self-serving goals at the communities' expense. Nonetheless, due to the veto power, protection will be more closely aligned with the local communities' preferences than under the TML, yet less so than with the SPML and the WDP. Table 8 summarizes these findings.

\footnotetext{
${ }^{32}$ The state agency has for instance an information advantage regarding external users' willingness to pay for accessing certain TCEs.
} 


\begin{tabular}{|c|c|c|c|}
\hline \multirow{2}{*}{} & \multicolumn{3}{|c|}{ Allocation of Rights } \\
\cline { 2 - 4 } & $\begin{array}{c}\text { Central } \\
\text { TML }\end{array}$ & $\begin{array}{c}\text { Mixed } \\
\text { ARIPO }\end{array}$ & $\begin{array}{c}\text { Local } \\
\text { WDP/SPML }\end{array}$ \\
\hline $\begin{array}{c}\text { Principal-agent } \\
\text { problem }\end{array}$ & stronger & weaker & Non-existent \\
\cline { 2 - 4 } & $\begin{array}{c}\text { No control of the } \\
\text { agency by } \\
\text { communities of origin }\end{array}$ & $\begin{array}{c}\text { Better control of the } \\
\text { agency by } \\
\text { communities of } \\
\text { origin }\end{array}$ & $\begin{array}{c}\text { External access } \\
\text { only if it increases } \\
\text { net utility for local } \\
\text { community }\end{array}$ \\
\hline $\begin{array}{c}\text { Whose interests } \\
\text { tend to be taken } \\
\text { into account in } \\
\text { the protection of } \\
\text { TCEs? }\end{array}$ & Agency & $\begin{array}{c}\text { Local community } \\
\text { and agency }\end{array}$ & $\begin{array}{c}\text { Local community } \\
\end{array}$ \\
\hline
\end{tabular}

Table 8: Consideration of Interests in the Protection of TCEs

The assumptions on the behavior of the state agency's bureaucrats decisively influence in how far local communities' protection preferences will be taken into account by the agency, since they ultimately determines the extent of the principal-agent problem. Nevertheless, the TML should cause a stronger representation problem than the ARIPO provisions.

\subsection{Creation, Preservation and Development of TCEs}

Both in the local as well as in the mixed system of rights allocation, local communities receive direct compensation for external uses of their TCEs. ${ }^{33}$ This raises the question as to how the possibility of realizing gains impacts on the creation, preservation and development of TCEs within the local groups. According to Frey and Oberholzer-Gee (1997, p. 15-17), installing extrinsic monetary incentives for actions, which individuals already take out of their intrinsic motivation, can displace the intrinsic motivation in whole or in part. A condition for this situation to arise is that the affected individuals feel controlled by the external intervention, impairing their freedom of expression, self-esteem or self-determination (1997). Under the assumption that group members maintain, develop and possibly even create TCEs out of pure intrinsic motivation, sui generis rights' extrinsic monetary incentives may hence at least partially displace this intrinsic motivation. If external incentives have a greater weight in communities' utility functions than intrinsic incentives, external demand will largely determine how the affected communities will deal with its TCEs. On the one hand, they could for instance neglect preservation of less demanded TCEs. In case of strongly demanded TCEs, on the other hand, incentives could arise to preserve these in accordance with demand. However, this hinders the natural, intrinsically

\footnotetext{
${ }^{33}$ Within the TML local communities do not receive direct monetary compensations (see section 2.2.1).
} 
motivated development of the concerned TCEs. Also, newly created forms of expression could increasingly reflect expectations on external demand.

\section{Conclusion and Policy Implications}

Sui generis rights are a separate kind of intellectual property law, which so far did not receive any academic attention from an economic perspective. While there is far-reaching normative as well as positive economic research on copyright and patent law, regulatory impacts of sui generis rights have been less or not at all illuminated. This is astonishing, since they depart from conventional legal doctrines by granting rights to entire groups, establishing protections, which are temporally unlimited and do not require fixation of the work. Consequently, under the assumption that TCE protection is a socially beneficial goal, this article addresses the question of how the economic effects of the sui generis model laws can be structurally analyzed and compared. Ultimately, this analysis should provide a first reference point for political decision-makers, who seek to establish a sui generis protection for TCEs.

On the one hand, this article comparatively assesses the sui generis rights' transaction costs. Here, the specifics of rights allocation to TCEs as well as their width prove to be of significant influence. On the other hand, it compares the character of TCE protection under each model law, focusing on the degree to which local communities' preferences for protection of their TCEs are respected. By merging these two levels of analysis, a clear trade-off emerges (see Table 9). The more a law respects local communities' preferences for protection, the higher the costs borne by the entire society. This is mainly due to comparatively high transaction costs of negotiating access to TCEs when property rights are fully assigned on a local level. Examples of this are the WIPO Draft Provisions or the South Pacific Model Law. In contrast, the more a model law reduces transaction costs, the higher the likelihood that local communities' preferences will be disregarded. The installation of a state agency acting as a negotiating partner to non-traditional actors saves transaction costs in negotiating access to TCEs. Yet, this entails principal-agent problems in the representation of the interests of the communities of origin. These effects are most likely to occur under the Tunis Model Law. The ARIPO provisions are a compromise between both criteria's extremes. Here, local interests will be respected to a higher degree than under the Tunis Model Law, but to a lesser degree than in the WIPO Draft Provisions and the South Pacific Model Law. 


\begin{tabular}{|c|c|c|c|c|c|}
\hline \multicolumn{2}{|c|}{} & \multicolumn{4}{|c|}{ Sui Generis Rights } \\
\cline { 3 - 6 } & TML & ARIPO & WDP & SPML \\
\hline \multirow{2}{*}{$\begin{array}{c}\text { Economic } \\
\text { effects }\end{array}$} & $\begin{array}{c}\text { Which interests tend } \\
\text { to be respected? }\end{array}$ & Agency & $\begin{array}{c}\text { Local community } \\
\text { and agency }\end{array}$ & $\begin{array}{c}\text { Local } \\
\text { community }\end{array}$ & $\begin{array}{c}\text { Local } \\
\text { community }\end{array}$ \\
\cline { 2 - 6 } & $\begin{array}{c}\text { Ranking of transaction } \\
\text { costs }\end{array}$ & (1) & (2) & (3-4) & (4) \\
\hline
\end{tabular}

Table 9: Protection and Cost Effects of the sui generis Model Laws

Additionally, the model laws that allow for direct compensation of local communities (ARIPO, WDP, SPML) risk inhibiting the group-intrinsic motivation for the generation, maintenance and development of TCEs. Thus, in the long run TCEs could develop in a way that is more compliant with market demand than with local communities' preferences without extrinsic incentives.

Consequently, policy-makers who wish to install sui generis protection of TCEs within their country must carefully weigh which effects they prioritize. Should the overriding objective be minimizing the law's cost for the general public, a completely centralized assignment of rights, such as in the Tunis Model Law, should be preferable. In case that the local communities' protection preferences have priority, a completely local rights assignment, such as in the WIPO Draft Provisions or the South Pacific Model Law, is to be chosen. If both preferences and social costs are included in the consideration, the manifestation of the principalagent problem between communities and state agency is crucial for the choice of the law. Hence, it is essential to assess bureaucrats' behavioral incentives.

Firstly, if bureaucrats are prone to corruption, then a law, which critically involves this administration, will in no way respect local interests for protection. Such a situation calls for a completely local assignment of rights. Due to their comparatively lower transaction costs, WIPO Draft Provisions are preferable to the South Pacific Model Law in this case. Secondly, if they pursue the maximization of social welfare, local interests for protection would be considered in the agency's decisions. Then, a completely centralized assignment of rights, such as in the Tunis Model Law, could be applicable, since it reduces transaction costs, as well. Lastly, bureaucrats' behavior that solely maximizes personal utility calls for a mixed allocation of rights such as in the ARIPO Provisions. It improves the agency's representation of local protection interests by means of providing local communities with veto powers, leading to lower transaction costs as compared to an entirely local allocation of rights. Yet, it would require a balanced administrative procedure that is sufficiently linked to the communities of origin.

Due to the principle of country of protection (lex loci protectionis) a sui generis right would initially apply only within the jurisdiction of the country that implements 
it. However, since TCEs are intangible in nature protection may be circumvented outside this country. Consequently, it is desirable to establish an international framework which is legally binding and sets out international minimum standards of protection. 


\section{References}

African Regional Intellectual Property Organization (ARIPO),2010. Draft Protocol on the Protection of Traditional Knowledge and Expressions of Folklore Within the Framework of the African Regional Intellectual Property Organization (ARIPO). http://www.wipo.int/edocs/mdocs/tk/en/wipo_grtkf_ic_16/wipo_grtkf_ic_16_inf_24.pdf (Accessed 26 March 2013).

Bessen, J., Meurer, M.J., 2008. Patent Failure. Princeton: Princeton University Press.

Bicskei, M., Bizer, K., Gubaydullina, Z., 2012. The Protection of Cultural Goods - Economics of Identity. International Journal of Cultural Property 19 (1), 97-118.

Bizer, K., Lankau, M., Spindler, G., Zimbehl, P., 2011. Sui Generis Rights for the Protection of Traditional Cultural Expressions: Policy Implications. JIPITEC 2 (2), 114-119.

Boldrin, M., Levine, D.K., 2008. Against Intellectual Monopoly. Cambridge: Cambridge University Press.

Engelbrecht, B., 2010. Ethnographische Filmarbeit und Copyright: Überlegungen zur Situation in Indonesien. In: Bendix, R., Bizer, K., Groth, S. (Eds.). Die Konstituierung von Cultural Property. Forschungsperspektiven, Göttingen: Universitätsverlag, 153-172.

Faber, M., Petersen, T., Schiller, J., 2002. Homo oeconomicus and homo politicus in Ecological Economics. Ecological Economics 40 (3), 323-333.

Frey, B., 1997. Not just for the money: An economic theory of personal motivation. Cheltenham, UK: Edward Elgar Publishing.

Frey, B.S., Oberholzer-Gee, F., 1997. The Cost of Price Incentives: An Empirical Analysis of Motivation Crowding- Out. The American Economic Review 87 (4), 746-755.

Heller, M.A., 2008. The Gridlock Economy: How Too Much Ownership Wrecks Markets, Stops Innovation, and Costs Lives. Philadelphia: Basic Books.

Hilty, R.M., 2009. Rationales for the Legal Protection of Intangible Goods and Cultural Heritage. International Review of Intellectual Property and Competition Law (IIC) 09 (8), 883-911.

Hughes, J., 2013. Traditional Knowledge, Cultural Expression, and the Siren's Call of Property. Cardozo Legal Studies Research Paper No. 381. http://ssrn.com/abstract=2215996 (accessed 06 May 2013).

Jaffe, A.B., Lerner, J., 2004. Innovation and Its Discontent. How Our Broken Patent System is Endangering Innovation and Progress, And What to Do about It. Princenton, Oxford: Princeton University Press.

Klenke, K., Socha, P., 2013. Emerging Indigeneity - Völkerrechtswissenschaft und ethnologische Praxis subnationaler kultureller Gemeinschaften. In: Bizer, K., Lankau, M., Spindler, G. (Eds.). Sui Generis Rechte zum Schutz traditioneller kultureller Ausdrucksweisen: Interdisziplinäre Perspektiven. Göttinger Studien zu Cultural Property, 5, Göttingen: Universitätsverlag, 21-42.

Lankau, M., Bizer, K., Gubaydullina, Z., 2010. Die verborgene Effektivität minimaler Resultate in internationalen Verhandlungen : der Fall der WIPO. In: Bendix, R., Bizer, K., Groth, S. (Eds.). Die Konstituierung von Cultural Property. Forschungsperspektiven, Göttingen: Universitätsverlag, 197-216.

Lechner, S., Gubaydullina, Z., Bizer, K., 2008. The allocation of property rights to intangible cultural assets, Discussion paper series 136. Volkswirtschaftliches Seminar. Göttingen, 1-16. 
Lewinski, S. von, 2007. Adequate protection of folklore - a work in progress. In: Torremans, P. (Ed.). Copyright Law - A Handbook of Contemporary Research, Cheltenham, UK: Edward Elgar Publishing Limited, 207-231.

Lewinski, S. von, 2013. Herausforderungen eines sui generis Rechts auf internationaler Ebene. In: Bizer, K., Lankau, M., Spindler, G. (Eds.). Sui Generis Rechte zum Schutz traditioneller kultureller Ausdrucksweisen: Interdisziplinäre Perspektiven. Göttinger Studien zu Cultural Property, 5, Göttingen: Universitätsverlag, 11-20.

Mackaay, E., 2013. Sui generis rights on folklore viewed from a property rights perspective. In: Bizer, K., Lankau, M., Spindler, G. (Eds.). Sui Generis Rechte zum Schutz traditioneller kultureller Ausdrucksweisen: Interdisziplinäre Perspektiven. Göttinger Studien zu Cultural Property, 5, Göttingen: Universitätsverlag, 139-163.

Mackaay, E., in press. The Economics of Life ++: Reflections on the Term of Copyright. In Proceedings of the ALAI Study Days Vienna, 9-11 September 2010, on the terms of copyright. Michel Walter, Hrsg. http://www.cirano.qc.ca/pdf/publication/2011s-38.pdf (accessed 01 July 2011).

Mueller, D.C., 2008. Public Choice III. Cambridge, UK: Cambridge Univ. Press.

Müller-Langer, F., Scheufen, M., 2011. Die ökonomische Analyse geistiger Eigentumsrechte. Wist Wirtschaftswissenschaftliches Studium. Zeitschrift für Studium und Forschung 40 (3), 137-142.

Niskanen, W.A., 1971. Bureaucracy and representative government. Chicago: Aldine-Atherton.

Posner, R.A., 1992. Economic Analysis of Law, 4th Edition. Boston: Little, Brown and Company.

Secretariat of the Pacific Community, 2002. Regional Framework for the Protection of Traditional Knowledge and Expressions of Culture.

http://www.spc.int/hdp/Documents/5th_CPA_Exec_Board/RegionalFramework_no_cover.pdf (accessed 26 March 2013).

Varian, H.R., 2005. Copying and Copyright. The Journal of Economic Perspectives 19 (2), 121-138.

WIPO, 2004. The Protection of Traditional Cultural Expressions / Expressions of Folklore: Outline of Policy Options and Legal Mechanisms. WIPO/GRTKF/IC/7/4. http://www.wipo.int/edocs/mdocs/tk/en/wipo_grtkf_ic_7/wipo_grtkf_ic_7_4.pdf (accessed 15 March 2013).

WIPO, 2006. The Protection of Traditional Cultural Expressions/Expressions of Folklore: Revised Objectives and Principles. WIPO/GRTKF/IC/9/4.

http://www.wipo.int/meetings/en/doc_details.jsp?doc_id=55137 (accessed 29 September 2011).

WIPO, 2010. Draft Provisions. http://www.wipo.int/tk/en/consultations/draft_provisions/draft_provisions.html (accessed 12 October 2011).

UNESCO und WIPO,1976. Tunis Model Law on Copyright for Developing Countries, no. 812.Paris, Geneva: UNESCO; WIPO. http://portal.unesco.org/culture/en/ev.phpURL_ID=31318\&URL_DO=DO_TOPIC\&URL_SECTION=201.html (accessed 29 September 2011).

UNESCO und WIPO,1982. Model Provisions for National Laws on the Protection of Expressions of Folklore against Illicit exploitation and other prejudicial actions. http://www.wipo.int/wipolex/en/text.jsp?file_id=184668 (Accessed 03 October 2011).

Zimbehl, P., 2013. Zwischen Innovation und Altbekanntem: Schutzrechte sui generis im systematischen Vergleich. In: Bizer, K., Lankau, M., Spindler, G. (Eds.). Sui Generis Rechte zum Schutz traditioneller kultureller Ausdrucksweisen: Interdisziplinäre Perspektiven. Göttinger Studien zu Cultural Property, 5, Göttingen: Universitätsverlag, 87-106. 


\title{
CHAPTER III
}

\section{Sui Generis Rights for the Protection of Traditional Cultural EXPRESSIONS - POLICY IMPLICATIONS}

\author{
Kilian Bizer, Matthias Lankau, Gerald Spindler and Philipp Zimbehl
}

Published in Journal of Intellectual Property, Information Technology and

E-Commerce Law (JIPITEC), 2012, Volume 2, Issue 2, 2011, pp. 114-119

Available at: http://www.jipitec.eu/issues/jipitec-2-2-2011/3083/jipitec\%202\%20-\%20a\%20\%20bizer\%20et\%20al.pdf

\begin{abstract}
Within the international community there have been many calls for better protection of traditional cultural expressions (TCEs), for which classic instruments of intellectual property rights do not seem to fit. In response, at least five model laws have been advanced within the last 40 years. These are referred to as sui generis because, though they generally belong to the realm of intellectual property they structurally depart from classic copyright law to accommodate the needs of the holders of TCEs. The purpose of this paper is to provide a well-founded basis for national policy makers who wish to implement protection for TCEs within their country. This is achieved by systematically comparing and evaluating economic effects that can be expected to result from these regulatory alternatives and a related system or private ordering. Specifically, we compare if and how protection preferences of local communities are met as well as the social costs that are likely to arise from the different model laws.
\end{abstract}




\title{
CHAPTER IV
}

\section{Cooperation Preferences in the Provision of Public Goods}

An Experimental Study on the Effects of Social Identity

\author{
Matthias Lankau, Marianna Bicskei, Kilian Bizer
}




\section{Introduction}

Recent literature on social identity demonstrates that social preferences vary depending on the social environment. Experimental research by Chen and Li (2009), for instance, shows that when interacting with individuals of a common identity subjects reveal a significantly higher degree of positive reciprocity than when interacting with individuals of different identities. Additionally, they are more likely to make social welfare maximizing choices. Although having immediate relevance for the provision of public goods, this relationship has not been experimentally analyzed, so far. Consequently, we ask whether subjects hold differing cooperation preferences in the provision of public goods under the institution of social identity, making salient the persons' identity with which an individual interacts. To this purpose, we induce social identity in the laboratory by having subjects solve a simple group identity task with anonymous communication via chat. The experiment features a within-subject design that is based on one-shot public good games using the strategy method, which is an often used method for the elicitation of cooperation preferences. ${ }^{1}$ Three matching protocols are in effect: in-group matching, when subjects interact with individuals of their own identity; out-group matching, when groups are composed of subjects of different identities and random matching, in which no identity is induced, serving as a control.

Our results clearly show that cooperation preferences in public good provision vary depending on the social environment. In particular, we find that when matched with individuals of a common identity, subjects consistently show the preference for higher levels of conditional cooperation and thus less self-serving bias than when interacting with individuals that are perceived to belong to different identities. What is more, we identify an elevated propensity to be a free-rider when being matched with individuals of a different identity than in in-group matching. These findings have direct relevance for positive predictions of policy effects. Social identity systematically activates different preferences to cooperate with one-another which directly influences social welfare. It is thus reasonable to device institutions that stress the belonging to the group providing a public good.

The remainder of the article is organized as follows. Section 2 reviews the relevant literature on cooperation preferences in public goods provision as well as on social identity and formulates the research hypotheses. Section 3 presents the experimental design, which is followed by a detailed presentation of our results. The article concludes in section 5 and derives implications for economic policy.

\footnotetext{
${ }^{1}$ Obviously, preferences do not lend themselves to direct measurement. We are aware of the fact that all the strategy method may enable us is to observe subjects' responses to other subjects' hypothetical behavior and to measure cooperation strategies. However, these allow for an approximation of actual cooperation preferences (cf. Volk et al., 2012).
} 


\section{State of Research and Hypotheses}

\subsection{Literature Review}

Cooperation preferences in public goods provision were first empirically analyzed by Fischbacher et al. (2001). Using a variant of the strategy method (Selten, 1967) in a one-shot public good game the authors elicited subjects' contributions as a function of the average contributions of their group members. The authors find that 50 percent of the subjects can be classified as conditional cooperators, i.e. subjects whose contributions are positively correlated with the level of others' average contributions, and 30 percent as free riders. ${ }^{2}$ Similar findings were reported in various replication studies, reviewed by Chaudhuri (2011).

While free-riding is best explained by assuming individuals maximize their own utility instead of the groups' utility based on purely selfish preferences, conditional cooperation may be understood best as social preference for positive reciprocity (cf. Falk, 2003, p. 147). ${ }^{3}$ As per Fehr and Fischbacher (2002, p. C3-C4) a positive reciprocal individual "[...] responds to actions that are perceived to be kind in a kind manner [...]". In that sense, conditional cooperators perceive high contributions of their remaining group members to be a kind action and reciprocate this kindness by high own contributions. It is to be noted, however, that even conditional cooperators show a self-serving bias to some extent since on average they do not reciprocate their team members' contributions by an equal own contribution (perfect conditional cooperation), but depart in the selfish direction. This has direct bearing on the amount of public good provided, especially in long term interactions. Fischbacher and Gächter (2010), for instance, argue that the self-serving bias alone may be responsible for decaying public good contributions in the long run. ${ }^{4}$

To which extent these heterogeneous cooperation preferences differ between institutional settings, has merely received little academic attention, so far. Existing studies typically compare individuals' decisions in different games or variants of the same game (cf. Blanco et al., 2011). Yet, to the best of our knowledge in case of public goods provision there exists no study that specifically examines differences in cooperation preferences in relation to social identity.

\footnotetext{
2 The remaining types are either "hump-shaped cooperators", i.e. individual whose contributions are positively correlated with the average of the others up to a maximum and then decline again, or belong to the class "others".

${ }^{3}$ Conditional cooperation may as well be explained by the social preference for inequity aversion, as modeled by Fehr and Schmidt (1999) and Bolton and Ockenfels (2000). Nevertheless, in this article we will proceed by referring to positive reciprocity.

${ }^{4}$ Additionally, the heterogeneity of cooperation types may explain decaying contributions to public goods as well. In the course of repeated interactions, conditional cooperators may get increasingly frustrated by interacting with individuals that are free-riding on their contributions and react with lower own contributions, as well (Burlando and Guala, 2005).
} 
The origin of experimental economic research on social identity defined as "[...] a person's sense of self derived from perceived membership in social groups" (Chen and Li, 2009, p. 431), lays in the social identity theory pioneered by Tajfel and Turner (1979). This theory was developed in order to establish the psychological foundations of discriminatory behavior and comprises three components - categorization, identification and comparison. Categorization denotes the apparently quick process of placing individuals including oneself into certain social categories such as religious, ethnic or other groups. The second process, identification, characterizes the process by which individuals associate themselves with certain groups - the in-group(s). Conversely, out-groups are social groups that an individual does not identify with. In the last process of social comparison individuals start to compare their in-group with the out-group, which generally leads to in-group favoritism and out-group discrimination (cf. Tajfel and Turner, 1986; Chen and Li, 2009; Hoff and Pandey, 2006). ${ }^{5}$ This phenomenon, termed as in-group bias, is increasingly attributed to the different expectations on the behavior of in-group as opposed to out-group members (cf. Yamagishi et al., 1999; Yamagishi and Kiyonari, 2000; Jackson, 2011; loannou et al., 2012).

Studies outside the public goods environment show furthermore that social identity positively influences social welfare when individuals interact with in-group matches as opposed to random ${ }^{6}$ and/or out-group matching. These findings thus provide a hint that in case of public good provision subjects may exhibit a stronger preference for cooperation, as well. Firstly, studying the effects of social identity on social preferences in dictator and two-person response games, Chen and Li (2009) find that group identity has a significant positive effect on the likelihood of social welfare maximizing choices. The authors consequently predict that "in games with a unique Pareto-efficient outcome, people with salient group identities are more likely to choose cooperation when matched with an ingroup member" (Chen and Li, 2009, p. 447). Next, employing a two-player coordination game with induced social identity Charness et al. (2007) equally find that a salient group identity may enhance social welfare, depending on the institutional structure. They manipulate the saliency of group membership by varying whether the decision maker's group is present when decisions are made, whether feedback is given about the outcome of the game and whether there is payoff dependence. Similarly, McLeish and Oxoby (2007), verify that individuals show higher cooperation with in-group than with out-group matches, measured by the offers extended by the proposer in a two person response experiment with induced social identity. Making use of real identification with Swiss army platoons, Goette at al. (2006) similarly identify greater cooperation in a prisoners' dilemma game when individuals are matched with members of their own platoon. Lastly, Chen and Chen (2011) detect that in in-group matching individuals coordinate to the socially efficient high effort

\footnotetext{
${ }^{5}$ See Chen and Li (2009) for a detailed account on theoretical and empirical findings on social identity theory.

${ }^{6}$ In random matching subjects interact with others that are not perceived to belong to any particular identity.
} 
equilibrium in minimum-effort games. All in all, these findings demonstrate that social identity renders individuals more likely to strive for social welfare when matched with in-group members.

What is more, two studies establish a direct connection between social identity and the preference for conditional cooperation, by revealing that social identity impacts on subjects' preferences for positive reciprocity. Firstly, based on the results of a series of two-person response games in a within-subject design, Chen and Li (2009) find that when matched with in-group members individuals reward perceived "good behavior" to a higher extent than when matched with out-group members. Specifically, individuals exhibit a significant 19 percent increase in positive reciprocity (Chen and Li, 2009, p. 445). ${ }^{7}$ Secondly, relying on a between-subject design and a similar game setting Currarini and Mengel (2012) report a 34 percent higher positive reciprocity in in-group matching. Since positive reciprocity is the theoretical foundation for conditional cooperation, we similarly expect social identity to impact on subjects' preferences for conditional cooperation in public goods provision by increasing the amounts individuals reciprocate to the rest of the group given their alternative average contributions.

At the moment, however, there are only two studies focusing on how social identity impacts on public goods provision (Solow and Kirkwood, 2002; Eckel and Grossman, 2005). Yet, neither of them specifically allows drawing conclusion on its impact on cooperation preferences. Most insights can be gained from Eckel and Grossman (2005), who employ different treatments designed to induce increasing strengths of identity. The authors find that enhanced team identification yields consistently higher cooperation levels indicating less free-riding in general. Unfortunately, the authors analyze aggregate data only making it impossible to elicit whether increased contributions are due to differences in conditional cooperation or for instance because free-riders adjust their behavior.

\subsection{Research Hypotheses}

Based on the current state of literature we formulate the following research hypothesis. Drawing on Chen and Li (2009), subjects exhibit the preference for higher degrees of positive reciprocity in inthan in out-group matching. Consequently, we expect in-group matches to reciprocate others' average contributions to a higher degree than out-group matches.

HYPOTHESIS 1A: When matched with in-group members, subjects reveal the preference for higher levels of conditional cooperation than in out-group matching.

\footnotetext{
${ }^{7}$ Additionally, subjects are significantly more forgiving for "bad behavior", i.e. they exhibit less negative reciprocity (Chen and Li, 2009, p. 445).
} 
A matching of subjects at random, without identity influence, nevertheless creates a general feeling of belonging together, since individuals interact with others that are perceived as "group members". This feeling might be less strong than between in-group matches where subjects saliently belong to their own identity. Yet, it might be stronger than in out-group matching, because here subjects saliently belong to different identities (cf. Chen and Chen, 2011), which often leads to out-group discrimination (see Section 2.1). Therefore:

HYPOTHESIS 1B: When subjects are matched randomly, they will reveal the preference for less conditional cooperation than when matched with in-group members.

HYPOTHESIS 1C: When subjects are matched randomly, they will reveal the preference for more conditional cooperation than when matched with out-group members.

Depending on the strength of the identity effect on conditional cooperation, individuals might exhibit different propensities to be a certain cooperation type. Therefore:

HYPOTHESIS 2A: When matched with in-group members, subjects show a higher propensity to be a conditional cooperator and a lower propensity to be a free-rider then in out-group matching.

HYPOTHESIS 2B: In-group matching yields a higher relative share of conditional cooperators than out-group matching. Similarly, there will be less free-rider in in- than in out-group matching.

\section{Experimental Design}

Our experiment follows a within-subject design and is based on a public good game in strategy method (cf. Fischbacher et al., 2001). Generally, groups comprised three subjects each possessing 20 points that could be invested either in their private account $\left(20-g_{i}\right)$ or into a project, symbolizing the public good. The payoffs associated with this decision were given by the following formula:

$$
\pi_{i}=\left(20-g_{i}\right)+0.4 \sum_{j=1}^{3} g_{j}
$$

Accordingly, it is individually more beneficial to invest into the private account, because it returns 1 point for each point invested instead of 0.4 points returned by the project. Basically, subjects had to make two decisions, an unconditional and a conditional contribution to the public good. Their unconditional contribution was simply the decision of how many of their 20 points they would like to invest in the public good. Here, they were asked to state what they expect the remaining group members will invest unconditionally, as well. For their conditional contribution subjects were asked to fill out a contribution table consisting of 21 entries for which they had to decide how much they would invest if their group members invested on average (round to the next higher integer value) 0 - 
20 points in the public good. After both decisions were taken, a random mechanism ${ }^{8}$ chose one group member that was to contribute according to her conditional contribution decision. The remaining two group members contributed according to their unconditional contributions.

The experimental design consisted of four stages in which subjects played the public good game in three different matching protocols (see Table 1). Please note that in each matching the game was played only once in order to directly conclude on subjects' cooperation preferences, ruling out any strategic or reputational motivations that might be prevalent in long term interactions with stable group membership (cf. Fehr and Fischbacher, 2002). ${ }^{9}$

\begin{tabular}{|c|c|c|c|}
\hline Stage & \multicolumn{2}{|c|}{ Identity (ID) Treatments } & Control Treatments \\
\hline 1 & \multicolumn{2}{|c|}{ Random Matching } & Random Matching \\
\hline 2 & Group Identity Task & Random Matching \\
\hline 3 & $\begin{array}{c}\text { In-Group } \\
\text { Matching }\end{array}$ & $\begin{array}{c}\text { Out-Group } \\
\text { Matching }\end{array}$ & Random Matching \\
\hline 4 & $\begin{array}{c}\text { Out-Group } \\
\text { Matching }\end{array}$ & $\begin{array}{c}\text { In-Group } \\
\text { Matching }\end{array}$ & \\
\hline
\end{tabular}

Table 1 - The Experimental Design

In stage 1 the public good game was played with subjects being randomly assigned to different groups (random matching). In stage 2 we induced a strong form of social identity based on insights of Eckel and Grossman (2005) and Chen and Li (2009) using a design pioneered by Ibañez and Schaffland (2012). We randomly assigned subjects to different groups with each group having been given a different color. These groups were then given a joint problem solving task in order to create a positive group experience (Eckel and Grossman, 2005). Given 10 minutes time, subjects had to jointly find hidden objects in a picture and report coordinates of their location (row and column). ${ }^{10}$ To this purpose, subjects could discuss solutions with their group members via an online chat tool. In order to elevate subjects' propensity to coordinate and to render this task a true group exercise, our instructions explicitly stated that answers would only count as correct should each group member enter them correctly. The task was played as a tournament in which the group with the highest number of objects found won. In order to prevent negative associations from not winning this task, only the winning team received a congratulation message at the end of the experimental session. The remaining teams were not provided with information about their results and position relative to

\footnotetext{
${ }^{8}$ A dice was thrown by one participant in a session that determined the respective group member.

${ }^{9}$ We are aware that the strategy method could be demanding and that subject could be confused making their initial decisions. Yet, since we mainly analyze stage 3 and 4 we are confident that confusion was reduced to a minimum.

${ }^{10}$ Please see Appendix 6 for the instructions used in this experiment.
} 
the other groups. Lastly, there were no monetary incentives for winning this game avoiding any income effects.

In the following two stages ( 3 and 4 ) subjects were matched with individuals belonging to the same group that solved the identity task (in-group matching, stage 3 or 4 ) as well as with subjects belonging to different identities (out-group matching, stage 4 or 3). The individuals' identities were made salient by indicating the color of their group. In out-group matching for instance subjects thus saw that they interacted with two individuals of different color groups (blue, red and green, for instance). We switched the order of playing in-group and out-group matching to control for possible sequence effects. In order to compare in- and out-group with random matching accounting for the stages when decisions are made, we carried out control treatment, in which subjects played three times the one-shot public good game in random matching.

Since the instructions were handed in successively, subjects learned the matching procedure only during the experiment. Additionally, any information on payoffs was only revealed after the experiment's last stage. In case of the ID-treatments random matching was always played in stage 1 followed by the induction of social identity. Its main purpose is to identify player types without any identity influence, as done by Fischbacher et al. (2001), for instance, and to analyze their behavior in our ID-treatments. Please note that due to the different time stages our design does not allow a coherent comparison of decisions taken in in- or out-group matching with random matching of the ID-treatments. To this purpose we ran the control treatments.

The experiment was carried out in the Göttingen Laboratory of Experimental Economics (GLOBE) at the University of Göttingen from October 2011 to January 2012 using the software z-Tree (Fischbacher, 2007). We observed decisions of 135 subjects in ID-treatments and 42 subjects in control treatments. The sessions took approximately 1.5 hours and the subjects earned $14 €$ on average including a show-up fee of $2.50 €$.

\section{Results}

\subsection{Social Identity and the Level of Conditional Cooperation}

\subsubsection{Conditional Cooperation in In-Group and Out-Group Matching}

Containing the core result of our analysis, Figure 1 depicts a comparison of subjects' average conditional cooperation in the ID-treatments. In line with recent literature, using a within-subject analysis we find that across the whole range of others' contribution (0-20) subjects in in-group matching are willing to contribute on average more to the public good than in out-group matching. Applying a fixed-effects panel regression using in-group matching as the base category and controlling for initial decisions in Stage 1 reveals that this difference is significant and amounts to 
approximately 0.48 points (Table 3, Model 1). ${ }^{11}$ Moreover, it tends to be robust to the order of the ID-treatments (Models 2 and 3). Accordingly, when subjects are matched with individuals of their own identity, they show the preference for reciprocating their group members' contribution by higher own contributions. Conversely, interacting with individuals of different identities triggers preferences for lower levels of conditional cooperation.

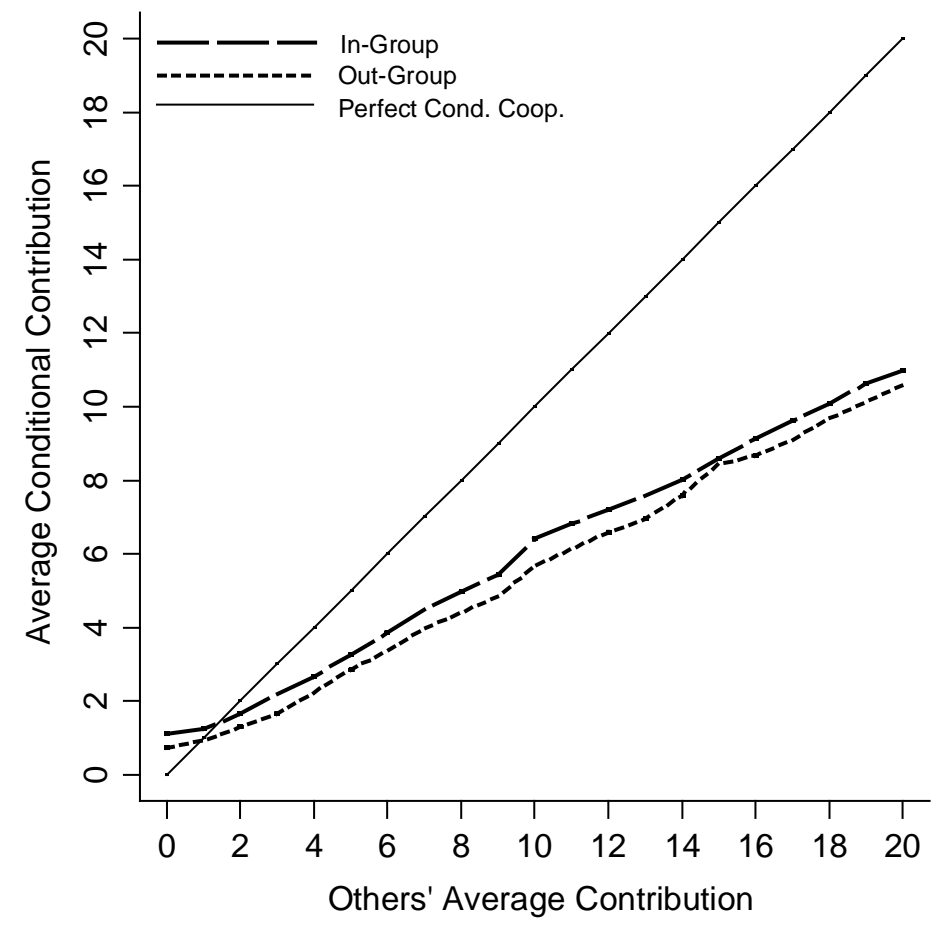

Figure 1 - The Degree of Conditional Cooperation in In- and Out-Group Matching (all subjects)

\footnotetext{
${ }^{11}$ The form of social identity that we induce in this experiment is still weak compared to social identity existing in real life, such family bonds or religious identification. Consequently, the rather small differences observed here provide a hint that real social identities invoke much stronger preference differences.
} 
Fixed Effects Panel Regression

\begin{tabular}{cccccc}
\multicolumn{7}{c}{ Model } \\
\hline All Subjects & $(2)$ & $(3)$ & $(4)$ & $(5)$ & $(6)$ \\
& All Subjects & All Subjects & FRs & CCs & OT \\
& In-Group First & Out-Group First
\end{tabular}

\begin{tabular}{lcccccc}
\hline \hline Dependent Variable: Conditional Contributions & & & & & & \\
& & & & & & \\
Random Matching (Stage 1) & 0.0511 & -0.2664 & 0.3831 & $-1.0714^{\star}$ & 0.1533 & 0.5357 \\
& $(0.230)$ & $(0.306)$ & $(0.343)$ & $(0.571)$ & $(0.282)$ & $(0.524)$ \\
Out-Group Matching & $-0.4801^{\star \star}$ & $-0.6453^{\star}$ & $-0.3074^{\star \star}$ & $-0.6405^{\star}$ & $-0.5419^{\star}$ & -0.1735 \\
& $(0.192)$ & $(0.351)$ & $(0.143)$ & $(0.327)$ & $(0.278)$ & $(0.244)$ \\
Group Average & $0.5303^{\star \star \star}$ & $0.5017^{\star \star \star}$ & $0.5602^{\star \star \star}$ & $0.0506^{\star}$ & $0.7891^{\star \star \star}$ & 0.0687 \\
& $(0.038)$ & $(0.052)$ & $(0.057)$ & $(0.029)$ & $(0.032)$ & $(0.051)$ \\
Constant & $0.6900^{\star}$ & 0.7948 & 0.5804 & $0.5656^{\star \star \star}$ & -0.0995 & $3.2318^{\star \star \star}$ \\
& $(0.394)$ & $(0.558)$ & $(0.553)$ & $(0.129)$ & $(0.359)$ & $(0.468)$ \\
Observations & & & & & & \\
R-squared & 8,505 & 4,347 & 4,158 & 1,260 & 5,481 & 1,764 \\
Number of $\mathrm{n}$ & 0.445 & 0.433 & 0.460 & 0.095 & 0.725 & 0.022 \\
\hline \hline
\end{tabular}

Note: Robust standard errors in parentheses, FR=Free-Rider, CC=Conditional Cooperator, OT=Others;

Significance levels: ${ }^{* \star *} p<0.01,{ }^{* \star} p<0.05,{ }^{*} p<0.1$

Table 2 - The Effect of ID-Matchings on Conditional Cooperation (Fixed Effects Panel Regression)

RESULT 1: The level of conditional cooperation is consistently and significantly higher when subjects interact with members of their own identity than with individuals perceived to belong to different identities.

Differences in cooperation preferences between in-group and out-group matches are not only identifiable when looking at all subjects, but also when scrutinizing the behavior of individual cooperation types. To this purpose, we used the contribution table entries of stage 1 (free of social identity influences) to classify subjects as conditional cooperators and free-riders ${ }^{12}$ and observed their behavior in the ID-treatments. As to be seen in Figure 2, in both ID-treatments free-riders on average depart from full free-riding. When matched with out-group members their average own contribution always remains below 1 point. Free-riders in in-group matching, however, reciprocate their group members' cooperation to a significantly higher degree (Model 4), which tends to increase with the level of others' cooperativeness. In full, this difference amounts to approximately 0.64 points. Consequently, even those subjects that exhibit purely selfish preferences turn to be more cooperative when interacting with individuals of their own identity than in out-group matching. Similarly, conditional cooperators reciprocate their in-group members' contribution to a significantly higher degree than when matched with out-group members (Model 5). This pattern holds for all levels of group members' contributions and overall amounts to approximately 0.54 points.

\footnotetext{
${ }^{12}$ We defined conditional cooperators as subjects who exhibit a positive significant Spearman rank correlation coefficient $(p<0.01)$ between own conditional contributions and others' average contributions. Subjects were classified as free-riders if they contributed nothing to the public good in any case.
} 


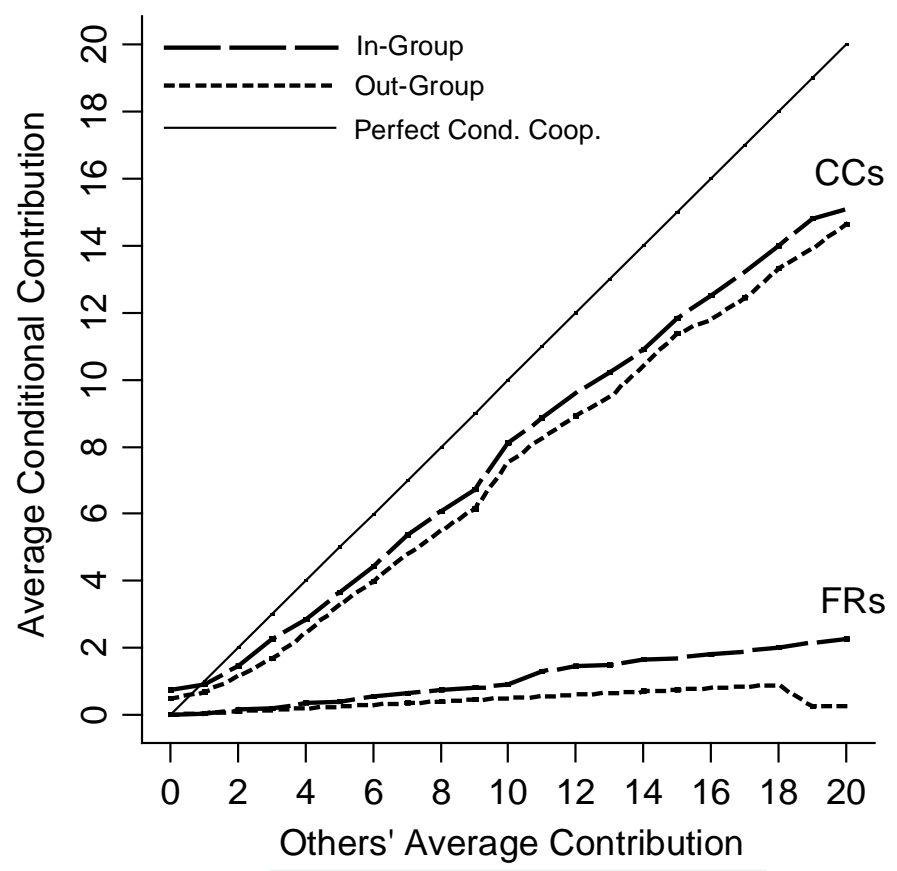

Figure 2 - The Degree of Conditional Cooperation of Free-Riders (FRs) and Conditional Cooperators (CCS) in In- and Out-Group Matching

RESULT 2: Free-riders and conditional cooperators are prone to show a preference for higher levels of conditional cooperation in in-group than in out-group matching.

All in all, we conclude that research hypothesis $1 \mathrm{~A}$ cannot be rejected. Our results clearly indicate that when matched with individuals of a common identity, subjects across the board reveal the preference for stronger forms of conditional cooperation and thus less self-serving bias than when matched with individuals of saliently different identities. These individuals will thus contribute more to the public good at a given level of (expected) contributions of their group members, leading to a higher social welfare. ${ }^{13}$ Accordingly, social identity can be a determining factor for cooperation in public goods, since it influences subjects' preferences for conditional cooperation.

\footnotetext{
${ }^{13}$ This is supported by our findings on the level of unconditional contributions to the public good. In in-group matching subjects contribute significantly more points than in out-group matching (on average 6.92 and 6.07, respectively, $z=$ 16.934, $p=0.000$, Wilcoxon signed-rank test). This holds true no matter if in-group or out-group matching is played first. Ingroup first yields: 6.81 (in) and 5.83 (out), $z=8.911, p=0.000$, Wilcoxon signed-rank test. Out-group matching first yields: 7.03 (in) and 6.32 (out), $z=15.422, p=0.000$, Wilcoxon signed-rank test).
} 


\subsubsection{Conditional Cooperation in ID-Matchings and in Random Matching of the Control Treatments}

For comparing cooperation preferences in both ID-matching protocols with random matching, we revert to the stages when decisions are taken, separately. ${ }^{14}$ This necessitates switching from withinto across-subject analyses using the random matching decisions of the control treatments in stages 3 and 4. Yet, in order to keep as much within-information as possible, we analyze how subjects - in their relative treatments - adjusted their conditional cooperation strategy compared to the preceding stage that contained a public goods game (stage 1 and 3, respectively). Comparing these changes allows drawing conclusion regarding differences in conditional cooperation between the treatments. The following two graphs depict how subjects adjusted their cooperation strategy in stage 3 as opposed to stage 1 (Figure 3 ) and in stage 4 compared to stage 3 (Figure 4). In addition, Table 4 reports the results of an according OLS regression that tests for differences between treatments and uses in-group matching as the base category.

In both decision stages we find that when subjects are matched with in-group members, they consistently exhibit higher changes in conditional cooperation compared to the benchmark stage than when randomly matched. The differences between both treatments are more pronounced in stage 3 , with approximately 1.27 point, than in stage 4 (0.70 points). Yet, in both stages they are highly significant (see Table 4, Model 1 and 2). We thus conclude that hypothesis $1 \mathrm{~B}$ cannot be rejected. Individuals, who interact with group members sharing the same identity, show preferences for higher levels of conditional contributions than in case of random matching.

\footnotetext{
${ }^{14}$ When analyzing subjects behavior in the control treatments, we find consistently falling conditional contributions in each decision stages (Wilcoxon signed-rank test, $p_{1-3}=0.000, p_{1-4}=0.000, p_{3-4}=0.000$, subscripts denote decision stages). This highlights that in- and out-group matching may only be meaningfully compared with random matching if it takes place in identical decision stages. We thus use the random matching decisions of the control treatments in stage 3 and 4 , to compare these with in- and out-group matching.
} 


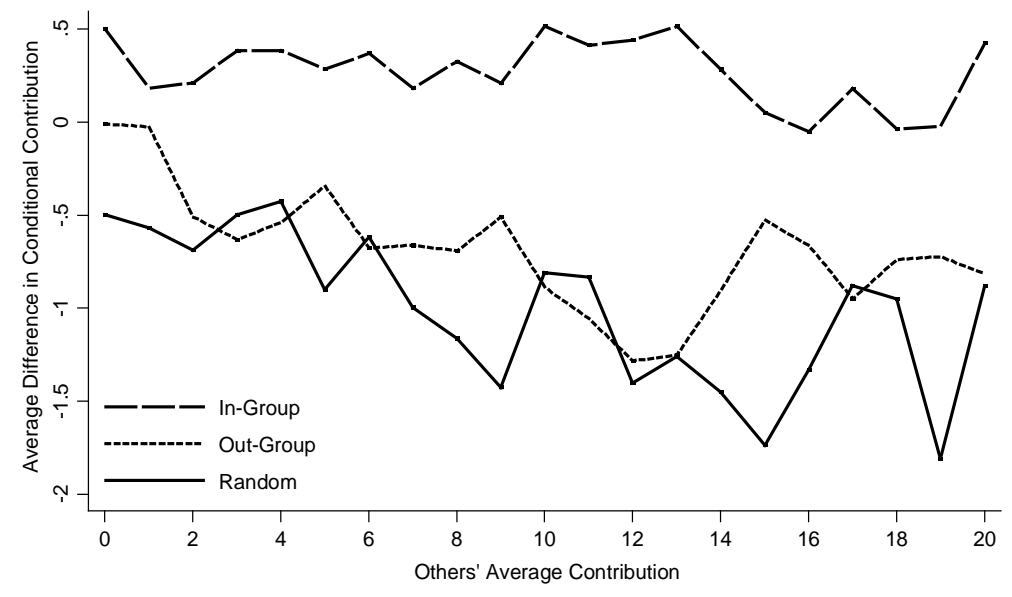

Figure 3 -Average Change in Conditional Contribution of Stage 3 compared to Stage 1

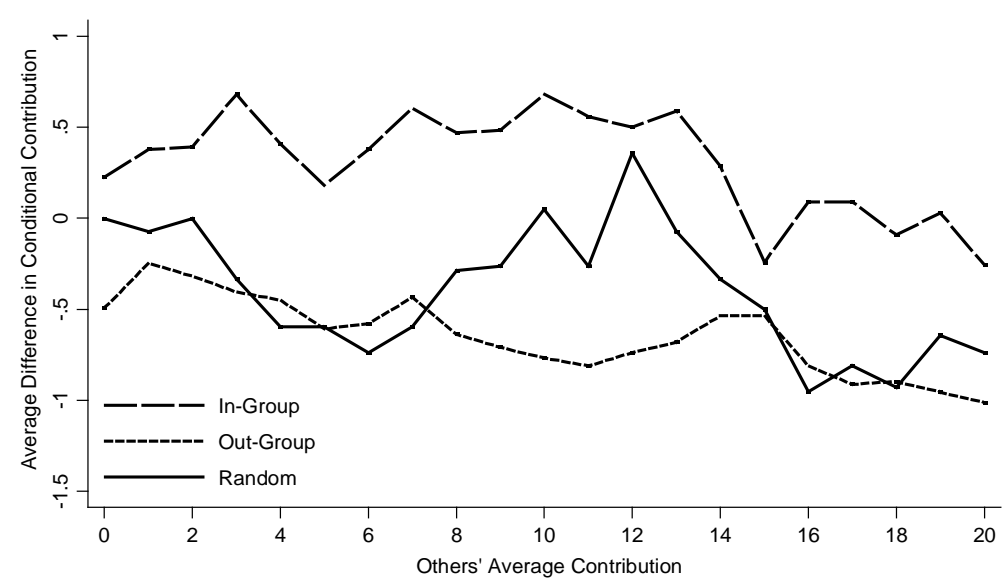

Figure 4 - Average Change in Conditional Contribution of Stage 4 compared to Stage 3

\begin{tabular}{ccc} 
Linear Regression (OLS) & \multicolumn{2}{c}{ Model } \\
\hline Dep. Var.: Change in & $(1)$ & $(2)$ \\
Conditional Cooperation from: & Stage 3 to Stage 1 & Stage 4 to Stage 3 \\
\hline \hline & & \\
Out-Group & $-0.9569^{\star \star}$ & $-0.9526^{\star \star}$ \\
& $(0.474)$ & $(0.377)$ \\
Random & $-1.2743^{\star \star}$ & $-0.7031^{\star \star \star}$ \\
& $(0.620)$ & $(0.254)$ \\
Constant & 0.2664 & $0.3074^{\star *}$ \\
& $(0.305)$ & $(0.143)$ \\
& & \\
Out-Group - Random $=0$ & $\mathrm{p}=0.6266$ & $\mathrm{p}=0.5411$ \\
& & \\
Observations & 3,717 & 3,717 \\
R-squared & 0.018 & 0.020 \\
\hline \hline
\end{tabular}

Note: Standard errors (in parentheses) are clustered by individuals

Significance levels: ${ }^{* * *} p<0.01,{ }^{* *} p<0.05,{ }^{*} p<0.1$

Table 3 - The Effects of Matching Conditions of Changes in Conditional Cooperation (OLS Regression) 
RESULT 3: When matched with in-group members, subjects consistently show a preference for higher levels of conditional cooperation than in random matching.

When subjects are matched with out-group members, average changes in conditional cooperation in Stage 3 (compared to stage 1 ) tend to be higher than in random matching for most of the range of group members' contributions. In contrast, in stage 4 (compared to stage 3 ) they are mostly lower. Importantly though, in neither period are those differences significant (Table 4, Model 1 and 2). We thus conclude that there is no consistent difference between preferences for conditional cooperation in random and out-group matching. Consequently, we reject hypothesis $1 \mathrm{C}$, which derives that the level of conditional cooperation should be consistently lower in out-group than in random matching.

RESULT 4: The level of conditional cooperation in out-group and random matching is not consistently different.

Lastly, this analysis reveals significantly higher changes in conditional cooperation in case of in-group compared to out-group matching for both decision stages (Table 4, Model 1 and 2). This effectively reinforces the results of the previous section.

RESULT 5: The difference in cooperation preferences between subjects matched with in-group and out-group members is consistently identifiable across subjects, as well.

\subsection{Social Identity and Cooperation Types}

In order to deepen our knowledge about cooperation type stability, we analyze whether and how subjects switched cooperation type when matched with in- and out-group members. Overall, the relative share of conditional cooperators, free-riders and others ${ }^{15}$ in random matching of stage 1 , ingroup and out-group matching is in line with the literature. Conditional cooperators form the most common type (63 percent), followed by free-riders (approximately 19 percent) and others (approximately 18 percent) and no significant treatment effects on type distribution can be found. ${ }^{16}$ Consequently, we have to reject hypothesis $2 \mathrm{~B}$, which derives that in-group matching ought to yield higher shares of conditional cooperators and lower shares of free-riders. Thus, social identity as we have induced in the experiment does not affect the aggregate distribution of cooperation types.

RESULT 6: The distribution of cooperation types is relatively stable across all treatments.

\footnotetext{
${ }^{15}$ The category "others" subsumes all subjects of which there were too few to be included as a separate category, such as hump-shaped and unconditional cooperators.

${ }^{16}$ We tested for statistical differences using a chi-square test. Usually, it is only applicable for independent observations, which is why we simulated a test statistic distribution using the relative share of cooperation types observed in the control treatments. This non-significant result is robust to various ways of testing, for instance analyzing treatment sequences independently or comparing the ID-treatments with control treatments.
} 
Looking at the changes in cooperation types at individual level, Table 5 contains the nine possible combinations, which are expressed in actual frequencies (upper number) and frequencies that are expected to occur by chance alone (lower number). Both numbers represent the shares of total participants taking part in the ID-treatments (135). ${ }^{17}$ In terms of actual frequencies there is a rather high stability of cooperation types. 88.2 percent of all subjects did not change their cooperation type in response to whom they were matched with - in both treatments 58.5 percent were conditional cooperators, 15.6 percent remained to be free-riders and 14.1 percent stayed in the "other" category. Using Cohen's Kappa as a measure of stability, automatically correcting for frequencies that are expected to occur by chance alone, we confirm that there is a very high overall stability of cooperation types, no matter how subjects are matched. ${ }^{18}$ Nevertheless, the kappa score is statistically different from perfect agreement $(x=1)$, so that we cannot rule out completely that shifts take place. Indeed, 5.2 percent of subjects switched from being in-group conditional cooperators to free-riders in out-group matching. In comparison, only 0.7 percent of subjects switched from outgroup conditional cooperator status to being a free-rider in in-group matching. Though merely weakly significant $(p=0.0730)$, a sign test for matched pairs confirms that when matched with individuals that do not belong to their own identity, subjects are more likely to choose to free-ride on the contributions of others. ${ }^{19}$ In contrast, we do not find an even marginally significant difference in the propensity to be a conditional cooperator in the different treatments. Hence, we have to partially reject hypothesis $2 \mathrm{~A}$ according to which subjects show a higher propensity to be a conditional cooperator in in-group than in out-group matching, as well.

RESULT 7: While the individual propensity to be a conditional cooperator is stable no matter how subjects are matched, there is a marginally increased probability to be a free-rider when subjects are matched with out-group members compared to in-group matching.

\footnotetext{
${ }^{17}$ Please note that we deliberately did not include random matching of stage 1 into this analysis, firstly because we are mainly interested in type shifts between the ID-treatments, yet also since random and ID matching never take place in identical decision stages.

${ }^{18} x_{\text {in,out }}=0.779$ (se= 0.0635, p=0.0000). See Landis and Koch (1977) for guidelines on the interpretation of Cohen's Kappa.

${ }^{19}$ As a robustness check we ran a fixed effects conditional logit regression on the probability to be a free-rider in the different matching settings (standard errors clustered around $n$ ). Here, we similarly find that there is an increased likelihood to become a free-rider when matched with out-group members, which is borderline significant $(t=0.103)$.
} 


\begin{tabular}{|c|c|c|c|c|}
\hline & \multicolumn{3}{|c|}{ Out-Group } \\
\hline & & $\mathrm{CC}$ & $F R$ & OT \\
\hline \multirow{6}{*}{ 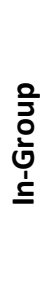 } & CC & 58.5 & 5.2 & 0.0 \\
\hline & & (39.6) & $(14.1)$ & (9.9) \\
\hline & 5 & 0.7 & 15.6 & 1.5 \\
\hline & $r n$ & (11.0) & (3.9) & (2.7) \\
\hline & TO & 3.0 & 1.5 & 14.1 \\
\hline & 1 & (11.6) & (4.1) & (2.9) \\
\hline
\end{tabular}

Table 4-Combinations of Cooperation Types in In-and Out-Group Matching as Share of Total Sample Size (135). Upper (Lower) Numbers Denote the Observed (Expected) Frequency of Being Conditional Cooperator (CC), Free-Rider (FR), Other (OT)

Summing up, although there is an increased propensity to be a free-rider when matched with individuals of a different identity, we do not find strong evidence that social identity significantly impacts on cooperation types in global. Yet, this is not totally surprising, since the common definition of conditional cooperators subsumes many different forms of contribution strategies. Hence, even if subjects' degree of conditional cooperation drops considerably when going from in-group to outgroup matching, they may still be classified as conditional cooperators. Consequently, an analysis of types may only be secondary to finer grained analyses of the quality of conditional cooperation as demonstrated by the previous section.

\section{Conclusion and Policy Implications}

This article contributes to the understanding of cooperation preferences in the provision of public goods by empirically analyzing whether these vary in decision situations involving salient identities of the subjects one interacts with. In line with recent literature on social identities' effect on positive reciprocity (Chen and $\mathrm{Li}, 2009$ ), our results indicate that cooperation preferences are indeed dependent on the social environment. Specifically, when matched with individuals of a common identity, subjects across all levels of their group members' cooperativeness exhibit significantly higher levels of conditional cooperation and thus less self-serving bias than when matched with individuals of different identities. At a given level of (expected) contributions of their group members, subjects in identity homogeneous groups can thus be expected to contribute more to the public good than in identity heterogeneous groups. What is more, while individuals are equally likely to be conditional cooperators under both ID-treatments, we identify an elevated propensity for subjects to be a free-rider, when interacting within out-groups. Consequently, social identity seems to be a determining factor which impacts on social welfare in the context of public goods provision by altering subjects' preference for conditional cooperation. 
From a policy perspective these results are of importance. By means of positive belief management, economic policy already tries to exploit that most people are willing to cooperate if others do so, as well. Yet, this mainly addresses conditional cooperators. Still not having any indication how purely selfish people react to this institution, we provide evidence that not only conditional cooperators' but also free-riders' affinity for cooperation can be systematically increased simply by mitigating one's perceived feeling of belonging to the group one interacts with. In order to enhance the provision of public goods, social identity thus seems to be an effective tool, in addition to the instruments of belief management, for improving social welfare. 


\section{Appendix - Instructions to the Experiment ${ }^{20}$}

Welcome to the experiment! Thank you very much for your participation.

If you read the following instructions carefully, you get the chance of winning money additional to the $€ 2.50$, which you receive in any case. Your earnings will depend on your decisions and on those by the other players in your group. At the end of the experiment all sums of money, which you will have earned through your decisions, will be added and given to you personally and in cash.

It is forbidden to speak during the experiment. If you have any questions, please raise your hand. A member of our team will come to you and answer your question privately.

We will be talking about points rather than Euros in the course of the experiment. Hence, your total income will be calculated in points in the first instance. The total number of points which you will achieve during the experiment will be converted in Euros at the end, using the following equation:

1 point $=17$ Cents

All participants will be divided in groups with 3 players each. Except for us, i.e. the conductors of the experiment, nobody will know who is in which group. All decisions will be made anonymously and your identity will neither be revealed during the experiment nor in public.

Each task of the experiment has its own instructions, which you have to read step by step. While doing so, please consider the respective hints which will appear on the monitor.

Please click on OK when you are ready.

\section{The Basic Decision Situation}

Later, you will be informed about the experiment's procedure in detail. At this point, we would like to introduce the basic decision conditions you will face in this experiment. Some example exercises can be found subsequently.

At each point in time, you will be a member of a group consisting of $\mathbf{3}$ players. In every task, you hold 20 points. Your task is to decide whether you invest these 20 points in a private account or whether you want to invest them fully or partly in a project. Each point which you do not invest in a project will be automatically deposited on your private account.

\section{Your income from your private account:}

For each point which you deposit on your private account (and, therefore, you do not invest in the project), you will earn one point. Hence, a deposit of 20 points on your private account will produce an income of 20 points from your private account. If you, for instance, deposit 6 points on your private account, you will earn 6 points from this account. Nobody except you will earn anything from your private account.

\section{Your income from the project:}

All group members will profit equally from your contribution to the project. Vice versa, you profit from the investments by other group members. The income every member gets from the project is calculated as follows:

income from the project $=$ (sum of all contributions to the project $) \times 0.4$

Should the sum of all contributions to the project be, for example, 30 points then you and all other group members gain $(30 \times 0.4)=12$ points each from the project. Should the sum of all contributions to the project be, for example, 10 points then you and all other group members gain $(10 \times 0.4)=4$ points each from the project.

\footnotetext{
${ }^{20}$ Instructions in German are available upon request (Matthias.Lankau@wiwi.uni-goettingen.de).
} 
Your total income:

Your total income is the sum of your income from your private account and your income from the project.

Income from the private account (=20-your contribution to the project)

+ Income from the project $=$ (sum of all contributions to the project) $\times 0.4$

total income

\section{Exercise Questions}

Please complete the following exercises. They do merely serve the purpose of familiarising you with the calculation of the different sorts of income, which may occur to you when making different decisions on the use of the 20 points starting capital.

Please complete all the exercises and always report your full mathematical procedure. While calculating, you may use the calculator function on the monitor. When you are done, you have to enter your results in the computer.

1. Each group member has 20 points at their disposal. Imagine that all three group members (including yourself) do not contribute anything to the project.

a. What is your total income? .....

b. What is the total income of each of the other group members? .....

2. Each group member has 20 points at their disposal. You invest 20 points in the project. The other two group members also contribute 20 points to the project.
a. What is your total income? .....
b. What is the total income of each of the other group members? .....

3. Each group member has 20 points at their disposal. The other two group members contribute 10 points each (i.e., 20 points in total) to the project.

a. What is your total income if you, additional to the 20 points, contribute 0 points to the project?

b. What is your total income if you, additional to the 20 points, contribute 5 points to the project?

c. What is your total income if you, additional to the 20 points, contribute 15 points to the project?

d.

4. Each group member has 20 points at their disposal. You contribute 7 points to the project.

a. What is your total income if the other group members, additionally to your 7 points, contribute 1.5 points each, i.e., 3 points in total, to the project?

b. What is your total income if the other group members, additionally to your 7 points, contribute 4 points each, i.e., 8 points in total, to the project?

c. What is your total income if the other group members, additionally to your 7 points, contribute 9 points each, i.e., 18 points in total, to the project?

d.

First Task

You are now the member of a group of three, which was put together randomly.

The task contains the decision, which was described at the beginning and is only conducted once.

As you know, you have $\mathbf{2 0}$ points at your disposal, which you can either invest in the project or deposit on your private account.

In this task, every group member has to make two types of decisions, which we will term (1) the "unconditional" contribution to the project, or the (2) "conditional" contribution to the project (the contribution table), respectively.

Both decisions are vital for your income from this task. So please make your decisions thoughtfully.

Step 1: Your Unconditional Contribution to the Project 
Please determine how many of your points you, without knowing the contributions of the other group members, want to invest in the project. Please enter this amount into the following computer screen:

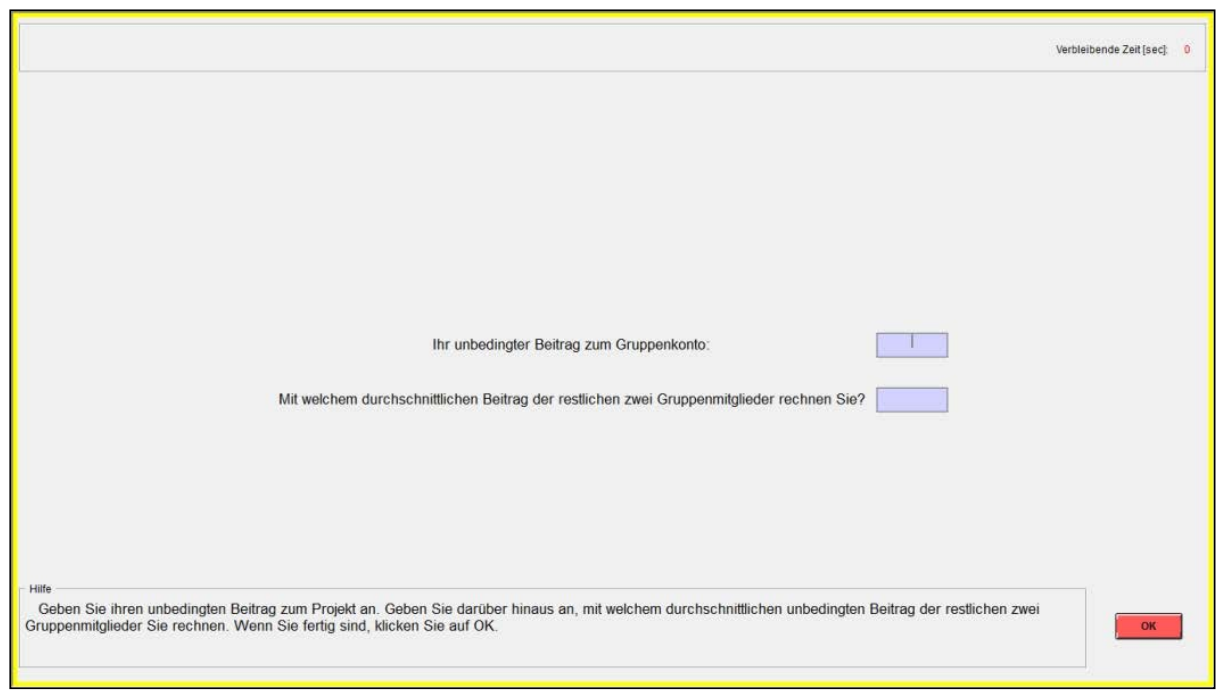

Please state what you expect each of the other two group members to contribute to the project (average amount of money they invest in the project).

Once you have made both statements, please click on OK.

\section{Step 2: Your Conditional Contribution to the Project - the Contribution Table}

With your second decision you have to fill in a contribution table. In the contribution table you have to enter your contribution to the project for every possible average contribution (rounded up) of the other group members. Hence, you can, dependent on the average contribution of the others, determine your decision on your contribution. You will get a clear hint of what to do when you take a look at the following screen.

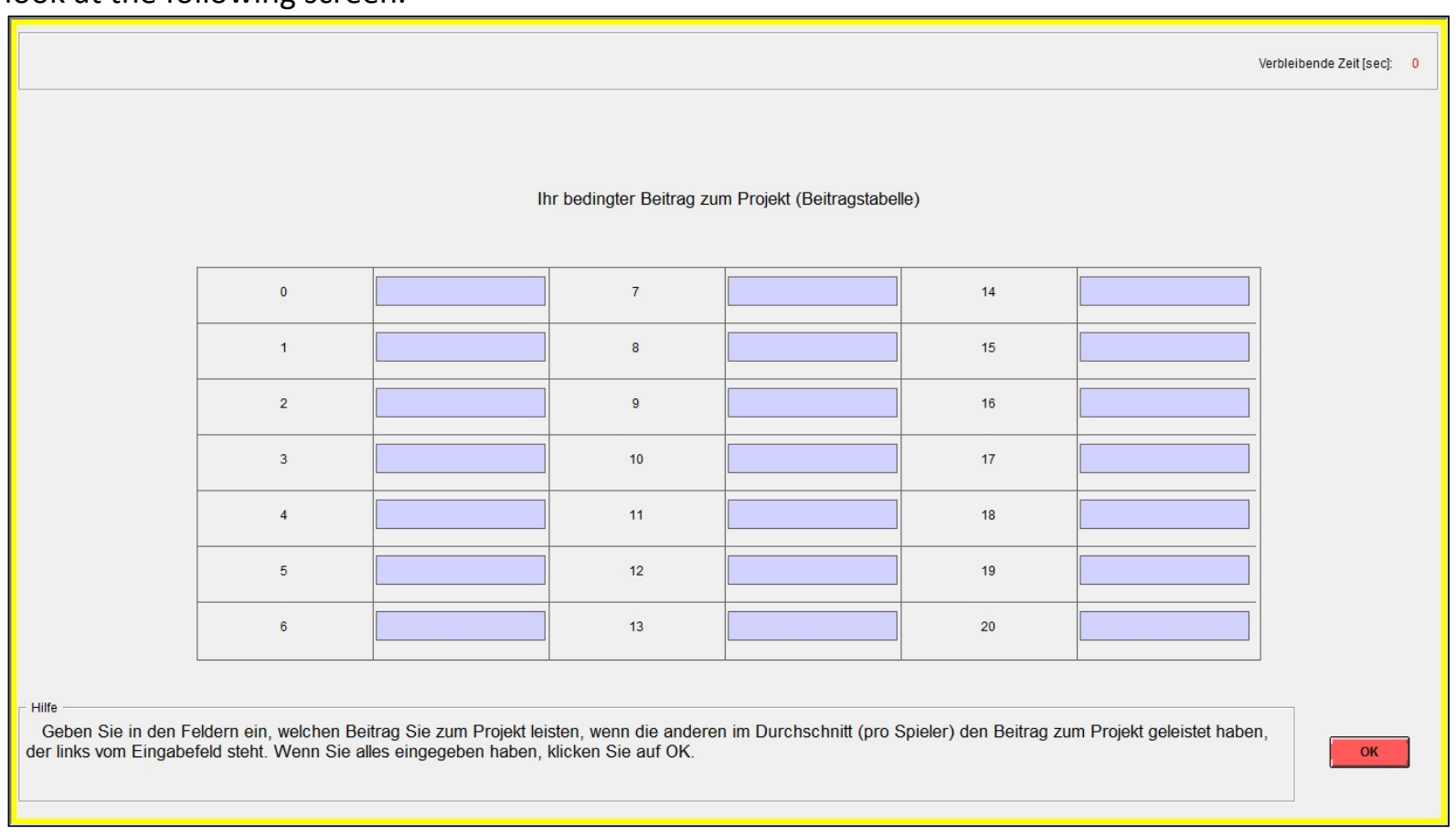


The numbers left to the boxes mark the possible average contributions, which the other members can make to the project. You just have to enter in each box how much you, under the condition that the others contribute the stated average amount, want to invest in the project. You have to make an entry in each box.

For example, you have to enter how many points you want to invest in the project if the other group members contribute 0 points; how many points you invest if the others contribute 1, 2 or 3 points and so on and so forth. You can enter integral numbers ranging from 0 to 20 in each box.

Once you have typed a number in each box, please click on OK.

After all participants in the experiment made their decision on their conditional contribution and filled in the contribution table, one member of each group is selected at random. For these selected members only the contribution table is relevant for their decisions and payoff. For the other two group members, who were not selected by the random choice mechanism, only the unconditional contribution is relevant for their decisions and payoff. The average of both unconditional contributions by these two group members defines which contribution by the selected member shall be invested in the project.

When you make the decision on your unconditional contribution and fill in the contribution table, you do of course not know if you will be picked at random. Hence, you have to make both decisions carefully, because both can become relevant for you. The following examples will explain the procedure:

Example 1: You are selected by the random choice mechanism. Therefore, the contribution table is relevant for your payoff. For the other two group members the unconditional contributions are relevant.

Let us assume that the other two group members invest 0 and 4 points in the project, which would mean an average contribution of two points. If you entered in the contribution chart that you would invest 1 point if the others averagely invested 2 points, then this would make a total contribution of $0+4+1=5$ points to the project. All group members would then earn $5 \times 0.4=2$ points from the project plus the respective incomes from their private accounts, in your case $20-1=19$ points. Your income would then be 21 points.

If you, however, stated that you would invest 16 points, if the others averagely invested 2 points, this would make a total investment of $0+4+16=20$ points in the project. As a result, all group members would receive a payoff of $20 \times 0.4=8$ points plus the income from their private accounts, in your case $20-16=4$ points. Your total income would then be 12 points.

Example 2: You are not selected by the random choice mechanism. For you and another group member then your unconditional contribution to the project is the relevant decision.

Let us assume that your unconditional contribution to the project is 16 points, the contribution by the other group member is 20 points. This makes an average contribution of 18 points to the project. Should the player who was selected by the random choice mechanism have stated that he or she would contribute 1 point to the project if the other group members averagely invested 18 points, then the total contribution to the project would be $16+20+1=37$ points. All group members then would earn $37 \times 0.4=14.8$ points from the project additional to their respective income from their private accounts. In your case you would earn $20-16=4$ points from your private account, which would then make a total income of 18.8 points.

Should the selected group member have stated an investment of 19 points to the project if the others averagely invested 18 points, then the total contribution to the project would be $16+20+19$ $=55$ points. Every group member would have a project income of $55 \times 0.4=22$ points plus their points from their private account, in your case 4 points. Your total income would then be 26 points. 


\section{The Random Choice Mechanism}

At the beginning of this game each group member receives a number between 1 and 3 . As you might remember, one participant, namely no. 8 , was selected at the beginning of the experiment. This participant will dice a number between 1 and 6 after all participants decided on their unconditional contribution and filled in the contribution table. The numbers 1 and 2 stand for group member one, 3 and 4 for group member two and 5 and 6 for member three. Participant no. 8 will enter these in the computer. In case no. 8 dices the numbers which correspond to your member number, the contribution table will be relevant for your decisions and payoff and for the other group members the unconditional contribution will be relevant. In any other case the unconditional contribution is relevant for you.

Please click on OK once you have read and understood the instructions.

\section{Second Task \\ Please note: Do not open the attached envelope before you are asked to do so!}

For the second task, you will be arbitrarily assigned a new group, which will be marked by a specific colour.

Only those solutions which are given correctly by ALL THREE group members will be considered correct in this group task.

During this task the group members are allowed to communicate with each other. By doing so, they can find a solution together. On the left hand side of the computer screen a chat box is positioned, which can be used for communication. Your conversation will be recorded. You have 10 minutes to solve the task. Only within this time span are you able to communicate with your team members. Please take into account that every group member has to type in the solutions which will have been found by your group. You have to click on OK before the 10 minutes have run out. The time left will be shown to you in the upper right hand corner of your screen.

All participants will be shown a picture and a list of objects. The task is to find the hidden objects in the picture. The inscriptions on the left and the upper side give the numbers of the lines and columns. You are asked to insert this information in the boxes which will be shown on the right hand side of the screen. The first box refers to a line, the second to a column. An example for this exercise is given below. 

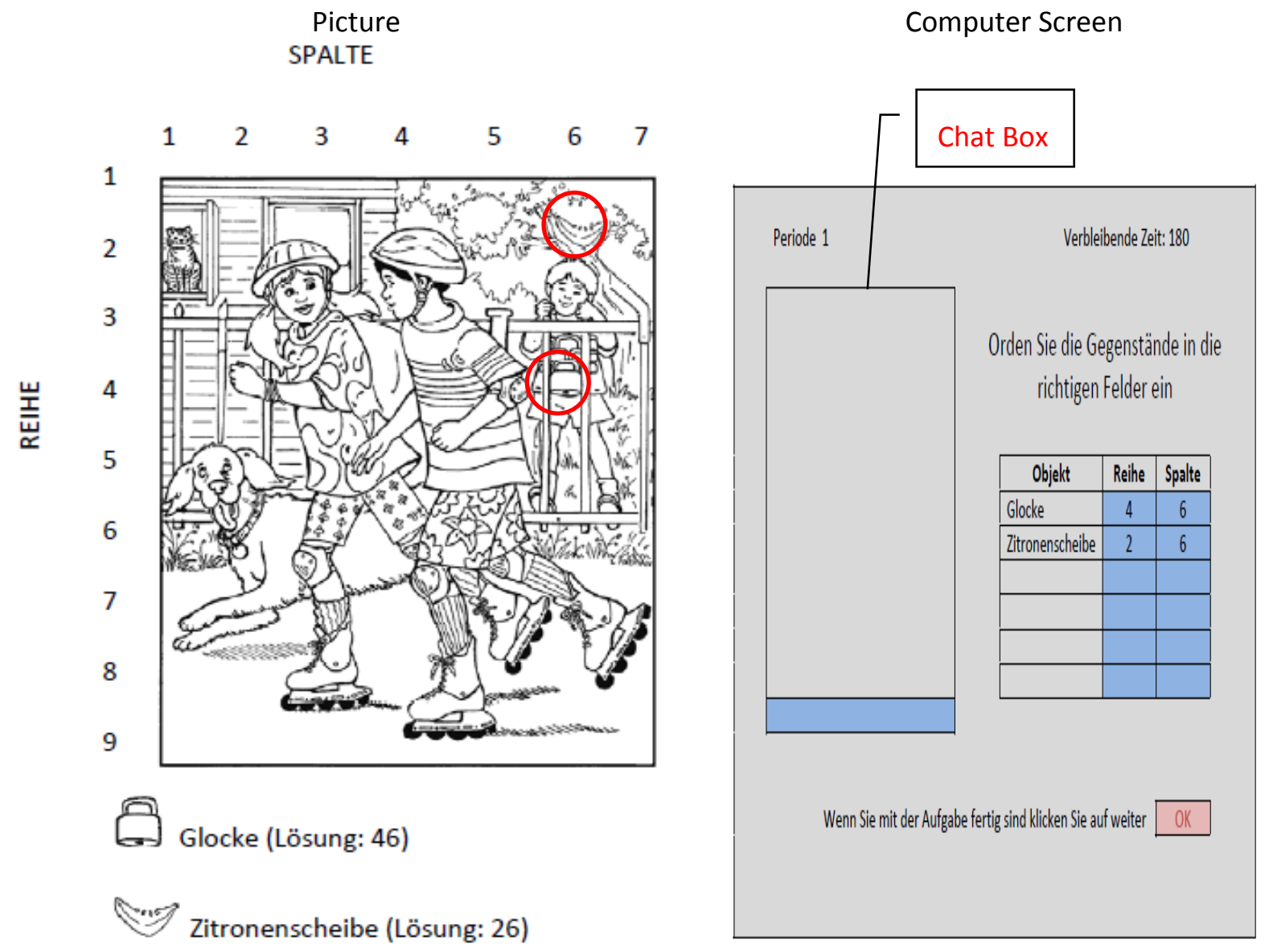

The group which finds most of the objects in the 10 minutes time is the winner group. At the end of the experiment you will be informed whether you are a member of the winner group. In this case, you will receive a congratulation message.

Please click on OK when you are ready.

\section{Third Task $^{21}$}

This task corresponds to the first one. It is conducted only once.

This time, however, you will only play together with members of your own group, with who you solved the picture puzzle in the second task.

Again, you hold a deposit of 20 points. Please decide how many points you want to invest in the project and how many you want to put on your private account.

This task also consists of two decisions, your (1) conditional contribution to the project and (2) the contribution table, with which you can make your decisions conditional on the other group members' contributions.

Please decide very carefully in both cases, for both the conditional contribution and your input into the contribution table are potentially relevant for the payoff. To determine the relevance of the decision, we will use the same random choice mechanism as before.

When you are ready, please click on OK.

\footnotetext{
${ }^{21}$ Three sessions of the experiment were played by matching subjects with in-group members in the third task and with out-group members in the fourth task. In another three sessions the order was reversed to control for possible sequence effects.
} 


\section{Fourth Task}

This task corresponds to the first one. It is conducted only once.

This time, however, you will only play together with members of different-coloured groups.

Again, you hold a deposit of 20 points. Please decide how many points you want to invest in the project and how many you want to put on your private account.

This task also consists of two decisions, your (1) conditional contribution to the project and (2) the contribution table, with which you can make your decisions conditional on the other group members' contributions.

Please decide very carefully in both cases, for both the conditional contribution and your input into the contribution table are potentially relevant for payoff. To determine the relevance of the decision, we will use the same random choice mechanism as before.

When you are ready, please click on OK. 


\section{References}

Blanco, M., Engelmann, D., Normann, H.T., 2011. A within-subject analysis of other-regarding preferences. Games and Economic Behavior 72 (2), 321-338.

Bolton, G.E., Ockenfels, A., 2000. ERC: A Theory of Equity, Reciprocity, and Competition. The American Economic Review 90 (1), 166-193.

Burlando, R., Guala, F., 2005. Heterogeneous Agents in Public Goods Experiments. Experimental Economics 8 (1), 35-54.

Charness, G., Rigotti, L., Rustichini, A., 2007. Individual behavior and group membership. The American Economic Review 97 (4), 1340-1352.

Chaudhuri, A., 2011. Sustaining cooperation in laboratory public goods experiments: a selective survey of the literature. Experimental Economics 14 (1), 47-83.

Chen, R., Chen, Y., 2011. The Potential of Social Identity for Equilibrium Selection. American Economic Review 101 (6), 2562-89.

Chen, Y., Li, S.X., 2009. Group Identity and Social Preferences. The American Economic Review 99 (1), 431-457.

Currarini, S., Mengel, F., 2012. Identity, Homophily and In-Group Bias. FEEM Working Paper No. 37.2012. http://papers.ssrn.com/sol3/papers.cfm?abstract_id=2088744 (accessed 17 August 2012).

Eckel, C.C., Grossman, P.J., 2005. Managing diversity by creating team identity. Journal of Economic Behavior \& Organization 58 (3), 371-392.

Falk, A., 2003. Homo Oeconomicus versus Homo Reciprocans: Ansätze für ein neues Wirtschaftspolitisches Leitbild? Perspektiven der Wirtschaftspolitik 4 (1), 141-172.

Fehr, E., Fischbacher, U., 2002. Why social preferences matter- the impact of non-selfish motives on competition, cooperation and incentives. The Economic Journal 112 (478), C1-C33.

Fehr, E., Schmidt, K.M., 1999. A THEORY OF FAIRNESS, COMPETITION, AND COOPERATION. Quarterly Journal of Economics 114 (3), 817-868.

Fischbacher, U., 2007. z-Tree: Zurich toolbox for ready-made economic experiments. Experimental Economics 10, 171-178.

Fischbacher, U., Gächter, S., 2010. Social preferences, beliefs, and the dynamics of free riding in public goods experiments. The American Economic Review 100 (1), 541-556.

Fischbacher, U., Gächter, S., Fehr, E., 2001. Are people conditionally cooperative? Evidence from a public goods experiment. Economics Letters 71 (3), 397-404.

Goette, L., Huffman, D., Meier, S., 2006. The impact of group membership on cooperation and norm enforcement: Evidence using random assignment to real social groups. The American Economic Review 96 (2), 212-216.

Hoff, K., Pandey, P., 2006. Discrimination, Social Identity, and Durable Inequalities. The American Economic Review 96 (2), 206-211.

Ibañez Diaz, M., Schaffland, E., 2012. Leadership Working Behavior and Group Cooperation: An Experiment of Group Identity: Unpublished Result. 
Ioannou, C.A., Qi, S., Rustichini, A., 2012. Group Outcomes As A Public Signal, Focal Point Effects And Reciprocity, Discussion Series in Economics and Econometrics 1106. University of Southampton, GB. http://eprints.soton.ac.uk/174997/ (accessed 27 September 2012).

Jackson, J.W., 2011. Intragroup cooperation as a function of group performance and group identity. Group Dynamics: Theory, Research, and Practice 15 (4), 343-356.

Landis, J.R., Koch, G.G., 1977. The Measurement of Observer Agreement for Categorical Data. Biometrics 33 (1), 159-174.

McLeish, K.N., Oxoby, R.J., 2007. Identity, cooperation, and punishment, IZA Discussion Paper 2572. Institute for the Study of Labor (IZA). http://papers.ssrn.com/sol3/papers.cfm?abstract_id=961379.

Selten, R., 1967. Die Strategiemethode zur Erforschung des eingeschränkt rationalen Verhaltens im Rahmen eines Oligopolexperiments. In: Sauerland, H. (Ed.). Beiträge zur experimentellen Wirtschaftsforschung, Tübingen: Mohr, 136-168.

Solow, J.L., Kirkwood, N., 2002. Group identity and gender in public goods experiments. Journal of Economic Behavior \& Organization 48 (4), 403-412.

Tajfel, H., Turner, J., 1979. An Integrative Theory of Intergroup Conflict. In: Worchel, S., Austin, W. (Eds.). The Psychology of Intergroup Relations, Monterey: CA: Brooks/Cole, 33-47.

Tajfel, H., Turner, J., 1986. The Social Identity Theory of Intergroup Behaviour. In: Worchel, S., Austin, W. (Eds.). The Psychology of Intergroup Relations, Chicago: Nelson-Hall, 7-24.

Volk, S., Thöni, C., Ruigrok, W., 2012. Temporal stability and psychological foundations of cooperation preferences. Journal of Economic Behavior \& Organization 81 (2), 664-676.

Yamagishi, T., Jin, N.a.K.T., 1999. Bounded Generalized Reciprocity: Ingroup Boasting and Ingroup Favoritism. Advances in Group Processes 16, 161-197.

Yamagishi, T., Kiyonari, T., 2000. The Group as the Container of Generalized Reciprocity. Social Psychology Quarterly 63 (2), 116-132. 


\section{ChAPTER V}

\section{The Role of Expectations in the Provision of Public Goods under the INFLUENCE OF SOCIAL IDENTITY}

Matthias Lankau, Marianna Bicskei, Kilian Bizer 


\section{Introduction}

Experimental evidence has shown that individuals' willingness to be cooperative is strongly contingent on the social environment (Chen and Li, 2009). Individuals tend to be more cooperative with individuals with whom they share a common social identity (in-group) than with individuals who belong to different social groups (out-group) (Solow and Kirkwood, 2002). Often referred to as ingroup bias, this behavioral pattern seems to be deeply rooted in human nature (Eaton et al., 2011) and can be found in many different cooperative settings (cf. McLeish and Oxoby, 2007; Chen and Li, 2009; Charness et al., 2007; Chen and Chen, 2011; Goette et al., 2006). In the social dilemma of privately providing public goods, field experiments have established that ethnically more homogenous groups are more successful in providing local public goods than heterogeneous communities. ${ }^{1}$ Likewise, laboratory experiments confirm consistently higher contribution levels among subjects sharing a common identity over multiple periods of a public good game (Eckel and Grossman, 2005). So far, however, the mechanisms of this increased cooperation in the provision of public goods are not precisely understood. Nevertheless, two independent streams of social identity research offer potential explanations: (1) subjects' expectations on the cooperation of their group members and (2) their degree of reciprocating these expectations by own contributions, i.e. their degree of conditional cooperation. Starting with the former, Yamagishi et al. (1999) propose that subjects expect a higher cooperativeness of group members with which they share a common identity than of members who belong to different identities. In return, they will cooperate to a higher extent with in-group members, as well. Experimental research on the latter suggests that subjects reciprocate their expectations on contributions of in-group members to a higher degree than expectations on out-group members' contributions. This view is initiated by Chen and Li (2009), who generally find that in-groups members exhibit higher degrees of positive reciprocity among each other compared to out-group members. On this basis Lankau et al. (2012) establish that in the context of public good provision in-group members reveal the preference for significantly higher levels of conditional cooperation than out-group members or mere strangers. Please note the difference between (1) subjects' reciprocating hypothetical group members' contributions elicited via strategy method and (2) the degree of reciprocation of expectations on group members' cooperation. For the sake of clarity, within this article we will generally refer to the former as cooperation preference or strategy (preference for conditional cooperation) and to the latter as (actual) conditional cooperation. In particular, the authors employ a series of one-shot public good games in strategy method in order to elicit how strongly subjects would be willing to reciprocate their group members' hypothetical average contributions to the public good by their own

\footnotetext{
${ }^{1}$ See Akerlof and Kranton (2010) and Eaton et al. (2011) referring to research of Alesina et al. (1999), Xiao-Ping (1996) and Paolo Mauro (1995).
} 
contributions. Based on their results, they conjecture that within the context of multiple-period public good games in-group subjects should reciprocate their expectations on their group members' cooperativeness to a higher degree than in out-groups, as well. Theoretically, it then follows that both subjects' expectations as well as their degree of reciprocating these expectations may determine the overall level of cooperation under social identity. At this point, however, this remains a hypothesis. Consequently, within this article we ask exactly how social identity influences individuals' cooperation in the context of multiple-period public good provision.

To this purpose, we artificially induce social identity in the lab through a simple group task, which subjects solve jointly by communicating anonymously via chat. Our experiment is mainly based on a ten-period public good game with stable group membership, in which subjects are matched with members of their own identity (in-group matching), of different identities (out-group matching) or with mere partners for whom no induction of social identity has taken place (partner matching). In addition to recording subjects' contributions to the public good in each period, we ask for their expectations on their group members' contributions throughout the game, as well. Our design is complemented by employing a variant of the strategy method (Selten, 1967) as pioneered by Fischbacher et al. (2001) in order to automatically classify subjects into certain types according to their cooperation preferences. This allows for finer grained analyses of the effects of social identity (cf. Lankau et al., 2012).

Our results indicate that despite recent progress in understanding social identity's impact on positive reciprocity, differences in cooperativeness are predominantly triggered by subjects' expectations. In particular, when matched with members of their own identity subjects hold significantly higher expectations on their cooperativeness than when interacting with out-group members. Yet, the degree of reciprocating these expectations is very similar. Nevertheless, we find that subjects initially characterized as free-riders do exhibit significantly higher levels of conditional cooperation in ingroup than in out-group matching.

Our article is organized as follows: Section 2 reviews the most relevant literature on this subject and derives our research hypotheses. While section 3 details the experimental design, we report the main results of this research in section 4. Finally, section 5 concludes.

\section{Literature Review and Research Hypotheses}

The origins of experimental economic research on social identity can be found in the social identity theory as pioneered by Tajfel and Turner (1979). Its core element is the deduction of discriminatory behavior's psychological foundations, which is routed in three distinct social processes: (1) Categorization - individuals associate themselves rather quickly with certain social categories; (2) identification - they derive self-esteem from these (in-) groups, and (3) comparison - they start to 
compare their in-groups with out-groups they do not identify with. Together, these processes trigger discriminatory behavior towards members of different identities (out-group members) and favorable treatment of members of their own identity (in-group members). ${ }^{2}$ This phenomenon, generally termed as in-group bias, seems to be deeply rooted in human nature (Eaton et al., 2011) and pervasive in many different forms of social interactions. Experimental investigations focusing on cooperative behavior, for instance, show that social identity increases cooperativeness when individuals interact with in-group members as opposed to random and/or out-group matching. This has been shown in two-player response games (McLeish and Oxoby, 2007), dictator games (Chen and $\mathrm{Li}, 2009$ ), two-player coordination games (Charness et al., 2007) and minimum-effort games (Chen and Chen, 2011) all using induced social identity, as well as in prisoners' dilemma games using preexisting social identification with real Swiss army platoons (Goette et al., 2006).

In the context of private public good provision there are two studies focusing on the impact of social identity on contributions to public goods. Both show that a common identity increases individuals' contribution despite the dominant strategy of free-riding (Solow and Kirkwood, 2002; Eckel and Grossman, 2005). Eckel and Grossman (2005), for instance, employ a ten-period public good game framed as a time allocation problem with different treatments designed to induce increasing strengths of social identity. The authors find that enhanced team identification yields consistently higher cooperation levels indicating less free-riding in general. Unfortunately, their research does not allow concluding on the driving forces of these increases in cooperation under social identity.

Nevertheless, there are two independent lines of thought from which hypotheses on the mechanisms of social identity in public good provision can be drawn. Originating in experimental psychology the first stream refines the understanding of social identity theory by stressing the pivotal role of expectations on group members' behavior. In particular, within the context of sequential minimal group reward allocation games Yamagishi et al. (1999) establish that when individuals interact with other members of their in-group, they expect their group members to reciprocate favors given to them. This occurs even if they merely know the social but not the personal identity of the individuals they were interacting with. ${ }^{3}$ Due to this elevated expectation in-group members cooperate more with each other than with out-group members from whom they expect less reciprocation. The authors termed this phenomenon the expectation of bounded - since confined to in-groups - generalized reciprocity. In the context of a simultaneous prisoners' dilemma situation they also show that subjects cooperate to a higher degree with their in-group than with out-group matches because they hold higher expectations on the contributions of in-group matches (see also Yamagishi and Kiyonari, 2000). Likewise, cooperation in the public good context under social identity

\footnotetext{
${ }^{2}$ See for instance Chen and Li (2009) for a more detailed summary.

${ }^{3}$ Thus, their design rules out direct reciprocation between two subjects.
} 
ought to be mainly driven by subjects' expectations, as well. This view is shared by Fischbacher et al. (2010), who generally argue that subjects' expectations determine cooperative patterns in public good contexts. ${ }^{4}$

The second stream of literature is driven by research on the impact of social identity on individuals' social preference for positive reciprocity. Generally, positive reciprocity captures individuals' inclination to reward acts that are perceived to be kind (cf. Fehr and Fischbacher 2002; Falk and Fischbacher 2006). In particular, in a series of two-person response games Chen and Li (2009) find that in-group members exhibit a 19 percent higher degree of positive reciprocity among each other than out-group members. ${ }^{5}$ Using a comparable game setting, Currarini and Mengel (2012) report a 34 percent higher positive reciprocity in in-group matching. Accordingly, when subjects interact with members of their own identity they exhibit the preference to reciprocate favors given to them to a significantly higher degree than when interacting with individual of different identities. Moreover, Lankau et al. (2012) show that social identity's impact on reciprocity preferences has direct bearing in the provision of public goods, as well. Within the context of one-shot public good games in strategy method, the authors elicit subjects' cooperation preferences. They establish that in-group members contribute significantly more to the public good independent of their group members' hypothetical average contributions than out-group members. ${ }^{6}$ Consequently, we argue that social identity tends to systematically affect subjects' cooperation preferences in the provision of public goods. The authors go on to conjecture that these distinct preferences will shape subjects' conditional cooperation in longer term public good provision, as well. ${ }^{7}$ Specifically, conditional cooperation within the context of multiple-period public good games is often captured by the degree to which subjects reciprocate their expectations on their group members' contribution as measured by own contributions (cf. for instance Chaudhuri and Ananish, 2011; Fischbacher and Gächter, 2010). ${ }^{8}$ However, so far little is known to what extent (if any) social identity leads to differences in conditional cooperation in multiple-period public good games, measured by subjects' degree of

\footnotetext{
${ }^{4}$ The causality of both variables is by no means a clear-cut. Daws $(1980 ; 1989)$ for instance argues that subjects project their own contributions onto others, which is then reflected in their expectations. Yet, based on the results of Yamagishi et al. (1999), Yamagishi and Kiyonari (2000) as well as Fischbacher et al. (2010) we view expectations to drive contributions.

${ }^{5}$ Additionally, subjects are significantly more forgiving for "bad behavior", i.e. they exhibit less negative reciprocity Chen and Li (2009). See also Bicskei et al. (2013).

${ }^{6}$ In order to elicit subjects' cooperation preferences the authors employed a series of one-shot games in strategy method (cf. Fischbacher et al., 2001; Fischbacher and Gächter, 2010; Volk et al., 2012) by asking subjects for their contributions conditional on hypothetical average contributions (0-20) of their group members.

${ }^{7}$ In general, results of the strategy method have been found to significantly predict subjects' cooperative behavior in response to their expectations on the average contributions of their group members (Fischbacher and Gächter, 2010).

${ }^{8}$ Alternatively, conditional cooperation can be captured by analyzing how subjects react to changes in cooperativeness of their group members in the previous game periods (Keser and van Winden, 2000). Yet, expectation should generally comprise previous group members' behavior (Fischbacher and Gächter, 2010), so that we use them as the base for establishing the degree of conditional cooperation.
} 
reciprocating their expectations on group members' behavior. This is by no means obvious, since in such an environment expectations tend to impact on cooperation in addition to subjects' cooperation preferences (Fischbacher and Gächter, 2010). ${ }^{9}$

From a theoretical perspective, both literature streams complement each other. Subjects may expect greater cooperation of their own identity's members than of out-group members and thus contribute more to the public good. Additionally, they could exhibit higher degrees of conditional cooperation and reciprocate these expectations by increased own contributions. Investigating to what extent this theoretical construct holds, is at the heart of this article. ${ }^{10}$ Accordingly, we formulate the following research hypotheses.

Based on Eckel and Grossman (2005), we first of all expect larger contributions in in-group matching than in out-group or partner matching ${ }^{11}$ throughout all periods of the public good game.

Hypothesis 1: Contributions to the public good are significantly higher when subjects are matched with members of their own identity than in partner or out-group matching.

Secondly, based on Yamagishi et al. (1999) and Yamagishi and Kiyonari (2000), we hypothesize that subjects expect significantly greater average contributions of their in-group members as compared to out-group members or in partner matching.

Hypothesis 2: Expectations on group members' average contributions to the public good are larger when subjects are matched with in- than with out-group members or with partners.

Lastly, following Chen and Li (2009) and Lankau et al. (2012) we expect that when subjects interact with members of their own identity they will display a higher degree of conditional cooperation expressed by the reciprocation of their expectations on group members' average contributions by their own contributions - than in out-group or partner matching.

Hypothesis 3: Subjects reciprocate their expectations on their group members' contributions to a significantly higher degree when interacting with in-group members than when interacting with partners or out-group members.

\footnotetext{
${ }^{9}$ The authors elicited cooperation preferences through a one-shot public good game in strategy method that was played in addition to a ten-period public good game in stranger matching. Conditional contributions from the strategy method were used to predict actual contributions in the ten-period game based on subjects expectations on group members' contributions.

${ }^{10}$ Of course, there may well be other factors that influence how social identity shapes cooperation. Yet, within this study we specifically seek to disentangle expectations and conditional cooperation.

${ }^{11}$ The term partner matching characterizes stable group membership over the periods of the public good game.
} 


\section{Experimental Design}

The participants of the experiment were assigned to groups comprising three subjects. Each group member was endowed with 20 points that could be invested either in their private account $\left(20-g_{i}\right)$ or into a public good, framed as a project $\left(g_{i}\right)$. The payoffs associated with this decision are given by the following formula:

$$
\pi_{i}=\left(20-g_{i}\right)+0.4 \sum_{j=1}^{3} g_{j}
$$

Accordingly, it is individually more beneficial to invest in the private account, because every point invested returns exactly 1 point, while the project only yields 0.4 points. Generally, we employ two techniques of collecting subjects' contributions to the public good: the standard method and the strategy method (cf. Fischbacher et al., 2001). Within the rounds carried out in strategy method, subjects had to make two decisions, an unconditional and a conditional contribution to the public good. At first, they had to decide how many of their 20 points they would like to invest in the public good irrespective of what their group members contribute (unconditional contribution). Then, subjects were asked to fill out a contribution table consisting of 21 entries in which they were asked to decide how much they would invest if their group members invested on average (round to the next higher integer value) 0-20 points in the public good (conditional contribution). In order to render both decisions potentially payoff-relevant, we randomly determined ${ }^{12}$ one group member who was to contribute according to the conditional contribution decision, while for the remaining two their unconditional contributions were applicable. Within the rounds that were played in standard method, subjects merely had to indicate how much they would like to invest in the project regardless of the contributions of their group members, with each decision being directly payoff-relevant (cf. similar to the unconditional contribution in the strategy method game).

In total, the experiment consisted of three stages (see Table 1). In Stage A subjects were randomly allocated into different groups (random matching) and played a one-shot public good game in strategy method. This followed the purpose of eliciting subjects' cooperation preferences without any influences of social identity (Lankau et al., 2012). Specifically, it helped to classify them as conditional cooperators or free-riders, allowing for a differentiated analysis of subjects behavior in later stages of the experiment (cf. Fischbacher et al., 2010; Burlando and Guala, 2005). ${ }^{13}$

\footnotetext{
${ }^{12}$ After both decisions were made, one participant in each session rolled a die to determine the respective group member.

${ }^{13}$ We defined conditional cooperators as subjects who exhibit a positive significant Spearman rank correlation coefficient $(p<0.01)$ between own conditional contributions and others' average contributions. Subjects were classified as free-riders if they contributed nothing to the public good in any case.
} 


\begin{tabular}{|c|c|c|c|}
\hline Stage & \multicolumn{2}{|c|}{ ID-Treatments } & Control Treatment \\
\hline A & \multicolumn{3}{|c|}{$\begin{array}{l}\text { Public Good Game in Strategy Method } \\
\text { Random Matching }\end{array}$} \\
\hline B & \multicolumn{2}{|c|}{ Group Identity Task } & - \\
\hline \multirow[b]{2}{*}{ C } & $\begin{array}{l}\text { In-Group } \\
\text { Matching }\end{array}$ & $\begin{array}{l}\text { Out-Group } \\
\text { Matching }\end{array}$ & $\begin{array}{l}\text { Partner } \\
\text { Matching }\end{array}$ \\
\hline & \multicolumn{3}{|c|}{$\begin{array}{l}\text { Ten-Period Public Good Game } \\
\text { Period 1: Strategy Method } \\
\text { Period 2-10: Standard Method }\end{array}$} \\
\hline
\end{tabular}

Table 1 - Experimental Design

Stage B served the purpose of inducing social identity in the laboratory using a design pioneered by Ibañez and Schaffland (2012), which is based on insights of Eckel and Grossman (2005) and Chen and Li (2009). Specifically, we randomly re-assigned subjects to different groups with each group having been given a different color indicated by a colored flag. These groups then had to solve a simple group task in order to create a positive group experience (Eckel and Grossman, 2005). Given 10 minutes time, subjects had to jointly find hidden objects in a picture and report coordinates of their location (row and column). ${ }^{14}$ To this purpose, subjects could discuss solutions with their group members via an anonymous online chat tool. In order to elevate subjects' propensity to coordinate and to render this task a true group exercise, our instructions explicitly stated that answers would only count as correct should each group member enter them correctly. What is more, the task was played as a tournament in which the group with the highest number of objects found won. Yet, in order to prevent negative associations from not winning this task, only the winning team received a congratulating message at the end of the experimental session. The remaining teams were not provided with information about their results and position relative to the other groups. Lastly, avoiding income effects there were no monetary incentives for winning this game.

In Stage $C$ three different matching protocols were in effect. On the one hand, subjects were either matched with individuals of their own identity with whom they solved the group task in Stage B (ingroup matching); or with subjects of different identities (out-group matching). Throughout Stage $C$ each group member' identity was made salient by showing special flags colored according to group membership from Stage B. Subjects matched with out-group members for instance saw a red and a green flag in addition their own flag of blue color, visually stressing differing group identities. On the other hand, we implemented a control treatment, in which subjects did not take part in the identity induction. Since all protocols are characterized by stable group membership throughout Stage $C$, the control treatment is effectively a mere partner matching condition (see for instance Andreoni, 1988;

\footnotetext{
${ }^{14}$ For the instructions and the picture used in the experiment please see Appendix 6.4.
} 
Andreoni and Croson, 2008). Subsequently, subjects played a ten-period public good game, ${ }^{15}$ with the first period played in strategy method analogous to Stage $A$, and the remaining periods in standard method. Additionally, throughout all decision periods of Stage $C$, subjects had to state what they expected their remaining two group members to (unconditionally) contribute on average, next to their own contribution decision. ${ }^{16}$ At the end of each game period subjects were informed about their payoff from this round, including how much their two group members contributed on average to the project.

The instructions to this experiment were provided successively in order to prevent subjects to adjust their behavior according to their expectation of events in later stages. Additionally, payoffs from Stage A were not revealed until the end of the experiment prior to the post-experimental questionnaire. At this point subjects were told about their total payoff, comprised of income from Stages $A$ and $C$ as well as the $2.50 €$ show-up fee.

\section{Results}

The experiment was carried out in the Göttingen Laboratory of Behavioral Economics (GLOBE) at the Göttingen University from December 2011 to January 2012 using the software z-Tree (Fischbacher, 2007). Altogether, we observed decisions of 300 subjects, of which 108 took part in in-group matching, 105 in out-group matching and 87 in control matching. The subjects were students recruited from the ORSEE Database and the canteen of the Göttingen University. Sessions took approximately 1.5 hours and the subjects earned $13.20 €$ on average including the show-up fee.

\subsection{Cooperation under Social Identity}

Figure 1 depicts the impact of our matching conditions on cooperation in the ten-period public good game of Stage C. Clearly, independent of the treatment we observe the usual pattern of diminishing contributions over the course of the game. In period 1, subjects start off by investing on average approximately 8 of their 20 points into the public good. ${ }^{17}$ In the following periods, average cooperation gradually decreases within each treatment condition. Importantly though, when subjects interact with members of their own identity they consistently show higher average cooperation levels than when matched with individuals who belong to different identity groups or

\footnotetext{
${ }^{15}$ The actual number of periods in Stage $C$ was randomly set to be between 11 and 15 . Subjects did not know about the actual length of the game in advance, which served the purpose of avoiding end-game effects in period 10 (cf. Andreoni and James, 1988).

${ }^{16}$ Accurate expectations were incentivized according to the following scheme: 3 points for correct expectations, 2 (1) point(s) for expectations that were 1 (2) point(s) off from actual average contributions.

${ }^{17}$ In period 1, which was carried out in strategy method subjects' unconditional contributions were chosen as their contribution to the public good. This ensures the highest degree of comparability to the remaining periods of the game, in which subjects were not asked for their conditional contributions.
} 
with partners. The Tobit-regression analysis in Table 2 (Model 1) confirms firstly that these differences are statistically significant and secondly that contributions decrease over time. ${ }^{18}$ Consequently, we find supporting evidence for Hypothesis 1 of a prevailing in-group bias in subjects' contributions.

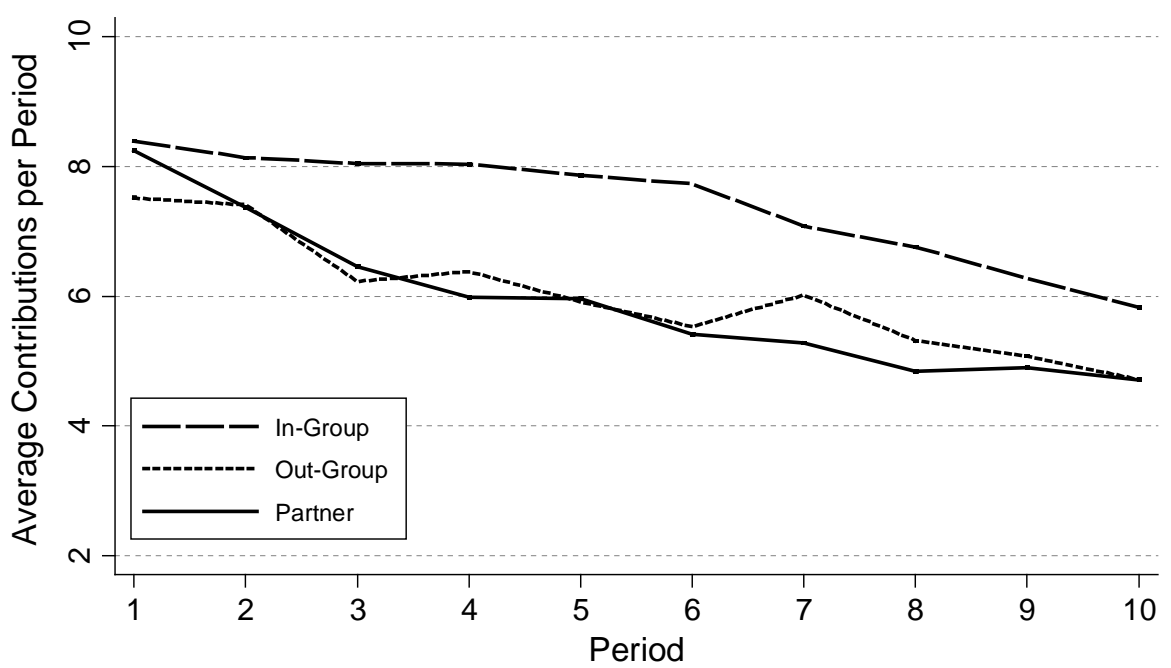

Figure 1: Average Cooperation Levels per Treatment

\begin{tabular}{ccc} 
Tobit Regression & \multicolumn{2}{c}{ Model } \\
\cline { 2 - 3 } & Contributions & $\begin{array}{c}(2) \\
\text { Expectations }\end{array}$ \\
\hline \hline Ingroup & $2.4037^{\star \star}$ & $2.1580^{\star \star \star}$ \\
& $(1.027)$ & $(0.738)$ \\
Outgroup & 0.3303 & 0.4265 \\
& $(1.066)$ & $(0.734)$ \\
Period & $-0.4738^{\star \star \star}$ & $-0.3984^{\star \star \star}$ \\
Constant & $(0.058)$ & $(0.046)$ \\
& $7.0276^{\star \star \star}$ & $8.2799^{\star \star \star}$ \\
& $(0.764)$ & $(0.484)$ \\
Ingroup - Outgroup $=0$ & $\mathrm{p}=0.0372$ & $\mathrm{p}=0.0183$ \\
& & \\
sigma Constant & $8.5439^{\star \star \star}$ & $6.3005^{\star \star *}$ \\
& $(0.385)$ & $(0.236)$ \\
Observations & 3,000 & 3,000 \\
Pseudo-R2 & 0.0068 & 0.0088 \\
\hline \hline
\end{tabular}

Note: Robust standard errors in parentheses, clustered around individuals, sign. levels: ${ }^{* \star *} p<0.01,{ }^{* *} p<0.05,{ }^{*} p<0.1$

Table 2: Tobit-Regression on Treatment Effects on Contributions and Expectations

\footnotetext{
${ }^{18}$ A Tobit-estimation is particularly suitable in this case, because it allows controlling for truncated data. In our case we observe comparably many contributions and expectations of 0 and 20 points. Standard errors are cluster over individuals to control for auto-correlation of the error-term. Please see Appendix 6.1 for a robustness check using an OLS-estimation.
} 
RESULT 1: Subjects showed significantly higher levels of cooperation when interacting with members of their own identity than in mere partner or out-group matching.

This result is in line with Eckel and Grossman (2005), who find strong social identity to raise cooperation compared to groups bound together by weaker identities.

Contrarily, we do not find any statistical differences in contributions between partner and outgroups. Following Yamagishi et al. (1999) this could be due to subjects holding similar expectations on partners' and out- group members' cooperation. In case their conditional cooperation - i.e. the degree to which they reciprocate their expectations with own contributions - is similar in both matching protocols as well, comparable average contribution levels result automatically.

After having established that relative to the other treatment conditions in-groups cooperate to the highest extent, we subsequently investigate the two explanatory factors that we derived from previous research: subjects' expectations on their group members' cooperativeness (Hypothesis 2) and subjects' conditional cooperation capturing the degree to which subjects reciprocate these expectations by their own contributions (Hypothesis 3 ).

\subsection{Explaining In-Group Biased Cooperation}

\subsubsection{Expectations on Group Members' Contributions}

Figure 2 compares the average levels of expectations in the different identity treatments. In line with the findings on cooperation levels, when subjects are matched with individuals of their own identity they expect much more cooperation of their group members than in partner or out-groups, with both differences being highly significant (see Table 2, Model 2). Although in eight of ten game periods out-group expectations are on average higher than partner expectations (periods 1 and 410), we do not find any statistically significant difference between these conditions (see Table 2 , Model 2). This serves as a first explanation of why subjects' cooperativeness in out-group and partner matching does not differ either. Overall, we thus cannot reject Hypothesis 2. Subjects in ingroup matching do hold higher expectations on their group members' contributions than in outgroup or partner matching.

RESULT 2: Subjects hold significantly higher expectations on their group members' cooperativeness when interacting with members of their own identity than when matched with partners or out-group members. 


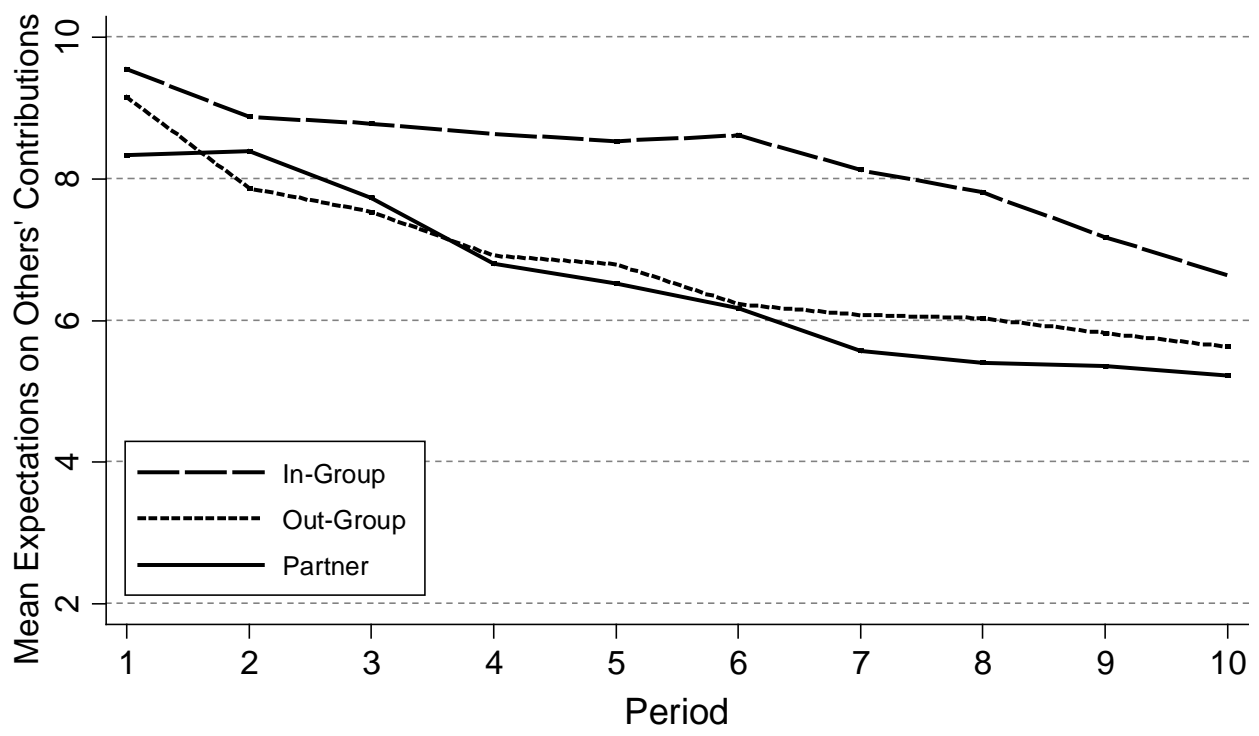

Figure 2: Average Expectations on Group Members' Average Cooperation

This result is in line with previous findings by Yamagishi et al. (1999). Within the context of prisoner's dilemma games, the authors show that subjects hold significantly higher expectations on the cooperativeness of in-group than of out-group members and thus cooperate to a higher extent, in return. Evidently, as to be seen in Figure 3, our results demonstrate that the level of subjects' expectations is highly correlated to their contributions. In each matching protocol, subjects' average contributions closely follow the pattern of their expectations. In the next section, we will elaborate subjects' conditional cooperation in each matching in detail.
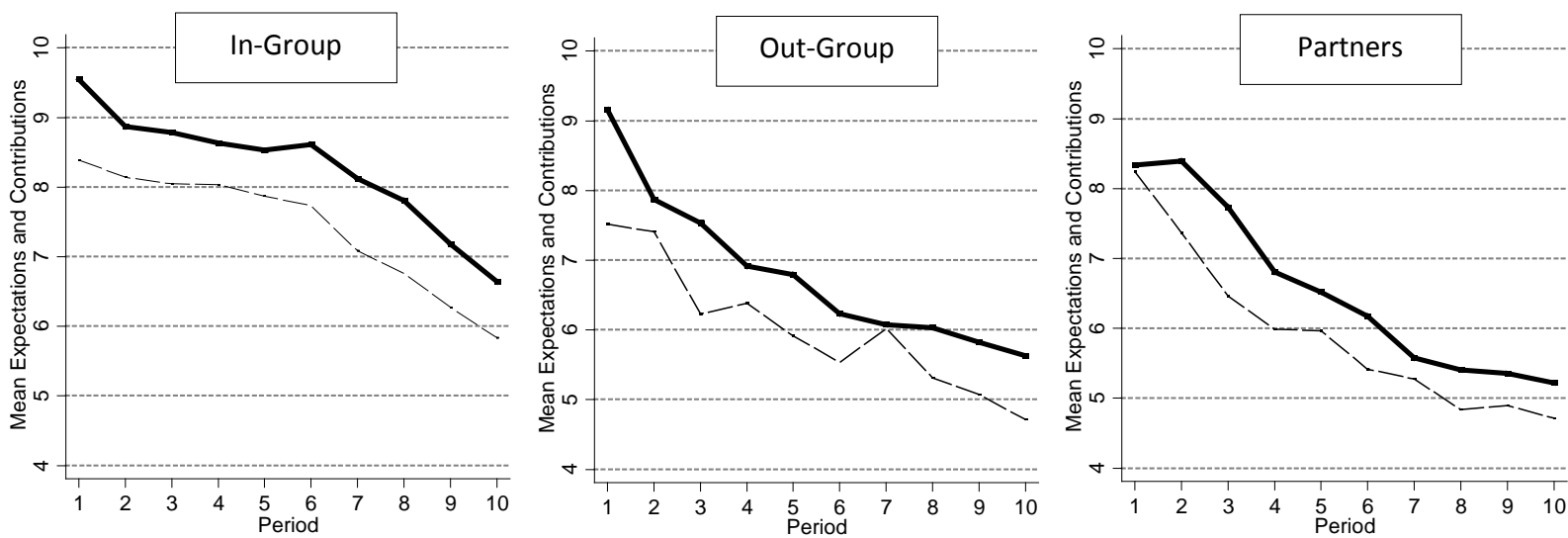

Expectations - - Contributions

Figure 3: Average Expectations and Contributions per Period and Matching Protocol 


\subsubsection{Conditional Cooperation}

The following analyses of subjects' degree of reciprocity will be split into two parts. At first, we will investigate subjects' initial cooperation strategies of the first period in Stage C. Please recall that the first period was carried out in strategy method by which we elicited how subjects reciprocate hypothetical contribution behavior of their group members (their conditional contributions). Next, we analyze their actual conditional cooperation, i.e. how they actually reciprocate expectations on their group members' cooperation throughout all of Stage C's periods. Please note that subjects were fully aware that they would be interacting with the same group members throughout Stage $C$. Such longer-term interactions with stable group membership typically give rise to strategic and future-oriented incentives. These can alter subjects' degree of reciprocity - captured by their cooperation strategy and their actual conditional cooperation - compared to their preferences for reciprocity in one-shot environments (cf. Fehr and Fischbacher, 2002). Nevertheless, these incentives are equally present in in-, out- and partner groups. Thus, we assume that any difference in subjects' observed reciprocity indicates differences in their reciprocity preferences, free of any strategy bias. ${ }^{19}$ To start with the former, Table 3 reports the results of three linear regressions on the influence of matching conditions on subjects' conditional contributions, which were elicited in Stage C's first period. ${ }^{20}$ Our findings first of all reveal that independent of the matching protocol subjects are willing to be conditionally cooperative. This is indicated by the highly significant coefficient on the "Group Average" variable in combination with the statistically insignificant interaction terms of in-group and control matching with "Group Average" (Model 1). Nevertheless, their strategies point towards a certain self-serving bias. Upon increase of their group members' average contributions by 1 point subjects merely increase their own conditional contributions by approximately half a point. Secondly, we find that subjects' cooperation strategies significantly differ between in-groups and out-groups (Model 1). Here, the coefficient on the in-group dummy variable reveals that across the whole range of others' average contributions to the public good (0-20) in-group members are willing to contribute approximately 1 point more than out-group members. Testing the linear combination of intercept and slope confirms the result, which is significant at the $10 \%$-level. What is more, controlling for subjects' experiences from the Stage A of the experiment, in which they already played a public good game in strategy method, reinforces the significance. Nevertheless, we do not find any difference neither in intercept nor in slope - between cooperation strategies of in-groups and control groups as well as of out-group and control groups.

\footnotetext{
${ }^{19}$ For the impact of social identity on cooperation preferences in a one-shot environment, please see Lankau et al. (2012).

${ }^{20}$ In this case we chose an OLS-regression, since we do not face the problem of truncated data. Subjects' conditional contributions are - due the experimental design - equally distributed over the whole range of group members' average contributions. For a graphical representation of subjects' average conditional contributions per treatment see Appendix 6.2.
} 


\begin{tabular}{|c|c|c|}
\hline \multirow{2}{*}{$\begin{array}{l}\text { Linear Regression (OLS) } \\
\text { Conditional Contributions }\end{array}$} & \multicolumn{2}{|c|}{ Model } \\
\hline & (1) & (2) \\
\hline In-group & $0.9858^{*}$ & $0.8418^{\star \star}$ \\
\hline \multirow[t]{2}{*}{ Control } & 0.6330 & 0.2624 \\
\hline & $(0.503)$ & $(0.271)$ \\
\hline \multirow[t]{2}{*}{ In-group x Group Average } & -0.0141 & -0.0293 \\
\hline & $(0.064)$ & $(0.038)$ \\
\hline \multirow{2}{*}{ Control x Group Average } & 0.0012 & -0.0307 \\
\hline & $(0.063)$ & $(0.039)$ \\
\hline \multirow[t]{2}{*}{ Group Average } & $0.5382^{\star * *}$ & $0.1828^{\star \star \star}$ \\
\hline & $(0.045)$ & $(0.035)$ \\
\hline Conditional Contributions (Stage A) & & $\begin{array}{l}0.7223^{\star \star \star} \\
(0.038)\end{array}$ \\
\hline \multirow[t]{2}{*}{ Constant } & 0.5045 & -0.0627 \\
\hline & $(0.306)$ & $(0.161)$ \\
\hline \multicolumn{3}{|l|}{ Tests of Linear Combinations } \\
\hline $\begin{array}{c}\text { Ingroup + In-group x Groupaverage }=0 \\
\text { (In-group vs. Outgroup) }\end{array}$ & $\begin{array}{l}0.9717^{*} \\
(0.5000)\end{array}$ & $\begin{array}{l}0.8125^{\star \star} \\
(0.349)\end{array}$ \\
\hline \multirow{4}{*}{$\begin{array}{c}\text { Control + Control xGroupaverage }=0 \\
\text { (Control vs. Outgroup) } \\
\text { In-group vs. Control }\end{array}$} & 0.6341 & 0.2318 \\
\hline & $(0.473)$ & $(0.251)$ \\
\hline & 0.3376 & 0.5808 \\
\hline & $(0.564)$ & $(0.372)$ \\
\hline Observations & 6,300 & 6,300 \\
\hline R-squared & 0.293 & 0.672 \\
\hline
\end{tabular}

Note: Robust standard errors in parentheses, clustered around individuals, sign. levels: ${ }^{* \star *} p<0.01,{ }^{* \star} p<0.05,{ }^{*} p<0.1$

Table 3: Linear Regressions on the effects of Matching Conditions on Conditional Contributions (Stage C, Period 1)

RESULT 3: In-group matches reveal a greater willingness to be conditionally cooperative than outgroup matches.

After having shown that subjects' initial cooperation strategies under social identity are characterized by a differing willingness to be conditionally cooperative, we proceed by analyzing their actual degree of conditional cooperation by measuring the correlation between subjects' expectations and contributions. Specifically, we run a Tobit-regression analysis (see Table 4) to compare slopes of the function that maps subjects' contributions on their expectations (contribution schedule). ${ }^{21}$ This allows us to exactly quantify marginal effects of expectations on contributions at each level of

\footnotetext{
${ }^{21}$ We opted for a non-linear estimation, since marginal effects may differ depending on the actual level of expectations. This regression includes expectations and contributions from each period of the public good game. We equally ran a Tobitregression using individual averages of expectation and contributions over the ten periods in order to better account for statistical dependencies that may occur over the course of the game. The results are not essentially different, which is why we did not include them in this paper.
} 
expectations from 0 to 20 . What is more, the models' intercepts will shed light on treatment differences in the position of the according contribution schedules. This analysis is carried out for all subjects combined (Model 1 and 2) as well for free-riders and conditional cooperators (Model 3 and 4 , respectively), which were identified in Stage A, separately. ${ }^{22}$ Figures 6 to 8 depict the conditional marginal effects based on Models 1, 3 and 4, respectively.

\begin{tabular}{|c|c|c|c|c|}
\hline \multirow{3}{*}{$\begin{array}{l}\text { Tobit-Regression } \\
\text { Contributions in Stage C }\end{array}$} & \multicolumn{4}{|c|}{ Model } \\
\hline & $(1)$ & $(2)$ & (3) & (4) \\
\hline & All Subjects & All Subjects & $\mathrm{FR}$ & $\mathrm{CC}$ \\
\hline \multirow[t]{2}{*}{ In-Group ${ }^{1}$} & 0.1593 & 0.2083 & -0.5001 & -0.4366 \\
\hline & $(0.9530)$ & $(0.8525)$ & $(6.4216)$ & $(1.1168)$ \\
\hline \multirow[t]{2}{*}{ Out-Group ${ }^{1}$} & 1.1895 & 1.0237 & 1.4609 & 0.5903 \\
\hline & (1.0171) & (0.8763) & (2.1722) & (1.2496) \\
\hline \multirow[t]{2}{*}{ Expectations $^{1}$} & $1.0187^{\star \star *}$ & $0.6840^{\star \star \star}$ & $1.2727^{\star \star \star}$ & $1.0298^{\star \star \star}$ \\
\hline & (0.0439) & $(0.0657)$ & $(0.2102)$ & $(0.0416)$ \\
\hline \multirow[t]{2}{*}{ Predicted Cooperation $^{1}$} & & $0.4322^{\star \star \star}$ & & \\
\hline & & $(0.0653)$ & & \\
\hline \multirow[t]{2}{*}{ In $\times$ c.Exp } & 0.0278 & -0.0200 & 0.7985 & -0.0673 \\
\hline & (0.094) & $(0.086)$ & $(0.492)$ & $(0.091)$ \\
\hline \multirow[t]{2}{*}{ Out $\times$ c.Exp } & 0.0048 & -0.0123 & -0.5994 & 0.0544 \\
\hline & $(0.097)$ & $(0.084)$ & $(0.467)$ & (0.091) \\
\hline \multicolumn{5}{|l|}{ Control Variables $^{2}$} \\
\hline \multirow[t]{2}{*}{ Constant } & $-1.7244^{*}$ & $-1.7935^{\star \star}$ & $-7.4228^{\star}$ & -1.1939 \\
\hline & $(0.947)$ & $(0.852)$ & (3.858) & $(1.076)$ \\
\hline \multirow[t]{2}{*}{ sigma Constant } & $4.9449 * \star \star$ & $4.6689^{\star \star \star}$ & $8.1526 * \star \star$ & $4.3509 * \star \star$ \\
\hline & $(0.259)$ & $(0.250)$ & $(1.470)$ & $(0.238)$ \\
\hline Observations & 3,000 & 3,000 & 360 & 2,090 \\
\hline \multicolumn{5}{|c|}{$\begin{array}{l}\text { Note: , Robust standard errors in parentheses, clustered around individuals, lower } \\
\text { limit } 0 \text {, upper } \lim \text { it } 20,{ }^{* *} p<0.01,{ }^{* *} p<0.05,{ }^{*} p<0.1\end{array}$} \\
\hline \multicolumn{5}{|c|}{$\begin{array}{l}1 \text { - Coefficients and standars errors are calculated at the mean value of these } \\
\text { variables using the post-regression Margins-command with the noestimcheck- } \\
\text { option, } 2 \text { - Control variables include sessions and contribution patterns of groups }\end{array}$} \\
\hline
\end{tabular}

Table 4: Tobit-Regression on Conditional Marginal Effects of Expectations on Contributions

First of all, marginal increases in expectations are reciprocated by an increase in contributions of approximately 1 point (Model 1 ). ${ }^{23}$ Consequently, subjects generally exhibit a nearly perfect degree of conditional cooperation. What is more, their cooperation strategies from period 1 have very high explanatory power for actual contributions in the course of the public good game, which is indicated

\footnotetext{
${ }^{22}$ Based on subjects' conditional contribution behavior in Stage A, we identified 209 conditional cooperators (69.7\%), 36 free-riders (12\%) and 55 subjects (18,3\%) who belonged to the "other" category.

${ }^{23}$ In this model, the coefficient is calculated using the mean value of expectation on group members' average contributions.
} 
by the highly significant coefficient on predicted cooperation in Model $2(0.4322) .{ }^{24}$ Nevertheless, expectations still strongly inform subjects' contributions. This indicates that subjects show conditional cooperation in addition to what is predicted based on their indicated cooperation strategy.

RESULT 4: Subjects generally exhibit a very high degree of conditional cooperation throughout Stage C. It is strongly influenced by the level of their expectations in addition to their initially indicated cooperation strategy.

This argumentation is in line with findings by Fischbacher and Gächter (2010). The authors argue that both subjects' beliefs and cooperation preferences explain actual contribution behavior in a multipleperiod public good game.

We now turn our attention to treatment differences in conditional cooperation. Figure 4 depicts conditional marginal effects of expectations on subjects' contributions differentiated by matching protocol (based on Model 1). Clearly, independent of the level of subjects' expectations, there is always a significantly positive effect of marginal increases in expectations on own contributions. The function approximates an inverted u-shape peaking at a level of expectations of around 11 points. However, we do not find any statistically significant differences in marginal effects between the matching protocols. Thus, no matter with whom subjects interact, they reciprocate marginal increases in expectations on group members' behavior to approximately similar degrees. What is more, the intercepts for the in-group, out-group and partner conditions in Model 1 are not statistically different from each other indicating similar contribution profiles' positions. ${ }^{25}$ On the whole, we consequently have to reject Hypothesis 3 . Despite the fact that subjects initially indicated matching-dependent cooperation strategies in period 1 , we do not find any differences in their actual degree of conditional cooperation.

\footnotetext{
${ }^{24}$ To be precise, we used subjects' entries from the conditional contribution table of period 1 to predict actual contributions given their expectations on their group members' contributions. These predicted contributions thus reflect subjects' contribution behavior in the ten-period game if they had exactly followed their contribution strategy of period 1 . Due to the random end point of Stage $C$ this should reflect their strategy in later game periods as well.

${ }^{25} \mathrm{H}_{0}$ : in-group-out-group $=0, \operatorname{chi} 2(1)=1.35$, Prob $>$ chi $2=0.2460$.
} 


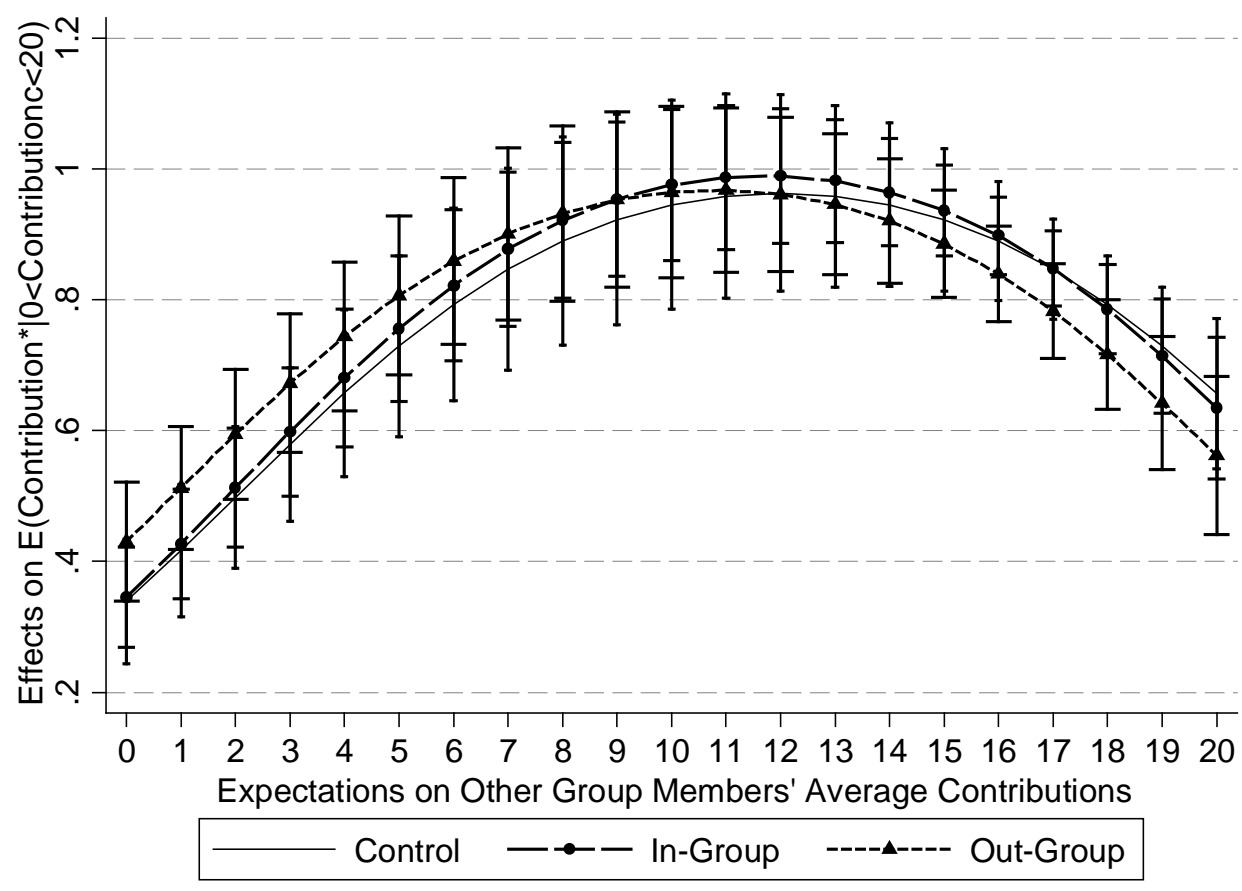

Figure 4: Conditional Marginal Effects of Expectations on Contributions (with 95\% Confidence Intervals)

Result 5: Throughout the ten-period public good game individuals exhibit similar degrees of conditional cooperation when interacting within in-, out and partner groups.

These findings diverge from subjects' initial matching-dependent cooperation strategies. Clearly, strategies offer merely limited insights into the impact of social identity on conditional cooperation in longer-term public good provision. This result rather points towards the paramount importance of subjects' expectations on the behavior of their group members. Obviously, expectations dominate any differences in cooperation preferences or strategies.

Offering a more differentiated analysis of social identity's effects conditional cooperation, we proceed by investigating conditional cooperators' and free-riders' reciprocation behavior, separately. On the one hand, we find some evidence that free-riders reveal behavioral adjustments (Figure 5 based on Model 3) depending on the matching protocol. When interacting within in-groups they exhibit significantly higher changes in cooperation upon marginal increases of expectations than in out-group matching in the range of expectations from $10-18 .{ }^{26}$ Here, the slope of their conditional contribution is consequently steeper. At a level of expectations of 14 points, for instance, the marginal effect of expectations on contributions for in-group free-riders is approximately 1.5 points.

\footnotetext{
${ }^{26}$ Please see Appendix 6.3 for the according test statistics.
} 
Yet, with regard to out-group free-riders it is merely approximately 0.4 points. The differences in intercepts of the contribution schedules are not statistically different from each other. ${ }^{27}$

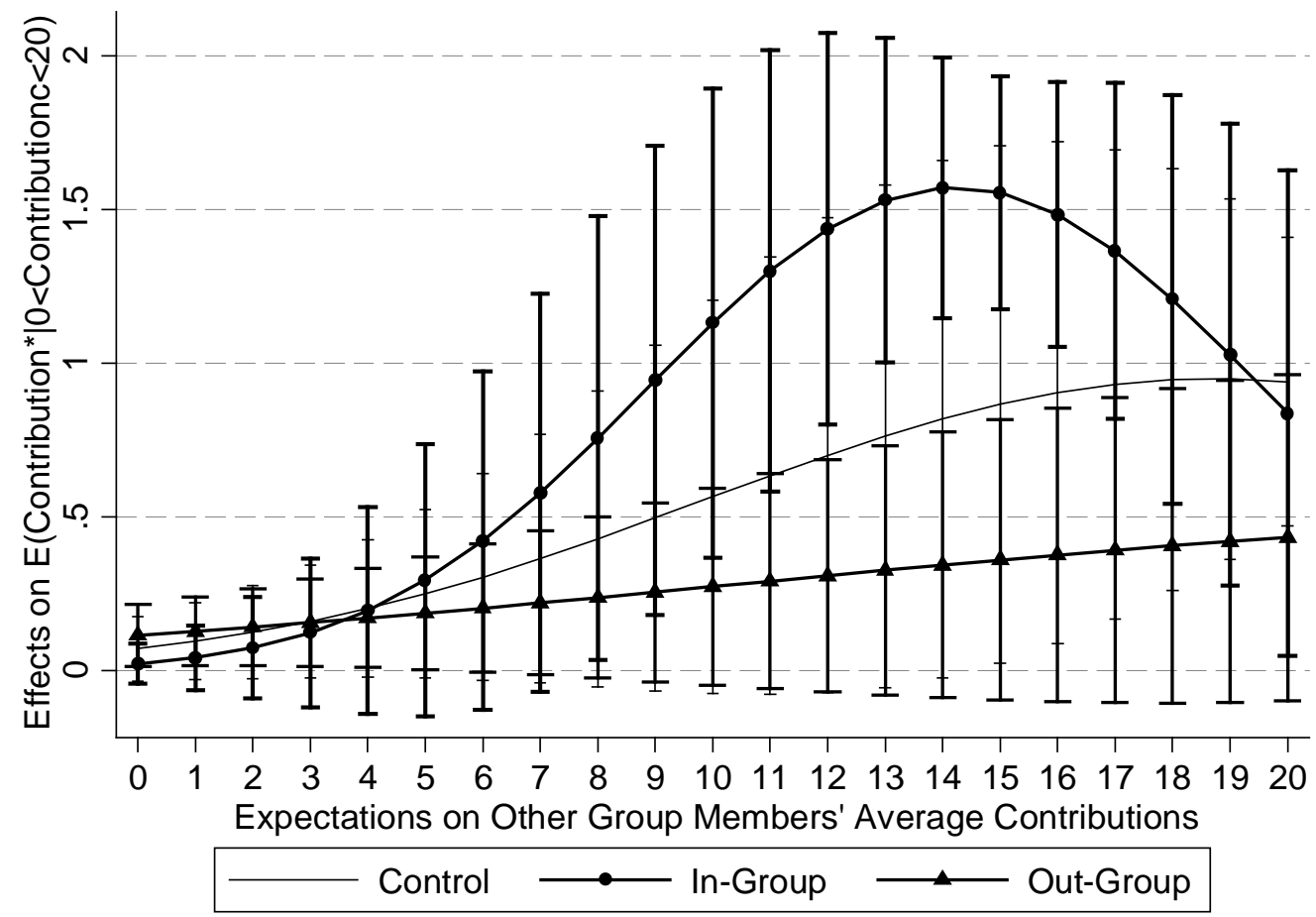

Figure 5: Conditional Marginal Effects of Expectations on Contributions in case of Free-Riders (with 95\% Confidence Intervals)

Result 6: For a limited range of expectations on group members' cooperativeness, free-riders seem to be more conditionally cooperative when matched with in-group than when matched with out-group members.

When interpreting Result 6, we would like to caution, however, that merely $12 \%$ of our subjects (36 in total) were classified as free-riders. Accordingly, further research is necessary to evaluate this result's robustness with a larger number of observations.

Conditional cooperators, on the other hand, reveal similar patterns of conditional cooperation in ingroup, out-group and partner matching. Although the marginal effects of expectations on contribution in out-groups are higher than in in-groups for most of the range of expectation (0-17), (Figure 6) we do not find any statistical significances. The same holds true for the intercepts of the contribution profiles. ${ }^{28}$

\footnotetext{
${ }^{27} \mathrm{H}_{0}$ : in-group-out-group $=0$ : chi2 $(1)=0.11$, Prob $>$ chi2 $=0.7452$.

${ }^{28} \mathrm{H}_{0}$ : in-group-out-group $=0$ : chi2 $(1)=0.82$, Prob $>$ chi2 $=0.3666$.
} 


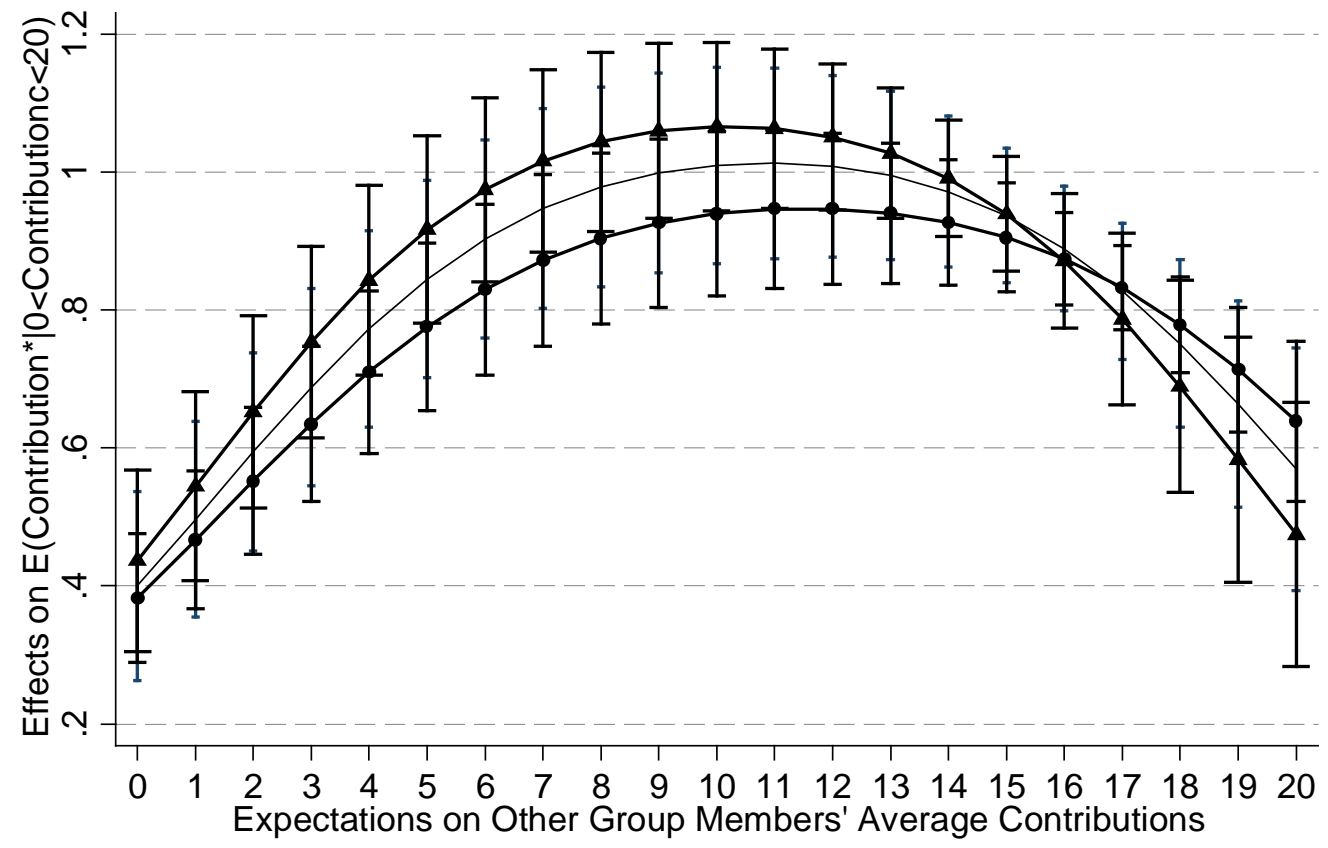

Control

In-Group

Out-Group

Figure 6: Conditional Marginal Effects of Expectations on Contributions in case of Conditional Cooperators (with 95\% Confidence Intervals)

Result 7: Conditional cooperators exhibit stable patterns of conditional cooperation under the influence of social identity.

These results contradict Lankau et al. (2012) who argue that both free-riders and conditional cooperators ought to show increased levels of conditional cooperation when interacting with members of their own identity as opposed to being matched with out-group members.

\section{Conclusion}

People tend to be more cooperative with individuals sharing a common identity than with individuals who belong to different identities. In the social dilemma of privately providing public goods this typically results in higher contribution levels among in-group members (Eckel and Grossman, 2005). Within this article we contribute to the understanding of why exactly we observe these increases in social welfare under the institution of social identity. In particular, we investigate its impact on subjects' expectations on the cooperativeness of their group members as well their degree of conditional cooperation, i.e. to what extent they reciprocate these expectations by their own contributions. To this purpose we designed a multiple-period public good game with stable group membership and induced social identity, implementing an in-group, out-group and partner matching treatment. Based on prior research, we hypothesize that social identity influences individuals' cooperation levels both via expectations and conditional cooperation. 
In line with previous findings our results show that subjects exhibit the highest levels of contributions when matched with members of their own identity (in-group matching). This seems to be mainly triggered by the expectation that group members with a common identity will themselves cooperate significantly more than members of different identities. However, the effects of social identity on conditional cooperation seem to play a much less important role. Although we find that subjects initially reveal the strategy to be most conditionally cooperative when matched with in-group members, their expectations tend to influence final contributions on top of that. Overall, subjects show very consistent degrees of actual conditional cooperation throughout the multiple-period public good game no matter with whom they are matched. Only for those subjects that have been classified as free-riders we find some evidence for effects of social identity on conditional cooperation. In in-group matching, free-riders seem to reciprocate expectations on their group members' contribution that range from 10 to 18 by higher own contributions than when interacting with out-group members. Yet, all in all, our study clearly reinforces that expectations are a very strong motivational factor for cooperation, which most often dominates differences in cooperation strategies.

In terms of policy implications our results point to the paramount importance of managing individuals beliefs on the contribution levels of the whole group. Even if subjects interact with members of different identities, it is their expectations and not predominantly the degree of how they reciprocate these expectations, which ultimately guides their cooperation behavior. Thus, in an environment consisting of heterogeneous identities, governmental policy that places special importance on convincing groups of high mutual cooperation may prove successful in raising contribution levels. 


\section{Appendix}

\subsection{OLS-Regression on Treatment Effects on Contributions and Expectations}

\begin{tabular}{|c|c|c|}
\hline \multirow[t]{2}{*}{ Linear Regression (OLS) } & \multicolumn{2}{|c|}{ Model } \\
\hline & $\begin{array}{c}\text { (1) } \\
\text { Contributions }\end{array}$ & $\begin{array}{c}(2) \\
\text { Expectations }\end{array}$ \\
\hline Ingroup & $\begin{array}{c}1.5006^{\star \star} \\
(0.730)\end{array}$ & $\begin{array}{c}1.7198^{\star \star \star} \\
(0.638)\end{array}$ \\
\hline Outgroup & $\begin{array}{l}0.0944 \\
(0.729)\end{array}$ & $\begin{array}{l}0.2532 \\
(0.622)\end{array}$ \\
\hline Period & $\begin{array}{c}-0.3053^{* * *} \\
(0.037)\end{array}$ & $\begin{array}{c}-0.3311^{* * *} \\
(0.038)\end{array}$ \\
\hline Constant & $\begin{array}{c}7.5952^{\star \star \star} \\
(0.532)\end{array}$ & $\begin{array}{c}8.3716^{\star \star \star} \\
(0.408)\end{array}$ \\
\hline Ingroup - Outgroup = 0 & $p=0.0556$ & $p=0.0271$ \\
\hline Observations & 3,000 & 3,000 \\
\hline R-squared & 0.031 & 0.046 \\
\hline
\end{tabular}

around individuals, sign. levels: *** $p<0.01,{ }^{* *} p<0.05,{ }^{*} p<0.1$

\subsection{Display of Average Conditional Contributions in Period 1 of Stage C}

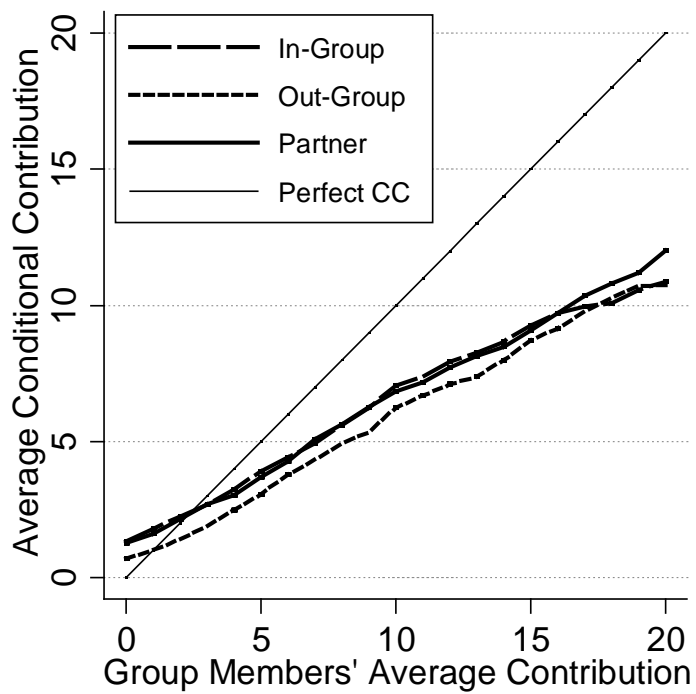

Figure 7: Average Conditional Contributions in Period 1 of Stage C 


\subsection{Test for Significant Differences in Marginal Effects of Model 4 in Table 2}

\begin{tabular}{|c|c|c|c|}
\hline Expectation & $\begin{array}{l}\text { H0: Marginal Effect of } \\
\text { In-Group Matching = } \\
\text { Matching }\end{array}$ & $\begin{array}{l}\text { ectation on Con } \\
\text { jinal Effect in } 0\end{array}$ & $\begin{array}{l}\text { tribution } \\
\text { ut-Group }\end{array}$ \\
\hline 0 & $\operatorname{chi} 2(1)=1.50$ & Prob $>$ chi $2=$ & 0.2204 \\
\hline 1 & $\operatorname{chi} 2(1)=0.73$ & Prob $>$ chi $2=$ & 0.3922 \\
\hline 2 & $\operatorname{chi} 2(1)=0.25$ & Prob $>$ chi2 $=$ & 0.6170 \\
\hline 3 & $\operatorname{chi} 2(1)=0.03$ & Prob $>$ chi2 $=$ & 0.8558 \\
\hline 4 & $\operatorname{chi} 2(1)=0.01$ & Prob $>$ chi $2=$ & 0.9189 \\
\hline 5 & $\operatorname{chi} 2(1)=0.13$ & Prob $>$ chi $2=$ & 0.7175 \\
\hline 6 & $\operatorname{chi} 2(1)=0.37$ & Prob $>$ chi $2=$ & 0.5409 \\
\hline 7 & $\operatorname{chi} 2(1)=0.74$ & Prob $>$ chi $2=$ & 0.3882 \\
\hline 8 & $\operatorname{chi} 2(1)=1.27$ & Prob $>$ chi $2=$ & 0.2593 \\
\hline 9 & $\operatorname{chi} 2(1)=2.01$ & Prob $>$ chi2 $=$ & 0.1558 \\
\hline 10 & $\operatorname{chi} 2(1)=3.07$ & Prob $>$ chi2 $=$ & 0.0799 \\
\hline 11 & $\operatorname{chi} 2(1)=4.59$ & Prob $>$ chi2 $=$ & 0.0322 \\
\hline 12 & $\operatorname{chi} 2(1)=6.85$ & Prob $>$ chi2 $=$ & 0.0089 \\
\hline 13 & $\operatorname{chi} 2(1)=10.25$ & Prob $>$ chi2 $=$ & 0.0014 \\
\hline 14 & $\operatorname{chi} 2(1)=15.02$ & Prob $>$ chi2 $=$ & 0.0001 \\
\hline 15 & $\operatorname{chi} 2(1)=19.39$ & Prob $>$ chi2 $=$ & 0.0000 \\
\hline 16 & $\operatorname{chi} 2(1)=17.97$ & Prob $>$ chi2 $=$ & 0.0000 \\
\hline 17 & $\operatorname{chi} 2(1)=11.24$ & Prob $>$ chi2 $=$ & 0.0008 \\
\hline 18 & $\operatorname{chi} 2(1)=5.64$ & Prob $>$ chi2 $=$ & 0.0175 \\
\hline 19 & $\operatorname{chi} 2(1)=2.55$ & Prob $>$ chi $2=$ & 0.1103 \\
\hline 20 & $\operatorname{chi} 2(1)=1.00$ & Prob $>$ chi2 $=$ & 0.3176 \\
\hline
\end{tabular}

\subsection{Instructions to the Experiment ${ }^{29}$}

Welcome to the experiment! Thank you very much for your participation.

If you read the following instructions carefully, you get the chance of winning money additional to the $€ 2.50$, which you receive in any case. Your earnings will depend on your decisions and on those by the other players in your group. At the end of the experiment all sums of money, which you will have earned through your decisions, will be counted up and given to you personally and in cash.

It is forbidden to speak during the experiment. If you have any questions, please raise your hand. A member of our team will come to you and answer your question privately.

We will be talking about points rather than Euros in the course of the experiment. Hence, your total income will be calculated in points in the first instance. The total number of points which you will achieve during the experiment will be converted in Euros at the end, using the following equation:

\footnotetext{
${ }^{29}$ Instructions in German language are available upon request (matthias.lankau@wiwi.uni-goettingen.de).
} 


$$
1 \text { Punkt }=3 \text { Cents }
$$

All participants will be divided in groups with 3 players each. Except for us, i.e. the conductors of the experiment, nobody will know who is in which group. All decisions will be made anonymously and your identity will neither be revealed during the experiment nor in public.

Each task of the experiment has its own instructions, which you have to read step by step. While doing so, please consider the respective hints which will appear on the monitor.

Please click on OK when you are ready.

\title{
The Decision and its Conditions
}

Later, you will be informed about the experiment's procedure in detail. Now, we would like to introduce the basic conditions for your decisions. Some example exercises can be found subsequently.

At each point in time, you will be a member of a group consisting of $\mathbf{3}$ players. In every task, you hold 20 points. Your task is to decide whether you deposit these 20 points on a private account or whether you want to invest them fully or partly in a project. Each point which you do not invest in a project will be automatically deposited on your private account.

\section{Your income from your private account:}

For each point which you deposit on your private account (and, therefore, you do not invest in the project), you will earn one point. Hence, a deposit of 20 points on your private account will produce an income of 20 points from your private account. If you, for instance, deposit 6 points on your private account, you will earn 6 points from this account. Nobody except you will earn anything from your private account.

\section{Your income from the project:}

All group members will profit equally from your contribution to the project. Vice versa, you profit from the investments by other group members. The income every member gets from the project is calculated as follows:

income from the project $=$ (sum of all contributions to the project) $\times 0,4$

Should the sum of all contributions to the project be, for example, 30 points then you and all other group members gain $(30 \times 0.4)=12$ points each from the project. Should the sum of all contributions to the project be, for example, 10 points then you and all other group members gain $(10 \times 0.4)=4$ points each from the project.

\section{Your total income:}

Your total income is the sum of your income from your private account and your income from the project.

income from the private account ( $=20-$ your contribution tot he project)

+ income from the project (=sum of all contributions to the project $\times 0,4$ )

\author{
total income
}




\section{Exercises}

Please complete the following exercises. They do merely serve the purpose of familiarising you with the calculation of the different sorts of income which may occur to you when making different decisions on the use of the 20 points starting capital.

Please complete all the exercises. While calculating, you may use the calculator function on the monitor. When you are done, you have to enter your results in the computer.

1. Each group member has 20 points at their disposal. Imagine that all three group members (including yourself) do not contribute anything to the project.

a. What is your total income? .....

b. What is the total income of each of the other group members? .....

2. Each group member has 20 points at their disposal. You invest 20 points in the project. The other two group members also contribute 20 points to the project.
a. What is your total income?
b. What is the total income of each of the other group members? .....

3. Each group member has 20 points at their disposal. The other two group members contribute 10 points each (i.e., 20 points in total) to the project.

a. What is your total income if you, additional to the 20 points, contribute 0 points to the project? .....

b. What is your total income if you, additional to the 20 points, contribute 5 points to the project? .....

c. What is your total income if you, additional to the 20 points, contribute 15 points to the project? .....

4. Each group member has 20 points at their disposal. You contribute 7 points to the project.

a. What is your total income if the other group members, additionally to your 7 points, contribute 1.5 points each, i.e., 3 points in total, to the project? .....

b. What is your total income if the other group members, additionally to your 7 points, contribute 4 points each, i.e., 8 points in total, to the project? .....

c. What is your total income if the other group members, additionally to your 7 points, contribute 9 points each, i.e., 18 points in total, to the project? ..... 


\section{First Task}

You are now the member of a group of three, which was put together randomly.

The task contains the decision which was described at the beginning and is only conducted once.

As you know, you have $\mathbf{2 0}$ points at your disposal, which you can either invest in the project or deposit on your private account.

In this task, every group member has to make two types of decisions, which we will term (1) the "unconditional" contribution to the project, or the (2) "conditional" contribution to the project (the contribution chart), respectively.

Both decisions are vital for your income from this task. So please make your decisions thoughtfully.

Step 1: Your Unconditional Contribution to the Project

Please determine how many of your points you, without knowing the contributions of the other group members, want to invest in the project. Please enter this amount into the following computer screening:

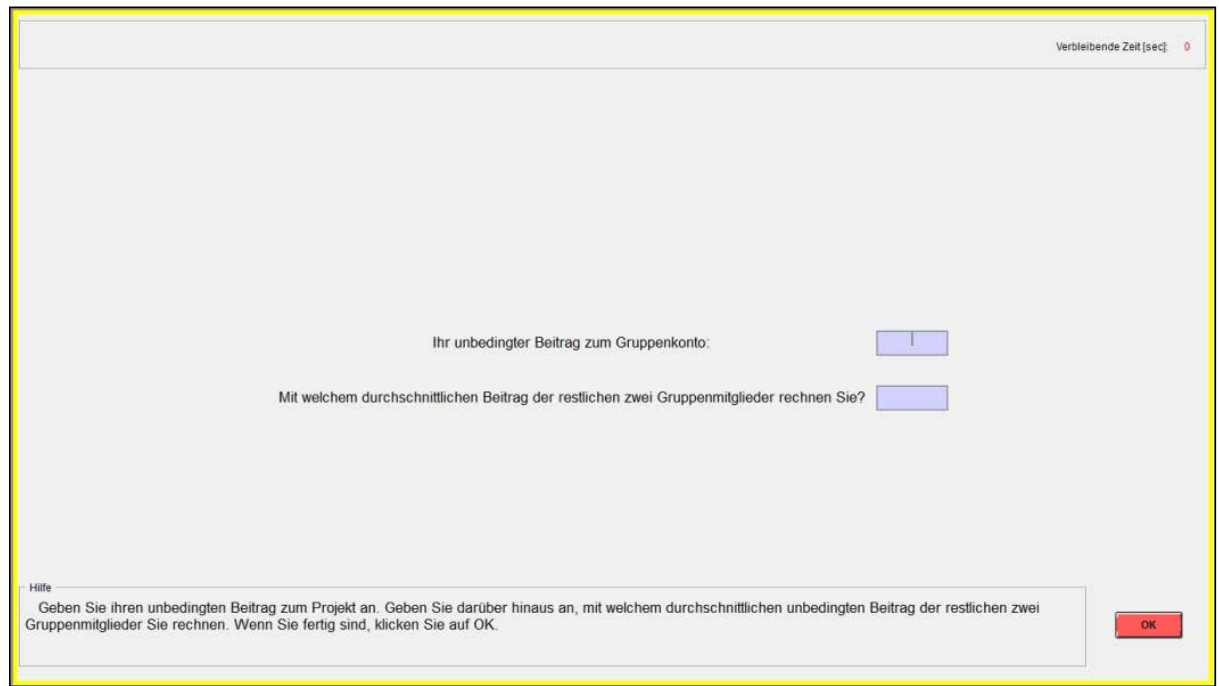

Please state also what you consider each of the other two group members to contribute to the project (average amount of money they invest in the project).

- Should your estimation be exact you receive three points additional to your income from this task.

- Should your estimation vary by one point you receive two points.

- Should your estimation vary by two points you receive one point.

— No points will be given to you if your estimation varies by more than two points.

Once you have made both statements, please click on OK.

Step 2: Your Conditional Contribution to the Project - the Contribution Chart

With your second decision you have to fill in a contribution chart. In the contribution chart you have to enter your contribution to the project for every possible (rounded up) contribution for the other group members. Hence, you can, dependent on the average contribution of the others, determine your decision on your contribution. You will get a clear hint of what to do when you take a look at the following screen. 


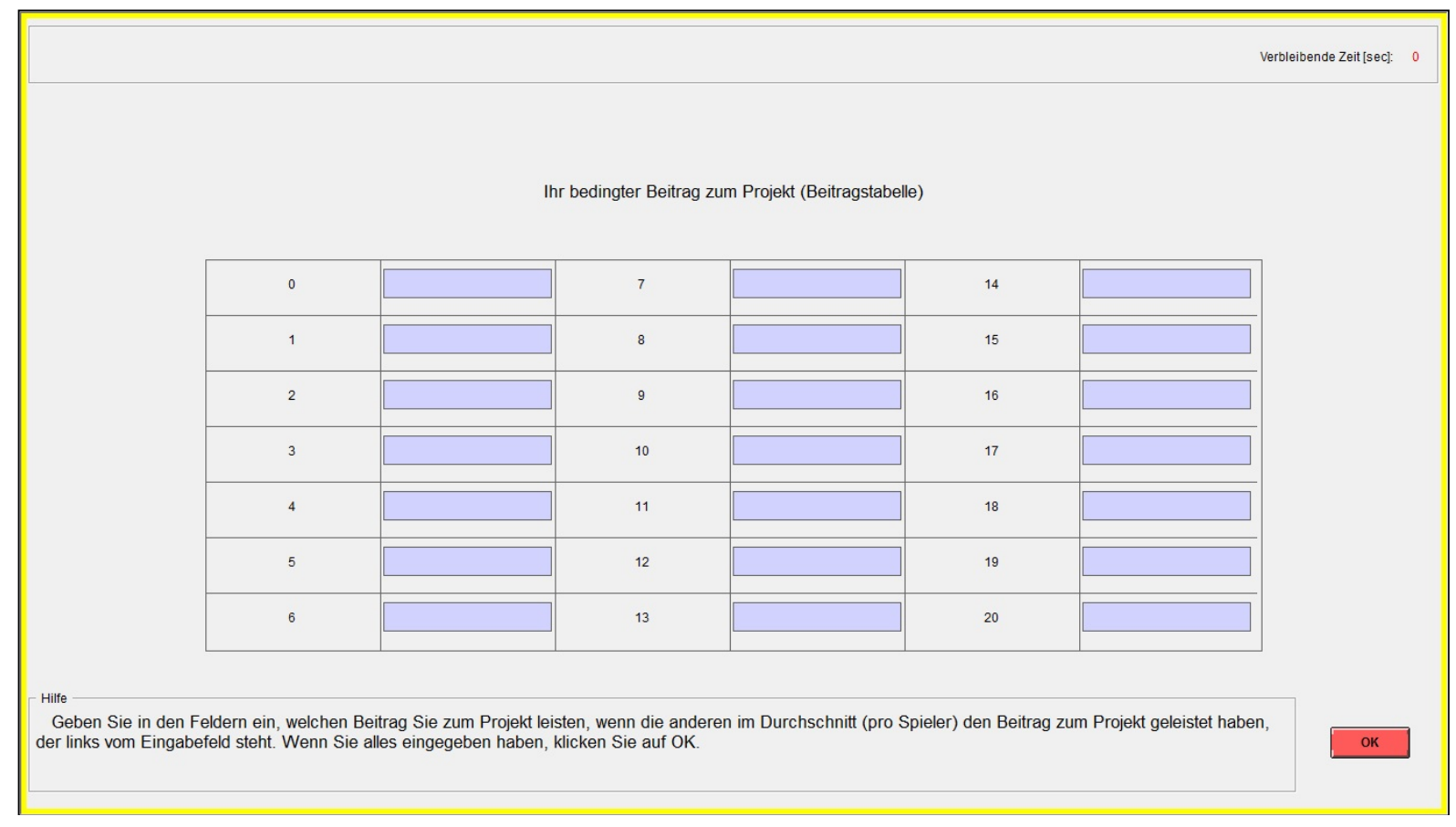

The numbers left to the boxes mark the possible average contributions which the other members make to the project. You just have to enter in each box how much you, under the condition that the others make their average contributions, want to invest in the project. You have to make an entry in each box.

For example, you have to enter how many points you want to invest in the project if the other group members contribute 0 points; how many points you invest if the others contribute 1, 2 or 3 points and so on and so forth. You can enter integral numbers ranging from 0 to 20 in each box.

Once you have typed a number in each box, please click on OK.

After all participants in the experiment made their decision on their conditional contribution and filled in the contribution chart, one member of each group is selected at random. For these selected members only the contribution chart is relevant for their decisions and payoff. For the other two group members, who were not selected by the random choice mechanism, only the unconditional contribution is relevant for their decisions and payoff. The average of both unconditional contributions by these two group members defines which contribution by the selected member shall be invested in the project.

When you make the decision on your unconditional contribution and fill in the contribution chart, you do of course not know if you will be picked at random. Hence, you have to make both decisions carefully, because both can become relevant for you. The following examples will explain the procedure:

Example 1: You are selected by the random choice mechanism. Therefore, the contribution chart is relevant for your payoff. For the other two group members the unconditional contributions are relevant.

Let us assume that the other two group members invest 0 and 4 points in the project, which would mean an average contribution of two points. If you entered in the contribution chart that you would invest 1 point if the others averagely invested 2 points, then this would make a total contribution of $0+4+1=5$ points to the project. All group members would then earn $5 \times 0.4=2$ points from the project plus the respective incomes from their private accounts, in your case $20-1=19$ points. Your income would then be 21 points. 
Example 2: You are not selected by the random choice mechanism. For you and another group member then your unconditional contribution to the project is the relevant decision.

Let us assume that your unconditional contribution to the project is 16 points, the contribution by the other group member is 20 points. This makes an average contribution of 18 points to the project. Should the player who was selected by the random choice mechanism have stated that he or she would contribute 1 point to the project if the other group members averagely invested 18 points, then the total contribution to the project would be $16+20+1=37$ points. All group members then would earn $37 \times 0.4=14.8$ points from the project additional to their respective income from their private accounts. In your case you would earn $20-16=4$ points from your private account, which would then make a total income of 18.8 points.

\section{The Random Choice Mechanism}

At the beginning of this game each group member receives a number between 1 and 3 . As you might remember, one participant, namely no. 8 , was selected at the beginning of the experiment. This participant will dice a number between 1 and 6 after all participants decided on their unconditional contribution and filled in the contribution chart. The numbers 1 and 2 stand for group member one, 3 and 4 for group member two and 5 and 6 for member three. Participant no. 8 will enter these in the computer. In case no. 8 dices the numbers which correspond to your member number, the contribution chart will be relevant for your decisions and payoff and for the other group members the unconditional contribution will be relevant. In any other case the unconditional contribution is relevant for you.

Please click on OK once you have read and understood the instructions.

\section{Second Task}

Please note: Do not open the attached envelope before you are asked to do so!

For the second task, you will be arbitrarily assigned a new group, which will be marked by a specific colour.

Only those solutions which are given correctly by ALL THREE group members will be considered correct in this group task.

During this task the group members are allowed to communicate with each other. By doing so, they can find a solution together. On the left hand side of the computer screen a chat box is positioned, which can be used for communication. Your conversation will be recorded. You have $\mathbf{1 0}$ minutes to solve the task. Only within this time span are you able to communicate with your team members. Please take into account that every group member has to type in the solutions which will have been found by your group. You have to click on OK before the $\mathbf{1 0}$ minutes have run out. The time left will be shown to you in the upper right hand corner of your screen.

All participants will be shown a picture and a list of objects. The task is to find the hidden objects in the picture. The inscriptions on the left and the upper side give the numbers of the lines and columns. You are asked to insert this information in the boxes which will be shown on the right hand side of the screen. The first box refers to a line, the second to a column. An example for this exercise is given below. 

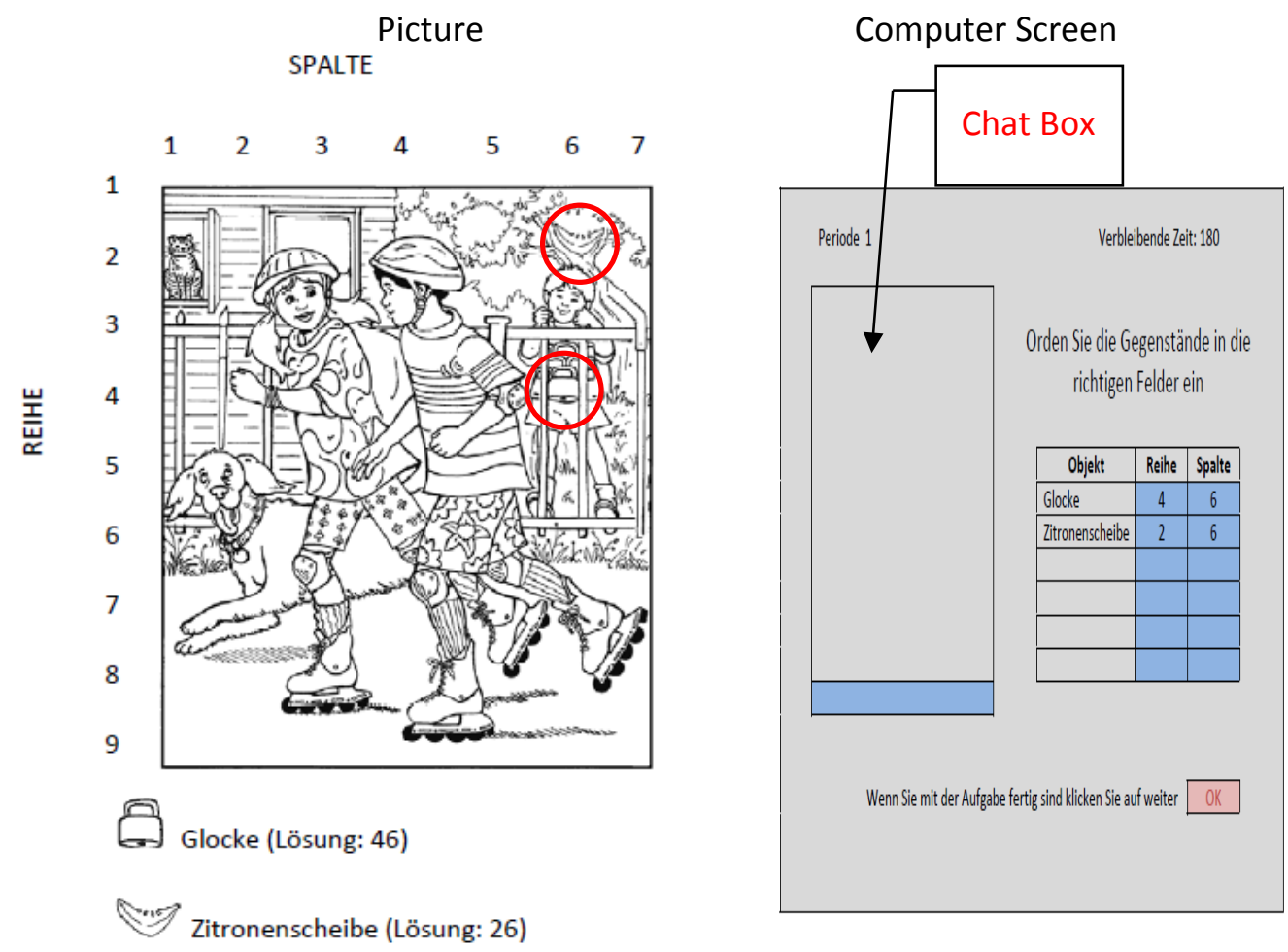

The group which finds most of the objects in the $\mathbf{1 0}$ minutes time is the winner group. At the end of the experiment you will be informed whether you are a member of the winner group. In this case, you will receive a congratulation message.

Please click on OK when you are ready.

\section{Third Task}

For the third task, you will work with the members of your group with whom you solved the picture puzzle in the second task.

This game is also based on the decision as introduced above. However, it consists of multiple rounds. The exact number of rounds is determined arbitrarily and varies from $\mathbf{1 1}$ to $\mathbf{1 5}$ rounds.

In each round you again have $\mathbf{2 0}$ points at your disposal. Please decide how many of your points you would like to invest in the project and how many you would like to put on your private account.

The First Round

In the first round your contribution to the project is again composed of two decisions, (1) the unconditional contribution to the project and your estimation regarding the average contribution by the other two group members and (2) the contribution chart, with which you can make your decisions dependent on the other group members' contribution behaviour.

The Other Rounds

All other rounds contain only one check of the project contribution as well as of your estimation how much the other two group members averagely contribute to the project. Hence, in these rounds, there will be no contribution chart.

All Rounds 
In each round you have the possibility to gain additional points by estimating the average contribution of the other group members.

— for an exact estimation: three points

— for a variation by one point: two points

— for a variation by two points: one point

— for higher variations: no points

After each round you will be informed about the total contribution to the project, the average contribution by the other group members and your total income from each round.

Please click on OK when you are ready. 


\section{References}

Akerlof, G.A., Kranton, R.E., 2010. Identity economics: How our identities shape our work, wages, and well-being. Princeton, N.J., Woodstock: Princeton University Press.

Alesina, A., Baqir, R., Easterly, W., 1999. Public Goods and Ethnic Divisions*. Quarterly Journal of Economics 114 (4), 1243-1284.

Andreoni, J., 1988. Why free ride? : Strategies and learning in public goods experiments. Journal of public economics 37 (3), 291-304.

Andreoni, J., Croson, R., 2008. Chapter 82 Partners versus Strangers: Random Rematching in Public Goods Experiments. In: Charles R. Plott and Vernon L. Smith (Ed.). Handbook of Experimental Economics Results: Elsevier, 776-783.

Bicskei, M., Lankau, M., Bizer, K., 2013. Negative reciprocity and related emotions in homogenous and heterogeneous groups: An experimental study with peer-punishment and social identity. Georg-August-Universität Göttingen.

Burlando, R., Guala, F., 2005. Heterogeneous Agents in Public Goods Experiments. Experimental Economics 8 (1), 35-54.

Charness, G., Rigotti, L., Rustichini, A., 2007. Individual behavior and group membership. The American Economic Review 97 (4), 1340-1352.

Chaudhuri, A., 2011. Sustaining cooperation in laboratory public goods experiments: a selective survey of the literature. Experimental Economics 14 (1), 47-83.

Chen, R., Chen, Y., 2011. The Potential of Social Identity for Equilibrium Selection. American Economic Review 101 (6), 2562-89.

Chen, Y., Li, S.X., 2009. Group Identity and Social Preferences. The American Economic Review 99 (1), 431-457.

Currarini, S., Mengel, F., 2012. Identity, Homophily and In-Group Bias. FEEM Working Paper No. 37.2012. http://papers.ssrn.com/sol3/papers.cfm?abstract_id=2088744 (accessed 17 August 2012).

Dawes, R.M., 1980. Social Dilemmas. Annu. Rev. Psychol 31 (1), 169-193.

Dawes, R.M., 1989. Statistical criteria for establishing a truly false consensus effect. Journal of Experimental Social Psychology 25 (1), 1-17.

Eaton, B.C., Eswaran, O.M., Robert J. Netzer, 2011. Us and Them: the origin of identity, and its economic implications. Canadian Journal of Economics 44 (3), 719-748.

Eckel, C.C., Grossman, P.J., 2005. Managing diversity by creating team identity. Journal of Economic Behavior \& Organization 58 (3), 371-392.

Falk, A., Fischbacher, U., 2006. A theory of reciprocity. Games and Economic Behavior 54 (2), 293315. 
Fehr, E., Fischbacher, U., 2002. Why social preferences matter- the impact of non-selfish motives on competition, cooperation and incentives. The Economic Journal 112 (478), C1-C33.

Fischbacher, U., 2007. z-Tree: Zurich toolbox for ready-made economic experiments. Experimental Economics 10, 171-178.

Fischbacher, U., Gächter, S., 2010. Social preferences, beliefs, and the dynamics of free riding in public goods experiments. The American Economic Review 100 (1), 541-556.

Fischbacher, U., Gächter, S., Fehr, E., 2001. Are people conditionally cooperative? Evidence from a public goods experiment. Economics Letters 71 (3), 397-404.

Goette, L., Huffman, D., Meier, S., 2006. The impact of group membership on cooperation and norm enforcement: Evidence using random assignment to real social groups. The American Economic Review 96 (2), 212-216.

Ibañez Diaz, M., Schaffland, E., 2012. Leadership Working Behavior and Group Cooperation: An Experiment of Group Identity: Unpublished Manuscript. Georg-August-Universität Göttingen.

Keser, C., van Winden, F., 2000. Conditional Cooperation and Voluntary Contributions to Public Goods. Scandinavian Journal of Economics 102 (1), 23.

Lankau, M., Bicskei, M., Bizer, K., 2012. Cooperation preferences in the provision of public goods: An experimental study on the effects of social identity, Cege Discussion Papers 148. Georg-AugustUniversität Göttingen. http://papers.ssrn.com/sol3/papers.cfm?abstract_id=2191469 (accessed 05 February 2013).

McLeish, K.N., Oxoby, R.J., 2007. Identity, cooperation, and punishment, IZA Discussion Paper 2572. Institute for the Study of Labor (IZA).

http://papers.ssrn.com/sol3/papers.cfm?abstract_id=961379 (accessed 16 August 2013).

Paolo Mauro, 1995. Corruption and Growth. The Quarterly Journal of Economics 110 (3), 681-712.

Selten, R., 1967. Die Strategiemethode zur Erforschung des eingeschränkt rationalen Verhaltens im Rahmen eines Oligopolexperiments. In: Sauerland, H. (Ed.). Beiträge zur experimentellen Wirtschaftsforschung, Tübingen: Mohr, 136-168.

Solow, J.L., Kirkwood, N., 2002. Group identity and gender in public goods experiments. Journal of Economic Behavior \& Organization 48 (4), 403-412.

Tajfel, H., Turner, J., 1979. An Integrative Theory of Intergroup Conflict. In: Worchel, S., Austin, W. (Eds.). The Psychology of Intergroup Relations, Monterey: CA: Brooks/Cole, 33-47.

Volk, S., Thöni, C., Ruigrok, W., 2012. Temporal stability and psychological foundations of cooperation preferences. Journal of Economic Behavior \& Organization 81 (2), 664-676.

Xiao-Ping, C., 1996. The Group-Based Binding Pledge as a Solution to Public Goods Problems. Organizational Behavior and Human Decision Processes 66 (2), 192-202.

Yamagishi, T., Jin, N.a.K.T., 1999. Bounded Generalized Reciprocity: Ingroup Boasting and Ingroup Favoritism. Advances in Group Processes 16, 161-197.

Yamagishi, T., Kiyonari, T., 2000. The Group as the Container of Generalized Reciprocity. Social Psychology Quarterly 63 (2), 116-132. 


\title{
CHAPTER VI
}

\section{How Peer-Punishment Affects Cooperativeness in Homogeneous and Heterogeneous Groups}

A Public Goods Experiment with Social Identity

\author{
Marianna Bicskei, Matthias Lankau, Kilian Bizer
}




\section{INTRODUCTION}

When a public good is provided, the social optimum is reached if all group members bear the costs and contribute to its provision. However, since no one can be excluded from the benefits the public good generates there is a strong incentive for self-interested individuals to free-ride on their peers' contributions. Although free-riding does not reveal itself as prominent a behavioral pattern as classic economic theory predicts, experimental evidence suggests that there is still a considerable lack in cooperativeness lowering social efficiency. Nevertheless, previous research showed that individuals have a proclivity to adjust their behavior depending on the institutional environment in which the public good is provided. In this respect, two factors are of crucial importance. Firstly, social identity of group members with whom individuals interact influences cooperation. Recently, Lankau et al. (2012) demonstrated that individuals reveal the preference for consistently higher conditional cooperation when matched with group members with a common identity (in-group matching) as opposed to being matched with individuals saliently belonging to different social groups (out-group matching) or randomly matched individuals. This in-group bias in the propensity to cooperate seems to be a deeply rooted phenomenon of human interactions (Eaton, Eswaran, and Oxoby 2011) and has been confirmed by numerous contributions both in psychological and economic experimental research (cf. for instance Taifel and Turner 1979; Chen and Li 2009). Secondly, it is a well-established phenomenon that the possibility of costly decentralized punishment by individual group members for uncooperative behavior strongly enhances cooperation (cf. Fehr and Gächter 2000; Masclet et al. 2003). Clearly, both institutions impact on people's cooperativeness and are thus highly relevant to the maintenance of common resources. However, their interaction in a public good environment did not receive any academic attention, so far. Consequently, the goal of this article is to provide initial evidence on 
subjects' cooperativeness in the provision of public goods in case their social identity is salient and there is a possibility to punish group members for misbehavior. In particular, we ask how the institution of costly peer-punishment impacts subjects' cooperativeness in homogeneous groups composed of members sharing a common social identity and in heterogeneous groups consisting of members of different identities. For this purpose, we artificially induce social identity with the help of a simple group task that subjects solve jointly by communicating anonymously via chat. Our experiment is based on one-shot public good games using the strategy method (Fischbacher, Gächter, and Fehr 2001; Selten 1967), which allows us to observe contributions to the public good conditional on every possible average contribution level of the remaining group members. It thus elicits subjects' cooperativeness in more detail than unconditional contributions alone, and serves us as a preferred measure of cooperativeness. What is more, it enables us to classify subjects into different cooperation types depending on their initial cooperation strategy providing deeper insights into cooperative adjustments under different institutional settings.

In summary, our findings provide hints that group composition in terms of individuals' identity decisively influences to what extent subjects alter their cooperativeness under punishment compared to equal matching conditions that are free of peer-sanctions. In particular, we prove that subjects who are matched with out-group members increase their cooperativeness to the highest degree. Based on the example of free-riders we are able to show that this is predominantly caused by an anticipation of comparatively strong punishment for uncooperative behavior by group members of different identities. What is more, under punishment subjects' cooperativeness is equal within in- and out-groups essentially revealing that peer-punishment eliminates the in-group bias that is present without peer-punishment. 
The remainder of the paper is structured as follows: Section 2 deals with the relevant literature and presents our hypotheses. While Section 3 introduces the experimental design, Section 4 discusses the relevant findings. The article ends with a conclusion in Section 5.

\section{LITERATURE REVIEW AND RESEARCH HYPOTHESES}

When people face social dilemmas, individual interest is at odds with social interest. Thus, much theoretical and empirical research has been devoted to understand how to enhance voluntary contributions to public goods. Research in experimental economics demonstrated that social identity as "the individual's self-concept derived from perceived membership in social groups” (Charness, Rigotti, and Rustichini 2007, 1342) and also peer-punishment are prone to foster cooperativeness in the provision of public goods.

To begin with, the experimental economic research on social identity is rooted in the social identity theory introduced by Tajfel and Turner (1979). The core element of this theory is the analysis of the psychological foundations of discriminatory behavior, which is determined through three processes. Accordingly, individuals relatively quickly sort themselves by certain social categories such as gender or race (categorization) and derive self-esteem from that (in-)group (identification). These processes are subsequently complemented by individuals comparing their in-group with out-groups they do not identify with (comparison). Taken together, these processes generally trigger in-group favoritism and thus out-group discrimination commonly referred to as in-group bias (cf. Tajfel and Turner 1986; Hoff and Pandey 2006). ${ }^{1}$ By now, there are several studies that focus on the effects of social identity on

\footnotetext{
${ }^{1}$ See Chen and Li (2009) for a detailed account on theoretical and empirical findings on social identity theory.
} 
subjects' cooperativeness in a public good context. Firstly, Eckel and Grossmann (2005) study the impact of team identification on cooperation in a repeated-play public good game with various degrees of enhanced team identification. The authors find that strengthening team identification (e.g., prior group task before the game, creation of in-group/out-group conflict) yields consistently higher cooperation levels and less free-riding. Secondly, Lankau et al. (2012) explicitly study the impact of social identity on cooperation preferences in public goods provision. Using the strategy method in multiple one-shot public good games, the authors confirm the existence of an in-group bias. Specifically, they find that when subjects interact with members of their own identity they show a consistently higher preference for conditional cooperation and thus less self-serving bias $^{2}$ than when matched with out-group and random individuals. What is more, even the least socially oriented cooperation types, initially identified as free-riders, reveal higher levels of conditional cooperation in in-group matching. Other recent studies documenting subjects' increased cooperativeness in providing public goods when bound together by a common identity include Blackwell and McKee (2013), Chakravarty and Fonseca (2012 and 2013). Similarly, various other experiments outside the public goods context demonstrate that social identity positively influences social welfare when individuals interact with in-group members as opposed to out-group members (cf. Chen and Li 2009; Charness, Rigotti, and Rustichini 2007; McLeish and Oxoby 2011; Goette, Huffman, and Meier 2006; Chen and Chen 2011). ${ }^{3}$ In sum, the existing experimental research provides solid evidence that salient social identity in terms of group composition

\footnotetext{
${ }^{2}$ Subjects reveal self-serving bias when they do not reciprocate their team members' contributions by an equal own contribution (perfect conditional cooperation), and depart in the selfish direction.

${ }^{3}$ For a detailed review of these studies, see Lankau et al. (2012).
} 
matters with regard to cooperativeness, and confirms the well-established in-group bias in human interactions. ${ }^{4}$

The possibility of costly decentralized punishment by individual group members without central authority has been identified as an effective instrument to maintain cooperation in the provision of public goods, as well. Initially, Fehr and Gächter (2000) studied the punishment institution in an environment where both the offender and the punisher bear tangible costs of the penalties, though one punishment point costs the offender three times more than the punisher. Specifically, the authors conducted two treatments with and without punishment and distinguished between stranger ${ }^{5}$ and partner matching. ${ }^{6}$ In both settings without punishment constraints they found that contributions to the public good decreased over the ten periods approaching almost complete free-riding. On the contrary, contribution levels steadily increased towards full cooperation under punishment in the partner matching condition. ${ }^{7}$ In another experiment Fehr and Gächter (2002) have identified similar tendencies for strangers, as well. ${ }^{8}$ Contribution levels increased under punishment, while they decreased when the opportunity to punish was removed. Likewise, Masclet et al. (2003) and Noussair and Tucker (2005) demonstrated that the fear of being punished drives subjects to increase their contribution to the public good. What is more, several other studies have replicated the experiments of Fehr and Gächter and by and large confirmed their findings (cf. Anderson and

\footnotetext{
${ }^{4}$ For further research on in-group favoritism see Hermann et al. (2012).

${ }^{5}$ Stranger matching meant a random group assignment in each period.

${ }^{6}$ The composition of the group was stable over the periods.

${ }^{7}$ Full cooperation was declared as a dominant behavioral standard regardless whether the punishment or the non-punishment treatment was conducted firstly. However, this behavioral norm was not found in the stranger treatment.

${ }^{8}$ This experiment was designed identically to the previous experiment (Fehr and Gächter 2000) with the exception that punishment and non-punishment treatments were conducted only with strangers. In this study a subject could never meet another subject more than once during the game (perfect stranger matching).
} 
Putterman 2006; Bochet et al. 2006; Nikiforakis 2008; Page et al. 2005; Sefton et al. 2007). All in all, these findings confirm that costly peer-punishment motivates individuals to behave more cooperatively in long term interactions.

However, the question of how costly punishment precisely affects cooperation when social identity is salient and subjects are interacting either in homogenous or heterogeneous groups, has not been examined in a one-shot public goods environment, yet. ${ }^{9}$ Using two-person bargaining games in between-subjects design, McLeish and Oxoby (2007) provide some insight on how these institutions simultaneously influence cooperation. The authors induced group identity by letting groups jointly solve a series of questions via face-to-face communication. Next, pairs were randomly matched and informed about the other's group affiliation. After the proposer decided how much of his endowment to keep for himself and how much to allocate to the responder, in the punishment treatment the responder had the opportunity to engage in costly punishment by reducing the proposer's income by 1.5 points for each point given. They demonstrated, first of all, that cooperation expressed by the level of offers extended both with and without punishment is higher within in-groups than in outgroup matching. Secondly, they did not find significantly different cooperation levels between punishment and no-punishment treatments. This finding, however, contradicts previous research emphasizing that the threat of peer-punishment increases cooperation levels (see Fehr and Gächter 2000; 2002; Masclet et al. 2003 and Noussair and Tucker 2005). Summing up, these results provide only limited insights on two-person interactions. Even more so, we still lack evidence whether the assumptions regarding the effects of peer-punishment are valid

\footnotetext{
${ }^{9}$ The interaction of social identity and third-party punishment has been the focus of a few studies already. See for instance Goette et al. (2006; 2012). In contrast to our emphasis on peer-punishment, the punisher in these studies is an individual whom the violation does not affect economically (Goette, Huffman, and Meier 2012).
} 
and stable across groups, in which social identity is salient. This is, however, highly relevant since in real life most interactions are multilateral rather than bilateral.

Based on previous findings, we formulate the following research hypotheses. As extracted from the literature on public good games, peer-punishment usually tends to influence cooperation positively. Thus, we hypothesize conservatively that peer-punishment uniformly increases cooperativeness independent of whether subjects are matched with in-group or outgroup members.

Hypothesis 1 (Punishment Effect Hypothesis): The threat of peer-punishment equally impacts subjects' cooperativeness under social identity independent of group composition.

What is more, research on social identity has shown that subjects' cooperativeness is biased to their in-group members as opposed to out-group members. Consequently, in line with our Hypothesis 1 we expect that when peer-punishment is present identity homogeneous groups tend to show higher cooperation than heterogeneous ones.

Hypothesis 2 (In-Group Bias Hypothesis): Under punishment-threat subjects reveal higher cooperativeness when matched with in-group members than in out-group matching.

\section{EXPERIMENTAL DESIGN}

To test the hypotheses presented above, our experiment features both within- and betweensubject design elements and contains two types of treatments (see Table 1). The nopunishment (NP) treatments are based on a public good game in strategy method as introduced by Fischbacher et al. (2001). In the punishment (P) treatments we complement this 
public good game with monetary peer-punishment relying on a design of Noussair and Tucker (2005). ${ }^{10,11}$

In total, the experiment consists of three stages (see Table 1). The participants of the experiment were assigned to groups comprising three subjects. In Stage A subjects were randomly assigned to groups (random matching) and played a one-shot public good game in strategy method without punishment - both in the P and the NP-treatments. Each group member was endowed with 20 points, which could be invested either into a public good $\left(c_{i}\right)$, framed as a project or in their private account $\left(20-c_{i}\right)$. The following formula (Formula 1) denotes the payoff function without punishment for each individual $i$ :

\section{FORMULA 1:}

Payoff function without punishment

$$
\pi_{i}=20-c_{i}+0.4 \sum_{k=1}^{3} c_{k}
$$

Accordingly, it is more beneficial to contribute nothing to the project because every point invested returns only 0.4 points, while the private account yields exactly 1 point. Given 20 points endowment each, subjects were required to make two investment decisions, their unconditional and conditional contribution to the project. Hence, they were asked to decide how much of their endowment they would like to invest in the public good regardless of what the other group members contribute (unconditional contribution). Here, they were also asked for their expectations regarding the average unconditional contribution of the remaining group

\footnotetext{
${ }^{10}$ Please note that the NP- and P-conditions originate from two independent experiments (see Lankau et al. 2012 and Bicskei et al. 2013, respectively). The present paper merges both datasets in order to holistically analyze the effects of punishment on cooperation under social identity.

${ }^{11}$ We are really grateful that C. Noussair and S. Tucker as well as U. Fischbacher have provided us with their experimental protocols.
} 
members. Next, subjects had to fill out a contribution table consisting of 21 entries asking them how much they would invest in the project if their two group members invested on average 0 -20 points (conditional contribution). ${ }^{12}$ Afterwards, in order to render both decisions potentially payoff-relevant, a random mechanism ${ }^{13}$ chose one group member who had to contribute according to the conditional contribution decision. For the other two group members their unconditional contributions were thus applicable.

\section{TABLE 1}

Experimental Design

\begin{tabular}{|c|c|c|c|}
\hline Treatments & Stage A & Stage B & Stage C \\
\hline \multirow{3}{*}{$\begin{array}{l}\text { No-Punishment } \\
\text { (NP) }\end{array}$} & \multirow{3}{*}{$\begin{array}{c}\text { Random Matching } \\
\text { without } \\
\text { Punishment }\end{array}$} & \multirow{2}{*}{$\begin{array}{l}\text { Induction of } \\
\text { Social Identity }\end{array}$} & In-Group Matching (NP) \\
\hline & & & Out-Group Matching (NP) \\
\hline & & - & Random Matching (NP) \\
\hline \multirow{3}{*}{$\begin{array}{l}\text { Punishment } \\
\text { (P) }\end{array}$} & \multirow{3}{*}{$\begin{array}{c}\text { Random Matching } \\
\text { without } \\
\text { Punishment }\end{array}$} & \multirow{2}{*}{$\begin{array}{l}\text { Induction of } \\
\text { Social Identity }\end{array}$} & In-Group Matching (P) \\
\hline & & & Out-Group Matching (P) \\
\hline & & - & Random Matching (P) \\
\hline
\end{tabular}

The main purpose of Stage A was to elicit subjects' initial cooperativeness independent of any identity or punishment influences, which facilitated analyses of treatment effects in later stages of the experiment. Furthermore, it helped classifying subjects based on their revealed cooperativeness into free-riders and conditional cooperators ${ }^{14}$ (cf. Fischbacher et al. 2001;

\footnotetext{
${ }^{12}$ Average investments of the other group members were rounded to the next higher integer value.

${ }^{13}$ One participant in each session rolled a dice to determine the respective group member. This served the purpose of making clear to the subjects that both investment decisions were to be taken seriously.

${ }^{14}$ Technically, free-riders are those subjects that reveal a conditional contribution of zero independent of how much their group members contribute to the public good. Subjects are classified as conditional cooperators when showing a positive and significant $(\mathrm{p}<0.01)$ spearman rank-correlation coefficient between own conditional contributions to the public good and the average contributions of their group members.
} 
2010; Burlando and Guala 2005) allowing for a differentiated analysis of their behavioral adjustments in later stages.

Stage B contained the group task, which served the purpose to induce social identity within the laboratory. The design we used was introduced by Ibañez and Schaffland (2012) and is based on insights from Eckel and Grossman (2005) and Chen and Li (2009). ${ }^{15}$ The subjects were randomly reassigned to groups of different colors and they had to jointly find hidden objects in a picture and report their location given 10 minutes time. Group members were in connection via chat enabling them to communicate anonymously and discuss solutions with their group members. The answers were counted as correct only if each group member entered them correctly. This was a necessary step to foster coordination and render this task a true group exercise. The winning group was the one, which found the most objects. Since this task was intended to induce positive group experience (Eckel and Grossman 2005), only the winning team received a message of congratulation at the end of the experimental session. ${ }^{16}$ In the NP-treatments of Stage C subjects played a public good game similar to Stage A. In the P-treatments, after being informed how many points their group members contributed separately to the project, subjects had the possibility to distribute punishment points to each group member. ${ }^{17}$ On the one hand, the distribution of punishment points was costly for the punisher (see Table 2). On the other hand, each punishment point distributed reduced this stage's earning of the punished by $10 \%$. If a group member received 10 or more points his income from that stage was reduced by $100 \%$. In order to account for possible costs of this

\footnotetext{
${ }^{15}$ We are thankful that M. Ibañez and E. Schaffland have provided us with the instructions to their identity game.

${ }^{16}$ In order to avoid any income effects, there were no monetary incentives for winning this game.

${ }^{17}$ During the experiment we used the neutral phrase of disapproval points to avoid any negative associations with punishment.
} 
stage of the P-treatment, and also to avoid the possibility of monetary losses, subjects received a one-off lump-sum payment of 60 points in addition to the basic endowment of 20 points (see Formula 2).

TABLE 2

Punishment Points $\left(\mathrm{P}_{\mathrm{ik}}\right)$ and Cost of Punishment $(\mathrm{K})$

\begin{tabular}{llllllllllll}
\hline $\mathrm{P}_{i k}$ & 0 & 1 & 2 & 3 & 4 & 5 & 6 & 7 & 8 & 9 & 10 \\
$\mathrm{~K}\left(\mathrm{P}_{i k}\right)$ & 0 & 1 & 2 & 4 & 6 & 9 & 12 & 16 & 20 & 25 & 30 \\
\hline
\end{tabular}

FORMULA 2

Payoff function with punishment

$$
\begin{aligned}
\pi_{i}=\left(20-c_{i}\right. & \left.+0.4 \sum_{k=1}^{3} c_{k}\right) \times \frac{\max \left\{0,10-\sum_{k \neq i} P_{k i}\right\}}{10}-\left(\sum_{k \neq i} K\left(P_{i k}\right)\right) \\
& + \text { lumpsumpayment }
\end{aligned}
$$

In Stage C, three different matching protocols were in effect (see Table 1). On the one hand, subjects were either matched with members of their own identity, with whom they shared the same color when solving the group identity task in Stage B (in-group matching); or with members of different colors, thus different identities (out-group matching). Both matching conditions are together referred to ID matchings. In order to make group identity salient, the color of an individuals' group as well as the color of her group members was clearly indicated during the game both in in-group and out-group matching. On the other hand, we carried out a control treatment both in P- and NP-treatments, in which subjects were randomly assigned to a group (random matching) and played the same one-shot public good game as in the ID matching protocols, yet without participating in Stage B (see Table 1). 
The instructions were handed out successively, so that subjects learned the group assignment rule and whether they were in a P- or NP-treatment only at the relevant stage during the experiment. What is more, in the NP-treatments any information on contributions and payoffs was only revealed after the experiment's last stage. The same holds true for the P-treatments with the exception that in Stage C subjects were provided with necessary information on the contribution behavior of their group members in order to be able to make decisions about punishment points. At the end of Stage C, all subjects received detailed information on the earnings of Stage A and C and the final payment including the $2.5 €$ show-up fee. Moreover, in the P-treatments, subjects were only informed about the total sum of punishment points they received, yet they did not learn which group member punished them exactly.

\section{EMPIRICAL RESULTS}

The experiment was conducted in the laboratory of a European university from October 2011 to July 2012 using the software z-Tree (Fischbacher 2007). We collected the decisions of 384 subjects $^{18}$ from different faculties, specifically, 177 subjects participated in the NP- and 207 subjects in the P-treatments. The subjects were recruited from volunteers of the ORSEE system of the university and at the university’s cafeteria. The sessions took approximately 1.5 hours and the subjects earned $15 €$ on average including the show-up fee.

\section{A comparison of the effects of punishment on cooperativeness under social identity}

At first, we investigate how the anticipation of peer-punishment affects subjects' cooperativeness in different group compositions under social identity compared to a setting

\footnotetext{
${ }^{18}$ The proportion of males was 48 percent, and the average age of the subjects was 24 years.
} 
without such threat (NP-treatment). Please note that although the basic decision situation of stage $\mathrm{C}$ was equally based on the 20 points endowment received in both $\mathrm{P}$ and NP-treatments, in contrast to the NP-treatment subjects in the P-treatment were given additional 60 points endowment in order to avoid bankruptcy (see section III). Consequently, differences in cooperativeness between the $\mathrm{P}$ and NP-treatments may be influenced by this lump-sum payment, as well. We assume, however, that this influence is equal independent of with whom subjects are matched. Given this assumption, any difference in the effect of punishment between the three matching conditions under social identity should then only be due to the effects of punishment in the respective matching. Therefore, our subsequent analyses focus on a difference-in-difference approach.

In order to keep as much within-information as possible we analyze how subjects - in their respective treatments - adjusted their conditional contributions in Stage C as opposed to Stage A. Comparing these changes between the treatments allows drawing more precise conclusions regarding differences in cooperativeness than the analysis of behavioral strategies in the particular stages independently.

To this purpose, Figure 1 depicts to what extent subjects adjusted their conditional contributions in Stage C as opposed to Stage A with and without punishment in the three matching protocols. When interacting with out-group members, punishment seems to induce the highest increase in cooperativeness amounting to almost 5 points at its peak (i.e., when the average contribution of the others is twenty). Especially, when matched with in-group members behavioral adjustments to punishment seem to be lower. Running a diff-in-diff analysis confirms that the increase in cooperativeness is significantly higher in out-group than in in-group matching (see Table 3, Model A, row 10). Comparing out-group with random matching reveals that the changes in cooperativeness are higher when interacting with out- 
group members. Yet, this difference is not significant. All in all, we thus have to reject Hypothesis 1. Our results clearly demonstrate that punishment has a differing effect on cooperativeness depending on group composition.

Result 1: Under the threat of peer-punishment subjects increase their cooperativeness significantly stronger when matched with individuals saliently belonging to different identities than with individuals of their own identity.

FIGURE 1

The Effects of Punishment on the Average Change in Conditional Contributions

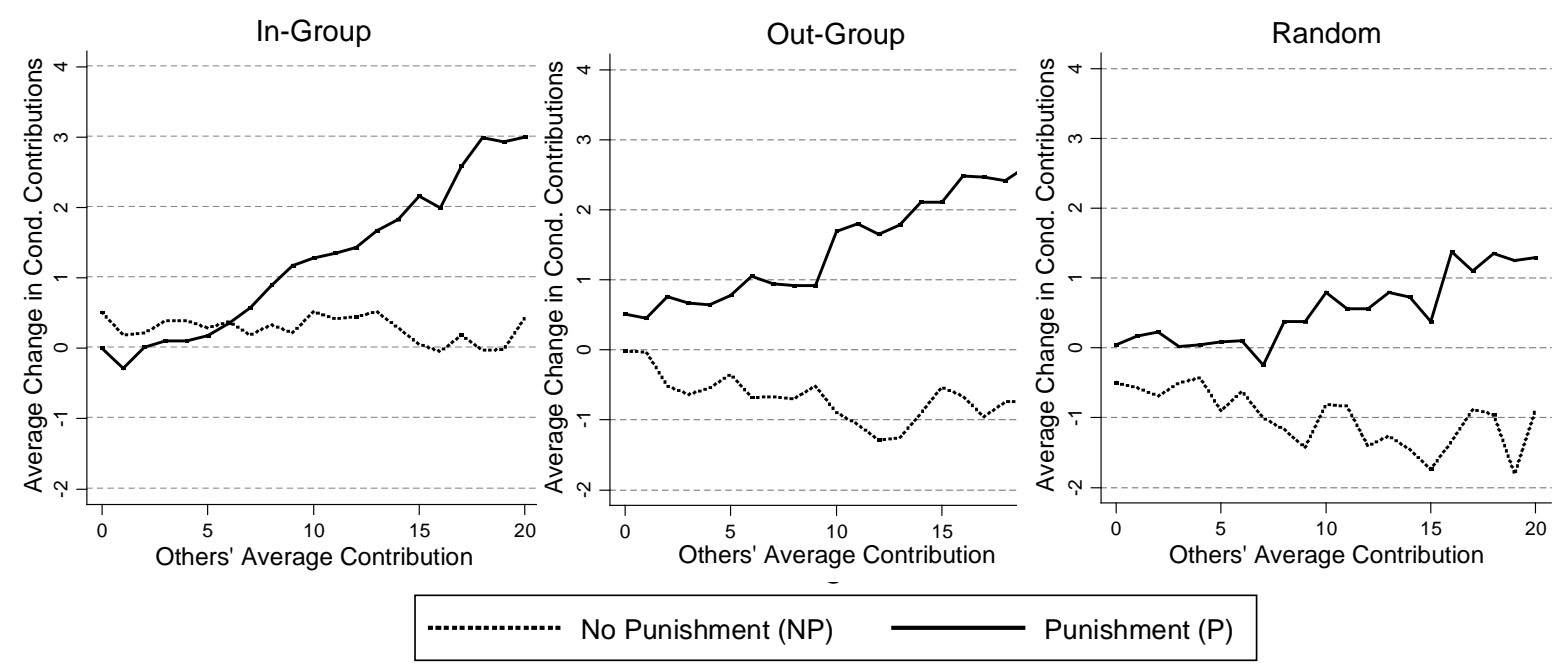


TABLE 3

The Impact of Punishment on Cooperativeness in Different Matching Conditions

\begin{tabular}{|c|c|c|c|c|c|c|c|}
\hline \multicolumn{3}{|l|}{ Linear Regression (OLS) } & \multicolumn{5}{|c|}{ Model } \\
\hline & & \multirow[b]{2}{*}{ Row } & \multirow{2}{*}{$\begin{array}{c}\text { (A) } \\
\text { All Subjects }\end{array}$} & \multirow{2}{*}{$\begin{array}{l}\text { (B) } \\
\mathrm{CCs}\end{array}$} & \multirow{2}{*}{$\begin{array}{l}\text { (C) } \\
\text { FRs } \\
\end{array}$} & \multirow{2}{*}{$\begin{array}{c}\text { (D) } \\
\text { Others }\end{array}$} & \multirow{2}{*}{$\begin{array}{c}\text { (E) } \\
\text { No FRs }\end{array}$} \\
\hline Change in Conditional $\mathrm{C}$ & Cooperation & & & & & & \\
\hline & Punishment $(P)$ & 1 & $0.542^{*}$ & $0.475^{*}$ & 3.000 & -0.387 & 0.318 \\
\hline & & & $(0.312)$ & $(0.269)$ & $(1.870)$ & $(0.837)$ & $(0.271)$ \\
\hline & OUT XP & 2 & $1.012^{*}$ & 0.322 & 3.250 & 0.218 & 0.341 \\
\hline & & & $(0.523)$ & $(0.468)$ & (2.254) & $(0.970)$ & $(0.434)$ \\
\hline & $\mathrm{IN} \times \mathrm{P}$ & 3 & 0.705 & 0.287 & 1.056 & 1.400 & 0.506 \\
\hline & & & $(0.460)$ & $(0.463)$ & $(2.240)$ & (1.001) & $(0.416)$ \\
\hline & No Punishment (NoP) & 4 & $-1.008^{*}$ & $-2.193 * * *$ & 1.177 & -0.179 & $-1.445^{* *}$ \\
\hline & & & $(0.540)$ & $(0.720)$ & (1.103) & $(0.888)$ & $(0.583)$ \\
\hline & OUT x NoP & 5 & 0.317 & $1.468^{*}$ & -1.177 & -0.959 & 0.631 \\
\hline & & & $(0.651)$ & $(0.831)$ & (1.103) & $(1.567)$ & $(0.722)$ \\
\hline & IN $x$ NoP & 6 & $1.274^{* *}$ & $2.365 * * *$ & 0.537 & -0.207 & $1.466^{* *}$ \\
\hline & & & $(0.620)$ & $(0.825)$ & (1.494) & (0.919) & $(0.656)$ \\
\hline & IN: P - NoP & 7 & $0.981^{*}$ & 0,589 & 2,342 & $1.400^{*}$ & $0.802^{*}$ \\
\hline & OUT: P-NoP & 8 & $2.244^{* * *}$ & $1.522 * * *$ & $6.25^{* * *}$ & 0,97 & $1.473^{* * *}$ \\
\hline & Control: P-NoP & 9 & $1.550^{*}$ & $2.668 * * *$ & 1,823 & $-0,207$ & $1.764 * * *$ \\
\hline \multirow[t]{3}{*}{ Diff-in-Diff Analyses } & OUT vs IN & 10 & $1.264^{*}$ & 0,933 & $3.908^{*}$ & -0.431 & 0.670 \\
\hline & OUT vs. Control & 11 & 0,695 & $-1,145$ & $4.427^{*}$ & $-1,177$ & -0.290 \\
\hline & IN vs. Control & 12 & $-0,569$ & $-2.078 * *$ & 0,519 & 1,608 & -0.960 \\
\hline \multirow[t]{2}{*}{ Punishment } & IN - OUT & 13 & -0.306 & -0.035 & -2.194 & 1,183 & 0,165 \\
\hline & & & $(0.540)$ & $(0.538)$ & $(1.767)$ & 0,736 & 0,462 \\
\hline \multirow[t]{2}{*}{ No Punishment } & IN - OUT & 14 & $0.957^{* *}$ & 0.898 & $1.714^{*}$ & 0,752 & 0,835 \\
\hline & & & $(0.474)$ & (0.578) & (1.007) & (1.312) & $(0.523)$ \\
\hline Number of obs & & & 8.064 & 5.334 & 1.134 & 1.596 & 6.930 \\
\hline R-squared & & & 0.058 & 0.060 & 0.390 & 0.022 & 0.038 \\
\hline
\end{tabular}

Next, we ask how certain cooperation types with differing social attitudes adjust their cooperativeness. To do so, we classify subjects - based on their initially revealed cooperativeness in Stage A of the experiment - into free-riders (FR) and conditional cooperators (CC). While free-riders reveal purely selfish cooperation preferences, conditional cooperators tend to be motivated by a social preference based on positive reciprocity (cf. Falk 2003; Lankau et al. 2012). Consequently, the more their group members contribute to the 
public good, the higher their own contribution is in return. Yet, even conditional cooperators do not perfectly reciprocate their group members' contributions and exhibit a certain selfserving bias by frequently contributing less to the public good than their group members (Fischbacher, Gächter, and Fehr 2001; Lankau, Bicskei, and Bizer 2012). Subjects, which fell into neither category, are termed "others". ${ }^{19}$ Table 4 summarizes the distribution of those cooperation types.

TABLE 4

Frequency and Distribution of Cooperation Types in Stage A

\begin{tabular}{lrr}
\hline Cooperation Type & Frequency & Percent \\
\hline Free-Rider (FR) & 54 & 14.06 \\
Conditional Cooperators (CC) & 254 & 66.15 \\
Other & 76 & 19.79 \\
\hline Total & $\mathbf{3 8 4}$ & $\mathbf{1 0 0}$ \\
\hline
\end{tabular}

Figure 2 and Figure 3 show the impact of peer-punishment on free-riders' and conditional cooperators' cooperativeness in in-group, out-group and control treatments, respectively. We find, on the one hand, that independent of how free-riders are matched, peer-punishment increases their cooperativeness. The strongest behavioral adjustment is present when freeriders interact with out-group members, which is significant at the 10 percent level (see Table 3, Model C, row 10). While they are not cooperative at all without the threat of peerpunishment, under punishment they are for instance willing to contribute 12 points on average to the public good if their group members contribute 20. When matched with in-group members or in random matching these differences are lower and merely amount to

${ }^{19}$ In our analysis we neglect "others", since their behavior subsumes many different cooperation patterns, which occur too infrequently to form separate categories. Such patterns are for instance characterized by hump-shaped cooperation, yet also by behavior not following any inherent logic. Clearly, treatment effects on the category of others will not yield insightful results. 
approximately 4 points on average. Indeed, the linear regression in Table 3 (Model C, row 10 and 11) confirms that the impact of punishment on free-riders' cooperativeness in out-group matching is significantly stronger than in the in-group or control treatment.

On the other hand, the punishment effect on conditional cooperators does not seem to be as pronounced as in case of free-riders (see Figure 3 and Table 3, Model B and C, row 7, 8). Moreover, we find that conditional cooperators reveal a very similar behavioral adjustment under punishment when matched with in-group and with out-group members (Table 3, Model B, row 10).

Result 2: In ID matchings free-riders are prone to show stronger adjustments in cooperativeness in response to peer-punishment than conditional cooperators. It is strongest when matched with out-group members.

In order to explain this differential reaction to punishment, we argue, on the one hand, that socially oriented conditional cooperators voluntarily contribute to the public good so that the threat of punishment does not evoke a particularly strong increase in their cooperativeness. Purely self-interested free-riders, on the other hand, strongly adjust their cooperation strategy under punishment due to the perceived threat of monetary losses following their uncooperative behavior. This anticipation of peer-sanctioning seems to be especially strong in groups with individuals of differing identities. 
FIGURE 2

The Effects of Punishment on Average Changes in Conditional Contribution of Free-Riders
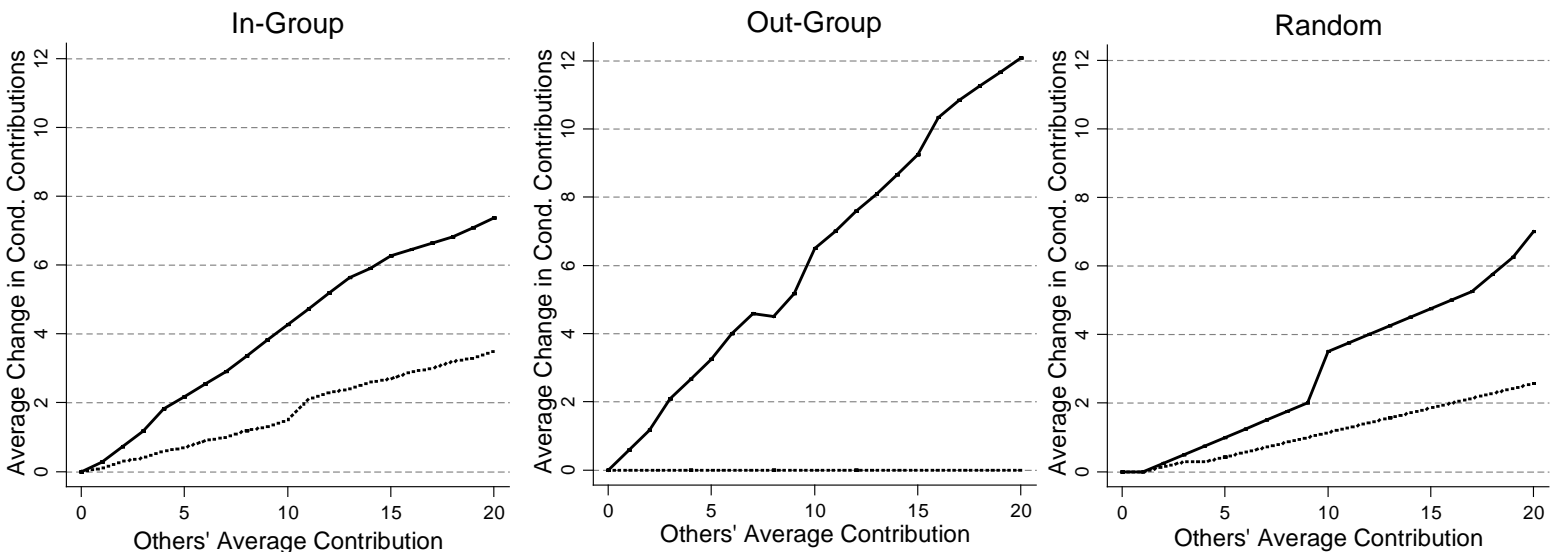

No-Punishment (NP)

Punishment $(P)$

FIGURE 3

The Effects of Punishment on Average Changes in Conditional Contribution of Conditional

Cooperators
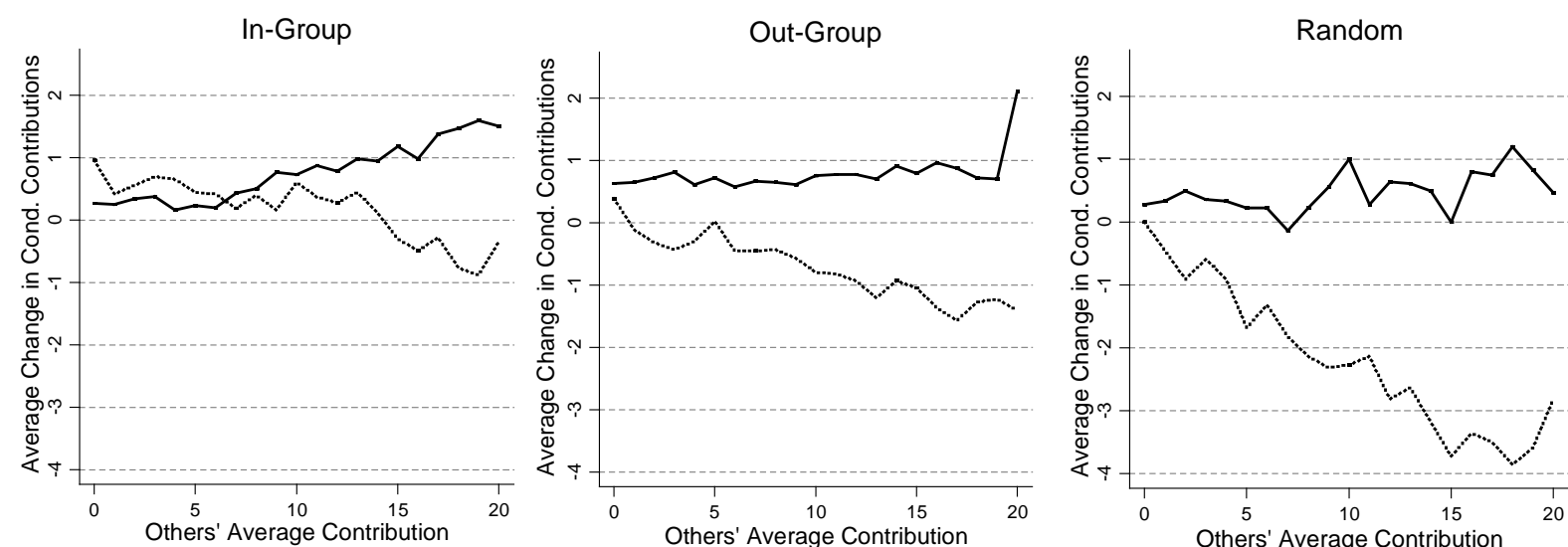

No-Punishment (NP)

Punishment $(P)$

\section{Effects of Social Identity under Peer-Punishment}

After having established that peer punishment drives cooperativeness particularly in identity heterogeneous groups, we proceed by analyzing whether subject's cooperativeness differs 
dependent on group composition when a punishment threat is present. Figure 4 depicts the average change in conditional cooperation between Stage C and A under punishment as influenced by the three group assignment conditions (left panel) contrasted by the corresponding cooperativeness without punishment (right panel).

\section{FIGURE 4}

ID Matchings Effects on Changes in Conditional Cooperation with and without Punishment
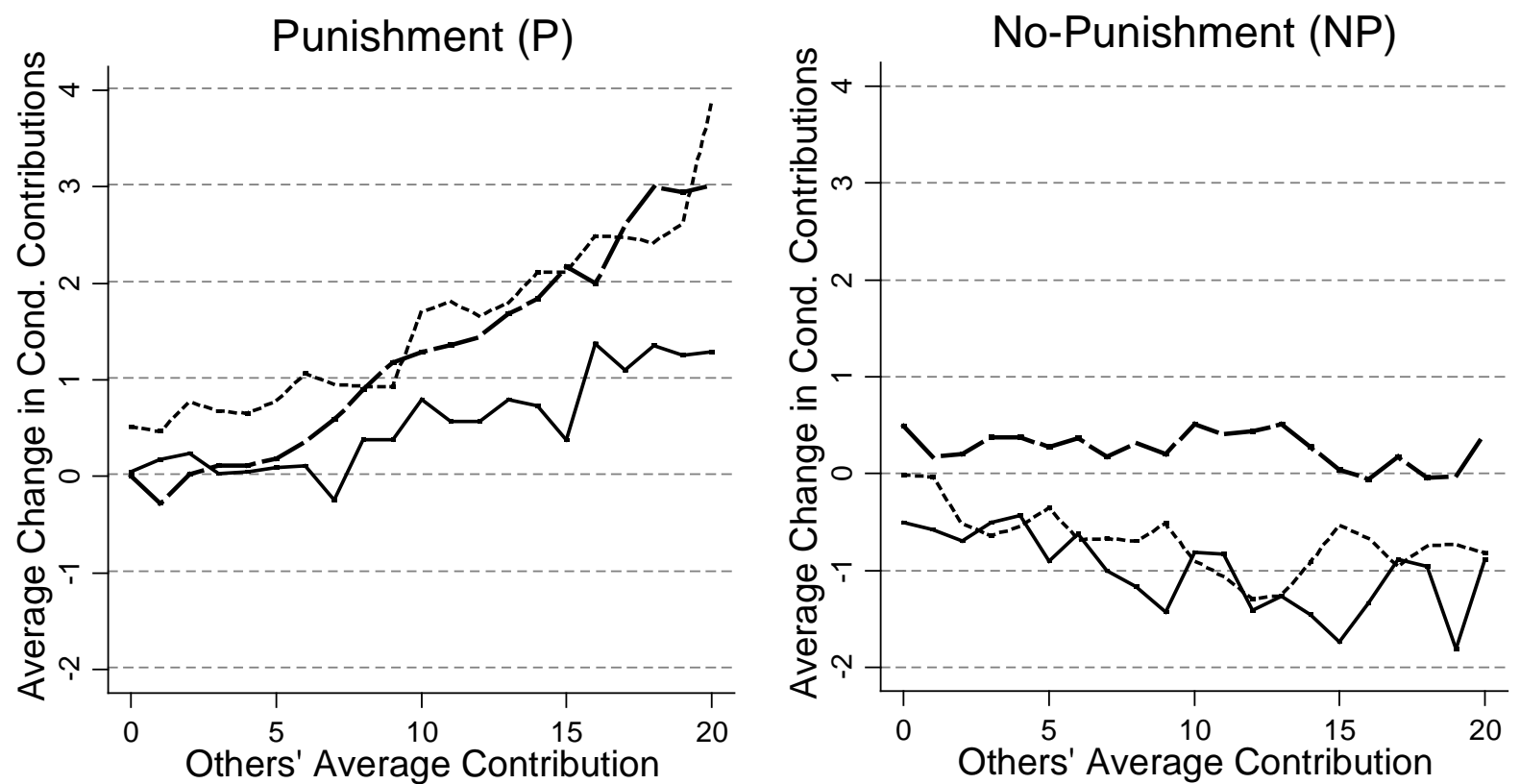

$$
\text { - - In-Group -------- Out-Group } \longleftarrow \text { Random }
$$

Firstly, under punishment subjects seem to be similarly cooperative in in- and out-group matching (left panel). For low levels of others' contribution to the public good they even contribute on average slightly more when matched with out-group members. On the whole, however, we do not find any significant difference in conditional cooperation between both ID treatments under punishment (see Table 3, Model A, row 13). This starkly contrasts the findings on subjects' cooperativeness without punishment (see Table 3, Model A, row 13). In line with prior research on the effects of social identity on cooperation (cf. Chen and Li 2009; 
Eckel and Grossman 2005), subjects’ cooperativeness without punishment is significantly biased towards their in-group members (right panel, for regression result see Table 3, Model A, row 14). ${ }^{20}$ Consequently, we argue that the fear created by a punishment institution overrides the reluctance to cooperate with out-group members and renders individuals to be as cooperative as in in-group matching. Evidently, as summarized by Result 1, behavioral adjustments through punishment seem to be comparatively strongest when subjects are matched with out-group members. This is most likely due to an anticipation of higher punishment by individuals that do not belong to their own identity, which seems to be mainly driven by free-riders. They exhibit the highest increase in cooperativeness under punishment when matched with out-group members (Result 2). Indeed, when dropping free-riders from the regression analysis in Table 3 (Model E, row 10), we no longer find a significant difference in punishments' impact on subjects' cooperativeness in in-group and out-group matching.

Overall, since we no longer observe an in-group bias, we have to reject Hypothesis 2, as well. This result is inconsistent with McLeish and Oxoby (2007) who find in two-person interactions that both with and without punishment cooperation is higher in in-groups than in out-groups. However, they did not find any punishment effect on cooperation.

Result 3: The presence of peer-punishment eliminates the existence of an in-group bias, which is prevalent when social identity is salient and no punishment is available.

\footnotetext{
${ }^{20}$ The induction of social identity in Stage B was identical both in the NP as well as the P treatments. Consequently, the existence of an in-group bias without punishment clearly shows that the non-existence of such bias with punishment cannot be explained by an unsuccessful identity induction.
} 
Lastly, subjects' cooperativeness under punishment both in in- and out-group matching is slightly elevated compared to random matching of the control treatment in which no social identity is induced (Figure 4, left panel). In in-group matching this difference is merely borderline significant (Table 3, Model A, row 3, p=0.127). In out-group matching significance is given at the 10 percent level (Table 3, Model A, row 2). Together, these results suggest that a simultaneous application of peer-punishment and social identity is a viable option to boost cooperativeness in public goods provision.

Result 4: Under punishment subjects reveal an increased cooperativeness in in- and outgroup matching compared to groups without saliency of social identity.

This result complements to some degree the findings by Noussair and Tucker (2005) who established that when peer-punishment is combined with another institution, namely with the possibility of non-monetary social sanctions, it results in a higher cooperativeness than when applied by itself.

\section{CONCLUSION}

In this article, we investigate the question of how the institutions of peer-punishment and social identity simultaneously affect cooperation in the provision of public goods. In particular, our aim is to provide insights on the influence of punishment on subjects' cooperativeness in homogeneous groups bound together by a common social identity and in heterogeneous groups consisting of individuals saliently belonging to different identities. To this purpose, we induce social identity in the laboratory and devise one-shot public good games using the strategy method both with and without the institution of costly peerpunishment. Our experiment is the first that asks for simultaneous effect of peer-punishment and social identity in a one-shot group setting. 
The results of our study indicate first of all that group composition plays a crucial role in how a peer-punishment threat affects cooperation under social identity. The strongest increase in cooperativeness can be observed among subjects in out-group matching, especially for those who were classified as free-riders based on their initially revealed cooperativeness. This is most likely due to an anticipation of comparably strong punishment by individuals who do not belong to their own identity. Secondly, in contrast to the institutional setting without peerpunishment, in which individuals' cooperativeness is clearly biased towards members of their own identity (in-group bias), the anticipation of stronger peer-punishment by out-group members generally seems to erode this reluctance to cooperate with out-group members and renders individuals as cooperative as in in-group matching. Lastly, our results indicate that social identity and peer-punishment complement each other. In in- and out-group matching under punishment subjects' cooperativeness is elevated compared to the control treatment, in which group members were randomly matched and no social identity was induced. Concluding, the combination of social identity with a peer-punishment institution seems to be a viable option to foster subjects' cooperativeness compared to situations when social identity is not salient.

Summing up, it is empirically established that fragmentation and polarization of societies restrain the provision of public goods (Eaton, Eswaran, and Oxoby 2011) since individuals strongly identifying with particular groups are willing to cooperate less with members of different identities. We established, however, that implementing peer-punishment erodes the reluctance to cooperate in identity heterogeneous groups and renders people as cooperative as when being part of an identity homogenous group. 


\section{APPENDIX - INSTRUCTIONS TO THE EXPERIMENT (NP-TREATMENT)}

Welcome to the experiment! Thank you very much for your participation.

If you read the following instructions carefully, you get the chance of winning money additional to the $€ 2.50$, which you receive in any case. Your earnings will depend on your decisions and on those by the other players in your group. At the end of the experiment all sums of money, which you will have earned through your decisions, will be added and given to you personally and in cash.

It is forbidden to speak during the experiment. If you have any questions, please raise your hand. A member of our team will come to you and answer your question privately.

We will be talking about points rather than Euros in the course of the experiment. Hence, your total income will be calculated in points in the first instance. The total number of points which you will achieve during the experiment will be converted in Euros at the end, using the following equation:

$$
1 \text { point }=17 \text { Cents }
$$

All participants will be divided in groups with 3 players each. Except for us, i.e. the conductors of the experiment, nobody will know who is in which group. All decisions will be made anonymously and your identity will neither be revealed during the experiment nor in public.

Each task of the experiment has its own instructions, which you have to read step by step. While doing so, please consider the respective hints which will appear on the monitor.

Please click on OK when you are ready.

\section{The Basic Decision Situation}

Later, you will be informed about the experiment's procedure in detail. At this point, we would like to introduce the basic decision conditions you will face in this experiment. Some example exercises can be found subsequently.

At each point in time, you will be a member of a group consisting of $\mathbf{3}$ players. In every task, you hold 20 points. Your task is to decide whether you invest these 20 points in a private account or whether you want to invest them fully or partly in a project. Each point which you do not invest in a project will be automatically deposited on your private account.

\section{Your income from your private account:}

For each point which you deposit on your private account (and, therefore, you do not invest in the project), you will earn one point. Hence, a deposit of 20 points on your private account will produce an income of 20 points from your private account. If you, for instance, deposit 6 points on your private account, you will earn 6 points from this account. Nobody except you will earn anything from your private account.

\section{Your income from the project:}

All group members will profit equally from your contribution to the project. Vice versa, you profit from the investments by other group members. The income every member gets from the project is calculated as follows: 
Should the sum of all contributions to the project be, for example, 30 points then you and all other group members gain $(30 \times 0.4)=12$ points each from the project. Should the sum of all contributions to the project be, for example, 10 points then you and all other group members gain $(10 \times 0.4)=4$ points each from the project.

\section{Your total income:}

Your total income is the sum of your income from your private account and your income from the project.

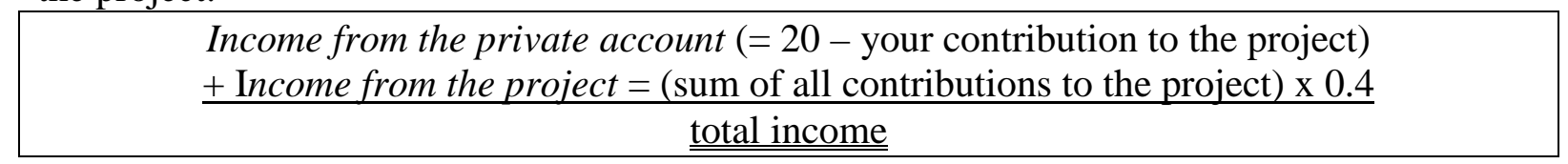

\section{Exercise Questions}

Please complete the following exercises. They do merely serve the purpose of familiarising you with the calculation of the different sorts of income, which may occur to you when making different decisions on the use of the 20 points starting capital.

Please complete all the exercises and always report your full mathematical procedure. While calculating, you may use the calculator function on the monitor. When you are done, you have to enter your results in the computer.

1. Each group member has 20 points at their disposal. Imagine that all three group members (including yourself) do not contribute anything to the project.

a. What is your total income? .....

b. What is the total income of each of the other group members? .....

2. Each group member has 20 points at their disposal. You invest 20 points in the project. The other two group members also contribute 20 points to the project.

a. What is your total income? .....

b. What is the total income of each of the other group members? .....

3. Each group member has 20 points at their disposal. The other two group members contribute 10 points each (i.e., 20 points in total) to the project.

a. What is your total income if you, additional to the 20 points, contribute 0 points to the project?

b. What is your total income if you, additional to the 20 points, contribute 5 points to the project?

c. What is your total income if you, additional to the 20 points, contribute 15 points to the project?

d.

4. Each group member has 20 points at their disposal. You contribute 7 points to the project.

a. What is your total income if the other group members, additionally to your 7 points, contribute 1.5 points each, i.e., 3 points in total, to the project?

b. What is your total income if the other group members, additionally to your 7 points, contribute 4 points each, i.e., 8 points in total, to the project?

c. What is your total income if the other group members, additionally to your 7 points, contribute 9 points each, i.e., 18 points in total, to the project? 


\section{First Task}

You are now the member of a group of three, which was put together randomly.

The task contains the decision, which was described at the beginning and is only conducted once.

As you know, you have 20 points at your disposal, which you can either invest in the project or deposit on your private account.

In this task, every group member has to make two types of decisions, which we will term (1) the "unconditional" contribution to the project, or the (2) "conditional" contribution to the project (the contribution table), respectively.

Both decisions are vital for your income from this task. So please make your decisions thoughtfully.

\section{Step 1: Your Unconditional Contribution to the Project}

Please determine how many of your points you, without knowing the contributions of the other group members, want to invest in the project. Please enter this amount into the following computer screen:

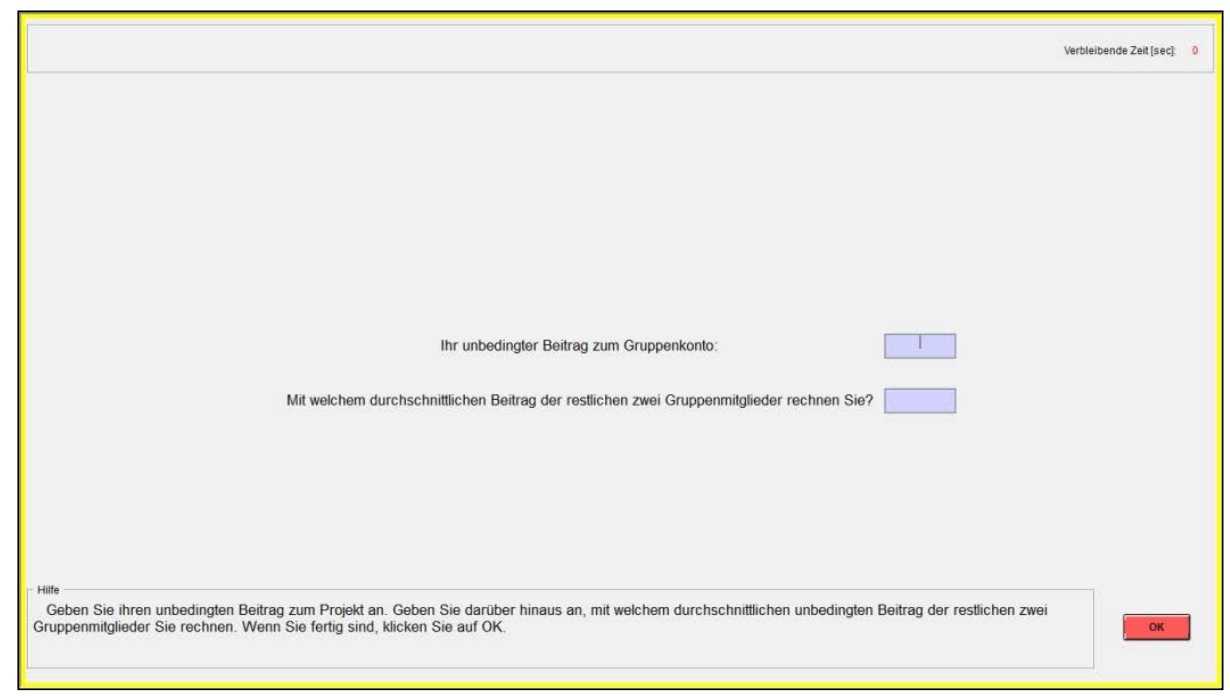

Please state what you expect each of the other two group members to contribute to the project (average amount of money they invest in the project).

Once you have made both statements, please click on OK.

\section{Step 2: Your Conditional Contribution to the Project - the Contribution Table}

With your second decision you have to fill in a contribution table. In the contribution table you have to enter your contribution to the project for every possible average contribution (rounded up) of the other group members. Hence, you can, dependent on the average contribution of the others, determine your decision on your contribution. You will get a clear hint of what to do when you take a look at the following screen. 


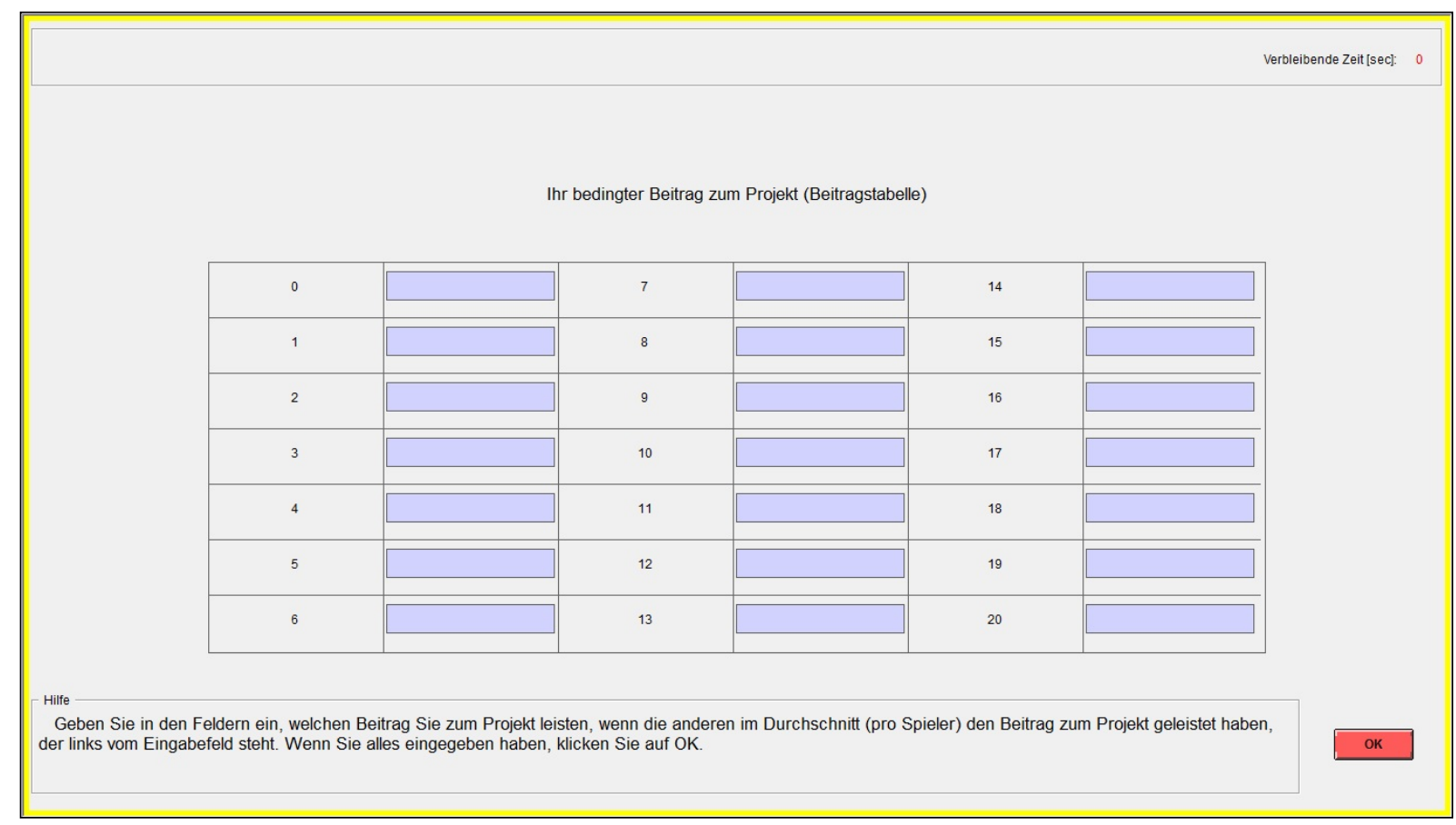

The numbers left to the boxes mark the possible average contributions, which the other members can make to the project. You just have to enter in each box how much you, under the condition that the others contribute the stated average amount, want to invest in the project. You have to make an entry in each box.

For example, you have to enter how many points you want to invest in the project if the other group members contribute 0 points; how many points you invest if the others contribute 1,2 or 3 points and so on and so forth. You can enter integral numbers ranging from 0 to 20 in each box.

Once you have typed a number in each box, please click on OK.

After all participants in the experiment made their decision on their conditional contribution and filled in the contribution table, one member of each group is selected at random. For these selected members only the contribution table is relevant for their decisions and payoff. For the other two group members, who were not selected by the random choice mechanism, only the unconditional contribution is relevant for their decisions and payoff. The average of both unconditional contributions by these two group members defines which contribution by the selected member shall be invested in the project.

When you make the decision on your unconditional contribution and fill in the contribution table, you do of course not know if you will be picked at random. Hence, you have to make both decisions carefully, because both can become relevant for you. The following examples will explain the procedure:

Example 1: You are selected by the random choice mechanism. Therefore, the contribution table is relevant for your payoff. For the other two group members the unconditional contributions are relevant.

Let us assume that the other two group members invest 0 and 4 points in the project, which would mean an average contribution of two points. If you entered in the contribution chart that you would invest 1 point if the others averagely invested 2 points, then this would make a total contribution of $0+4+1=5$ points to the project. All group members would then earn $5 \mathrm{x}$ 
$0.4=2$ points from the project plus the respective incomes from their private accounts, in your case $20-1=19$ points. Your income would then be 21 points.

If you, however, stated that you would invest 16 points, if the others averagely invested 2 points, this would make a total investment of $0+4+16=20$ points in the project. As a result, all group members would receive a payoff of $20 \times 0.4=8$ points plus the income from their private accounts, in your case $20-16=4$ points. Your total income would then be 12 points.

Example 2: You are not selected by the random choice mechanism. For you and another group member then your unconditional contribution to the project is the relevant decision.

Let us assume that your unconditional contribution to the project is 16 points, the contribution by the other group member is 20 points. This makes an average contribution of 18 points to the project. Should the player who was selected by the random choice mechanism have stated that he or she would contribute 1 point to the project if the other group members averagely invested 18 points, then the total contribution to the project would be $16+20+1=37$ points. All group members then would earn $37 \times 0.4=14.8$ points from the project additional to their respective income from their private accounts. In your case you would earn $20-16=4$ points from your private account, which would then make a total income of 18.8 points.

Should the selected group member have stated an investment of 19 points to the project if the others averagely invested 18 points, then the total contribution to the project would be $16+20$ $+19=55$ points. Every group member would have a project income of $55 \times 0.4=22$ points plus their points from their private account, in your case 4 points. Your total income would then be 26 points.

\section{The Random Choice Mechanism}

At the beginning of this game each group member receives a number between 1 and 3 . As you might remember, one participant, namely no. 8, was selected at the beginning of the experiment. This participant will dice a number between 1 and 6 after all participants decided on their unconditional contribution and filled in the contribution table. The numbers 1 and 2 stand for group member one, 3 and 4 for group member two and 5 and 6 for member three. Participant no. 8 will enter these in the computer. In case no. 8 dices the numbers which correspond to your member number, the contribution table will be relevant for your decisions and payoff and for the other group members the unconditional contribution will be relevant. In any other case the unconditional contribution is relevant for you.

Please click on OK once you have read and understood the instructions.

\section{Second Task \\ Please note: Do not open the attached envelope before you are asked to do so!}

For the second task, you will be arbitrarily assigned a new group, which will be marked by a specific colour.

Only those solutions which are given correctly by ALL THREE group members will be considered correct in this group task.

During this task the group members are allowed to communicate with each other. By doing so, they can find a solution together. On the left hand side of the computer screen a chat box is positioned, which can be used for communication. Your conversation will be recorded. You have 10 minutes to solve the task. Only within this time span are you able to communicate with your team members. Please take into account that every group member has to type in the solutions which will have been found by your group. You have to click on OK before the 10 
minutes have run out. The time left will be shown to you in the upper right hand corner of your screen.

All participants will be shown a picture and a list of objects. The task is to find the hidden objects in the picture. The inscriptions on the left and the upper side give the numbers of the lines and columns. You are asked to insert this information in the boxes which will be shown on the right hand side of the screen. The first box refers to a line, the second to a column. An example for this exercise is given below.
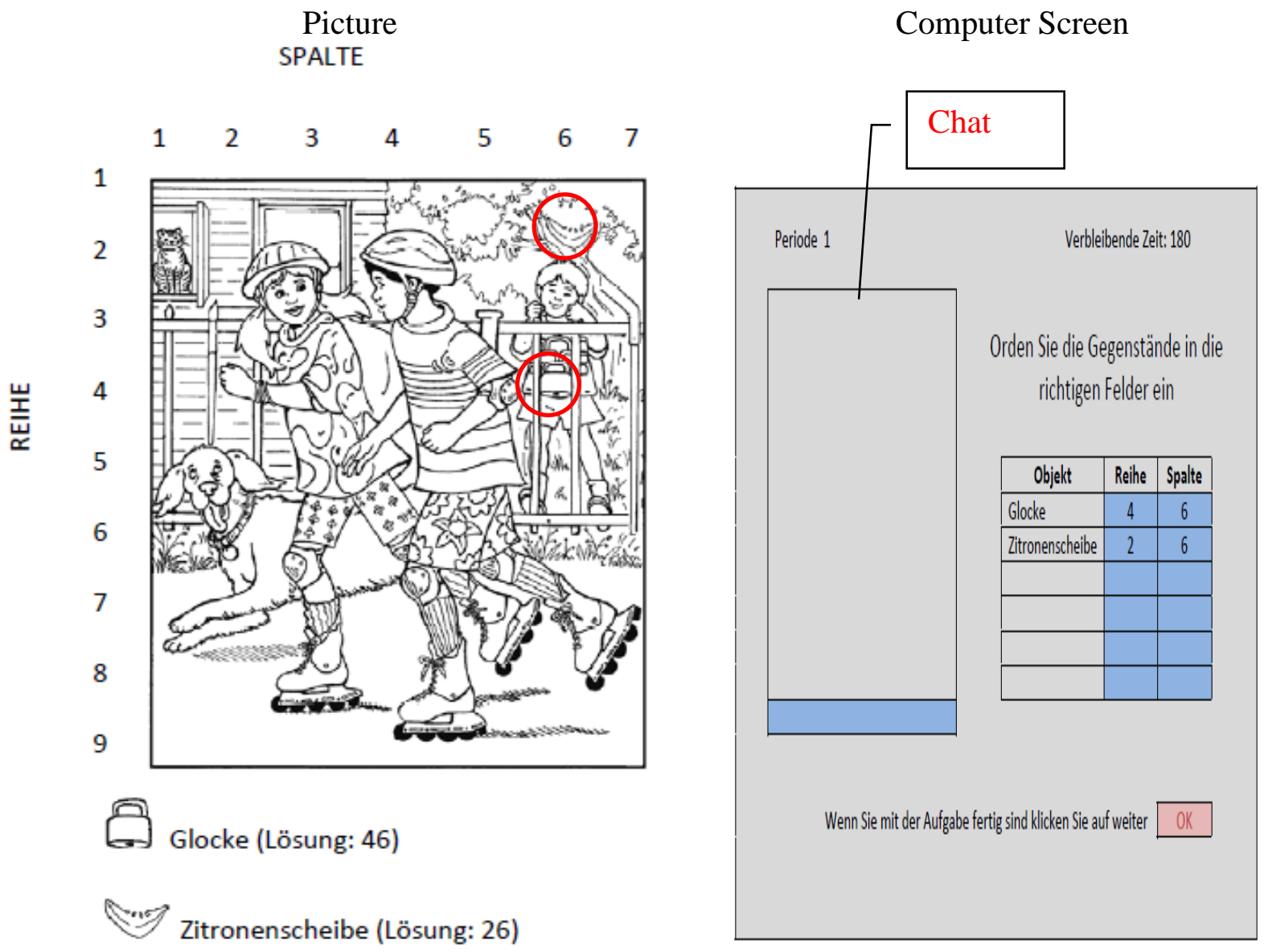

The group which finds most of the objects in the 10 minutes time is the winner group. At the end of the experiment you will be informed whether you are a member of the winner group. In this case, you will receive a congratulation message.

Please click on OK when you are ready.

\section{Third Task}

This task corresponds to the first one. It is conducted only once.

This time, however, you will only play together with members of your own group, with who you solved the picture puzzle in the second task.

Again, you hold a deposit of 20 points. Please decide how many points you want to invest in the project and how many you want to put on your private account.

This task also consists of two decisions, your (1) conditional contribution to the project and (2) the contribution table, with which you can make your decisions conditional on the other group members' contributions. 
Please decide very carefully in both cases, for both the conditional contribution and your input into the contribution table are potentially relevant for the payoff. To determine the relevance of the decision, we will use the same random choice mechanism as before.

When you are ready, please click on OK.

VI.1.1 Punishment Treatment (only Stage C)

\section{Third Task (P-Treatment)}

This time, however, you will only play together with members of your own group, with who you solved the picture puzzle in the second task.

Again, you receive a basic endowment of 20 points.

In addition to this basic endowment, every participant receives an amount of $\mathbf{6 0}$ points (extra endowment) in this task. This one-off payment can be used to pay for possible costs during this task.

This task consists of two stages and is conducted only once.

\section{Stage 1:}

Please decide how many of your 20 points (basic endowment) you want to invest in the project and how many you want to put on your private account.

This task also consists of two decisions, your (1) unconditional contribution to the project and (2) the contribution chart, with which you can make your decisions conditional on the other group members' contributions.

Please decide very carefully in both cases, for both the unconditional contribution and your input into the contribution chart are potentially relevant for the payoff. To determine the relevance of the decision, we will use the same random choice mechanism as before.

Your income from this stage will be displayed on the screen.

\section{Stage 2:}

At the beginning of the second stage, you will receive information how much each of your group members contributed to the project. In this stage you have the opportunity to register your approval or disapproval of each other group member's decision by distributing points.

In this stage you have the opportunity to reduce or leave equal the income of each group member by distributing points. You can award a large number of points to any member of your group if you disapprove of his or her decision $(10$ points for the most disapproval, 0 points for the least disapproval). Each point you distribute to a particular player lowers his or her payment by $10 \%$.

You incur a cost for allocating points to other members, which is discussed in detail below.

You must decide how many points to give to each of the other two group members and enter these into the following computer screening: 


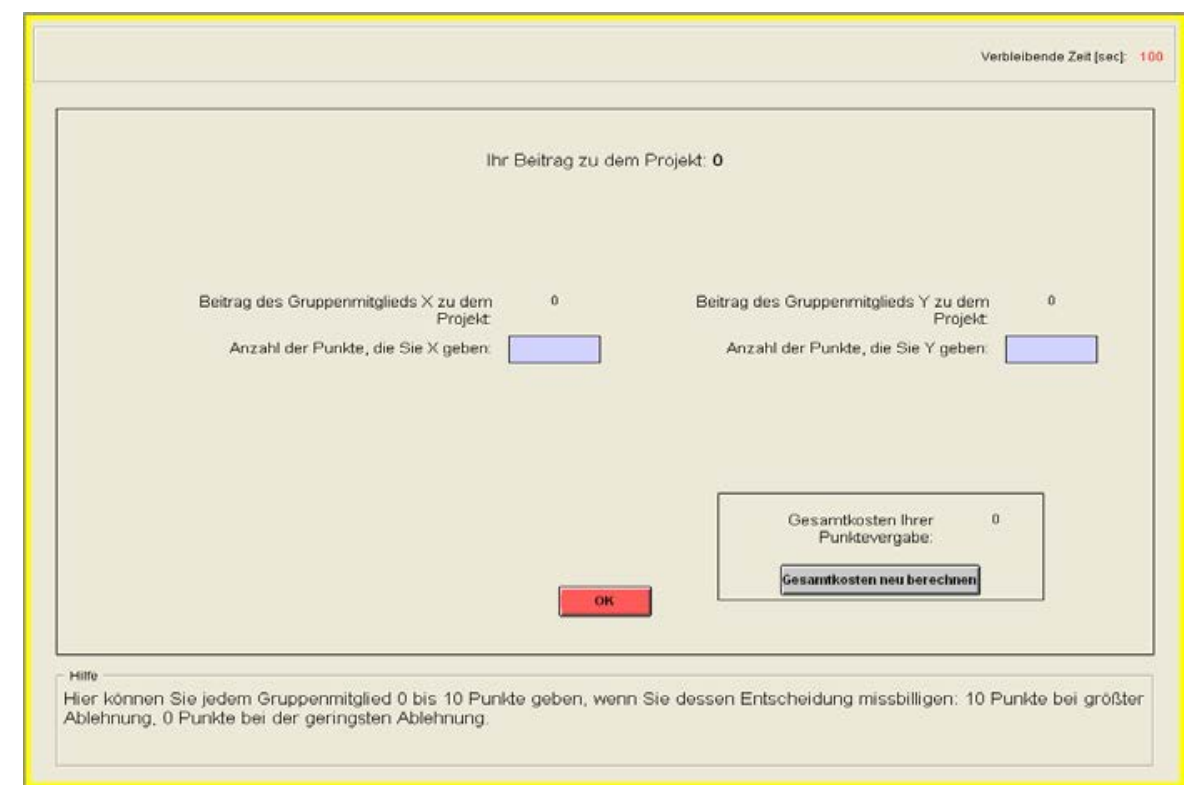

If you do not wish to change the income of a specific group member then you must enter 0 . If you distribute points, you have costs in points, which depend on the amount of points you distribute. You can distribute between 0 and 10 points to each group member. The more points you give to any group member, the higher your costs. Your total costs are equal to the sum of the costs of distributing points to each of the other two group members. The following table illustrates the relation between distributed points to each group member and the cost of doing so in points.

Suppose for example that you give 2 points to one member. This costs you 2 points. If you give 9 points to another member this costs you an additional 25 points. In this case your total costs of distributing points would be $27(2+25)$ points. Your total cost of distributing points can be calculated on the input screen (on the right hand side). As long as you have not pressed the ok button you can revise your decision.

If you choose 0 points for a particular group member, you do not change his or her income. However if you give a member 1 point (by choosing 1) you reduce his or her income by 10 percent, etc. The amount of points you distribute to each member determines therefore how much you reduce their income from the first stage.

Whether or by how much the income from the first stage is totally reduced depends on the total of the received points from all other group members. If somebody received a total of 3 points (from all other group members in this period) his or her income would be reduced by 30 percent. If somebody received a total of 4 points his or her income would be reduced by 40 percent. If anybody receives $\mathbf{1 0}$ or more points their income from the first stage will be reduced by 100 percent. The income from the first stage for this member would in this case be reduced to zero.

The other group members can also assign points to you if they wish to.

Please state hereafter what you consider how many points you will receive in total from the other two group members. 


\section{Your total income}

Your total income from the two stages is therefore calculated as follows:

If you receive less than 10 points:

$=[($ income from the 1 st stage $) \times(10-$ received points $) / 10]$

- (cost to you of points you distribute) + extra endowment

If you receive 10 or more points:

$=0-($ cost to you of points you distribute $)+$ extra endowment

After all participants have made their decision, your income from the task will be displayed on the screen.

\section{Exercises}

To check your understanding of the experiment, please answer the following questions. While calculating, you may use the calculator function on the monitor. When you are done, you have to enter your results in the computer.

1. Suppose in the second stage of this task, you distribute the following amounts of points to the other two group members: 9 and 5 . What is the total cost of the points you distribute?

2. What are your costs if you distribute a total of 0 points?

3. By how many percent will your income from the first stage be reduced, when you receive a total of 0 points from the other group members?

4. By how many percent will your income from the first stage be reduced, when you receive a total of 4 points from the other group members?

5. By how many percent will your income from the first stage be reduced, when you receive a total of 15 points from the other group members?

When you are ready, please click on OK. 


\section{References}

Anderson, Christopher M., and Louis Putterman. 2006. "Do non-strategic sanctions obey the law of demand? The demand for punishment in the voluntary contribution mechanism." Games and Economic Behavior 54 (1) 1-24.

Bicskei, Marianna, Matthias Lankau and Kilian Bizer. 2013. Negative Reciprocity and AngerLike Emotions in Homogenous and Heterogeneous Groups. Unpublished Manuscript.

Blackwell, Calvin, and Michael McKee. 2003. “Only for my own neighborhood? Preferences and voluntary provision of local and global public goods "Journal of Economic Behavior \& Organization 52 (1) 115-131.

Bochet, Olivier, Talbot Page, and Louis Putterman. 2006. “Communication and punishment in voluntary contribution experiments.” Journal of Economic Behavior \& Organization 60 (1): 11-26.

Burlando, Roberto, and Francesco Guala. 2005. "Heterogeneous Agents in Public Goods Experiments.” Experimental Economics 8 (1): 35-54.

Chakravarti, Surajeet, and Miguel A. Fonseca. 2012. "The effect of social fragmentation on public good provision: an experimental study” University of Exeter Economics Department Discussion Paper Series, Paper No. 12/07.

Chakravarti, Surajeet, and Miguel A. Fonseca. 2012. "Discrimination via Exclusion: An Experiment on Group Identity and Club Goods” University of Exeter Economics Department Discussion Paper Series, Paper No. 13/02.

Charness, G., L. Rigotti, and A. Rustichini. 2007. "Individual behavior and group membership.” The American Economic Review 97 (4): 1340-52.

Chen, Roy, and Yan Chen. 2011. "The Potential of Social Identity for Equilibrium Selection.” American Economic Review 101 (6): 2562-89.

Chen, Yan, and Sherry X. Li. 2009. “Group Identity and Social Preferences.” The American Economic Review 99 (1): 431-57.

Eaton, B. C., Mukesh Eswaran, and Robert J. Oxoby. 2011. "Us and Them: the origin of identity, and its economic implications." Canadian Journal of Economics 44 (3): 719-48.

Eckel, C. C., and P. J. Grossman. 2005. "Managing diversity by creating team identity.” Journal of Economic Behavior \& Organization 58 (3): 371-92.

Falk, Armin. 2003. "Homo Oeconomicus versus Homo Reciprocans: Ansätze für ein neues Wirtschaftspolitisches Leitbild?” Perspektiven der Wirtschaftspolitik 4 (1): 141-72.

Fehr, Ernst, and Simon Gächter. 2000. "Cooperation and Punishment in Public Goods Experiments.” The American Economic Review 90 (4): 980-94.

—. 2002. “Altruistic punishment in humans.” Nature 415 (6868): 137-40. doi: 10.1038/415137a.

Fischbacher, Urs. 2007. "z-Tree: Zurich toolbox for ready-made economic experiments.” Experimental Economics 10: 171-78.

Fischbacher, Urs, and Simon Gächter. 2010. "Social preferences, beliefs, and the dynamics of free riding in public goods experiments.” The American Economic Review 100 (1): 541-56. 
Fischbacher, Urs, Simon Gächter, and Ernst Fehr. 2001. “Are people conditionally cooperative? Evidence from a public goods experiment.” Economics Letters 71 (3): 397404.

Goette, Lorenz, David Huffman, and Stephan Meier. 2006. “The Impact of Group Membership on Cooperation and Norm Enforcement: Evidence Using Random Assignment to Real Social Groups.” American Economic Review 96 (2): 212-16.

2012. "The Impact of Social Ties on Group Interactions: Evidence from Minimal Groups and Randomly Assigned Real Groups.” American Economic Journal: Microeconomics 4 (1): 101-15.

Harris, Donna, Benedikt Herrmann, and Andreas Kontoleon. 2012. "When to Favour Your Own Group? The Threats of Costly Punishments and In-group Favouritism.” ISSN 14710498.

Hoff, Karla, and Priyanka Pandey. 2006.” Discrimination, Social Identity, and Durable Inequalities.” American Economic Review 96 (2): 206-211.

Ibañez Diaz, Marcela, and Elke R. Schaffland. 2012. Group identity and leadership: An experimental analysis. Unpublished Manuscript.

Lankau, Matthias, Marianna Bicskei, and Kilian Bizer. 2012. "Cooperation preferences in the provision of public goods: An experimental study on the effects of social identity.” Cege Discussion Papers 148. http://papers.ssrn.com/sol3/papers.cfm?abstract_id=2191469.

Masclet, David, Charles Noussair, Steven Tucker, and Marie-Claire Villeval. 2003. "Monetary and Nonmonetary Punishment in the Voluntary Contributions Mechanism." American Economic Review 93 (1): 366-80.

McLeish, K. N., and R. J. Oxoby. 2007. “Identity, cooperation, and punishment.” IZA Discussion Paper 2572. http://papers.ssrn.com/sol3/papers.cfm?abstract_id=961379.

McLeish, Kendra N., and Robert J. Oxoby. 2011. "Social interactions and the salience of social identity.” Journal of Economic Psychology 32 (1): 172-78.

Nikiforakis, N. 2008. "Punishment and counter-punishment in public good games: Can we really govern ourselves?” Journal of Public Economics 92 (1-2): 91-112.

Noussair, Charles, and Steven Tucker. 2005. "Combining monetary and social sanctions to ptomote cooperation.” Economic Inquiry 43 (3): 649-60.

Page, Talbot, Louis Putterman, and Bulent Unel. 2005. "Voluntary Association in Public Goods Experiments: Reciprocity, Mimicry and Efficiency.” Economic Journal 115 (506): 1032-53.

Sefton, Martin, Robert Shupp, and James M. Walker. 2007. "The Effect of Rewards and Sanctions in Provision of Public Goods.” Economic Inquiry 45 (4): 671-90.

Selten, Reinhard. 1967. "Die Strategiemethode zur Erforschung des eingeschränkt rationalen Verhaltens im Rahmen eines Oligopolexperiments.” In Beiträge zur experimentellen Wirtschaftsforschung. Vol. 1. Edited by H. Sauerland, 136-68. Tübingen: Mohr.

Tajfel, Henri, and John Turner. 1979. “An Integrative Theory of Intergroup Conflict.” In The Psychology of Intergroup Relations. Edited by Stephen Worchel and William Austin, 3347. Monterey: CA: Brooks/Cole. 
- 1986. “The Social Identity Theory of Intergroup Behaviour.” In The Psychology of Intergroup Relations. Edited by Stephen Worchel and William Austin, 7-24. Chicago:

Nelson-Hall. 


\section{ChAPTER VII}

\section{Negative ReCiprocity and its Relation to ANGeR-LIKe \\ Emotions in Homogeneous and Heterogeneous Groups}

An Experimental Study with Peer-Punishment

Marianna Bicskei, Matthias Lankau, Kilian Bizer 


\section{Introduction}

Classic economic theory assumes that individuals with selfish preferences maximize their own material utility. On the contrary, experimental research has confirmed that a considerable proportion of subjects reveal social preferences and exhibit a behavioral pattern based on reciprocity. Specifically, reciprocity captures the tendency of individuals to reward cooperative and punish unkind behavior even if this does not yield material benefits in the future (cf. Falk and Fischbacher, 2000). Recently, experiments have provided evidence that such reciprocal preferences are positively influenced by social identity depending on the group composition (see Chen and Li 2009; Charness et al. 2007, Lankau et al. 2012). Namely, the sense of belonging to a particular group - and the importance ascribed to it - affect an individual's connotations and behavior towards his own group (in-group) as well as towards other groups they do not belong to (out-group). Therefore, in-group members are willing to cooperate more with individuals that share the same identity than with individuals of different identities (see e.g., Solow and Kirkwood 2002). This accounts for the intragroup (within-group) sensitivity and intergroup hostility (Chen and Li 2009; Eaton et al. 2011). Likewise, field experiments also revealed that individuals in ethnically more homogenous groups contribute more to local public goods such as education than in less homogenous communities. ${ }^{1}$ What is more, in many real life examples we can additionally observe that groups often make efforts to evoke a person's particular identity in order to turn this person into an insider. Examples of such behavior include election campaigns, induction into the military, or in the workplace (see Akerlof and Kranton 2010 2005). All these examples provide evidence that identity is viable for the voluntary contribution of individuals to common resources.

The question of how social identity affects negative reciprocity in identity homogenous and heterogeneous groups in the provision of public goods has received no particular attention, yet. A limited number of contributions outside the public good context provide rather conflicting insights into how individuals engage in punishment in response to acts perceived as unkind, even if this is costly. ${ }^{2}$ Firstly, McLeish and Oxoby (2007) based on two-person bargaining games report that ingroup punishment is greater and more frequent than out-group punishment. Secondly, using twoperson sequential allocation games Chen and Li (2009) establish that in-group members are more forgiving towards other in-group members' misbehavior and engage in less negative reciprocity than out-group members. Despite this apparent controversy in two person interactions, to the best of our knowledge, there is still no research that specifically compares negative reciprocity between identity

\footnotetext{
${ }^{1}$ See Akerlof and Kranton (2010, p. 124) and Eaton et al. (2011) referring to research by Alesina et al. (1999), Miguel and Gugerty (2005) and Mauro (1995).

${ }^{2}$ Some authors suggest that negative reciprocity occurs in case actions are perceived as unfair or anti-social (cf. Fehr and Gächter 2000b). Therefore, we use the phrase unkind to be as neutral as possible when referring to triggers of punishment behavior.
} 
homogenous and heterogeneous groups when providing a public good. Consequently, the aim of this paper is to examine whether social identity affects how individuals sanction group members if they are confronted by an act that is deemed unkind. To this purpose, we conduct a public good experiment on the basis of one-shot games, comprising two identity treatments (ID treatments). Subjects either interact in in-group (i.e. identity homogenous) or out-group (i.e. identity heterogeneous) matching. A stranger (random) matching protocol serves as a control treatment. We induce social identity in the laboratory using a simple group task to be solved jointly. Since the public good games are carried out in strategy method, we additionally analyze the behavior of individuals classified into different cooperation types based on their initially revealed cooperation preferences. This delivers more refined insights into the effects of social identity on negative reciprocity. Another aim of this paper is to assess of the role of emotions as they account for negative reciprocity. The specific emotions may help us to better understand decision-makers' goals and motivations and hence to predict their specific behavior (Zeelenberg and Pieters 2006). By now, a few studies (cf. Reuben and van Winden 2008, Bosman and van Winden 2002, Bosman et al. 2005) address emotions to determine negative reciprocity. However, these did not focus on the social environment in which decisions were made, namely, whether individuals are interacting within identity homogenous or heterogeneous groups. Our study is, therefore, unique in bringing these aspects together.

The paper proceeds in five parts: Chapter 2 highlights the most important findings in the existing literature, followed by our research hypotheses. The experimental design is presented in Chapter 3 , while Chapter 4 presents the main results. Finally, Chapter 5 summarizes the findings and its implications for public policy.

\section{Background and hypotheses}

Negative reciprocity is a behavioral pattern, which plays a crucial role in many economic settings. The relevance of the impact of negative reciprocity on conflict resolution (Eisenberger et al. 2004), tax evasion (Falk 2003), state-society relationship (Etienne 2012) or exchange processes (Caliendo et al. 2012, Pereira et al. 2006) is well-documented. Experimental researchers have also laid focus onto this behavioral pattern and revealed that individuals engage in punishing others in response to acts perceived as unkind even if this is costly and does not yield future benefits. Generally, negative reciprocity constitutes a conditional behavior, which is even present in one-shot interactions (Falk 2003). In public good experiments negative reciprocity is identified as individuals punishing other group members after observing their voluntary contributions to the public good, which is costly for both the punisher and the punished. Two studies by Fehr and Gächter $(2000 a, 2002)$ have focused on 
long-term interactions and established that the more the participants' contribution is below the average contribution of their group members, the heavier is the punishment they receive. ${ }^{3}$

The question if and to what extent negative reciprocity is different between identity homogenous and heterogeneous groups in a public good context has not been addressed, yet. This question is highly relevant since individuals who belong to a particular group (based on some common characteristics) derive self-esteem from that group and are influenced in their behavior by stereotypes associated with the group identity (Chen and Li 2009). ${ }^{4}$ Therefore, the subjects' proclivity to make 'us' and 'them' distinctions (Eaton et al. 2011) may determine how 'unkind' they perceive contributions to the public good that are lower than their own.

Outside the public good context research by Reuben and van Winden (2008) provides some evidence on how social identity affects punishment. However, they only make comparisons to stranger groups. Specifically, they implemented two treatments, one with groups composed of friends and another with stranger groups that of unrelated individuals. They investigated this question using three-player power-to-take games, in which a proposer made a claim on the endowments of two responders. As a next step, each responder had a possibility to destroy any part of his own resources, thus reducing the income of the proposer as well. They found that friends with real social ties destroy more and they do it more frequently than strangers, signaling that group identity impacts on how strongly they are affected by others' behavior and well-being (Reuben and van Winden 2008). Unfortunately, the authors do not make a comparison to identity heterogeneous groups.

Two studies use two-person games provide insights into the very issue of negative reciprocity in identity homogenous and heterogeneous matches. Yet, they follow two divergent lines of reasoning about why participants reveal different reciprocity preferences dependent on the social environment. On the one hand, McLeish and Oxoby (2007) conducted two-person bargaining games and induced group identity by letting the groups work together on a series of questions. The pairs were randomly assigned and their group affiliation was common knowledge. After the proposers decided how much of their endowment they want to keep for themselves and how much they are willing to allocate to the responder, the responder had an opportunity to engage in costly punishment reducing the proposer's income. One punishment point assigned cost the offender a deduction of 1.5 points. They demonstrated that individuals imposed more punishment and more frequently when an in-group member engaged in uncooperative behavior than when an out-group member did so. Additionally, the responder's behaviour was much more dependent on the invested

\footnotetext{
${ }^{3}$ They also observed that contributions above the average were punished much less and did not trigger a systematic punishment response. For research on "spiteful punishment" targeted to above-average contributors (see e.g., Falk et al. 2005, Herrmann et al. 2008).

${ }^{4}$ The social identity theory developed by Tajfel and Turner (1979) is specifically devoted to the analysis of the psychological basis for intragroup conflicts and intergroup discrimination.
} 
amount from in-group members than from the out-group members. They interpreted their results applying Akerlof and Kranton's identity-model (2000), according to which one's social identity can be threatened by the behavior of one's group members. Consequently, social identity triggers a special type of externality, meaning that the behavior of an in-group member affects other group members' identity and evokes responses in turn. Thus, the offers, which are considered as unfair by in-group members (as allocating too low amounts to the responder) might be seen as an identity-threat. ${ }^{5}$ Individuals will then invest in sanctioning more when faced by an unkind act of an in-group member than by an out-group member. Consequently, more negative reciprocity with in-group matches may be a means of reacting to the identity-threat (McLeish and Oxoby 2007).

On the contrary, Chen and Li (2009) reached opposite conclusions. They induced group identity based on preferences of Klee and Kandinsky paintings (for this method see Tajfel et al. 1971). Within two-person dictator and response games they found that participants are less likely to punish an ingroup member for misbehavior than an out-group member, thus being more forgiving towards a defection by an in-group member. Secondly, they established that in-group members show less envy in case the other group member receives higher payoffs than they do. It can thus be assumed that the well-being of in-group members constitutes a positive weight in an individual's utility function and that of outsiders a negative weight (Eaton et al. 2011). Consequently, the infliction of costly punishment on in-group members is not to be expected. Moreover, groups with high levels of identification tend to maintain group loyalties even after group failures or anticipated failures (cf. Jackson 2011, S. 345), which supports the findings of Chen and Li (2009). Thus individuals are not prone to punish their in-group matches, which is why less negative reciprocity may occur in in-groups than in out-groups.

Summing up, the existing literature suggests that social identity has an impact on subjects' preferences for negative reciprocity. The findings regarding the direction of its effect are, however, controversial and have only been tested in two-person games. Therefore, the aim of is article it to investigate how social identity affects negative reciprocity in identity homogeneous and heterogeneous groups in the provision of public goods. To investigate this question and gain more detailed insights on negative reciprocity in different social environments, we also devote particular attention to emotions that determine negative reciprocity. Emotion-specificity is important since its motivational implications are proximal causes of behavior (Zeelenberg and Pieters 2006, Elster 1998). Emotions often increase one's preference for acts that are contrary to economic interest, such as engaging in costly punishment when people believe they have been treated unfairly (Loewenstein 2000). Indeed, existing experimental research has shown that negative emotions such as anger, contempt, irritation (also referred to as anger-like emotions, ALEs) fuel negative reciprocity (e.g.,

\footnotetext{
${ }^{5}$ See the theoretical works of Akerlof and Kranton (2000) and Bénabou and Tirole (2006) on identity.
} 
Reuben and van Winden 2008, Bosman and van Winden 2002). Other negative emotions such as sadness and grief are declared as passive in evoking behavioral responses (Elster 1996). ${ }^{6}$ Since we have still no evidence of how ALEs fuel behavior depending on the social environment, it will be of particular interest over the course of this study.

Considering the existing findings and theories, we formulate the following hypotheses.

Hypothesis 1: Negative reciprocity is dependent on social environment.

We base this hypothesis on prior research of social psychology and economics on identity and assume that social environment does influence negative reciprocal preferences.

Furthermore, psychological research suggests that subjects reveal emotional reactions dependent on the social context (see Reuben and van Winden 2008 referring to works of Jakobs et al. 1996, 1999). Consequently, we assume that acts that are deemed unkind trigger different emotional intensities in in- and out-groups as the individual's connotations and behavior towards his group is influenced by social identity. Therefore, the intensity of ALEs felt when confronted by an unkind act can vary based on the matching protocol. Subsequently, the different action tendencies in the different social environments are attributable to the different intensity of emotions felt when facing unkind acts.

Hypothesis 2: Unkind acts trigger different emotional intensities in in- and out-groups.

\section{Experimental Design}

We designed an experiment that builds on and extends the studies of Noussair and Tucker (2005) ${ }^{7}$ and Reuben and van Winden (2008) and features three different subject matching treatments: an ingroup, an out-group and a control treatment (see Table 1). Each subject participated only in one of the treatments, so that our experiment follows a between subject design.

The experimental design was composed of three stages. In each stage every subject was a member of a group of three. Equally applying to all treatments, Stage A comprised a one-shot public good game (PGG) that was played in strategy method (SM).

\footnotetext{
${ }^{6}$ For thoughts on classification of emotions based on their motivational functions see Zeelenberg and Pieters (2006).

${ }^{7}$ We gratefully acknowledge Ch. Noussair, S. Tucker and U. Fischbacher for providing us with their experimental instructions.
} 


\begin{tabular}{|c|c|c|c|}
\hline Treatment Type & Stage A & Stage B & Stage $\mathrm{C}$ \\
\hline In-Group & \multirow{3}{*}{$\begin{array}{l}\text { One-Shot } \\
\text { PGG } \\
\text { in SM } \\
\text { Random } \\
\text { Matching }\end{array}$} & \multirow{2}{*}{$\begin{array}{l}\text { Induction of Social } \\
\text { Identity } \\
\text { Random Matching }\end{array}$} & $\begin{array}{c}\text { One-Shot PGG (SM) with Punishment } \\
\text { In-Group Matching }\end{array}$ \\
\hline Out-Group & & & $\begin{array}{l}\text { One-Shot PGG (SM) with Punishment } \\
\text { Out-Group Matching }\end{array}$ \\
\hline Control & & - & $\begin{array}{c}\text { One-Shot PGG (SM) with Punishment } \\
\text { Random Matching }\end{array}$ \\
\hline
\end{tabular}

Table 1 - The experimental design

Specifically, subjects were randomly assigned to groups and received an initial endowment of 20 points. ${ }^{8}$ Each group member (k) had to decide how many points to contribute to the public good, framed as a project $\left(c_{i}\right)$. The remaining points $\left(20-c_{i}\right)$ were automatically put into the subject's private account. The payoff function was as follows (Formula 1):

$$
E_{i}=20-c_{i}+0.4 \times \sum_{k=1}^{3} c_{k}
$$

\section{Formula 1 - Payoff function of stage $A$}

Consequently, each point invested into the project returned 0.4 points and each group member profited equally from contributions to the public good. Therefore, for every individual it is more beneficial to deposit all the endowment on the private account. Overall, the participants were required to make two types of decisions. On the one hand, they had to state their unconditional contribution to the project independent of the others' contributions. On the other hand, they were required to make 21 entries in a contribution table stating how much they would contribute to the project if their group members invested on average 0-20 points (conditional contribution). They were also required to state their expectations regarding the others' unconditional contribution. Finally, a random mechanism determined for which two group members their unconditional contributions were payoff-relevant, leaving the third group member with their conditional contribution in effect. ${ }^{9}$ Subjects did not receive any information about the outcome of Stage A in order to avoid any income effects. Stage A served the main purpose to classify subjects according to their revealed preferences ${ }^{10}$ into different cooperation types (see in detail in Section 4.4), unaffected by social

\footnotetext{
${ }^{8}$ During the course of the experiment we talked about points. The total number of points earned during the experiment was converted in Euros at the end of the experiment. The conversion rate was: 1 point $=15$ eurocents.

${ }^{9} \mathrm{~A}$ die was rolled by one participant in the session determining the respective group member. This served the purpose of making clear to the subjects that both investment decisions were potentially payoff-relevant and to be taken seriously.

${ }^{10}$ We are aware of the fact that preferences are not directly observable. Subjects' decisions are assessed first and preferences are then presumed from these observations (cf. Sen 1973).
} 
identity and/or punishment. This classification allows us to observe to what extent subjects with different preferences adjust their behavior dependent on group composition.

Stage B was in effect only in the in-group and out-group treatments. In order to induce social identity subjects were randomly reassigned to groups of three and they were asked to jointly solve a simple group task within 10 minutes time. An online chat tool allowed anonymous communication among the group members to create positive group experiences (Eckel and Grossman 2005). By developing this task, we relied on insights of Eckel and Grossman (2005) and Chen and Li (2009) and applied a design pioneered by Ibañez and Schaffland (2012). For this task, the participants of the experiment were assigned to groups of different colors. To avoid any income effects and to prevent negative associations with this task, only the winning group received a congratulating message at the end of the whole experiment.

Advancing to the next stage, treatment groups were either comprised of members from groups of the same color and thus of the same identity as in the previous stage (in-group treatment), or from groups with different colors and identities (out-group treatment). Additionally, we added a control treatment where participants were simply randomly assigned to the groups. In order to make group identity salient, the color of an individuals' group as well as the color of their group members were clearly indicated during the game both in in-group and out-group matching. Stage $C$ contained a one-shot public good game, the same as Stage A, but combined with the institution of peer punishment. After subjects stated their unconditional and conditional contributions and a random mechanism determined the payoff relevant decisions, they received information on how much each of their group members contributed to the project (anonymously). Simultaneously, they were asked to indicate how intensely they feel each of the listed emotions towards each of the other two players after knowing the amount that the others invested into the group account. ${ }^{11}$ In order to avoid an experimenter demand effect the list included many different emotions both of negative and positive valence based on Hopfensitz and Reuben (2009) and Reuben and van Winden (2008): admiration, anger, contempt, disappointment, envy, gratitude, irritation, happiness, pride, sadness, shame and surprise. After having indicated the intensity of specific emotions on a 7 point Likert-Scale (1=not at all, 7=very strongly), subjects had an opportunity to register their disapproval of each other group member's decision by distributing points $\left(P_{i k}\right)$ between 0 and 10 to each group member. Specifically, 10 points for the most disapproval, 0 points for the least disapproval. ${ }^{12}$ For each point a subject received $\left(\mathrm{P}_{\mathrm{ki}}\right)$ his/her income from this stage was lowered by 10 percent. If a group member received 10 or more

\footnotetext{
${ }^{11}$ Self-reports have been successfully applied in investigating subjects' emotional states. For detailed description see Reuben and van Winden (2008, pp. 37-38).

12 In the course of the experiment we used the phrase disapproval to be as neutral as possible when talking about punishment.
} 
points his/her income from this stage was reduced by 100 percent (see Formula 2). However, allocating points were costly (see Table 2).

$$
E_{i}=\left(20-c_{i}+0.4 \sum_{k=1}^{3} c_{k}\right) \times \frac{\max \left\{0,10-\sum_{k \neq i} P_{k i}\right\}}{10}-\left(\sum_{k \neq i} K\left(P_{i k}\right)\right)+\text { lumpsumpayment }
$$

Formula 2 - Payoff function of Stage C

In order to account for increased costs, subjects received a lump-sum payment of 60 points in addition to the basic endowment of 20 points from this stage (see Formula 2).

\begin{tabular}{llllllllllll}
\hline $\mathrm{P}_{i k}$ & 0 & 1 & 2 & 3 & 4 & 5 & 6 & 7 & 8 & 9 & 10 \\
$\mathrm{~K}\left(\mathrm{P}_{i k}\right)$ & 0 & 1 & 2 & 4 & 6 & 9 & 12 & 16 & 20 & 25 & 30 \\
\hline
\end{tabular}

Table 2 - Punishment points $\left(P_{i k}\right)$ and cost of punishment $(K)$

This one-off payment could be used to pay for possible costs during this task. Afterwards, subjects had to state how many punishment points they expected to receive in sum from the other group members. At the end of Stage $C$ subjects were informed about their income from Stage $A$ and $C$ and their final payment converted into Euro including the 2.5 Euro show-up fee.

The experimental instructions were handed out successively. After all subjects have completed the exercise questions regarding the one-shot public good game without punishment at the beginning of the experiment, they received the detailed instructions of stage A. At the beginning of stage $C$ participants had to complete another exercise concerning punishment's income effects. Finally, subjects were asked to fill out a post-experimental questionnaire before receiving payment. ${ }^{13}$

\section{Results}

The experiment was conducted during June and July of 2012 in the Göttingen Laboratory of Behavioral Economics (GLOBE) of the University of Göttingen applying the Z-tree software (Fischbacher 2007). The subjects were recruited through the ORSEE database of the University of Göttingen and at the campus' cafeterias. In sum, we observed the decisions of 207 subjects. In particular, 84 subjects participated in the in-group, 75 in the out-group and 48 in the control treatment. 50.2 percent of the subjects were female. The average age of the subjects was 23.4 years. The sessions took approximately 1.5 hours and the subjects on average earned 16.4 Euro including the show-up fee.

\footnotetext{
${ }^{13}$ Please see Appendix F for the English instructions to this experiment. The German Instructions are available upon request (Matthias.Lankau@wiwi.uni-goettingen.de).
} 
The main results of the experiment are represented in three parts. Firstly, we present the effects of social environment on negative reciprocity. Afterwards the intensity of specific emotions and their influence on punishment are discussed. Finally, the punishment behavior of specific cooperation types of subjects is investigated. ${ }^{14}$

\subsection{Dependency of negative reciprocity on social environment}

Initially, we compare the level of punishment points assigned between the treatments in case group members contributed less than the subject. Subjects assigned on average 1.5 points in in-groups and 2.3 points both in the out-group and control treatments. Overall, in-groups' punishment level is significantly lower as compared to the out-group $(p=0.0260)$ as well as to the control treatment $(p=0.0072)$. However, we cannot reject the hypothesis that subjects in the out-group and control conditions impose different levels of punishment. With regard to the frequency of sanctioning other group members when they contributed at least one point less than the subject, we find that within in-groups punishment occurred in only half (50.7 percent) of the cases. In contrast, out-group members punished significantly more frequently, namely in 67.7 percent of the cases. ${ }^{15}$ Likewise, in the control treatment - where no social identity was induced - punishment occurred at a significantly higher rate (80 percent) as compared to the in-group treatment. ${ }^{16}$ Furthermore, we notice that punishment is also present in situations when the group members contributed the same amount or even more to the public good than the subject did. The presence of the so called spiteful punishment is not entirely surprising and has been documented by many authors. ${ }^{17}$ However, neither the frequency nor the strength of such punishment was significantly different between the treatments. $^{18}$

The comparison of the relative punishment costs subjects were willing to incur serves as another measure of the differences in punishment behavior. These are expressed by the average share of punishment cost over profit earned in stage $C$ before punishment decisions were taken. Considering these, we find that in-group members dedicated the smallest share of their profit to punishment when their group members contributed inferior amounts than the subjects themselves. They were

\footnotetext{
${ }^{14}$ Please note that within this article we do not address the question of how punishment affects the willingness to cooperate in the different treatments. Consequently, we do not analyze unconditional and conditional contributions per se. For research on this subject see Bicskei et al. (2013).

${ }^{15}$ Pearson Chi-square test, chi2(1) $=4.0733, \mathrm{p}_{\text {in vs out }}=0.044$.

${ }^{16}$ Pearson Chi-square test, $\operatorname{chi} 2(1)=9.4239, \mathrm{p}_{\text {in v cont }}=0.002 ; \operatorname{chi} 2(1)=1.8345, \mathrm{p}_{\text {out vs cont }}=0.176$

${ }^{17}$ See footnote 4 .

${ }^{18}$ Please note that spiteful punishment distributed towards subjects contributing more than the punisher is not to be rationalized as "true" negative reciprocity. In case a subject contributes the same or higher amount to the public good than the punisher, it generates at least the same or even more income for the punisher. Therefore, this act is not to be perceived as "unkind". Consequently, only punishment, which is not of spiteful interest, is considered in the analysis.
} 
willing to devote only 14.1 percent of their income to signal their disapproval, while out-group and control members spent significantly more, specifically, 26.4 percent and 21.1 percent ( $p_{\text {in vs }}$ out $=0.0219, p_{\text {in vs cont }}=0.0034$ and $p_{\text {out vs cont }}=0.5128$ ) of their income on punishment. ${ }^{19}$

RESULT 1a: On average in-group members punish each other less and less frequently than outgroup and control members.

RESULT 1b: On average in-group members are willing to invest smaller shares of their profit in punishment than out-group and control members.

Result $1 \mathrm{a}$ and $1 \mathrm{~b}$ confirm the findings of Chen and Li (2009) highlighting that subjects matched with in-group members engage in less negative reciprocity than when interacting with out-group members. Consequently, these results contradict the findings of McLeish and Oxoby (2007) according to which punishment is greater within in-groups due to the perceived identity-threat caused by deviant behavior. Likewise, they oppose Reuben and van Winden (2008) who identified that there is an elevated propensity of in-group members to punish each other as compared to strangers in threeplayer power-to-take games.

For support of Result 1a we test first of all, whether there is a higher probability to engage in negative reciprocity in groups comprising individuals of different identities or unrelated individuals as compared to in-groups. Here, the dependent variable is coded as 1 when a subject engaged in negative reciprocity; otherwise it takes the value of 0 (Model A). Secondly, we investigate whether there is a higher probability of revealing higher negative reciprocity within out-groups as compared to in-groups. In this case the dependent variable equals 1 if the amount of punishment points the subject distributed is higher than the average punishment level (of the whole sample), and 0 otherwise (Model B). The results of these logistic estimations are summarized in Table 3. In both models, we included explanatory variables for treatments, different emotions, department and gender.

Our results support the previous finding that negative reciprocity is dependent on the social environment. In particular, within out-groups and stranger groups there is a significantly higher probability of being punished for behavior perceived as unkind than is the case within in-groups. For instance, the odds of punishing out-group members over the odds of punishing in-group members are 2.6. Moreover, there is a significantly higher probability for receiving punishment in randomly assigned groups than in identity homogenous groups. Additionally, we are able to show that there is a significantly higher likelihood of engaging in higher negative reciprocity in identity heterogeneous groups than in identity homogeneous groups. Similarly, the probability for higher negative reciprocity is much higher in the control treatment than in groups where group members share the same group

\footnotetext{
${ }^{19}$ Again, for spiteful punishment we did not find any significant treatment effect.
} 
identity. Summing up, we conclude that Hypothesis 1 cannot be rejected. Based on our data, we show that social environment decisively influences negative reciprocity. Lastly, our models point towards a significant influence of ALEs on negative reciprocity. An in-depth analysis of the ALEs' role on punishment will be provided in the next section.

\begin{tabular}{|c|c|c|c|c|c|c|}
\hline \multirow[b]{2}{*}{ Variable } & \multicolumn{3}{|c|}{ Model A - Negative Reciprocity } & \multicolumn{3}{|c|}{$\begin{array}{c}\text { Model B - Higher Negative } \\
\text { Reciprocity } \\
\end{array}$} \\
\hline & Odds Ratio & $\begin{array}{l}\text { Robust } \\
\text { Std. Error }\end{array}$ & p-value & Odds Ratio & $\begin{array}{l}\text { Robust } \\
\text { Std. Error }\end{array}$ & $\mathrm{p}$-value \\
\hline Out-group & $2.644^{* *}$ & 1.1662 & 0.028 & $2.521^{* *}$ & 1.0712 & 0.030 \\
\hline Control & $4.132 * * *$ & 2.2517 & 0.009 & $2.902^{* *}$ & 1.4054 & 0.028 \\
\hline Anger-like emotions & $1.497^{* * *}$ & 0.1849 & 0.001 & $1.529 * * *$ & 0.1648 & 0.000 \\
\hline Constant & $0.279 * *$ & 0.1337 & 0.008 & $0.160 * * *$ & 0.0754 & 0.000 \\
\hline Number of Obs. & 177 & & & 177 & & \\
\hline Log pseudolikelihood & -101.76933 & & & -107.10792 & & \\
\hline Wald chi2(3) & 16.83 & & & 18.59 & & \\
\hline Pseudo R2 & 0.1255 & & & 0.1265 & & \\
\hline Prob > Chi2 & 0.0008 & & & 0.0003 & & \\
\hline
\end{tabular}

Note: Variables: Out-group, Control are indicator variables, when In-group $=1$.

Anger-like emotions are calculated as a mean of emotions of anger, irritation and contempt

Clustered standard errors over Individuals. Stat. Sign.: ${ }^{*}<0.1,{ }^{* *} p<0.05,{ }^{* * *} p<0.01$

Table 3: Logistic regression estimates ${ }^{20}$ on the probability of engaging in negative reciprocity (Model

A) and of engaging in higher negative reciprocity (Model $B$ )

\subsection{The role of anger-like emotions in negative reciprocity}

In order to explain the differences in punishment behavior, in this section we address the question of whether the intensity of specific emotions differs between in-group and out-group members when facing unkind acts. ${ }^{21}$ We especially focus on anger-like emotions (anger, contempt and irritation) since they have a particularly high tendency to motivate punishment (see Elster 1998, Zeelenberg et al. 2008, Hopfensitz and Reuben 2009). In contrast, negative emotions such as disappointment and sadness are assumed as rather passive in the sense that they impact mainly on subjects' general negative mood (cf. Zeelenberg et al. 2008, Zeelenberg et al. 1998). Since anger, contempt and irritation are highly correlated emotions (see Appendix A), in subsequent analyses we combine these emotions into one variable by using their aggregate mean.

\footnotetext{
${ }^{20}$ We are aware of the fact that the standard errors of logit regressions could be biased (see Ai 2003). In our case the sign of the treatment variables is of crucial importance and must be interpreted according to the research hypothesis.

${ }^{21}$ Generally, we identify a relationship between negative emotions and punishment: pooling all subjects of all treatments, punishers report significantly higher intensities of negative emotions, while non-punishers report higher positive emotions. The emotion of surprise can be of dual valence. Evidently, as can be seen in Appendix B it seems to be irrelevant for punishment.
} 
Comparing the level of ALEs across the treatments, we find that the intensity of ALEs does not vary based on the matching protocol in case of negative deviation from a subject's own contribution ( $p_{\text {in vs }}$ out $=0.124, p_{\text {in vs cont }}=0.5635$ and $p_{\text {out vs cont }}=0.1706$ ). Consequently, our observation of differing punishment behavior depending on the social environment (see previous section) cannot be directly attributable to subjects' ALEs. Thus, we conjecture that group composition affects how a particular emotional intensity shapes behavior. ${ }^{22}$

In order to examine our conjecture, we subsequently investigate to what extent punishment is dependent on negative emotions. To this purpose, we classify subjects according to whether they indicated anger-like emotions. In particular, subjects who revealed ALEs higher than or equal to 2 are classified as "angry" subjects, while the remaining ones are defined as "non-angry" subjects. ${ }^{23}$ This classification allows us to capture the basic impact of ALEs on punishment.

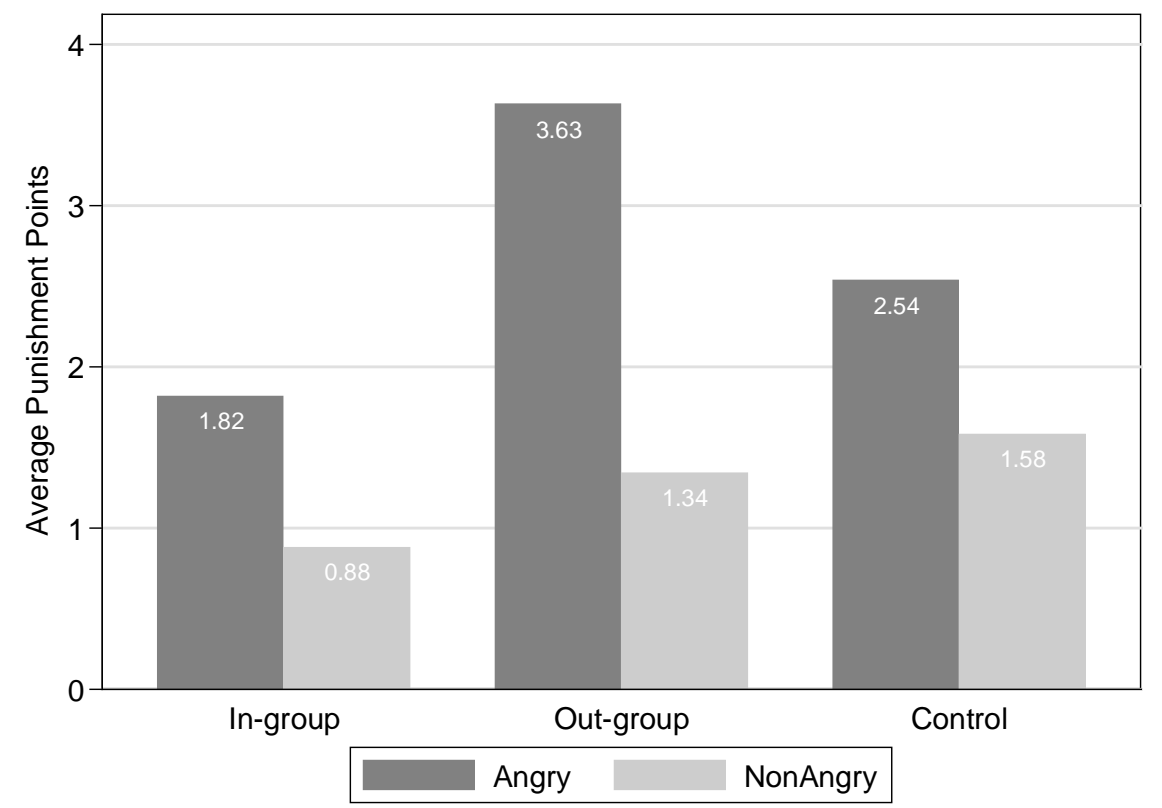

Figure 1 - Punishment dependent on anger-like emotions

As can be seen in Figure 1, across all treatments average levels of punishment points imposed by angry subjects are always higher than those of non-angry subjects. However, in contrast to the ID treatments in which these differences are highly significant $\left(p_{\text {in }}=0.015 ; p_{\text {out }}=0.0002\right)$, we do not find a marked difference between angry and non-angry punishment in the control matching $(p=0.1124)$. Moreover, the effect of ALEs tends to be strongest in out-group matching. While in-group subjects

\footnotetext{
${ }^{22}$ We tested whether the difference between a subject's own contribution and the contribution of the other group members triggers different levels of ALEs, but did not find statistically significant interaction terms. See Appendix C.

${ }^{23}$ Please recall that the intensity of specific emotions was indicated on a 7 -point Likert-Scale $(1=$ not at all, $7=$ very strongly). Thus, level 2 on this scale means the presence of ALEs.
} 
distributed approximately one punishment point more when they were angry, in out-group matching, this difference averaged 2.3 points. In addition, angry punishment within in-groups is significantly lower relative to angry punishment within out-groups and control groups $(p=0.0013$, $p=0.0292$, respectively), yet non-angry punishment does not differ significantly between the ID treatments $(p=0.1809)$. In sum, these results show that subjects are much more influenced by their emotional states when interacting in identity heterogeneous than in identity homogenous groups.

Regarding the occurrence of punishment (see Figure 2) we find that in all treatment conditions punishment is more frequent by angry than by non-angry subjects. In in-groups angry subjects imposed sanctions in 60 percent of the cases, while non-angry subjects distributed punishment points only in every fourth case. Compared to that, in identity heterogeneous groups there is a much higher proportion of angry subjects who distributed disapproval points for contributing less than they did, namely 90 percent. ${ }^{24}$ Non-angry punishment among out-group members occurred half as many times as angry punishment. In the control treatment the difference in the frequency of assignment of disapproval points among angry and non-angry subjects is less prominent than in case of the ID treatments. Nevertheless, control punishment among angry subjects is also more frequent than in-group angry punishment. ${ }^{25}$

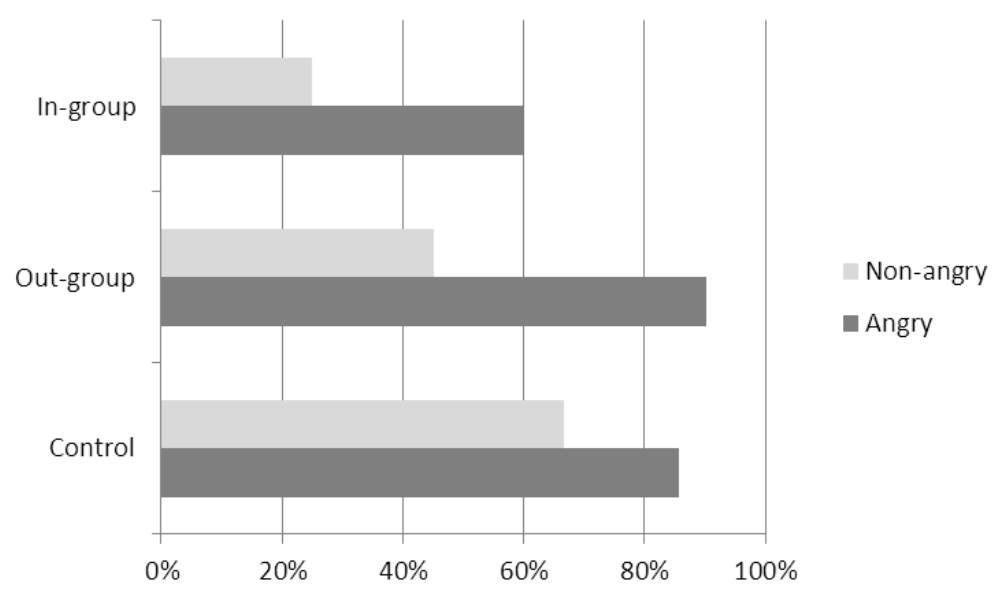

Figure 2 -The frequency of punishment among angry and non-angry subjects

These findings provide twofold insights about emotions and group composition. On the one hand, the high frequency of punishment among angry subjects and the relative high level of punishment points given in identity heterogeneous groups compared to identity homogeneous ones provide a hint that ALEs play a much more prominent role in motivating punishment behavior of out-group members than of in-group members. Put differently, we could conclude that in spite of the presence of ALEs, in-group members hesitate to punish other group members compared to subjects who

\footnotetext{
${ }^{24}$ Pearson chi2(1)=8.8407, $\mathrm{p}_{\text {in vs out }}=0.003$ (angry punishment) .

${ }^{25}$ Pearson chi2(1) $=5.7029, \mathrm{p}_{\text {in vs cont }}=0.017$ (angry punishment).
} 
interact in identity heterogonous groups. This indicates that group identity impacts on how subjects control their emotions. On the other hand, the effect of ALEs on punishment seems to be strongly present only when identity affiliation is salient.

In order to provide further support to what extent these conjectures are valid, we evaluate the influence of ALEs on punishment in the different matchings employing multivariate linear regressions (see Table 4). ${ }^{26}$ Beside ALEs, model C1 also includes the emotions of envy and shame as explanatory variables. ${ }^{27}$ We used control variables for gender and department (only in Model C1) and included interaction terms in order to detect differences in the impact of ALEs on punishment across treatments. Model C2 includes only the interactions terms.

\begin{tabular}{|c|c|c|c|c|c|c|}
\hline \multirow[b]{2}{*}{ Variable } & \multicolumn{3}{|c|}{ Model C 1} & \multicolumn{3}{|c|}{ Model C 2} \\
\hline & Coefficient & Std.Error & $\mathrm{p}$-value & Coefficient & Std.Error & $\mathrm{p}$-value \\
\hline \multicolumn{7}{|c|}{ Dependent Variable: Punishment Points } \\
\hline ALEs*Ingroup & $0.3734 * * *$ & 0.1310 & 0.005 & $0.435^{* * *}$ & 0.0803 & 0.000 \\
\hline ALEs*Outgroup & $0.686 * * *$ & 0.1467 & 0.000 & $0.718^{* * *}$ & 0.1226 & 0.000 \\
\hline ALEs*Control & $0.485^{* * *}$ & 0.1519 & 0.002 & $0.553 * * *$ & 0.1041 & 0.000 \\
\hline Envy & -0.021 & 0.1548 & 0.892 & & & \\
\hline Shame & 0.159 & 0.1987 & 0.425 & & & \\
\hline Economics & 0.068 & 0.3477 & 0.846 & & & \\
\hline Male & -0.127 & 0.3620 & 0.727 & & & \\
\hline
\end{tabular}

\begin{tabular}{lcc} 
ALEs*Ingroup - ALEs*Outgroup $=0$ & $F(1,118)=4.57 ;$ Prob $>F=0.0345$ & $F(1,118)=3.72 ;$ Prob $>F=0.0562$ \\
ALEs*Outgroup - ALEs*Control=0 & $F(1,118)=1.43 ;$ Prob $>F=0.2339$ & $F(1,118)=1.05 ;$ Prob $>F=0.3082$ \\
ALEs*Ingroup - ALEs*Control=0 & $F(1,118)=0.62 ;$ Prob $>F=0.4334$ & $F(1,118)=0.81 ;$ Prob $>F=0.3709$ \\
Number of obs & 177 & 177 \\
$F(7,118)$ & 15.48 & 30.62 \\
Prob $>F$ & 0.000 & 0.000 \\
R-squared & 0.5164 & 0.5114 \\
R-squared adj. & 0.4965 & 0.5030 \\
Root MSE & 2.12 & 2.11 \\
\hline \hline
\end{tabular}

Note: Clustered standard errors over Individuals.

Stat. Sign. ${ }^{*} p<0.1,{ }^{* *} p<0.05,{ }^{* * *} p<0.01 ;$ Male $=1$ if male, 0 if female;

Economics $=1$ if field of economics, 0 otherwise;

Table 4 - The impact of anger-like emotions on negative reciprocity ${ }^{28}$

First of all, our results show that ALEs significantly impact punishment behavior independent of whether subjects interact within in-group, out-group or randomly matched individuals. In line with our conjecture, the post-estimation Wald-tests of Models C1 and C2 support that the effect of ALEs on punishment is greater in out-groups relative to in-groups. An equivalent increase of ALEs by one

\footnotetext{
${ }^{26}$ Poisson estimation yields similar results, see Appendix E.

${ }^{27}$ Emotions of disappointment and sadness are omitted from the model due to their very high correlation with ALEs (see Appendix D).

${ }^{28}$ For robustness check see Appendix E.
} 
unit yields a higher increase in punishment in out-groups than in in-groups. Therefore, we conclude that ALEs indeed affect negative reciprocity more in identity heterogeneous than in identity homogenous groups. However, contrary to the initial conjecture, the effect of ALEs on punishment in the control treatment does not differ significantly from the ID treatments.

The results of this section can be summarized as follows:

RESULT 2a: Based on the social environment there is no significant difference in the intensity of anger-like emotions when facing unkind acts.

Consequently, we can reject our Hypothesis 2 that acts that are deemed unkind trigger different emotional intensities based on the social environment. Our data rather suggest that ALEs' impact on negative reciprocity varies based on the social environment. ALEs result in different action tendencies dependent on the group composition.

RESULT 2b: Anger-like emotions drive members of identity heterogeneous groups much more strongly to engage in negative reciprocity than members of identity homogenous groups.

RESULT 2c: In identity homogenous groups angry subjects distribute less punishment points and punish less frequently than angry subjects of identity heterogeneous groups.

\subsection{Cooperation Types and Punishment Behavior}

Having seen how anger-like emotions affect negative reciprocity in different group compositions, we now examine to what extent differences in punishment behavior are driven by certain cooperation types. These were identified based on their initially revealed preferences in Stage A without any influence of social identity and/or peer punishment. Specifically, we distinguish four cooperation types based on subjects' entries in the conditional contribution table. "Perfect conditional cooperators" (PCC) are individuals who exhibit a significant Spearman rank correlation coefficient higher than $0.8(p<0.1)$ between own conditional contributions and others' average contributions ( 0 20) and do not contribute to the public good in case the others' average contribution is zero. This restriction allows eliminating a possible altruistic motivation for cooperation. Accordingly, these subjects are almost perfectly willing to reciprocate their group members' behavior. In order to be classified as "weak conditional cooperators" (WCC) conditional contributions and others' average contributions need to be only positively correlated $(p<0.1)$ allowing for greater deviations in contributions. Thus, individuals of this group are willing to reciprocate the behavior of group members only to a limited extent. Subjects are classified as self-interested "free-riders" (FR) in case they invest all their endowment (both conditionally and unconditionally) in their private account, thus contributing nothing to the public good. Remaining subjects were classified as "others" (OT). 
As can be seen in Table 5, the level of punishment points distributed by perfect conditional cooperators is 1.8 points on average in all matching protocols. Moreover, the frequency with which PCCs distributed punishment points is similar, as well. ${ }^{29}$ Consequently, we assume that the punishment behavior of subjects with high levels of revealed reciprocal preferences was not influenced by the ID matching protocol, and PCCs do not drive differences in punishment behavior.

Weak conditional cooperators behaved slightly differently dependent on the matching protocol. They punished group members with lower contributions more in out- and control groups than in ingroups. However, these differences cannot be verified as statistically significant $\left(p_{\text {in v out }}=0.5023, p_{\text {in vs }}\right.$ $\left.{ }_{\text {cont }}=0.2174\right)$. Regarding the frequency of punishment, we only find differences between in-group and control treatments. ${ }^{30}$ As a result, we conclude, that WCCs are not responsible for possible differences in punishment behavior between in- and out-groups, either.

\begin{tabular}{crrrr} 
& \multicolumn{4}{c}{ Cooperation Type } \\
\cline { 2 - 5 } Treatment Type & PCC & WCC & FR & OT \\
\hline \hline In-group & & & & \\
Punishment & 1.8 & 2.0 & 0.0 & 0.5 \\
Frequency & $58 \%$ & $55 \%$ & $0 \%$ & $33 \%$ \\
\hline Out-group & & & & \\
Punishment & 1.8 & 2.5 & 3.6 & 2.6 \\
Frequency & $67 \%$ & $67 \%$ & $80 \%$ & $57 \%$ \\
\hline Control & & & & \\
Punishment & 1.8 & 3.2 & 0.0 & 3.0 \\
Frequency & $69 \%$ & $100 \%$ & $0 \%$ & $100 \%$ \\
\hline \hline
\end{tabular}

Table 5 - Average punishment points assigned by cooperation types and the frequency of punishment

As Table 5 illustrates, free-riders exhibit considerable differences in punishment depending on the matching protocol. Before interpreting the data, please note that free-riders identified in Stage $A^{31}$ contributed positive amounts to the public good under punishment (in stage C). Especially, while they were willing to invest in the project on average 3.5 points in the in-group and 2.25 in the control treatment, in out-groups they increased their contributions to the public good up to 9.1 points ( $p_{\text {in vs }}$ out $=0.0153) .{ }^{32}$ On the one hand, this provides a hint that the fear of being punished for misbehavior is greater in out-groups than in in-groups (cf. Bicskei et al. 2013). On the other hand, it clarifies why the frequency of punishment by free-riders in in- and random groups is zero. In the analysis we pay attention only to non-spiteful punishment, thus inflicting sanctions for lower contributions. Since

\footnotetext{
${ }^{29}$ Pearson chi-square test, chi2 $(1)=0.6356, p_{\text {in vs out }}=0.425 ; \operatorname{chi} 2(1)=0.9172, p_{\text {in vs cont }}=0.338 ; \operatorname{chi} 2(1)=0.0438, p_{\text {out vs cont }}=0.834$.

${ }^{30}$ Pearson chi-square test, chi2(1)=0.3540, $p_{\text {in v out }}=0.552 ; \operatorname{chi} 2(1)=3.8636, p_{\text {in v cont }}=0.049 ; \operatorname{chi} 2(1)=2.5714, p_{\text {out vs cont }}=0.109$.

${ }^{31}$ In stage $A$ an identical number of free-riders was found both in in-groups and out-groups (18 subjects).

${ }^{32}$ Furthermore, free-riders in out-group expected higher average group contribution (10.1 points) than free-riders in ingroup (5.7 points). The hypothesis, however, that these amounts are equal cannot be rejected $(p=0.2224)$.
} 
free-riders of the mentioned groups contributed very low amounts, their group members' cooperation was higher. Thus, in control treatment not a single free-rider allocated punishment points. In in-groups there was only one free-rider fulfilling this, however, he did not assign any punishment points to the other group members for contributing less than he did. In out-groups 8 of 10 free-riders distributed punishment points (4.5 points on average)..$^{33}$ Due to the low number of punishing in-group free-riders, the difference in punishment between in- and out-groups is not significant $(p=0.1965)$. Nevertheless, we conjecture that the difference in punishment level of ingroups and out-groups might be partly driven by the behavior of free-riders.

Subjects, classified as "others", disclose different punishment attitudes based on social environment, as well ( $p_{\text {in vs out }}=0.0804, p_{\text {in vs cont }}=0.0002, p_{\text {out v cont }}=0.4799$ ). The frequency of punishment among these subjects varies also depending on the matching protocol. ${ }^{34}$ Therefore, this class also accounts to some extent for detected differences in punishment attitudes between identity homogenous and heterogeneous groups or groups of unrelated individuals.

RESULT 3: Differences in negative reciprocity between identity homogenous and heterogeneous groups or groups of unrelated individuals cannot be solely explained by cooperation types.

\section{Summary}

"The endogeneity of preferences implies that not only individual preferences [...] determine economic outcomes, but also that the economic, social, legal, and cultural structure of society affects preferences" (Palacios-Huerta and Santos 2004, S. 601). Within this article our aim is to show how the social environment in which interactions take place affects negative reciprocity. In particular, our interest is, first of all, to contribute to the understanding of how social identity shapes punishment behavior in identity homogenous and heterogeneous groups when providing public goods. Secondly, we pay particular attention to the role of anger-like emotions as they account for negative reciprocity depending on the social environment. We conducted one-shot public good games with in-group, outgroup and random matching protocols to investigate these questions.

At the start we demonstrate that in-group subjects clearly engage in the lowest degree of negative reciprocity. In particular, we find that contributions perceived as unkind are punished less frequently and with lower intensity among subjects who share the same identity than in out- and stranger groups. Interestingly, in contrast to our expectations, deviant behavior does not evoke different intensities of anger-like emotions (anger, contempt, irritation) depending on the matching protocols.

\footnotetext{
${ }^{33}$ The fact that under punishment free-riders adjust their behavior and contribute to the public good, seems to be rational since they want to avoid monetary losses. The fact, however, that they engage in punishment in spite of the costs involved in one-shot interactions, is quite surprising.

${ }^{34}$ Pearson chi2(1)=1.1905, $\mathrm{p}_{\text {invsout }}=0.275 ; \operatorname{chi} 2(1)=9.9048, \mathrm{p}_{\text {in v cont }}=0.002 ; \operatorname{chi} 2(1)=4.2857, \mathrm{p}_{\text {out v cont }}=0.038$.
} 
Thus, we argue that these emotions could not be responsible for the differences in punishment behavior. Building on these findings, we investigated the dependency of negative reciprocity on ALES across treatments. Generally, we demonstrate that negative emotions have a decisive impact on punishment. In case group identities are salient, however, marked differences emerge between the ID matching protocols. Specifically, we posit that anger-like emotions fuel negative reciprocity in ingroups much less than in out-groups signaling that identity homogenous matching situations can mitigate the effect of emotions on punishment. Thus, group-identity impacts on how subjects control their emotions to the benefit of their group. Summing up, our results suggest that subjects in identity heterogeneous groups will engage in negative reciprocity with higher probability when they are confronted with an act they perceive as unkind than in identity homogenous groups. In addition, anger-like emotions exhibit a particularly higher propensity to invoke negative reactions in such situations.

Accordingly, our findings deliver an additional explanation of why the level of social welfare achieved in identity heterogeneous groups tends to be lower than in homogenous groups. ${ }^{35}$ On the one hand, previous research revealed that members of homogenous groups reciprocate cooperation of their ingroup members by much higher own cooperation than members of heterogeneous groups among each other (Chen and Li 2009, Lankau et al. 2012), which increases social welfare. Our results show clearly, on the other hand, that social identity creates an environment in which negative reciprocal preferences are differently affected depending on group composition, as well. Heterogeneous groups tend to react more negatively to defections than homogenous groups. This bears the consequence of decreasing social welfare as engaging in negative reciprocity is costly for both the punished and punishers. Moreover, if we assume that a determining part of human behavior is mostly of reciprocal nature (cf. Falk and Fischbacher 2000, Falk 2003 ), our results provide an additional explanation of why real life instances of negative reciprocity such as crime and exploitation of common goods are rather widespread in fragmented and polarized (heterogeneous) societies (Eaton et al. 2011).

Thus, understanding the nature of social identity and its impact on reciprocity is of crucial importance in improving economists' ability to predict behavior in order to draw policy recommendations. In particular, our study delivers insights about the impact of group composition when public policy addresses one's social identity. This is of high relevance since next to positive reciprocity subjects' preferences for negative reciprocity are affected, as well. We demonstrate that this may equally result in losses of social welfare depending on the group composition.

\footnotetext{
${ }^{35}$ For experimental evidence see Lankau et al. (2012). The empirical non-experimental evidence is nicely overviewed by Eaton et al. (2011).
} 


\section{Acknowledgement:}

We gratefully acknowledge the comments of Marcela Ibañez Diaz, Claudia Keser, András Dobó, Torben Behmer, Laura Birg, and Maximilian Riedl. We also thank of the participants of the Thurgau Experimental Meeting 2012 and the CEGE research colloquium 2012 for the constructive comments to the previous version of this paper. 


\section{Appendix}

A. Correlation matrix of anger-like emotions

\begin{tabular}{|l|l|l|l|}
\hline & Anger & Contempt & Irritation \\
\hline Anger & 1.0000 & & \\
\hline Contempt & $0.8419^{* * *}$ & 1.0000 & \\
\hline Irritation & $0.7814^{* * *}$ & $0.7730^{* * *}$ & 1.0000 \\
\hline
\end{tabular}

Note: ${ }^{* *} \mathrm{p}<0.01$

B. Emotions of Punishers (P) and Non-Punishers (NP) (all subjects)

\begin{tabular}{|c|c|c|c|c|c|c|}
\hline & Admiration(1) & Anger(2) & Contempt(3) & Disappointment(4) & Envy(5) & Gratitude(6) \\
\hline In-group & - & $\mathrm{NP}<\mathrm{P}^{* * *}$ & $\mathrm{NP}<\mathrm{P} * * *$ & $\mathrm{NP}<\mathrm{P} * * *$ & $\mathrm{NP}<\mathrm{P} *$ & $\mathrm{P}<\mathrm{NP} *$ \\
\hline Out-group & $\mathrm{P}<\mathrm{NP} * * *$ & $\mathrm{NP}<\mathrm{P} * * *$ & $\mathrm{NP}<\mathrm{P} * * *$ & $\mathrm{NP}<\mathrm{P}^{* * *}$ & $\mathrm{NP}<\mathrm{P} *$ & $\mathrm{P}<\mathrm{NP} * * *$ \\
\hline Control & $\mathrm{p}<\mathrm{NP} * * *$ & $\mathrm{NP}<\mathrm{P}^{* * *}$ & $\mathrm{NP}<\mathrm{P}^{* * *}$ & $\mathrm{NP}<\mathrm{P}^{* * *}$ & - & $\mathrm{P}<\mathrm{NP} * * *$ \\
\hline Total & $\mathrm{P}<\mathrm{NP} * * *$ & $\mathrm{NP}<\mathrm{P}^{* * *}$ & $\mathrm{NP}<\mathrm{P} * * *$ & $\mathrm{NP}<\mathrm{P} * * *$ & $\mathrm{NP}<\mathrm{P} * * *$ & $\mathrm{P}<\mathrm{NP} * * *$ \\
\hline
\end{tabular}

\begin{tabular}{|c|c|c|c|c|c|c|}
\hline & Irritation(7) & Joy(8) & Pride(9) & Sadness(10) & Shame(11) & Surprise(12) \\
\hline In-group & $\mathrm{NP}<\mathrm{P} * * *$ & $\mathrm{P}<\mathrm{NP} * * *$ & - & $\mathrm{NP}<\mathrm{P} *$ & - & - \\
\hline Out-group & $\mathrm{NP}<\mathrm{P} * * *$ & $\mathrm{P}<\mathrm{NP} * * *$ & $\mathrm{P}<\mathrm{NP} * *$ & $\mathrm{NP}<\mathrm{P} * * *$ & - & - \\
\hline Control & $\mathrm{NP}<\mathrm{P} * * *$ & $\mathrm{P}<\mathrm{NP} * * *$ & $\mathrm{P}<\mathrm{NP} *$ & $\mathrm{NP}<\mathrm{P} * * *$ & $\mathrm{NP}<\mathrm{P}^{*}$ & - \\
\hline Total & $\mathrm{NP}<\mathrm{P} * * *$ & $\mathrm{P}<\mathrm{NP} * * *$ & $\mathrm{P}<\mathrm{NP} * * *$ & $\mathrm{NP}<\mathrm{P} * * *$ & $\mathrm{NP}<\mathrm{P} *$ & - \\
\hline
\end{tabular}

Sign.: $\left({ }^{*} p<0.1,{ }^{* *} p<0.05, * * * p<0.01\right)$ 
C. Comparison of the effect of contribution difference on anger-like emotions between the treatments

$\underline{\text { Linear Regression }}$

\begin{tabular}{lccc}
\hline \hline \multicolumn{1}{c}{ Variable } & Coefficient & Std.Error & p-value \\
\hline \hline Dependent Variable: ALEs & & & \\
& & & \\
Negative Devition from own contribution & $0.2026^{* * *}$ & 0.0411 & 0.000 \\
Positive Devition from own contribution & -0.0259 & 0.0183 & 0.158 \\
Field of economics & 0.2456 & 0.1844 & 0.184 \\
Male & 0.0222 & 0.1889 & 0.907 \\
Outgroup & -0.1249 & 0.2101 & 0.553 \\
Control & -0.0245 & 0.2510 & 0.922 \\
Outgroup*Neg.Dev. & -0.0272 & 0.0604 & 0.653 \\
Control*Neg.Dev. & 0.0072 & 0.0638 & 0.911 \\
Constant & $1.7354^{* * *}$ & 0.2172 & 0.000 \\
& & & \\
F( 8, 206) & 10.22 & & \\
Number of Obs. & 414 & & \\
Prob > F & 0.000 & & \\
R-squared & 0.281 & & \\
Root MSE & 1.4793 & & \\
\hline \hline
\end{tabular}

Note: Clustered standard errors over Individuals.

Stat. Sign.: ${ }^{*} p<0.1,{ }^{* *} p<0.05,{ }^{* * *} p<0.01$; Male $=1$ if male, 0 if female;

Economics $=1$ if field of economics, 0 otherwise;

Outgroup, Control are indicator variables, when In-group $=1$.

\section{Correlation of the determinants of punishment}

\begin{tabular}{|l|c|c|c|c|c|}
\hline & ALEs & Disappointment & Sadness & Envy & Shame \\
\hline ALEs & 1.0000 & & & & \\
\hline Disappointment & $0.7827 * * *$ & 1.0000 & & & \\
\hline Sadness & $0.5822^{* * *}$ & $0.4913^{* * *}$ & 1.0000 & & \\
\hline Envy & $0.3400^{* * *}$ & $0.2166^{* * *}$ & $0.3953^{* * *}$ & 1.0000 & \\
\hline Shame & $0.2870^{* * *}$ & $0.2468^{* * *}$ & $0.5054 * * *$ & $0.3844^{* * *}$ & 1.0000 \\
\hline
\end{tabular}

Sign.:***p<0.01 


\section{E. Robustness check}

Poisson Regression

\begin{tabular}{lrrr}
\hline \multicolumn{3}{c}{ Model C 1 } \\
\hline \hline Variable & Coefficient & Std.Error & p-value \\
\hline \hline Dependent Variable: Punishment Points & & \\
& & & \\
ALEs*Ingroup & $0.1570^{* * *}$ & 0.0602 & 0.009 \\
ALEs*Outgroup & $0.2575^{* * *}$ & 0.0426 & 0.000 \\
ALEs*Control & $0.2052^{* * *}$ & 0.0562 & 0.000 \\
Envy & -0.0404 & 0.0692 & 0.560 \\
Shame & 0.0496 & 0.0812 & 0.541 \\
Economics & -0.0296 & 0.1765 & 0.867 \\
Male & -0.1875 & 0.1893 & 0.322
\end{tabular}

ALEs*Ingroup - ALEs*Outgroup $=0$ ALEs*Outgroup - ALEs*Control $=0$ ALEs*Ingroup - ALEs*Control $=0$

Number of obs

Wald chi2(7)

Prob $>$ F

Log pseudolikelihood chi $2(1)=3.58$ Prob $>$ chi $2=0.0585^{*}$

chi $2(1)=1.0$ Prob $>$ chi $2=0.3163$

chi2(1) $=0.85$ Prob $>$ chi $2=0.3559$

177

107.02

0.000

$-353.04806$

Note: Clustered standard errors over Individuals.

Stat. Sign.: ${ }^{*} p<0.1,{ }^{* *} p<0.05,{ }^{* * *} p<0.01$; Male $=1$ if male, 0 if female;

Economics $=1$ if field of economics, 0 otherwise;

\section{F. Instructions to the Experiment}

Welcome to the experiment! Thank you very much for your participation.

If you read the following instructions carefully, you get the chance of winning money additional to the $€ 2.50$, which you receive in any case. Your earnings will depend on your decisions and on those by the other players in your group. At the end of the experiment all sums of money, which you will have earned through your decisions, will be added and given to you personally and in cash.

It is forbidden to speak during the experiment. If you have any questions, please raise your hand. A member of our team will come to you and answer your question privately.

We will be talking about points rather than Euros in the course of the experiment. Hence, your total income will be calculated in points in the first instance. The total number of points which you will achieve during the experiment will be converted in Euros at the end, using the following equation:

1 point $=17$ Cents

All participants will be divided in groups with 3 players each. Except for us, i.e. the conductors of the experiment, nobody will know who is in which group. All decisions will be made anonymously and your identity will neither be revealed during the experiment nor in public.

Each task of the experiment has its own instructions, which you have to read step by step. While doing so, please consider the respective hints which will appear on the monitor.

Please click on OK when you are ready. 


\section{The Basic Decision Situation}

Later, you will be informed about the experiment's procedure in detail. At this point, we would like to introduce the basic decision conditions you will face in this experiment. Some example exercises can be found subsequently.

At each point in time, you will be a member of a group consisting of $\mathbf{3}$ players. In every task, you hold 20 points. Your task is to decide whether you invest these 20 points in a private account or whether you want to invest them fully or partly in a project. Each point which you do not invest in a project will be automatically deposited on your private account.

\section{Your income from your private account:}

For each point which you deposit on your private account (and, therefore, you do not invest in the project), you will earn one point. Hence, a deposit of 20 points on your private account will produce an income of 20 points from your private account. If you, for instance, deposit 6 points on your private account, you will earn 6 points from this account. Nobody except you will earn anything from your private account.

\section{Your income from the project:}

All group members will profit equally from your contribution to the project. Vice versa, you profit from the investments by other group members. The income every member gets from the project is calculated as follows:

income from the project $=$ (sum of all contributions to the project) $\times 0.4$

Should the sum of all contributions to the project be, for example, 30 points then you and all other group members gain $(30 \times 0.4)=12$ points each from the project. Should the sum of all contributions to the project be, for example, 10 points then you and all other group members gain $(10 \times 0.4)=4$ points each from the project.

Your total income:

Your total income is the sum of your income from your private account and your income from the project.

$\begin{aligned} & \text { Income from the private account }(=20-\text { your contribution to the project) } \\ & + \text { Income from the project }=(\text { sum of all contributions to the project }) \times 0.4\end{aligned}$
total income

\section{Exercise Questions}

Please complete the following exercises. They do merely serve the purpose of familiarising you with the calculation of the different sorts of income, which may occur to you when making different decisions on the use of the 20 points starting capital.

Please complete all the exercises and always report your full mathematical procedure. While calculating, you may use the calculator function on the monitor. When you are done, you have to enter your results in the computer.

1. Each group member has 20 points at their disposal. Imagine that all three group members (including yourself) do not contribute anything to the project.

a. What is your total income? .....

b. What is the total income of each of the other group members? .....

2. Each group member has 20 points at their disposal. You invest 20 points in the project. The other two group members also contribute 20 points to the project.

a. What is your total income? .....

b. What is the total income of each of the other group members? ..... 
3. Each group member has 20 points at their disposal. The other two group members contribute 10 points each (i.e., 20 points in total) to the project.

a. What is your total income if you, additional to the 20 points, contribute 0 points to the project?

b. What is your total income if you, additional to the 20 points, contribute 5 points to the project?

c. What is your total income if you, additional to the 20 points, contribute 15 points to the project?

d.

4. Each group member has 20 points at their disposal. You contribute 7 points to the project.

a. What is your total income if the other group members, additionally to your 7 points, contribute 1.5 points each, i.e., 3 points in total, to the project?

b. What is your total income if the other group members, additionally to your 7 points, contribute 4 points each, i.e., 8 points in total, to the project?

c. What is your total income if the other group members, additionally to your 7 points, contribute 9 points each, i.e., 18 points in total, to the project?

d.

\section{First Task}

You are now the member of a group of three, which was put together randomly.

The task contains the decision, which was described at the beginning and is only conducted once.

As you know, you have $\mathbf{2 0}$ points at your disposal, which you can either invest in the project or deposit on your private account.

In this task, every group member has to make two types of decisions, which we will term (1) the "unconditional" contribution to the project, or the (2) "conditional" contribution to the project (the contribution table), respectively.

Both decisions are vital for your income from this task. So please make your decisions thoughtfully.

Step 1: Your Unconditional Contribution to the Project

Please determine how many of your points you, without knowing the contributions of the other group members, want to invest in the project. Please enter this amount into the following computer screen:

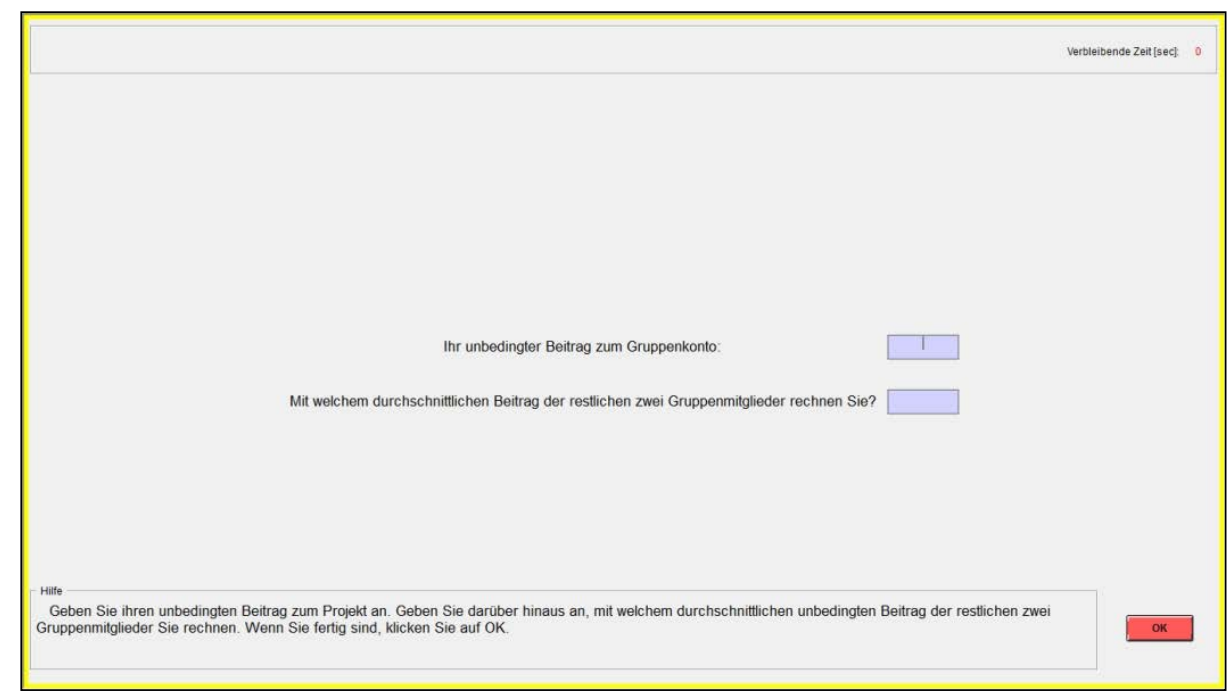

Please state what you expect each of the other two group members to contribute to the project (average amount of money they invest in the project).

Once you have made both statements, please click on OK. 


\section{Step 2: Your Conditional Contribution to the Project - the Contribution Table}

With your second decision you have to fill in a contribution table. In the contribution table you have to enter your contribution to the project for every possible average contribution (rounded up) of the other group members. Hence, you can, dependent on the average contribution of the others, determine your decision on your contribution. You will get a clear hint of what to do when you take a look at the following screen.

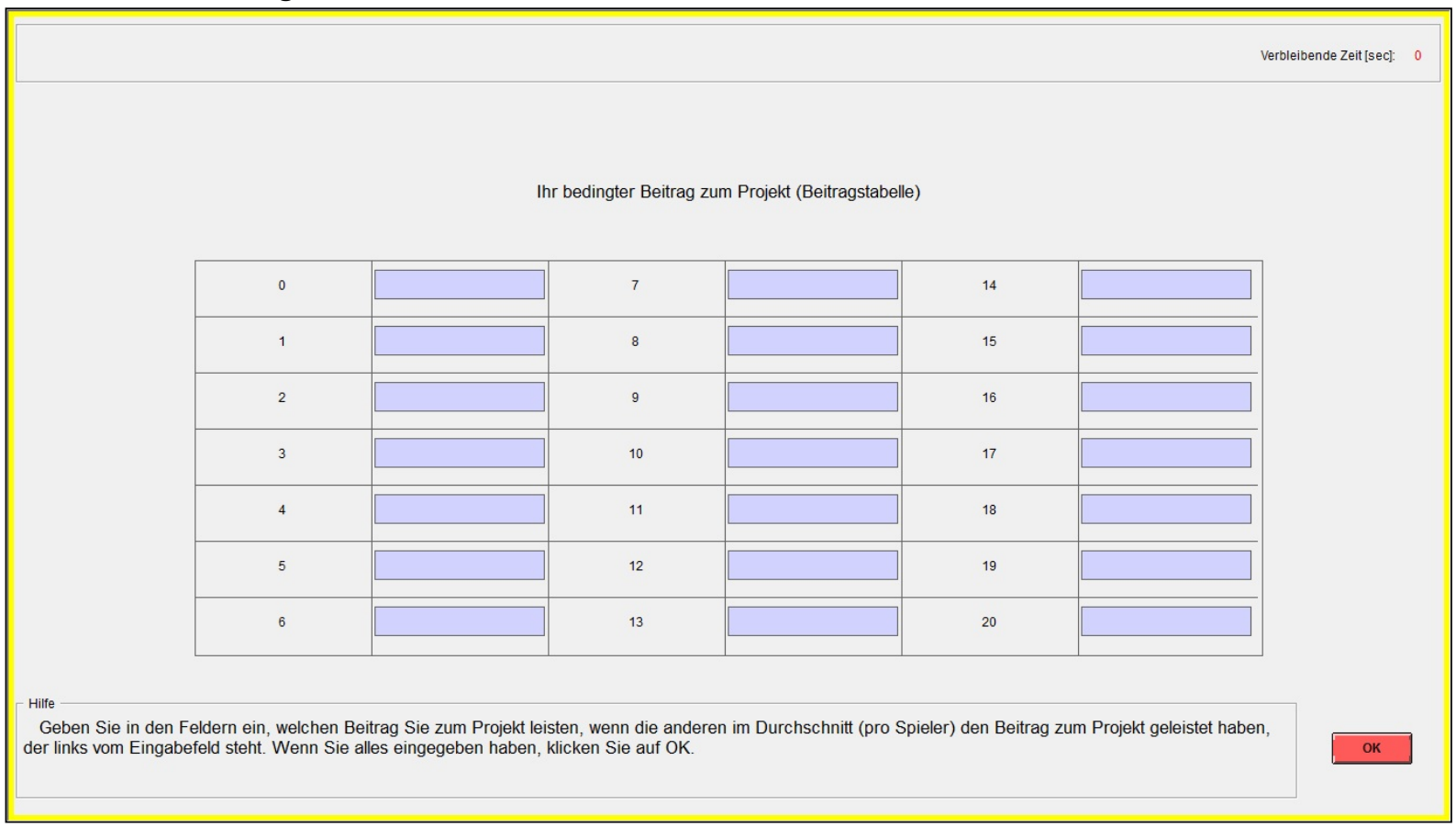

The numbers left to the boxes mark the possible average contributions, which the other members can make to the project. You just have to enter in each box how much you, under the condition that the others contribute the stated average amount, want to invest in the project. You have to make an entry in each box.

For example, you have to enter how many points you want to invest in the project if the other group members contribute 0 points; how many points you invest if the others contribute 1, 2 or 3 points and so on and so forth. You can enter integral numbers ranging from 0 to 20 in each box.

Once you have typed a number in each box, please click on OK.

After all participants in the experiment made their decision on their conditional contribution and filled in the contribution table, one member of each group is selected at random. For these selected members only the contribution table is relevant for their decisions and payoff. For the other two group members, who were not selected by the random choice mechanism, only the unconditional contribution is relevant for their decisions and payoff. The average of both unconditional contributions by these two group members defines which contribution by the selected member shall be invested in the project.

When you make the decision on your unconditional contribution and fill in the contribution table, you do of course not know if you will be picked at random. Hence, you have to make both decisions carefully, because both can become relevant for you. The following examples will explain the procedure:

Example 1: You are selected by the random choice mechanism. Therefore, the contribution table is relevant for your payoff. For the other two group members the unconditional contributions are relevant. 
Let us assume that the other two group members invest 0 and 4 points in the project, which would mean an average contribution of two points. If you entered in the contribution chart that you would invest 1 point if the others averagely invested 2 points, then this would make a total contribution of $0+4+1=5$ points to the project. All group members would then earn $5 \times 0.4=2$ points from the project plus the respective incomes from their private accounts, in your case $20-1=19$ points. Your income would then be 21 points.

If you, however, stated that you would invest 16 points, if the others averagely invested 2 points, this would make a total investment of $0+4+16=20$ points in the project. As a result, all group members would receive a payoff of $20 \times 0.4=8$ points plus the income from their private accounts, in your case $20-16=4$ points. Your total income would then be 12 points.

Example 2: You are not selected by the random choice mechanism. For you and another group member then your unconditional contribution to the project is the relevant decision.

Let us assume that your unconditional contribution to the project is 16 points, the contribution by the other group member is 20 points. This makes an average contribution of 18 points to the project. Should the player who was selected by the random choice mechanism have stated that he or she would contribute 1 point to the project if the other group members averagely invested 18 points, then the total contribution to the project would be $16+20+1=37$ points. All group members then would earn $37 \times 0.4=14.8$ points from the project additional to their respective income from their private accounts. In your case you would earn $20-16=4$ points from your private account, which would then make a total income of 18.8 points.

Should the selected group member have stated an investment of 19 points to the project if the others averagely invested 18 points, then the total contribution to the project would be $16+20+19$ $=55$ points. Every group member would have a project income of $55 \times 0.4=22$ points plus their points from their private account, in your case 4 points. Your total income would then be 26 points.

\section{The Random Choice Mechanism}

At the beginning of this game each group member receives a number between 1 and 3 . As you might remember, one participant, namely no. 8 , was selected at the beginning of the experiment. This participant will dice a number between 1 and 6 after all participants decided on their unconditional contribution and filled in the contribution table. The numbers 1 and 2 stand for group member one, 3 and 4 for group member two and 5 and 6 for member three. Participant no. 8 will enter these in the computer. In case no. 8 dices the numbers which correspond to your member number, the contribution table will be relevant for your decisions and payoff and for the other group members the unconditional contribution will be relevant. In any other case the unconditional contribution is relevant for you.

Please click on OK once you have read and understood the instructions.

\section{Second Task}

\section{Please note: Do not open the attached envelope before you are asked to do so!}

For the second task, you will be arbitrarily assigned a new group, which will be marked by a specific colour.

Only those solutions which are given correctly by ALL THREE group members will be considered correct in this group task.

During this task the group members are allowed to communicate with each other. By doing so, they can find a solution together. On the left hand side of the computer screen a chat box is positioned, which can be used for communication. Your conversation will be recorded. You have 10 minutes to solve the task. Only within this time span are you able to communicate with your team members. Please take into account that every group member has to type in the solutions which will have been 
found by your group. You have to click on OK before the 10 minutes have run out. The time left will be shown to you in the upper right hand corner of your screen.

All participants will be shown a picture and a list of objects. The task is to find the hidden objects in the picture. The inscriptions on the left and the upper side give the numbers of the lines and columns. You are asked to insert this information in the boxes which will be shown on the right hand side of the screen. The first box refers to a line, the second to a column. An example for this exercise is given below.

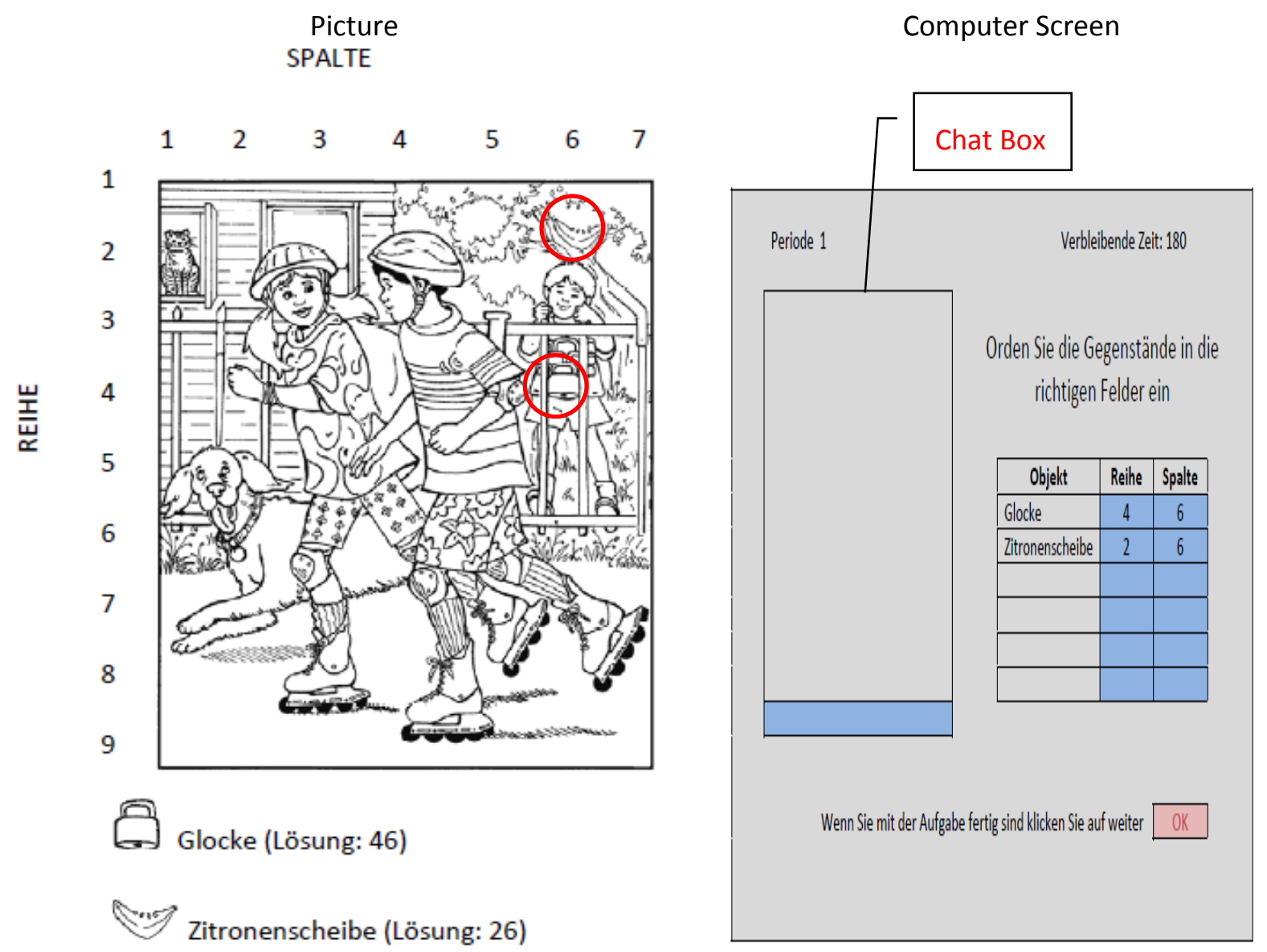

The group which finds most of the objects in the 10 minutes time is the winner group. At the end of the experiment you will be informed whether you are a member of the winner group. In this case, you will receive a congratulation message.

Please click on OK when you are ready.

\section{Third Task}

This task corresponds to the first one. It is conducted only once.

This time, however, you will only play together with members of your own group, with who you solved the picture puzzle in the second task.

Again, you receive a basic endowment of 20 points.

In addition to this basic endowment, every participant receives an amount of 60 points (extra endowment) in this task. This one-off payment can be used to pay for possible costs during this task. This task consists of two stages and is conducted only once. 


\section{Stage 1:}

Please decide how many of your $\mathbf{2 0}$ points (basic endowment) you want to invest in the project and how many you want to put on your private account.

This task also consists of two decisions, your (1) unconditional contribution to the project and (2) the contribution chart, with which you can make your decisions conditional on the other group members' contributions.

Please decide very carefully in both cases, for both the unconditional contribution and your input into the contribution chart are potentially relevant for the payoff. To determine the relevance of the decision, we will use the same random choice mechanism as before.

Your income from this stage will be displayed on the screen.

\section{Stage 2:}

At the beginning of the second stage, you will receive information how much each of your group members contributed to the project. In this stage you have the opportunity to register your approval or disapproval of each other group member's decision by distributing points.

In this stage you have the opportunity to reduce or leave equal the income of each group member by distributing points. You can award a large number of points to any member of your group if you disapprove of his or her decision (10 points for the most disapproval, 0 points for the least disapproval). Each point you distribute to a particular player lowers his or her payment by $10 \%$. You incur a cost for allocating points to other members, which is discussed in detail below.

You must decide how many points to give to each of the other two group members and enter these into the following computer screening:

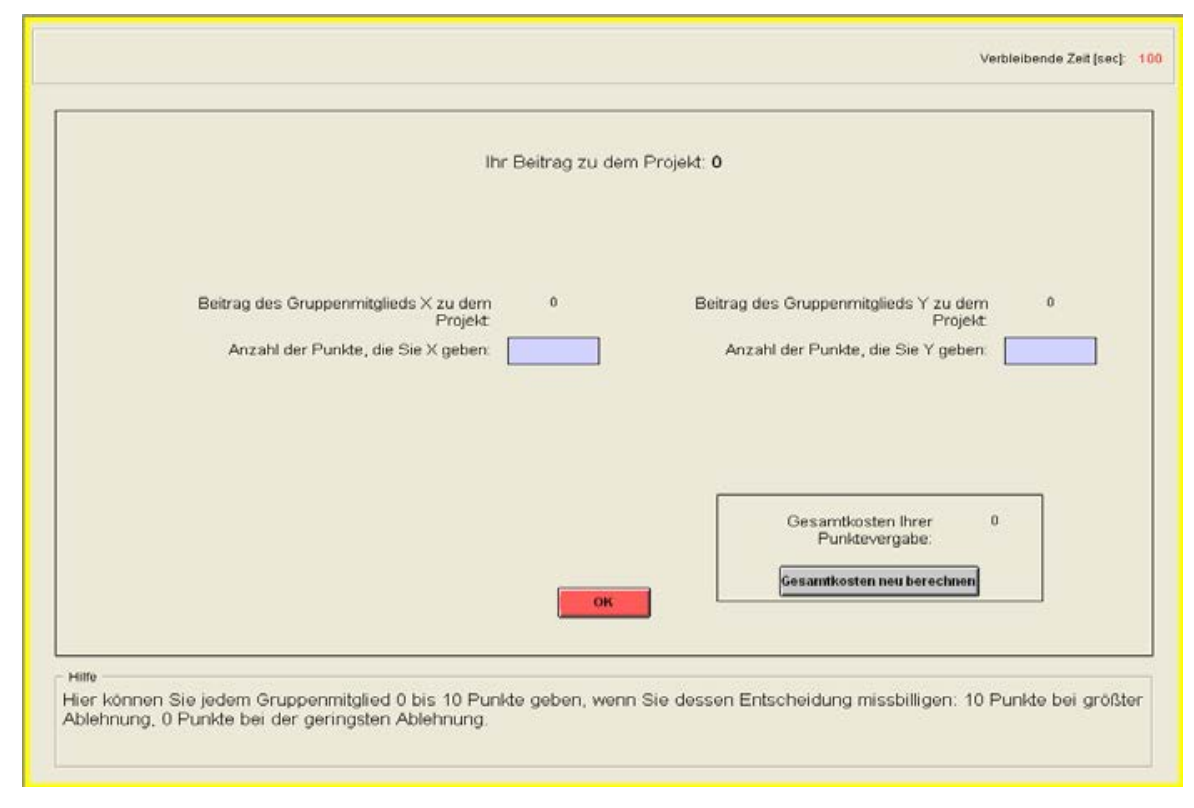

If you do not wish to change the income of a specific group member then you must enter 0 . If you distribute points, you have costs in points, which depend on the amount of points you distribute. You can distribute between 0 and 10 points to each group member. The more points you give to any group member, the higher your costs. Your total costs are equal to the sum of the costs of distributing points to each of the other two group members. The following table illustrates the relation between distributed points to each group member and the cost of doing so in points. 
Suppose for example that you give 2 points to one member. This costs you 2 points. If you give 9 points to another member this costs you an additional 25 points. In this case your total costs of distributing points would be $27(2+25)$ points. Your total cost of distributing points can be calculated on the input screen (on the right hand side). As long as you have not pressed the ok button you can revise your decision.

If you choose 0 points for a particular group member, you do not change his or her income. However if you give a member 1 point (by choosing 1 ) you reduce his or her income by 10 percent, etc. The amount of points you distribute to each member determines therefore how much you reduce their income from the first stage.

Whether or by how much the income from the first stage is totally reduced depends on the total of the received points from all other group members. If somebody received a total of 3 points (from all other group members in this period) his or her income would be reduced by 30 percent. If somebody received a total of 4 points his or her income would be reduced by 40 percent. If anybody receives 10 or more points their income from the first stage will be reduced by 100 percent. The income from the first stage for this member would in this case be reduced to zero.

The other group members can also assign points to you if they wish to.

Please state hereafter what you consider how many points you will receive in total from the other two group members.

\section{Your total income}

Your total income from the two stages is therefore calculated as follows:

If you receive less than 10 points:

\section{Your total income}

$=[($ income from the 1 st stage $) \times(10-$ received points $) / 10]$

- (cost to you of points you distribute) + extra endowment

If you receive 10 or more points:

$=0-($ cost to you of points you distribute $)+$ extra endowment

After all participants have made their decision, your income from the task will be displayed on the screen.

\section{Exercises}

To check your understanding of the experiment, please answer the following questions. While calculating, you may use the calculator function on the monitor. When you are done, you have to enter your results in the computer.

1. Suppose in the second stage of this task, you distribute the following amounts of points to the other two group members: 9 and 5 . What is the total cost of the points you distribute?

2. What are your costs if you distribute a total of 0 points?

3. By how many percent will your income from the first stage be reduced, when you receive a total of 0 points from the other group members?

4. By how many percent will your income from the first stage be reduced, when you receive a total of 4 points from the other group members?

5. By how many percent will your income from the first stage be reduced, when you receive a total of 15 points from the other group members?

When you are ready, please click on OK. 


\section{References}

Ai, C., Norton, E.C., 2003. Interaction terms in logit and probit models. Economics Letters 80 (1), 123129.

Akerlof, G.A., Kranton, R.E., 2000. Economics and Identity. The Quarterly Journal of Economics 115 (3), 715-753.

Akerlof, G.A., Kranton, R.E., 2005. Identity and the Economics of Organizations. Journal of Economic Perspectives 19 (1), 9-32.

Akerlof, G.A., Kranton, R.E., 2010. Identity economics: How our identities shape our work, wages, and well-being. Princeton, N.J., Woodstock: Princeton University Press.

Alesina, A., Baqir, R., Easterly, W., 1999. Public Goods and Ethnic Divisions. The Quarterly Journal of Economics 114 (4), 1243-1284.

Bénabou, R., Tirole, J., 2006. Incentives and Prosocial Behavior. American Economic Review 96 (5), 1652-1678.

Bicskei, M., Lankau, M., Bizer, K., 2013. How Peer-Punishment affects the Willingness to Cooperate in Homogeneous and Heterogeneous Groups - A Public Goods Experiment with Social Identity: Working Paper. A comparative study. Georg-August-Universität Göttingen.

Bosman, R., Sutter, M., van Winden, F., 2005. The impact of real effort and emotions in the power-totake game. Journal of Economic Psychology 26 (3), 407-429.

Bosman, R., van Winden, F., 2002. Emotional Hazard in a Power-to-take Experiment. The Economic Journal 112 (476), 147-169.

Caliendo, M., Fossen, F., Kritikos, A., 2012. Trust, Positive Reciprocity, and Negative Reciprocity: Do these Traits Impact Entrepreneurial Dynamics?: Discussion Paper No. 5370. Institute for the Study of Labor (IZA), $37 \mathrm{pp}$.

Charness, G., Rigotti, L., Rustichini, A., 2007. Individual behavior and group membership. The American Economic Review 97 (4), 1340-1352.

Chen, Y., Li, S.X., 2009. Group Identity and Social Preferences. The American Economic Review 99 (1), 431-457.

Eaton, B.C., Eswaran, M., Oxoby, R.J., 2011. Us and Them: the origin of identity, and its economic implications. Canadian Journal of Economics 44 (3), 719-748.

Eckel, C.C., Grossman, P.J., 2005. Managing diversity by creating team identity. Journal of Economic Behavior \& Organization 58 (3), 371-392.

Eisenberger, R., Lynch, P., Aselage, J., Rohdieck, S., 2004. Who Takes the most Revenge? Individual Differences in Negative Reciprocity Norm Endorsement. Personality and Social Psychology Bulletin 30 (6), 787-799.

Elster, J., 1996. Rationality and the Emotions. The Economic Journal 106 (438), 1386-1397.

Elster, J., 1998. Emotions and Economic Theory. Journal of Economic Literature 36 (1), 47-74.

Etienne, J., 2013. Controlled Negative Reciprocity Between the State and Civil Society: The Greek Case, Hellenic Observatory Papers on Greece and Southeast Europe GreeSE Paper No.71. London School of Economics and Political Science. http://ssrn.com/abstract=2178721 (accessed 16 October 2013). 
Falk, A., 2003. Homo Oeconomicus versus Homo Reciprocans: Ansätze für ein neues Wirtschaftspolitisches Leitbild? Perspektiven der Wirtschaftspolitik 4 (1), 141-172.

Falk, A., Fehr, E., Fischbacher, U., 2005. Driving Forces behind Informal Sanctions. Econometrica 73 (6), 2017-2030.

Falk, A., Fischbacher, U., 2006. A theory of reciprocity. Games and Economic Behavior 54 (2), 293315.

Fehr, E., Gächter, S., 2000a. Cooperation and Punishment in Public Goods Experiments. The American Economic Review 90 (4), 980-994.

Fehr, E., Gächter, S., 2000b. Fairness and Retaliation: The Economics of Reciprocity. Journal of Economic Perspectives 14 (3), 159-182.

Fehr, E., Gächter, S., 2002. Altruistic punishment in humans. Nature 415 (6868), 137-140.

Fischbacher, U., 2007. z-Tree: Zurich toolbox for ready-made economic experiments. Experimental Economics 10 (2), 171-178.

Herrmann, B., Thoni, C., Gachter, S., 2008. Antisocial Punishment Across Societies. Science 319 (5868), 1362-1367.

Hopfensitz, A., Reuben, E., 2009. The Importance of Emotions for the Effectiveness of Social Punishment. The Economic Journal 119 (540), 1534-1559.

Ibañez Diaz, M., Schaffland, E.R., 2012. Group identity and leadership: An experimental analysis: Unpublished Manuscript. Georg-August-Universität Göttingen.

Jackson, J.W., 2011. Intragroup cooperation as a function of group performance and group identity. Group Dynamics: Theory, Research, and Practice 15 (4), 343-356.

Jakobs, E., Manstead, A.S., Fischer, A.H., 1999. Social Motives, Emotional Feelings, and Smiling. Cognition \& Emotion 13 (4), 321-345.

Jakobs, E., Manstead, A.S.R., Fischer, A.H., 1996. Social context and the experience of emotion. Journal of Nonverbal Behavior 20 (2), 123-142.

Lankau, M., Bicskei, M., Bizer, K. Cooperation Preferences in the Provision of Public Goods: An Experimental Study on the Effects of Social Identity, cege Discussion Papers 148. Georg-AugustUniversität Göttingen. Göttingen. http://www.uni-goettingen.de/de/sh/60864.html (accessed 06 March 2013).

Loewenstein, G., 2000. Emotions in Economic Theory and Economic Behavior. The American Economic Review 90 (2), 426-432.

McLeish, K.N., Oxoby, R.J., 2007. Identity, cooperation, and punishment, IZA Discussion Paper 2572. Institute for the Study of Labor (IZA). http://papers.ssrn.com/sol3/papers.cfm?abstract_id=961379 (accessed 03 March 2013).

Miguel, E., Gugerty, M.K., 2005. Ethnic diversity, social sanctions, and public goods in Kenya. Journal of Public Economics 89 (11-12), 2325-2368.

Noussair, C., Tucker, S., 2005. Combining monetary and social sanctions to promote cooperation. Economic Inquiry 43 (3), 649-660.

Palacios-Huerta, I., Santos, T.J., 2004. A theory of markets, institutions, and endogenous preferences. Journal of Public Economics 88 (3-4), 601-627.

Paolo Mauro, 1995. Corruption and Growth. The Quarterly Journal of Economics 110 (3), 681-712. 
Pereira, P.T., Silva, N., Silva, J.A.e., 2006. Positive and negative reciprocity in the labor market. Journal of Economic Behavior \& Organization 59 (3), 406-422.

Reuben, E., van Winden, F., 2008. Social ties and coordination on negative reciprocity: The role of affect. Journal of Public Economics 92 (1-2), 34-53.

Sen, A., 1973. Behaviour and the concept of preference. Economica 40 (159), 241-259.

Solow, J.L., Kirkwood, N., 2002. Group identity and gender in public goods experiments. Journal of Economic Behavior \& Organization 48 (4), 403-412.

Tajfel, H., Billig, M.G., Bundy, R.P., Flament, C., 1971. Social categorization and intergroup behaviour. European Journal of Social Psychology 1 (2), 149-178.

Tajfel, H., Turner, J., 1979. An Integrative Theory of Intergroup Conflict. In: Worchel, S., Austin, W. (Eds.). The Psychology of Intergroup Relations, Monterey: CA: Brooks/Cole, 33-47.

Zeelenberg, M., Nelissen, R.M.A., Breugelmans, S.M., Pieters, R., 2008. On emotion specificity in decision making: Why feeling is for doing. Judgment and Decision Making 3 (1), 18-27.

Zeelenberg, M., Pieters, R., 2006. Feeling Is for Doing: A Pragmatic Approach to the Study of Emotions in Economic Behavior. In: Cremer, D. de, Zeelenberg, M., Murnighan, K. (Eds.). Social Psychology and Economics, NJ: Erlbaum: Mahwah, 117-137.

Zeelenberg, M., van Dijk, W.W., Manstead, A.S., van der Pligt, J., 1998. The Experience of Regret and Disappointment. Cognition \& Emotion 12 (2), 221-230. 


\section{Eidesstattliche Versicherung}

Ich versichere an Eides Statt, dass ich die eingereichte Dissertation „Institutional Designs of Public Goods in the Context of Cultural Property" selbstständig verfasst habe. Anderer als der von mir angegebenen Hilfsmittel und Schriften habe ich mich nicht bedient. Alle wörtlich oder sinngemäß den Schriften anderer Autorinnen und/oder Autoren entnommenen Stellen habe ich kenntlich gemacht.

Göttingen, Februar 2014 